Zweiter Beratungsgegenstand:

\title{
Gewährleistung von Freiheit und Sicherheit im Lichte unterschiedlicher Staats- und Verfassungsverständnisse
}

1. Bericht von Prof. Dr. Winfried Brugger, Heidelberg

\section{Inhalt}

Seite

I. Vormoderne Sichtweisen von Freiheit und Sicherheit . . . 103

II. Moderne Staatszwecklehren in der Gesellschafts-

vertragstheorie ..................... 111

III. Wandlungen von Polizei, Rechtsstaat und Sozialstaat . . . . 121

IV. Anschlussfähigkeit des klassischen Theorierahmens für die Ordnungsprobleme der Gegenwart? . . . . . . . . . . . . 124

V. Freiheit und Sicherheit im Grundgesetz . . . . . . . . . . 129

VI. Das Beispiel Volksverhetzung . . . . . . . . . . . . . 133

VII. Das Beispiel Parteiverbot ... . . . . . . . . . . . . . 140 
Sicherheit, securitas, se cura - das Wort sagt es schon: ohne Sorge. ${ }^{1}$ Ein Mensch, der ohne Furcht und Angst lebt, ist frei, und entfaltet sich persönliche Freiheit in Sachen, entsteht vor uns das Bild von Leben, Freiheit und Eigentum in Sicherheit. Dieser Schutzgüter-Dreiklang, verstärkt durch den Sicherheits-Gleichklang, tönt so vollkommen wie die ersten Takte von Beethovens 5. Symphonie, erscheint so verheißungsvoll wie das Füllhorn in der Hand der Frauengestalt Securitas auf römischen Münzen, das Sicherheit in Hülle und Fülle verspricht. ${ }^{2}$

Die Realität belehrt uns jedoch schnell eines Besseren: Umfassende Sicherheit in all den Beziehungen und Aktionsfeldern, die für ein gelungenes Leben bedeutsam sind, ist nicht zu haben. Statt auf natürliche und göttliche Vorsehung bauen zu können, ${ }^{3}$ müssen wir uns selbst vorsehen, Vorsorge gegen Risiken und Gefahren treffen, soweit dies möglich, sinnvoll und für freie Menschen angemessen ist. Wir können uns zwar mit René Descartes bei Abwägungen von Freiheit und Sicherheit unserer Existenz sicher sein, cogito et dubito ergo sum, aber deren Entfaltung bleibt in risikoreiche Verhältnisse gebannt. ${ }^{4}$

Da verwundert es nicht, dass das Bedürfnis nach Sicherheit sich inzwischen ein Begriffsfeld geschaffen hat, das von individueller, sozialer, politischer, nationaler, internationaler, innerer, äußerer, technischer, wirtschaftlicher, medizinischer, Rechts-, System-, Reaktor-, Betriebs-, StraBen- und Verkehrssicherheit bis zur Datensicherheit reicht. ${ }^{5}$

Allen diesen Sicherheitsfeldern kann hier nicht nachgegangen werden, schon gar nicht in der eigentlich gebotenen Mehrebenenanalyse vom

${ }^{1}$ S. M. Makropoulos Art. Sicherheit, in: Historisches Wörterbuch der Philosophie, Bd. 9, 1995, Sp. 745; A. Schrimm-Heins Gewissheit und Sicherheit. Geschichte und Bedeutungswandel der Begriffe certitudo und securitas, Teil I, Archiv für Begriffsgeschichte 34 (1991), 123, 133. S. auch F.-X. Kaufmann Sicherheit als soziologisches und sozialpolitisches Problem, 2. Aufl. 1973, 148, 167 Fn. 49.

${ }^{2}$ S. Schrimm-Heins I (Fn. 1), 139; G. Robbers Sicherheit als Menschenrecht. Aspekte der Geschichte, Begründung und Wirkung einer Grundrechtsfunktion, 1987, 29; Kaufmann (Fn. 1), 52.

${ }^{3}$ Zum vorneuzeitlichen, vorgegebenen, „archaischen“ Selbst- und Weltverständnis ausführlich Kaufmann (Fn. 1), Kap. 4, z.B. 211 f. S. auch J. Huizinga Herbst des Mittelalters, 2. Aufl. 1928, 77f., 333, zur mittelalterlichen Weltsicht: „Alles, was sich im Leben einen festen Platz erobert, was zur Lebensform wird, gilt als göttliche Einsetzung, die gewöhnlichsten Sitten und Gebräuche so gut wie die höchsten Dinge in Gottes Weltplan.“

${ }^{4}$ Hierzu A. Schrimm-Heins Gewissheit und Sicherheit. Geschichte und Bedeutungswandel der Begriffe certitudo und securitas, Teil II, Archiv für Begriffsgeschichte 35 (1992), 115, 127f.

5 S. etwa Schrimm-Heins I (Fn. 1), 123f. und $I$ (Fn. 4), 212, sowie Kaufmann (Fn. 1), $49 \mathrm{ff} ., 140 \mathrm{ff} ., 344$. 
deutschen öffentlichen Recht über den europäischen „Raum der Freiheit, der Sicherheit und des Rechts" 6 bis zur Rechtsvergleichung und zum Völkerrecht. ${ }^{7}$ Ich konzentriere mich auf eine staats- und verfassungstheoretische Skizze, einen Blick ins Grundgesetz und zwei Fallbeispiele, deren verbindende Klammer das Anliegen des politischen Klimaschutzes ist.

\section{Vormoderne Sichtweisen von Freiheit und Sicherheit}

Für das moderne Verhältnis von Freiheit und Sicherheit am wichtigsten ist die neuzeitliche Entwicklung großflächiger Territorialgebilde mit einheitlicher Herrschaftsgewalt, für die sich die Theorie des Staates im engeren oder modernen Sinn entwickelt hat. Doch ist schon für die vorhergehenden Stadien herrschaftlicher Organisation im Römischen Reich und im christlichen Mittelalter eine Ausrichtung an Sicherheit und Freiheit oder begrifflichen Äquivalenten charakteristisch.

Securitas wurde im 1. Jahrhundert nach Christus zum politischen Begriff, der die Pax Romana repräsentierte. Seit der augusteischen Zeit standen die Begriffe „pax“, „securitas“ und „libertas“ für den Herrschaftsund Stabilitätsanspruch des Römischen Reichs, der vom christlichen Mittelalter übernommen und auf Kaiser und Könige als Verteidiger von Sicherheit und Freiheit unter der Schutzherrschaft Gottes übertragen wurde. ${ }^{8}$

Im Mittelalter waren Bedrohungen von Leib und Leben sowie Gefahren für den Bestand und den Austausch von Gütern allgegenwärtig, ${ }^{9}$ bei

\footnotetext{
${ }^{6}$ S. Art. 2 und 29 EUV sowie Art. $61 \mathrm{EGV}$; ausführlich hierzu M. Möstl Die staatliche Garantie für die öffentliche Sicherheit und Ordnung, 2002, $557 \mathrm{ff}$., $618 \mathrm{ff}$.

${ }^{7}$ Hierzu jüngst C. Walter/S. Vöneky/V. Röben/F. Schorkopf (eds.) Terrorism as a Challenge for National and International Law: Security versus Liberty (erscheint 2004).

${ }^{8}$ Näher $W$. Conze Art. Sicherheit, Schutz, in: Geschichtliche Grundbegriffe, Bd. 5, 1984, 831, $832 \mathrm{ff}$.; Schrimm-Heins I(Fn. 1), $137 \mathrm{ff}$; $D$. Willoweit Deutsche Verfassungsgeschichte, 3. Aufl. 1997, 29; Makropoulos (Fn. 1), Sp. 745 ff.; Kaufmann (Fn. 1), 52 f.

${ }^{9}$ Eine eindrückliche Beschreibung findet sich bei Huizinga (Fn. 3), Kap. 1, insbesondere 25f., 34f.: „Das Volk kann sein eigenes Schicksal und die Ereignisse jener Zeit nicht anders erfassen, denn als eine fortwährende Abfolge von Mißwirtschaft und Aussaugerei, Krieg und Räuberei, Teuerung, Not und Pestilenz. Die chronischen Formen, die der Krieg anzunehmen pflegte, die fortwährende Beunruhigung von Stadt und Land durch allerlei gefährliches Gesindel, die ewige Bedrohung einer harten und unzuverlässigen Gerichtsbarkeit und außerdem noch der Druck von Höllenfurcht, Teufel- und Hexenangst nährten ein Gefühl allgemeiner Unsicherheit, das wohl dazu angetan war, den Hintergrund des Lebens schwarz zu färben.“
} 
Rechtsverletzungen drohten Blutrache und Fehde. ${ }^{10}$ Dagegen sollten vielfältige lehens-, land-, korporations- und kirchenrechtliche Eide, Schutzbünde sowie der Aufbau herrschaftlicher Gerichtsbarkeit helfen, ${ }^{11}$ die einen wichtigen Teil der polyarchischen ${ }^{12}$ mittelalterlichen Verfassung ${ }^{13}$ bildeten. „Friede und Freiheit" oder „Friede und Sicherheit" sollten vertikal - etwa zwischen dem Papst und dem künftigen Kaiser ${ }^{14}$ - und horizontal - zum Beispiel zwischen Städte- und Ritterbünden - gewährleistet werden; daneben traten Bündnisse zur Sicherung von Verkehrswegen für Händler und Pilger, ${ }^{15}$ schließlich auch mit der Zunahme europäischer Fürstentümer immer mehr Bündnis-, Neutralitäts- und Protektionsverträge zwischen den Landesherren. ${ }^{16}$ Damit entwickelten sich begriffliche Unterscheidungen zwischen Privatrecht und öffentlichem Recht, ${ }^{17}$ innerer und äußerer Sicherheit ${ }^{18}$ und mit zeitlichem Abstand auch Vorformen

10 S. H.-J. Becker Das Gewaltmonopol des Staates und die Sicherheit der Bürger, NJW 1995, 2077, 2078: „Seit der archaischen Zeit sind die Rechtskulturen Europas von den Gesetzen der Blutrache und der Sippenfehde bestimmt. Die Zeugnisse aus germanischer bzw. fränkischer Zeit lassen erkennen, dass jeder freigeborene Mann zur Rache nicht nur berechtigt, sondern verpflichtet war, wenn Leben, Ehre oder Besitz seiner Familie verletzt worden waren."

${ }^{11}$ Zur Entwicklung der Gerichtsbarkeit Willoweit (Fn. 8), \$§ 7 I 4; 9 II; 10 II 3; 12 III 2, IV 1; 15 I 4, sowie die Artikel Gerichtsverfassung (G. Buchda Sp. $1563 \mathrm{ff}$.); Gesetzlicher Richter ( $P$. Knauer Sp. $1620 \mathrm{ff}$ ) in: Handwörterbuch zur deutschen Rechtsgeschichte, Bd. I, 1971, sowie den Artikel Landesfürstliche Gerichte ( $G$. Theuerkauf Sp. 1375f.) in: ebd., Bd. 2, 1978.

12 So der Ausdruck von G.W.F. Hegel Vorlesungen über die Philosophie der Geschichte, Theorie-Werkausgabe Bd. 12, 1970, 478.

${ }_{13}$ Zur Verwendung des Begriffs Verfassung für diese Periode s. H. Mohnhaupt/ D. Grimm Verfassung. Zur Geschichte des Begriffs von der Antike bis zur Gegenwart, $1995,14 \mathrm{ff} ., 53 \mathrm{ff}$.

14 S. Conze (Fn. 8), 835: „Regelmäßig wurde seit der Karolingerzeit nach vorliegenden Formeln dem Papst vom künftigen Kaiser vor seiner Krönung ein Sicherheitseid geschworen (promissio regis), ein Schutzversprechen zunächst nur für die Kirche, sodann auch für die Person des Papstes und (seit Otto I.) seine Nachfolger mit der Versicherung: securitatem de vita, de membris, de papatu, de captione ...". S. auch Schrimm-Heins I (Fn. 1), $149 \mathrm{ff}$.

is S. allgemein Becker (Fn. 10), 2079f., und Conze (Fn. 8), 834ff., 836f., im Speziellen zum Straßenfrieden. „Nicht nur der Kaiser, sondern ... die Landesherren sahen im Schutz der Verkehrswege ihre Aufgabe und schlossen miteinander Bündnisse zu diesem Zweck ....".

16 S. Conze (Fn. 8), 838f.

17 S. M. Stolleis Geschichte des öffentlichen Rechts in Deutschland, Bd. I: Reichspublizistik und Policeywissenschaft 1600-1800, 1980, 70f., 394ff.

$18 \mathrm{~S}$. Conze (Fn. 8), 842f. 
von Völkerrecht. ${ }^{19}$ „Securitas publica“ wurde allmählich zum übergreifenden Begriff politischer Herrschaft. ${ }^{20}$

Dass diesen Sicherheitsbündnissen im Inneren wie im Äußeren oft kein tatsächlicher Friedenszustand entsprach, machten die schwer zu unterdrückenden Fehden durch das ganze Mittelalter sowie politische und religiöse Rivalitäten seit dem Spätmittelalter ${ }^{21}$ und besonders sinnfällig der 30-jährige Krieg deutlich. ${ }^{22}$ Mit dem Westfälischen Frieden von 1648 übernimmt das Völkerrecht seine Aufgabe kollektiver Sicherheitsgewährleistung. ${ }^{23}$

Fasst man diese Entwicklung bis zur frühen Neuzeit zusammen, so lässt sich eine erstaunliche Kontinuität in der normativen Bestimmung herrschaftlicher Aufgaben feststellen: Schaffung von Frieden und Recht

${ }^{19}$ S. O. Kimminich/St. Hobe Einführung in das Völkerrecht, 7. Aufl. 2000, $35 \mathrm{ff}$;; H. Schulze Staat und Nation in der europäischen Geschichte, 2. Aufl. 1995, 85ff.; W. Reinhard Geschichte der Staatsgewalt, 1999, 382ff.; Stolleis I (Fn. 17), 186ff., 398; Huizinga (Fn. 3), 344.

${ }^{20}$ Eine gelungene Systematisierung findet sich bei $J$. Althusius Politica methodice digesta atque exemplis sacris et profanis illustrata, Nachdruck der 3. Aufl., Herborn 1614, 1961, XVI, 13, 245: „Sicherheit muß also im Gebiet allen gewährt werden, damit jeder, der in ihm lebt, geht, durchwandert, sich aufhält, seine Angelegenheiten ohne eines anderen Beleidigung, Verletzung oder Hinderung besorgen kann, also daß das ganze Gebiet und jedes seiner Teile stets geschützt, in Frieden und frei seien, ohne irgend eine Gefahr oder Furcht vor Gewalt und Gewalttätigkeit." Zitiert bei Robbers (Fn. 2), 34f. Parallel dazu kann man die Beschreibung des Herrschaftsverhältnisses zwischen Fürst und Untertanen in der frühen Neuzeit bei J. Bodin lesen. Die Schutzpflicht des Fürsten erstreckt sich in „Sechs Bücher über den Staat“ von 1576 ,ganz allgemein genommen auf alle Untertanen, die einem Fürsten oder einer souveränen Herrschaft unterstehen ... der Fürst [hat] die Pflicht, mit Mitteln der Waffengewalt und der Gesetzgebung die Sicherheit von Leib und Leben, Eigentum und Familie seiner Untertanen zu gewährleisten und ... umgekehrt [schuldet] der Untertan seinem Fürsten Treue, Ergebenheit, Gehorsam, Unterstützung und Hilfe ...": 1. Buch, 7. Kap., zitiert nach der von P. C. Mayer-Tasch hrsg. Ausgabe von 1981, 187. S. auch 188: „Kein Versprechen ist aber ernster zu nehmen als das, Eigentum, Leben und Ehre des Schwachen gegen den Stärkeren, des Armen gegen den Reichen, des notgepeinigten Rechtschaffenen gegen die Willkür des Schurken zu verteidigen.“

21 S. Schulze (Fn. 19), 43f., und schon oben Fn. 3.

22 Seine Ablösung durch einen realen Friedenszustand führte zu einer Stärkung des Ziels von Freiheit und Sicherheit, wie die Worte des Prager Friedens von 1635 bezeugen. Dieser sollte geschlossen werden, um „die werte Teutsche Nation, zu voriger Integrität, Tranquillität, Libertät und Sicherheit“" zurückzuführen. Zitiert nach Conze (Fn. 8), 841. Libertät meint hier allerdings noch nicht moderne Selbstbestimmung, sondern „das Verbot einer allumfassenden kaiserlichen Monarchie, das Lebensrecht der drei großen Konfessionen, die Mitsprache in Reichsangelegenheiten und nicht zuletzt den Schutz der kleinen Herrschaftsträger vor den machtpolitischen Ambitionen der größeren deutschen Staaten". So Willoweit (Fn. 8), 170 f.

${ }^{23}$ Hierzu Kimminich/Hobe (Fn. 19), 40; Willoweit (Fn. 8), 143 f. 
sowie Herstellung des Landfriedens, ${ }^{24}$ Schutz und Sicherung von Leib, Leben, Besitz und Familie der Untertanen, im Ausgleich für Treue- und Dienstpflichten. ${ }^{25}$ Dass diese Güter auch heute noch schutzwürdig sind, steht außer Frage. Trotzdem kann eine moderne Reflexion nur beschränkt an die geistigen Voraussetzungen dieser Tradition anknüpfen. Das hat mehrere Gründe.

Zum Ersten erfolgt die normative Verankerung dieser Ziele in antiken oder christlichen Ordoverständnissen vorgegebener und vernünftiger Natur- oder Gottesordnung, in der den Menschen - Herrschern wie Untertanen - Status und Entfaltungsmöglichkeiten mehr oder weniger vorgezeichnet sind; ${ }^{26}$ der Schritt von objektiv vorgegebener zu subjektiv aufgegebener Ordnung ${ }^{27}$ ist noch nicht getan. ${ }^{28}$ Wahrung und Besserung des

24 S. H. P. Bull Die Staatsaufgaben nach dem Grundgesetz, 2. Aufl. 1977, 60, 347; Willoweit (Fn. 8), 29, 44, 59, 66, 81, 101; Möstl (Fn. 6), 5.

25 Diese Kontinuität in der Betonung von Sicherheit führt K.-P. Sommermann Staatsziele und Staatszielbestimmungen, 1997, 3 und öfter, zur Einstufung der „Rechtssicherheit" als zeitloser Staatszweck. Ferner ist Sicherheit in aller Regel ein relationaler Staatszweck, also auf konkrete Schutzgüter bezogen und dann ins Spiel gebracht, wenn Unsicherheitslagen drohen. S. U. K. Preu $\beta$ Verfassungstheoretische Überlegungen zur normativen Begründung des Wohlfahrtsstaates, in: Chr. SachBe/H. T. Engelhardt (Hrsg.) Sicherheit und Freiheit. Zur Ethik des Wohlfahrtsstaates, 1990, 106, 107.

${ }^{26} \mathrm{~S}$. die Zusammenfassungen einschlägiger Rechts- und Staatsphilosophien bei E.-W. Böckenförde Geschichte der Rechts- und Staatsphilosophie, 2002, 95, $125 \mathrm{f} ., 142$, 176, 263, 286, 308; ferner Hans Maier Die ältere deutsche Staats- und Verwaltungslehre, 2. Aufl. 1980, 50ff.; Schrimm-Heins II (Fn. 4), 115; P. Graf Kielmannsegg Volkssouveränität. Eine Untersuchung der Bedingungen demokratischer Legitimität, 1977, 18f.; Stolleis I (Fn. 17), 90; Huizinga (Fn. 3), 76 ff., und schon Fn. 3.

${ }^{27}$ S. H. Ryffel Rechts- und Staatsphilosophie, 1969, 299ff.; G. Geismann/K. Herb Einleitung, in: dies. (Hrsg.) Hobbes über die Freiheit (Widmungsschreiben, Vorwort an die Leser und Kap. I-III aus „De Cive“), 1988, 9, 11 ff.; W. Euchner Einleitung in J. Locke Zwei Abhandlungen über die Regierung, 1977, 9, 16, 44; E. Heintel Die naturrechtliche Fundierung des Ordogedankens in der Tradition, in: J. Schwartländer (Hrsg.) Menschenrechte. Aspekte ihrer Begründung und Verwirklichung, 1978, $19 \mathrm{ff}$. zu der aristotelischen Formel „ens et bonum convertuntur" und mit einer Zusammenfassung auf S. 23: „Der Ordogedanke geht aus von dem Kosmos als Inbegriff alles natürlich seienden Individuellen, versteht diesen Kosmos jedoch als ,Schöpfung;, d.h. bezogen auf eine höchste Sinninstanz (Gott), die sich in Natur und Geschichte offenbart und ihr alles umschließendes Heilshandeln besonders dem (gefallenen) Menschen und seiner ,Rechtfertigung bzw. ,Erlösung' zuwendet, jenem Geschöpf, das auch in seiner Sündhaftigkeit und mit seiner Freiheit eingegliedert bleibt in die, Vernünftigkeit des Wirklichen' im Zeichen der Vorsehung."

${ }^{28}$ Hierzu Bodins eindrückliche Beschreibung in "Sechs Bücher“ (Fn. 20), 1. Buch, 1. Kap., 103, von der Minimalaufgabe des Staates zum Lebensschutz bis hin zur Aufgabe von Staaten wie Untertanen, zur Klarheit des Denkens zu finden, sich den Naturschönheiten zuzuwenden, um schließlich , die vollendete Harmonie dieser unserer ganzen Welt 
überkommenen Rechts stehen vor freibestimmter Rechtsetzung. ${ }^{29}$ Gutes Recht ist bis in die Neuzeit alt, neues Recht muss sich als alt ausgeben, um akzeptiert zu werden. ${ }^{30}$

Zum Zweiten sind die Minimalziele politischer Organisation - Herstellung des Landfriedens und Rechtsgüterschutz - tendenziell verknüpft mit Maximalzielen wie Tugend und Glückseligkeit im Gemeinwesen. Die Herrschaftsorganisation ist auch für das materielle und spirituelle Wohlergehen des Volkes zuständig, ${ }^{31}$ sei diese Zuständigkeit vermittelt über den sakralen Charakter des mittelalterlichen Königtums, die Verbund-

erkennen“ zu können. So gelange man zur „Entdeckung der ersten Ursache und des Schöpfers eines so großartigen Meisterwerks“. S. demgegenüber Sommermann (Fn. 25), 21 , im Vorgriff auf die Wende in der 2. Hälfte des 18. Jahrhunderts: „Je weiter sich das [18.] Jahrhundert neigt, desto stärker verlagert sich im Einklang mit dem Zeitgeist der Bedeutungsschwerpunkt der Begriffe, Wohlfahrt' oder, Glückseligkeit' vom Gemeinwesen zur Person, vom Kollektiven zum Individuellen“, und Robbers (Fn. 2), 30, 33 f.: „Die Voraussetzungen für die Idee der Sicherheit als Menschenrecht sind erst dort gegeben, wo dem Einzelnen selbst seine Verwirklichung und Verteidigung im Staat in die Hand gegeben ist, sei es durch Widerstandsrecht, durch Wahlrecht der politischen Vertreter oder endlich durch die Möglichkeit, Gerichte zur Durchsetzung seines Rechts anzurufen.“

29 S. Willoweit (Fn. 8), $119 \mathrm{ff}$.

${ }^{30}$ So Reinhard (Fn. 19), 283. S. auch F. Kern Gottesgnadentum und Widerstandsrecht im früheren Mittelalter, 6. Aufl. 1973, $123 \mathrm{ff}$. mit notwendigen Differenzierungen: „Der Staatszweck ist nach dem germanischen Staatsbegriff beharrend, erhaltend: er liegt in der Bewahrung der bestehenden Ordnung, des guten alten Rechts. Das germanische Gemeinwesen ist seinem Begriff nach vor allem Rechts- und Ordnungsstaat" (123). „Der Staatszweck der christlichen Weltanschauung ist daneben von fortschreitender, tätiger, ausgreifender Natur. Nicht das überlieferte und seiende Gewohnheitsrecht, sondern das niemals ganz erreichte, aber ewig zu erstrebende göttlich-natürliche Vernunftrecht ... und vor allem seine biblisch-theologischen Untergründe: das ist es, was der Staat achten und zur Geltung bringen soll. Der christlich-mittelalterliche Staat ist nicht reine Rechtsanstalt, sondern stellt das Ideal des intensiven Wohlfahrts- oder Kulturstaats auf“ (124). „Das göttliche Recht fällt also nicht immer mit dem Gewohnheitsrecht der Völker zusammen und steht oft im Gegensatz zu ihm als das sittliche Postulat, das neue Recht, der umwälzende, reformatorische Kulturgedanke“ (125). Eine noch größere Gestaltungsmacht nimmt dann der absolutistische Staat für sich in Anspruch. Dazu zusammenfassend Stolleis I(Fn. 17), 397.

31 S. etwa Huizinga (Fn. 3), 78: „Die höchste Aufgabe im Staat, die Beschirmung der Kirche, die Verbreitung des Glaubens, der Schutz des Volkes vor Unterdrückung, die Handhabung des allgemeinen Wohls, Bekämpfung von Gewalt und Tyrannei, Befestigung des Friedens ..." sowie Bodin Sechs Bücher (Fn. 20), 1. Buch, 1. Kap., 101: „Wenn nun aber die wahre Glückseligkeit des Staates gleichzusetzen ist mit der des einzelnen Menschen und wenn das höchste Gut des Staates ... in den Tugenden des Verstandes und der Kontemplation besteht, dann folgt daraus zwingend, daß ein Volk wahrer Glückseligkeit teilhaftig ist, wenn es als Ziel vor Augen hat, sich in der Betrachtung der natürlichen, menschlichen und göttlichen Dinge zu üben und für alles den mächtigen Fürsten der Natur zu lobpreisen." S. schon oben Fn. 27 zu Geismann/Herb. 
herrschaft von Kaiser und Papst, aristotelisch inspirierte Vorstellungen sittlich vollkommenen Lebens oder das landesherrliche Kirchenregiment. ${ }^{32}$ Der liberale Schritt zur Beschränkung der Staatszwecke ist noch nicht getan.

Zum Dritten bewegen wir uns bis zu diesem Zeitpunkt trotz des theoretischen Vorrangs der einheitlichen Reichsidee ${ }^{33}$ in vielfältig feudal und ständisch gestuften Ordnungen mit asymmetrischen Freiheiten und Würden. ${ }^{34}$ Diesen eignet zwar ein personales Gegenseitigkeits- und Fürsorgemoment zwischen Lehnsherr und Vasall, Herrscher und Untertan, ${ }^{35}$ doch ist dieses noch nicht verankert in der Zweipoligkeit von politischer Einheitsgewalt ${ }^{36}$ und homogenem Staatsvolk. ${ }^{37}$ Schon gar nicht kommt den

${ }^{32}$ S. Willoweit (Fn. 8), 27f., 49ff., 85f., 103, 121, 126, 133 f. Speziell zum aristotelischen Einfluss Kielmannsegg (Fn. 26), 36ff.

${ }^{33}$ S. Kimminich/Hobe (Fn. 19), $34 \mathrm{ff}$; R. Zippelius Kleine deutsche Verfassungsgeschichte, 3. Aufl. 1996, 35, 46; Schulze (Fn. 19), 19ff., 41f., 58ff., 85; Hegel (Fn. 12), 447: „Die kaiserliche Gewalt wurde im ganzen für etwas sehr Großes und Hohes ausgegeben: der Kaiser galt für das weltliche Oberhaupt der gesamten Christenheit; je größer aber diese Vorstellung war, desto weniger galt die Macht der Kaiser in der Wirklichkeit." Ähnlich J. Burckhardt, zitiert in H. Fuhrmann Überall ist Mittelalter. Von der Gegenwart einer vergangenen Zeit, 1997, 71: „Die deutsche Krone, mit ihrem römischen Kaisertum behaftet, [war] zu schwach zum Leben und zum Sterben [und] aller nationalen Aufgaben ... unfähig." S. schon oben Fn. 12.

${ }^{34}$ S. G. Dilcher Art. Freiheit (MA), in: HRG Bd. 1 (Fn. 11), Sp. 1227 ff.; Kielmannsegg (Fn. 26), 24; D. Willoweit Geschichtliche Wandlungen der Eigentumsordnung und ihre Bedeutung für die Menschenrechtsdiskussion, in: J. Schwartländer/D. Willoweit (Hrsg.) Das Recht des Menschen auf Eigentum, 1983, 7 ff.; Maier (Fn. 26), 33 ff.; Robbers (Fn. 2), $29 \mathrm{f} .:$,Stets war der alte Gedanke der allgemeinen Schutzpflicht des Landesherrn für die Erhaltung des Landfriedens gegenwärtig. Unterhalb dieser Ebene jedoch war die Sicherheitsgarantie des der Sicherung Bedürftigen aufgesplittert in vielfältig abgestufte Schutzprivilegien ..."; Mayer-Tasch Einführung in Bodin (Fn. 20), 27: „Die politische Verfassung des Ständestaates zeigte im 16. Jahrhundert noch eine Pyramidalstruktur weitverzweigter vertikaler Rechtsbeziehungen. Der Rechtsbefehl des Königs erreichte die ... ,Familien` in aller Regel nicht direkt, sondern allenfalls durch Vermittlung eines regional gestuften Systems politischer Institutionen und Amtsträger."

35 S. Kern (Fn. 30), 152, 241; Zippelius (Fn. 33), 26f., $61 \mathrm{ff}$.

${ }_{36}$ Schulze (Fn. 19), 42, spricht von den Territorialstaaten, aus denen sich das Reich zusammensetzte, als „eine[r] fast zoologische[n] Fülle von Kurfürstentümern, Herzogtümern, Fürstentümern, Bistümern, Grafschaften, Reichsstädten, Abteien und Balleien.“ S. auch Willoweit (Fn. 8), 31; Reinhard(Fn. 19), 407; U. Volkmann Relativität des Staates. Staatsbegriff und Staatsverständnis im Spiegel der jüngeren Geschichte, JuS 1996, 1058f.; Stolleis I(Fn. 17), 397, 402.

${ }^{37}$ S. Kern (Fn. 30), 243: „Das frühe Mittelalter (bis zur Ausbildung konkreter ständischer Verfassungsformen) läßt die Gesamtheit, welche dem Herrscher gegenübersteht, wesentlich unbestimmt und formlos vertreten werden durch proceres, maiores und meliores usf." Erst nach Ablösung auch der feudal-ständischen Gesellschaftsordnung ist der 
Untertanen ein allgemeiner Freiheits-, Gleichheits- und Würdestatus ${ }^{38}$ zu, der sie der Herrschaftsgewalt nicht mehr nachordnen, sondern legitimatorisch vorordnen würde.

Zum Vierten gründet die Verpflichtung des Herrschers zur Wahrung von Frieden und Recht oft ununterschieden in Tradition, Gott, Natur oder Vernunft. ${ }^{39}$ Der Herrscher soll überkommene Machtstrukturen und religiöse Gebote achten, Fürstentugenden nachkommen und zunehmend auch pragmatisch seine Macht erhalten, etwa bei Machiavelli. ${ }^{40}$ Der Rechtscharakter der Schutzverpflichtungen bildet in der Regel keinen von Natur, Religion und Tradition isolierten Verbindlichkeitsgrund; dazu sind die Einbindungen von Herrschaft zu verwoben. ${ }^{41}$ Bei Schutzversprechen oder Verträgen tritt das Moment rechtlichen Gebundenseins zwar

Boden bereitet für ein einheitliches Verständnis von „Staatsvolk“. Zur Änderung in der frühen Neuzeit Stolleis I(Fn. 17), 70; D. Grimm Der Staat in der kontinentaleuropäischen Tradition, in: ders. Recht und Staat der bürgerlichen Gesellschaft, 1987, 53, $58 \mathrm{ff}$.

${ }^{38}$ Zum Unterschied von vorneuzeitlichen „Würden“ und „Würdigkeiten“ gegenüber der modernen, einem jeden Menschen zukommenden „Würde“ s. H. Bielefeldt Zum Ethos der menschenrechtlichen Demokratie. Eine Einführung am Beispiel des Grundgesetzes, $1991,17 \mathrm{ff}$.

${ }^{39}$ S. neben Fn. 3, 27, 28, 30 Stolleis I(Fn. 17), 268f.; Robbers (Fn. 2), 33f. Ausführlich zu den Fürstenspiegeln Sommermann (Fn. 25), 9 ff. Zur Bindung an natürliche und göttliche Gesetze s. exemplarisch Bodin Sechs Bücher (Fn. 20), 38ff., 207, 214, 230. Man kann allerdings im Vorrang dieser Verpflichtungsmodi auch eine Bindung der nachrangigen Rechtsmodalität sehen. Wenn diese Folgerung oft nicht (klar) gezogen wurde, dann vielleicht auch wegen der unvermeidlichen Streitigkeiten über die Umsetzung dieser vorrechtlichen Kriterien zwischen Herrscher und Rechtsunterworfenen. Dieses Streitigkeitsproblem findet dann Eingang in die Reflexion der Vertragstheoretiker Hobbes, Locke und Kant.

${ }^{40}$ Pragmatisch geboten kann Rechtsgüterschutz des Volkes sein, um die Herrschaft zu erringen oder gegen rivalisierende Kräfte zu bewahren. S. Grimm (Fn. 37), 60. In diesem Sinne argumentiert N. Machiavelli in den „Discorsi“ (1531), 1. Buch, 5. Kap.: „Von den weisen Gesetzgebern wurde die Sicherung der Freiheit immer zu den notwendigsten Einrichtungen einer Republik gezählt." Zitiert nach $H$. Münkler Niccolò Machiavelli, Politische Schriften, 1990, 139. Je nach den Umständen kann es auch um andere Maßnahmen bis hin zur Unterdrückung gehen, weil Machiavelli vor allem die Erhaltung (auch Erweiterung) der Republik in Krisenzeiten vor Augen steht. Vgl. die bei Münkler ebd. zitierten Stellen 13, $34 \mathrm{ff}$., 55f., 57, sowie Schulze (Fn. 19), 45ff., 49, zur die Schutzdimension bei Machiavelli doch einschließenden Staatsraison: „denn das Verlangen des Volkes ist berechtigter als das Verlangen der Großen, da diese auf Bedrückung ausgehen, das Volk aber auf Schutz von Bedrückung“.

${ }^{41}$ S. Kern (Fn. 30), § 6, 131 ff., 245: „Da die mittelalterliche Weltanschauung zwischen Sittlichkeit, Sitte und Recht grundsätzlich nicht unterschied, so kam einer solchen [Rechtsgebundenheit des Fürsten] ... nicht nur sittliche oder naturrechtliche, sondern positivrechtliche Geltung zu“ (131). Kern fügt in einer Anmerkung hinzu: „Diese Ausdrucksweise würde das Mittelalter selbstverständlich kaum verstanden haben.“ 
deutlich hervor, ${ }^{42}$ es wirkt aber vorrangig zwischen einzelnen Herrschaftsverbänden und Ständen ${ }^{43}$ und weniger in der dualen Gegenüberstellung von Souverän und Volk. Zudem ist die Rechtsbindung lange stärker personalrechtlich als territorial und staatsrechtlich geprägt. ${ }^{44}$ In diesem Sinne existieren Verfassungsverträge zwischen Herrschaftsträgern, aber eine Staatsverfassung im engeren Sinn mit umfassender Souveränität oder gar eingebauter Rechtsbindung und Bindungskontrolle liegt noch nicht vor. ${ }^{45}$ Dafür wird oft ein Widerstandsrecht als letzte Schranke gegen Herrschaftswillkür in Anspruch genommen. ${ }^{46}$

Dem entspricht es, dass - fünftens - noch kein ausgebildetes subjektives Recht des Volkes gegen den Herrscher auf effektiven Schutz der einschlägigen Rechtsgüter vorliegt, das mit einem Recht auf Durchsetzung durch unabhängige Gerichte gekoppelt wäre. Gerichte als Foren zur Streitentschei-

\footnotetext{
${ }^{42} \mathrm{~S}$. exemplarisch die Ambivalenz bei Bodin, der am Übergang zum neuzeitlichen Staat und zu Hobbes steht. Er vertritt einerseits wie Hobbes eine starke Souveränitätsthese, über die der Herrscher die höchste und umfassende Macht hat und „beliebig“ regieren, d.h. vor allem einseitig Gesetze erlassen und durchsetzen kann. Andererseits ist der Herrscher über „Verträge“ und „Versprechen“ dann doch horizontal und vertikal gebunden: Sechs Bücher (Fn. 20), 1. Buch, 8. Kap., 210, gegenüber ebd., 214ff., und 1. Buch, 7. Kap., 188.

43 Anschaulich beschrieben von $\mathrm{Hegel}$ (Fn. 12), $447 \mathrm{ff}$., $460 \mathrm{ff}$. S. auch die Zusammenstellung bei Zippelius (Fn. 33), 36ff., und H. Vorländer Verfassung. Idee und Geschichte, 1999, 13 f., $30 \mathrm{f}$.

${ }^{44}$ S. Kimminich/Hobe (Fn. 19), 35, 41; Schulze(Fn. 19), 23, 38; Stolleis I(Fn. 17), 70f., 82.

45 S. K. Stern Staatsrecht I, 2. Aufl. 1984, § 3 I; Willoweit (Fn. 8), § 25 III 2.

${ }^{46}$ S. Kern (Fn. 30), XI f., $\$ \S 5$ ff. mit einer Zusammenfassung auf 144f.; Chr. Link Jus resistendi. Zum Widerstandsrecht im deutschen Staatsdenken, FS Dordet, 1976, $55 \mathrm{ff}$; Kielmannsegg (Fn. 26), 22f., 80 ff. u. ö.; R. v. Friedeburg (Hrsg.) Widerstandsrecht in der frühen Neuzeit. Erträge und Perspektiven der Forschung im deutsch-britischen Vergleich, 2001; ders. Widerstandsrecht und Konfessionskonflikt. Notwehr und Gemeiner Mann im deutsch-britischen Vergleich 1530 bis 1669, 1999. Zusammenfassend zu den Argumentationstypen für ein Widerstandsrecht 16: „Als Grundtypen widerstandsrechtlicher Begründungen wurden ... der Hinweis auf ständische und in den leges fundamentales festgelegte Rechtsbestände, auf die Bindung des Herrschers durch das Naturrecht und auf einen Vertrag zwischen Herrscher und Unterworfenen insgesamt genannt." S. schon die Zusammenstellung von $K$. WolzendorffStaatsrecht und Naturrecht in der Lehre vom Widerstandsrecht des Volkes gegen rechtswidrige Ausübung der Staatsgewalt, 1916, $522 \mathrm{ff}$ : Gemeindienlichkeit der Herrschaft; Achtung naturrechtlich-religiöser Gebote; Respektierung des Herrschaftsvertrags; Achtung von Menschenrechten. Im Einzelnen gibt es viele Unterschiede und Differenzierungen: Das Widerstandsrecht kann religiös, moralisch oder rechtlich begründet sein. Es kann sich auf besondere Stände oder das Volk beziehen. Es kann den Rechtsunterworfenen prinzipiell zugestanden sein, aber relativiert werden durch die Unsicherheit über die Frage, ob die verbindlichen Schranken oder Zwecke der Herrschaft wirklich verfehlt wurden, die dann zu einer Prärogative des Herrschers führt.
} 
dung existierten zwar schon lange, ${ }^{47}$ und die Landfriedensbewegung kämpfte jahrhundertelang um die Ersetzung der Fehde durch eine geordnete Streitentscheidung, ${ }^{48}$ aber Herrschen und Richten gehörten weitgehend noch zusammen. ${ }^{49}$ Die Gerichtskörper blieben in wesentlichen Aspekten vormodern: Landesherr und höhere Stände dominierten die Besetzung der Richterbank, ${ }^{50}$ höhere und niedrigere sowie geistliche und weltliche Gerichte konkurrierten, ${ }^{51}$ der Zugang war oft beschränkt, und die Entscheidung als Rechtsspruch war nicht frei von politischen Pressionen, wie die Existenz von Machtsprüchen bis ins aufgeklärte Preußen hinein belegt. ${ }^{52}$

\section{Moderne Staatszwecklehren in der Gesellschaftsvertragstheorie}

Die Entwicklung der Gesellschaftsvertragstheorie von Thomas Hobbes über John Locke und Jean-Jacques Rousseau zu Immanuel Kant stellt einen unverzichtbaren Schritt für das moderne Verständnis von Freiheit und

${ }^{47}$ Dazu schon Fn. 11 sowie Beispiele aus den Jahrhunderten bei Willoweit (Fn. 8), 35, 44, 58, 66, 78, 83, 101, 160, 177f., 195; zusammenfassend Reinhard (Fn. 19), $282 \mathrm{ff}$.

48 S. speziell zum auf dem Wormser Reichstag von 1495 abgeschlossenen „Ewigen Landfrieden" Becker (Fn. 10). Generell zur Bedeutung der Eliminierung der Selbsthilfe auch Bull (Fn. 24), 71.

49 S. Kielmannsegg (Fn. 26), 19: „Die Funktion von Herrschaft konnte [im Mittelalter] nur die Bewahrung des Rechts sein, die Sicherung des Rechts für jeden einzelnen. Das Amt des mittelalterlichen Herrschers wurde denn auch bis in das Spätmittelalter hinein im Kern als richterliches Amt begriffen ... Die Vorstellung vom Herrscher als Richter hat bis tief in die Neuzeit hinein nachgewirkt ..."; $M$. Stolleis Geschichte des öffentlichen Rechts in Deutschland, Band II: Staatsrechtslehre und Verwaltungswissenschaft 1800-1914, 1992, $116 \mathrm{f}$.

$50 \mathrm{~S}$. die raffinierte Begründung von Machiavelli für die Einrichtung einer Gerichtsbarkeit, in: Der Fürst, Reclam-Ausgabe 1961, 110: „Wohlgeordnete Staaten und kluge Fürsten waren stets mit allem Fleiße darauf bedacht, die Großen nicht zur Verzweiflung zu treiben und das Volk zufriedenzustellen. Denn das ist eine der wichtigsten Obliegenheiten eines Herrschers ... Deshalb schuf [der König von Frankreich] ein unparteiisches Gericht, das ohne Nachteil für den König die Großen züchtigte und das Volk begünstigte. Diese Einrichtung war so vorzüglich und weise wie nur möglich und die beste Gewähr für die Sicherheit des Königs und des Reiches. Hieraus kann man die weitere Lehre entnehmen, daß die Fürsten alles Unliebsame andern übertragen, alle Gnaden aber selbst verteilen sollen."

51 Dazu schon oben Fn. 11.

$52 \mathrm{Vgl}$. U. Seif Recht und Gerechtigkeit. Die Garantie des gesetzlichen Richters und die Gewaltenteilungskonzeptionen des 17. bis 19. Jahrhunderts, Der Staat 42 (2003), 110, $124 \mathrm{ff}$; Reinhard (Fn. 19), $297 \mathrm{ff}$.; Chr.-F. Menger Deutsche Verfassungsgeschichte der Neuzeit, 8. Aufl. 1993, Rn. 103, 106, 141, 145, 149; W. Frotscher/B. Pieroth Verfassungsgeschichte, 3. Aufl. 2002, Rn. 128 ff.; Willoweit (Fn. 8), \$26 III 2. 
Sicherheit dar. ${ }^{53}$ Die Hauptpunkte dieser Entwicklung werden meist wie folgt zusammengefasst: Bei Hobbes hat der Staat vor allem für den Lebensschutz einzustehen, bei Locke wird die Sicherung des Eigentums betont, bei Rousseau die Demokratie und bei Kant die Freiheit. ${ }^{4}$

So richtig das ist, trifft es doch noch nicht den entscheidenden Unterschied zwischen den genannten Gesellschaftsvertragstheorien und den früheren Staatszweckbestimmungen, die ja auch schon auf innere und äuBere Sicherheit und Frieden durch Schutz wichtiger Individualgüter abgestellt hatten. Werfen wir deshalb einen kurzen Blick auf die Autoren.

Bei Thomas Hobbes ${ }^{55}$ steht zwar die Sicherung von Leben gegen innere und äußere Aggressoren im Vordergrund seiner Werke De Cive (1642) und Leviathan (1651), aber der Zweck der politischen Vergemeinschaftung geht weit über die Sicherung des Überlebens hinaus - Ziel ist das gute Leben. „So ist es für das menschliche Leben notwendig, einige Rechte beizubehalten, wie das Recht, über den eigenen Körper zu herrschen, das Recht auf Wasser, Luft, Körperbewegung, auf Verbindungswege von Ort zu Ort, sowie auf alle Dinge, ohne die ein Mensch nicht oder nicht angenehm leben kann." ${ }^{66}$ Das umfasst auch die Sicherheit, „sich durch eigenen Fleiß und von den Früchten der Erde ernähren und zufrieden leben [zu] können." 57

Die Differenz zu vorneuzeitlichen Staatstheorien besteht nicht in den Schutzgütern, sondern in der Umkehrung der Begründungsrelation: Gemeinschaft ordnet nicht mehr Freiheit, sondern die Freiheit der Menschen führt zu einer Ordnungsaufgabe. ${ }^{58}$ Hobbes argumentiert wie alle

\footnotetext{
${ }^{53} \mathrm{~S}$. exemplarisch die Untersuchungen von $H$. Bielefeldt Neuzeitliches Freiheitsrecht und politische Gerechtigkeit. Perspektiven der Gesellschaftsvertragstheorien, 1990; W. Kersting Die politische Philosophie des Gesellschaftsvertrags, 1994; P. Koller Neue Theorien des Sozialkontrakts, 1987. Letzterer behandelt nur neuere Autoren (John Rawls, Robert Nozick, James Buchanan).

${ }^{54}$ S. J. Isensee Das Grundrecht auf Sicherheit. Zu den Schutzpflichten des freiheitlichen Verfassungsstaates, 1983, 4; D. Murswiek Umweltschutz als Staatszweck. Die ökologischen Legitimitätsgrundlagen des Staates, 1995, 18; Bull (Fn. 24), 22f.; Preuß (Fn. 25), $106 \mathrm{f}$.

55 Hobbes' unmittelbarer Einfluss in Deutschland war gering, s. Willoweit (Fn. 8), 154; hier geht es um die langfristige staatstheoretische Wirkung, die immens war.

${ }^{56}$ Hobbes Leviathan oder Stoff, Form und Gewalt eines bürgerlichen und kirchlichen Staates, Kap. 15, 118, zitiert nach der von I. Fetscher hrsg. Fassung, 1966. Vgl. auch die Einleitung, 5: „Wohlstand und Reichtum aller einzelnen Glieder stellen die Stärke dar, salus populi (die Sicherheit des Volkes) seine Aufgabe ... Eintracht ist Gesundheit, Aufruhr, Krankheit und Bürgerkrieg Tod.“

${ }^{57}$ Hobbes Leviathan (Fn. 56), Kap. 17, 134.

58 Näher Geismann/Herb (Fn. 27), 13 ff. mit einer Darstellung der antiaristotelisch vom Einzelnen zum Ganzen und vom Naturzustand zum politischen Zustand voranschreiten-
} 
Gesellschaftsvertragstheoretiker im fiktiven Übergang vom Naturzustand zum politisch verfassten Zustand, den die Vernunft gebietet. ${ }^{59} \mathrm{Im}$ Naturzustand trachten wir alle nach Lebenserhaltung und Lustgewinn. Zudem sind wir alle frei, ${ }^{60}$ können nämlich ein Recht auf alles in Anspruch nehmen. ${ }^{61}$ Wir sind auch alle gleich, weil ein jeder von uns jeden anderen in seinem Leben und seinen Gütern bedrohen kann. ${ }^{62}$ Damit werden antike und mittelalterliche Sichtweisen vorgegebener Ordnungen und prästabilierter Harmonie aufgegeben, ${ }^{63}$ an ihre Stelle tritt die von der Selbsterhaltungsvernunft gestellte Aufgabe, politische Ordnungen zu konstruieren und zu gestalten, um der prästabilierten Disharmonie und der im Naturzustand immer drohenden Unsicherheit in den natürlichen Rechten Herr zu werden. ${ }^{64}$ Gleichzeitig ziehen der moderne Empirismus, Rationalismus, Individualismus und Atomismus ${ }^{65}$ in die politische Theorie ein. Allerdings führt die gleiche Freiheit bei Hobbes, aus der historischen Situation von Anarchie und Bürgerkrieg heraus durchaus verständlich, zu radikalen Gefährdungen von innerer und äußerer Sicherheit, die er anthropologisiert ${ }^{66}$ und damit tendenziell entkontextualisiert: ${ }^{67}$ Homo homini lupus, bellum omnium in omnes. ${ }^{68}$ Dieser Zustand kann nur noch durch einen drittbegünstigenden Unterwerfungsvertrag bewältigt wer-

den ,geometrischen“, resolutiv-kompositorischen Methode. Vgl. demgegenüber die Bodin-Zitate oben Fn. 28, 31. S. auch die folgende Fußnote und schon oben Fn. 27 zu Ryffel.

${ }^{59}$ Speziell zu Hobbes' Methode Fetscher Einleitung zu Leviathan (Fn. 56), IX, XIII, XLVf.

${ }^{60}$ Leviathan (Fn. 56), Kap. 21, 168: ,alle Menschen sind von Natur aus gleichermaßen frei".

${ }^{61}$ S. Leviathan (Fn. 56), Kap. 14, 99, 100; Kap. 15, 110; Kap. 18, 140.

${ }^{62}$ S. Leviathan (Fn. 56), Kap. 13 und 14, 105.

${ }^{63} \mathrm{Vgl}$. Fetscher Einleitung zu Leviathan (Fn. 56), XX, und allgemein Euchner Einleitung zu Locke (Fn. 27), 16, und oben Fn. 27 zu Geismann/Herb.

${ }^{64}$ S. Geismann/Herb (Fn. 27), 12, 15, die bei Hobbes das Problem der Rechtsunsicherheit im vorpolitischen Zustand als Kernpunkt der Theorie ansehen, nicht das im Folgenden erwähnte anthropologische Argument. Aus Sicht dieser Autoren steht Hobbes also Locke und Kant ganz nahe, weil auch bei diesen Autoren die Rechtsunsicherheit zentral ist, unabhängig von positiveren oder negativeren Menschenbildern.

${ }^{65}$ Dazu ein schönes Zitat von Chr. Hill in "The Century of Revolution (1603-1714)“, 1963, 4, hier zitiert nach Euchner (Fn. 27), 47 Fn. 54: „Shakespeare had thought of the universe and of society in terms of degree, hierarchy; in 1714 both society and the universe seemed to consist of competing atoms."

${ }^{66}$ S. Leviathan (Fn. 56), Kap. 13, 95, zu den drei hauptsächlichen Konfliktsursachen: „Erstens Konkurrenz, zweitens Mißtrauen, drittens Ruhmsucht“.

${ }^{67} \mathrm{~S}$. Mayer-Tasch (Fn. 20), 30, zu der „Überakzentuierung der Ordnungslegitimität“ bei Bodin und Hobbes, ferner Schrimm-Heins II (Fn. 4), 175, 180.

${ }^{68}$ S. Leviathan (Fn. 56), Kap. 13, 96, 98; De Cive (Fn. 27), Widmungsschreiben, 40 f. und Kap. I 12, $128 \mathrm{f}$. 
den. ${ }^{69}$ Bei dem gedachten Abschluss taucht kurz, einmalig, ein Demokratiekriterium auf - es geht um vernünftige Selbst- und nicht Fremdherrschaft. ${ }^{70}$ Aber kaum ist diese eingerichtet, ersetzt die Übermacht des Souveräns die Privatmacht bedrohlicher Individuen, Gruppen und Stände, die um Leben, Güter, Ehre und Religion streiten. Der Staat hat die Zwangsgewalt monopolisiert. Sicherheit ist weitgehend hergestellt, ${ }^{71}$ aber um welchen Preis? 72

Der Preis ist nicht eine Tyrannenherrschaft. ${ }^{73}$ Der Souverän soll Überleben und Wohlleben der Untertanen sichern, das ist Sinn und Zweck seiner Existenz, dazu verpflichten ihn die natürlichen Gesetze, Gott und der Unterwerfungsvertrag, der ein Vertrauensverhältnis zwischen ihm und dem Volk begründet. ${ }^{74}$ Aber all diese Einbindungen souveräner Macht liegen außerhalb des Staatsrechts. ${ }^{75}$ Rechtlich bildet der Wille des Souve-

${ }^{69} \mathrm{~S}$. die eindrückliche Kontrastierung in De Cive, Kap. X, 1, zitiert nach Geismann/ Herb Einleitung (Fn. 27), 29f.: „Außerhalb des Staates hat zwar jeder das Recht auf alles, aber kann sich doch keines Besitzes erfreuen; im Staate kann ein jeder sein beschränktes Recht sicher genießen ... Endlich besteht außerhalb des Staates die Herrschaft der Leidenschaften, Krieg, Furcht, Armut, Häßlichkeit, Einsamkeit, Barbarei, Unwissenheit, Rohheit; dagegen besteht im Staate die Herrschaft der Vernunft, Frieden, Sicherheit, Reichtum, Schmuck, Gemeinschaft, Glanz, Wissenschaft und Wohlwollen." Zur Dialektik dieser Machtverteilung s. auch Schrimm-Heins II (Fn. 4), 186: „In Hobbes' System bedingen sich die Macht des Souveräns und die Ohnmacht der Untertanen wechselseitig.“

70 S. Leviathan (Fn. 56), Kap. 16, 17 am Ende, sowie z.B. Kap. 21, 168: „Ferner ist die Zustimmung eines Untertans zur souveränen Gewalt in den Worten enthalten: ,Ich autorisiere alle ihre Handlungen oder nehme sie auf mich'. “

${ }^{71}$ Absolute Sicherheit wird als offenbar unrealistisch nicht angezielt. S. Hobbes De Cive, Kap. VI 3, zitiert bei Isensee (Fn. 54), 4: „Allerdings ist es unmöglich, die Menschen gänzlich vor gegenseitigen Schädigungen zu schützen ... Dagegen kann man Vorsorge treffen, daß kein gerechter Grund zur Furcht bestehe. “

${ }^{72}$ Hierzu M. Kriele Einführung in die Staatslehre, 1975, $§ 11$ : Risiko: Bürgerkrieg mit Polizeimitteln.

${ }^{73}$ S. Fetscher (Fn. 59), XXXI: „Der mächtige Leviathan bleibt immer ein Mittel, kein Selbstzweck."

74 S. Leviathan (Fn. 56), Kap. 30 am Anfang, 255: „Die Aufgabe des Souveräns, ob Monarch oder Versammlung, ergibt sich aus dem Zweck, zu dem er mit der souveränen Gewalt betraut wurde, nämlich der Sorge für die Sicherheit des Volkes. Hierzu ist er kraft natürlichen Gesetzes verpflichtet, sowie zur Rechenschaft vor Gott, dem Schöpfer dieses Gesetzes, und nur vor ihm. Mit ,Sicherheit' ist hier aber nicht die bloße Erhaltung des Lebens gemeint, sondern auch alle anderen Annehmlichkeiten, die sich jedermann durch rechtmäßige Arbeit ohne Gefahr oder Schaden für den Staat erwirbt.“

75 S. Leviathan (Fn. 56), Kap. 18, 137: „Da von den Vertragsschließenden das Recht, ihre Person zu verkörpern, demjenigen, den sie zum Souverän ernennen, nur durch einen untereinander und nicht zwischen ihm und jedem einzelnen von ihnen abgeschlossenen Vertrag übertragen wurde, kann seitens des Souveräns der Vertrag nicht gebrochen werden." Es handelt sich eben, wie schon angeführt, um einen drittbegünstigenden Vertrag, 
räns das Gesetz, das wiederum Recht und Gerechtigkeit determiniert. ${ }^{76}$ Auctoritas non veritas facit legem. ${ }^{77}$

Bei John Locke finden wir in den „Zwei Abhandlungen über die Regierung“ (1690) parallele Schutzgüterbestimmungen: Der Staat hat Leben, Freiheit und Eigentum zu sichern. Auch bei ihm ist der Naturzustand freier und gleicher Menschen ${ }^{78}$ potenziell unfriedlich. Allerdings scheint das $\mathrm{Maß}$ an drohender Lebensgefahr etwas geringer, ${ }^{79}$ da Locke das Hobbessche „Recht auf alles“ von vornherein auf durch das natürliche und göttliche Gesetz beschränkte, allseitig verträgliche Freiheitsentfaltung reduziert. ${ }^{80}$ Nach Erfindung des Geldes kommen jedoch größere Ungleichheiten und Konflikte zwischen Menschen auf, ${ }^{81}$ über geldvermittelte Raffgier entsteht so doch noch das Hobbessche Bild eines drohenden Kriegs aller gegen alle. Was auf der ökonomischen Makroebene gut und produktiv ist, die Entstehung einer Geld- und Wettbewerbswirtschaft, ist auf der psychologischen Mikroebene höchst gefahrenträchtig: Die Tugend der überschaubaren ökonomischen Selbstvorsorge wird in der Geldwirtschaft abgelöst durch zunehmende Habgier und Neigung zum verbrecherischen Mehrbesitz. ${ }^{82}$ Locke vertritt nicht wie Bernhard de Mandeville ${ }^{83}$ oder Adam Smith $^{84}$ die These eines aus vielen Egoismen sich automatisch herausbildenden Gemeinwohls, ${ }^{85}$ vielmehr entsteht für ihn ein Zustand „voll von Furcht und beständiger Gefahr“, in dem der Genuss des „Eigentum[s] ... sehr ungewiß und sehr unsicher" wird. Kein

der den Dritten nicht gleichzeitig verpflichtet. Man könnte auch so sagen: Horizontal, im Gesellschaftsvertragsverhältnis, ist der Vertrag gegenseitig bindend, vertikal, bei der Machtübergabe, ist der Vertrag einseitig bindend.

${ }^{76}$ S. Leviathan (Fn. 56), Kap. 13, 98; Kap. 30, 264: „Unter einem guten Gesetz verstehe ich nicht ein gerechtes Gesetz, denn kein Gesetz kann ungerecht sein. Das Gesetz wird von der souveränen Macht erlassen ...".

77 S. zu diesem Gedanken Leviathan (Fn. 56), Kap. 26, 210: „Autorität des Gesetzes, die nur im Befehl des Souveräns besteht“. In einer Originalfassung, Amsterdam 1668, 133 heißt es: „Authoritas, non Veritas facit Legem“.

78 S. Zwei Abhandlungen (Fn. 27), 2. Abhandlung, §4.

79 Anders noch der frühe Locke, zitiert bei Euchner (Fn. 27), 14, in einer Passage, die von Hobbes stammen könnte: Ohne Regierung gibt es „.... keinen Frieden, keine Sicherheit, keinen Genuß, Feindschaft unter den Menschen, keinen sicheren Besitz, und jene Schwärme stechenden Elends, die Anarchie und Rebellion begleiten".

${ }^{80} \mathrm{~S}$. Zwei Abhandlungen (Fn. 27), 2. Abhandlung, § 6.

${ }^{81}$ S. Zwei Abhandlungen (Fn. 27), 2. Abhandlung, \$\$ $47 \mathrm{ff}$.

${ }^{82} \mathrm{~S}$. Zwei Abhandlungen (Fn. 27), 2. Abhandlung, $\$ \$ 37,111$.

${ }^{83}$ S. The Fable of the Bees or Private Vices Made Public Benefits, London 1714.

${ }^{84}$ S. An Enquiry into the Nature and Causes of the Wealth of Nations, London 1776.

${ }^{85}$ Zum Verhältnis von Locke, Mandeville und Adam Smith s. I. Fetscher Rousseaus politische Philosophie. Zur Geschichte des demokratischen Freiheitsbegriffs, 1960, Kap. 1, ferner Euchner (Fn. 27), 34f. 
Wunder, dass die Lockesche Vernunft in einer solchen Situation den Menschen den Eintritt in einen bürgerlichen Zustand empfiehlt „zum Schutz ihres Lebens, ihrer Freiheiten und ihres Vermögens, was ich mit der allgemeinen Bezeichnung Eigentum zusammenfasse." ${ }^{\text {"86 }}$

Die von Hobbes abweichende Schwerpunktbildung wird an folgenden Punkten deutlich: (1) Bei Locke werden die natürlichen Rechte auf Leben, Freiheit und Eigentum aus dem Naturzustand über den Gesellschaftsvertrag - eine Art von treuhänderischer Übereinkunft - mit in den bürgerlichen Zustand als Rechtstitel hineingenommen; der Souverän bei Locke ist nicht nur wie bei Hobbes gut beraten, diese Güter zu schützen, er ist dazu von Rechts wegen verpflichtet. ${ }^{87}$ (2) Damit steht in Übereinstimmung, dass nach Locke dem Volk bei einer willkürlichen Verletzung dieser Schutzgüter ein Widerstandsrecht zukommt, ${ }^{88}$ während bei Hobbes ein solches nach der Konstruktion nicht möglich ist - dort kann das politische Gebilde bei Zweckverfehlung nur in den Naturzustand zurückfallen, was die natürlichen Rechte quasi wieder aufleben lässt. (3) Weiterhin positioniert Locke den Staat neu: Dieser ist durch seine Machtfülle nicht nur Garant von Frieden, sondern selbst Gefahr für Leben, Freiheit und Eigentum seiner Bürger. Deshalb tritt Locke für eine gewaltenteilige Wahrnehmung der Staatsgewalten ein, ${ }^{89}$ eine für Hobbes nicht friedensund freiheitssichernde, sondern -gefährdende Einrichtung!90 (4) Schließ-

${ }^{86}$ Zwei Abhandlungen (Fn. 27), 2. Abhandlung, § 123.

${ }^{87}$ S. Zwei Abhandlungen (Fn. 27), 2. Abhandlung, $§ 131$ : strikte Bindung der Staatsmacht an das Gemeinwohl i.S.d. Schutzgüterformel.

${ }^{88}$ S. Zwei Abhandlungen (Fn. 27), 2. Abhandlung, $\$ 149$ mit Formulierungen, die später in der Unabhängigkeitserklärung der Vereinigten Staaten und in der Präambel der USVerfassung wiederkehren.

${ }^{89} \mathrm{~S}$. Zwei Abhandlungen (Fn. 27), 2. Abhandlung, $\$ \$ 134$ ff. Insoweit liegt eine starke Ähnlichkeit mit Montesquieus „Vom Geist der Gesetze“ (1748) vor, der allerdings kein Vertragstheoretiker ist, sondern Freiheit und Sicherheit der Bürger aus der Entwicklung konkreter Gemeinschaften in ihrer natürlichen Umgebung und im Rahmen ihrer Sitten und Gebräuche bestimmt. Nach Montesquieu bedarf die Freiheit der Bürger der Sicherung durch gewaltenteilig umzusetzende Gesetze, die horizontal gegen andere Bürger und vertikal gegen die Staatsgewalt Leben, Freiheit und Eigentum schützen. Bei Montesquieu wird auch schon der Schritt zur Gerichtskontrolle sowie zur Subjektivierung von Rechtspositionen getan. Das zeigt sich vor allem, wie auch später bei Kant (Fn. 109), bei der Meinungsfreiheit: Vom Geist der Gesetze, Ausgabe Weigand, 1965, Buch XII, Kap. 11 und Buch XIX, Kap. 27: „Zum Genuß der Freiheit ist es nötig, daß jeder sagen kann, was er denkt“", 309. In diesem Kapitel finden sich auch erhellende Passagen zur unten VII. behandelten Volksverhetzung. Montesquieu behandelt in Buch XIII, Kap. $12 \mathrm{ff}$. auch den Beitrag von Steuern zur Sicherung von Freiheit.

${ }_{90}$ S. Leviathan (Fn. 56), Kap. 29, 248, gegen die Lehre: „Die souveräne Gewalt ist teilbar. Denn heißt die souveräne Gewalt teilen etwas anderes als sie auflösen? Geteilte Gewalten zerstören sich nämlich gegenseitig." 
lich betont Locke die bei Hobbes nicht vorhandene Rechtsbindung durch einmal erlassene, allgemeine Gesetze, während bei Hobbes der Souverän lediglich gut beraten, aber nicht rechtlich dazu verpflichtet ist, sich an sein einmal erlassenes Gesetz zu halten. ${ }^{91}$

Ähnlich wie bei Locke steht auch in Jean-Jacques Rousseaus „Du contrat social“ (1762) das Gefährdungspotenzial staatlicher Macht für menschliche Freiheit im Vordergrund. „Der Mensch ist frei geboren und überall liegt er in Ketten." ${ }^{\prime 92}$ Bei Rousseau sind die Menschen zwar auf Selbsterhaltung bedacht, aber eigentlich genügsam. ${ }^{93}$ Konflikte entstehen erst durch fortschreitende Zivilisation. Bei Locke war dies die Erfindung des Geldes und damit des wirtschaftlichen Wettbewerbs, bei Rousseau fungieren als Krisenherde das gesellschaftliche Zusammenwirken, das den Hang zur Vergleichung und zum Mehr-Sein und Mehr-Haben mit sich führt, sodann das Streben nach Eigentum. Beides führt zu erheblichen Ungleichheiten und letztlich zur Tyrannei der Gewalt, die den Hintergrund der Eingangssätze des Contrat social bildet.

Rousseau schlägt zur Verhinderung von Gewalt und Fremdherrschaft den Abschluss eines Urvertrags durch freie und gleiche Bürger vor, ${ }^{94}$ der die Anerkennung von Leben, Freiheit und Eigentum gewährleisten soll. ${ }^{95}$ Mit diesem Urvertrag haben die Bürger das ursprüngliche Recht auf alles ${ }^{96}$ aufgegeben, aber dafür gleichzeitig „einen vorteilhaften Tausch vorgenommen - zwischen einer ungewissen und misslichen Daseinsweise und einer besseren und sicheren anderen, zwischen der natürlichen Unabhängigkeit und der Freiheit, zwischen der Macht, anderen zu schaden und ihrer eigenen Sicherheit ...".97 Durch den Gesellschaftsvertrag

\footnotetext{
91 S. Zwei Abhandlungen (Fn. 27), 2. Abhandlung, $\$ \S 136 \mathrm{ff}$.

92 1. Buch, Kap. 1, 10, zitiert nach der von Kurt Weigand besorgten Ausgabe „Staat und Gesellschaft", o.J. (Goldmann-Taschenbuch Nr. 532).

${ }_{93} \mathrm{Zu}$ Rousseaus Menschenbild, das dem Contrat social zugrunde liegt, s. den Discours sur l'origine et les fondements de l'inégalité parmi les hommes (1755).

${ }_{94}^{4} \mathrm{~S}$. Contrat social (Fn. 92), 1. Buch, Kap. 2, 11: „Da alle gleich und frei geboren sind ....".

${ }_{95} \mathrm{~S}$. Contrat social (Fn. 92), 1. Buch, Kap. 6, 18: „Es ist eine Form der Vergesellschaftung zu finden, die mit der gesamten gemeinsamen Kraft die Person und die Habe jedes Teilhabers verteidigt und schützt. In ihr soll sich jeder mit allen vereinigen und dennoch nur sich selbst gehorchen, und ebenso frei bleiben wie zuvor." $\mathrm{S}$. auch 1. Buch, Kap. 8, 21: „Freiheit und ... Eigentum“; 1. Buch, Kap. 9, 24: „Anerkennung der Güter ... das gesetzliche Eigentum“; 2. Buch, Kap. 4, 30: „Leben und Freiheit“; 2. Buch, Kap. 4, 32 zu Freiheits- und Lebensschutz; 2. Buch, Kap. 5, 33 zur „Erhaltung“ der VertragsschlieBenden.

96 S. Contrat social (Fn. 92), 1. Buch, Kap. 8, 21.

97 Contrat social (Fn. 92), 1. Buch, Kap. 4, 32. S. auch 3. Buch, Kap. 9, 73: „Die Untertanen rühmen sich der öffentlichen Ruhe, die Staatsbürger der Freiheit der einzelnen.
} 
wird, ganz wie bei Hobbes und Locke, eine überwältigende Macht eingesetzt. ${ }^{98}$ Die Bildung des politischen Gemeinwillens geschieht aber nicht wie bei Hobbes durch einen einmaligen demokratischen Akt der Unterwerfung unter einen konkreten Willensträger, der fürderhin Fremdbestimmung an die Stelle von Selbstbestimmung setzt, sondern durch die Übereignung aller natürlichen Rechte an den Gemeinwillen als einen politischen Körper und Souverän, der in Permanenz auf das Gemeinwohl i.S. allgemeiner Freiheits-, Gleichheits- und Güterachtung sowie der Wohlstandsmehrung verpflichtet ist. Freiheit und Sicherheit fließen so im demokratischen Akt der Einsetzung des Volkes als Souverän und bei der Verpflichtung auf den Gemeinwillen zusammen: „Gehorsam gegen das Gesetz, das man sich vorgeschrieben hat, ist Freiheit." ${ }^{\text {"99 }}$ Damit ist das demokratische Prinzip in der Staatstheorie verankert. Gleichzeitig fällt Rousseau in der Ausformung dieses Prinzips hinter Locke und Kant zurück, ${ }^{100}$ weil seine Souveränitätskonzeption identitär und nicht repräsentativ ist; weil er keine wirkliche Gewaltenteilungslehre zur Mäßigung des Souveräns entworfen hat; und weil er das politische Gemeinwesen mit seiner Zwangsgewalt nicht wie Kant auf äußere gesetzwidrige Handlungen beschränkt, sondern den Zugriff auf die Innerlichkeit erlaubt. ${ }^{101}$

Immanuel Kant schließt in der Rechtslehre der „Metaphysik der Sitten“ $(1797)^{102}$ und in der Theorie-Praxis-Schrift (1793) ${ }^{103}$ in vielem an Hobbes, Locke und Rousseau an: Die politische Ordnung hat sich vor den Menschen und ihrer Freiheit und Gleichheit zu rechtfertigen und nicht umgekehrt. Bei Kant ist der fiktive Naturzustand weder ein Krieg aller gegen alle noch ein Zustand prästabilierter Harmonie. Sein Problem liegt in der Unsicherheit der rechtlichen Bestimmtheit und Durchsetzbarkeit des rechtlichen Mein und Dein. So entsteht die Gefahr von Streit, Gewalt und Anarchie, ein durchaus Hobbesscher und Lockescher Gedanke.104

\footnotetext{
Der eine zieht die Sicherheit der Besitztümer vor, und der andere die Sicherheit der Personen."

${ }_{98}$ Contrat social (Fn. 92), 1. Buch, Kap. 4, 29 f.

${ }_{99}$ Contrat social (Fn. 92), 1. Buch, Kap. 8, 22.

${ }_{100}$ Zusammenfassend zur Rousseau-Kritik Bielefeldt (Fn. 53), 86ff.; Kersting (Fn. 53), $165 \mathrm{ff}$., $170 \mathrm{ff}$.

${ }^{101}$ Zum Rousseauschen Zwang, frei zu sein, s. Contrat social (Fn. 92), 1. Buch, Kap. 7, 21.

102 Werke, Akademieausgabe, Bd. VI, 1968, $203 \mathrm{ff}$.

103 Über den Gemeinspruch: Das mag in der Theorie richtig sein, taugt aber nicht für die Praxis: Werke, Akademieausgabe, Bd. VIII, 1968, $273 \mathrm{ff}$.

104 In der Theorie-Praxis-Schrift (Fn. 103) spricht Kant im Zusammenhang mit seiner Ablehnung eines Widerstandsrechts vom „Zustand der Anarchie mit all ihren Greueln“, $302 \mathrm{Anm}$. Das lässt sich nicht nur auf das Stadium des Zurückfallens in den Naturzustand aus dem bürgerlichen Zustand beziehen, sondern auch schon auf den fiktiven Zeit-
} 
Die Vernunft gebietet dann den Austritt aus dem natürlichen oder privativen Zustand in den bürgerlichen Rechtszustand, in dem allein ,jedem das Seine bestimmt und gegen jedes Anderen Eingriff gesichert werden kann". ${ }^{105}$ Dazu zählen Leben, Freiheit und Eigentum, die das öffentliche Recht mit seinen Zwangsmöglichkeiten zu sichern hat. Wie bei Hobbes, Locke und Rousseau ist die Zwangsausübung beim Staat monopolisiert und mit einer Friedenspflicht für die Bürger verbunden. ${ }^{106}$ Allerdings ist Zwangsausübung von vornherein an die Durchsetzung gegenseitig verträglicher Freiheit gebunden, ${ }^{107}$ was bei Hobbes' Souverän nicht der Fall ist, während bei Locke über die Anbindung der Staatsgewalt an „Leben, Freiheit und Eigentum" eine vergleichbare Bindung vorgenommen wird. Die reziproke Freiheit bezeichnet Kant als ein angeborenes, das „einzige, ursprüngliche, jedem Menschen kraft seiner Menschheit zustehende Recht"108; damit wird über die Rechtsmaßstäblichkeit hinaus der Gedanke von Menschenrechten und deren Subjektivierung eingeführt, ${ }^{109}$ ein Schritt über Hobbes und Locke hinaus. ${ }^{110}$ Wie Locke will Kant den Staat gewaltenteilig organisieren und eingrenzen. ${ }^{111}$ Partizipatorisch ist bei Kant der Zustimmungsgedanke schon aufgenommen und repräsentativ ausgeformt, wenngleich noch nicht explizit zur Forderung demokratischer Staatsorganisation weiterentwickelt. ${ }^{112}$

Mit Kant ist in der Staatstheorie eine bis heute unabdingbare Argumentationslinie entwickelt worden: Mensch vor Staat, Autonomie vor Hete-

punkt des noch nicht erfolgten Eintretens in ebendiesen Zustand. S. auch Metaphysik der Sitten (Fn. 102), $\$$ 41, 42, 44. Zur Rechtsunsicherheit im Naturzustand als alle drei Autoren übergreifender Gesichtspunkt schon oben Geismann/Herb (Fn. 27, 64).

105 Theorie-Praxis-Schrift (Fn. 103), 289.

106 S. Theorie-Praxis-Schrift (Fn. 103), 305: „Es muß in jedem gemeinen Wesen ein Gehorsam unter dem Mechanismus der Staatsverfassung nach Zwangsgesetzen ... aber zugleich ein Geist der Freiheit sein .....

107 S. etwa Theorie-Praxis-Schrift (Fn. 103), 289 f.

108 Metaphysik der Sitten (Fn. 102), 237.

109 Ganz deutlich wird dies, wenn Kant von der Freiheit der Feder, dem Palladium der Volksrechte spricht: Theorie-Praxis-Schrift (Fn. 103), 304. Ähnlich schon Montesquieu, oben Fn. 89.

${ }^{110}$ Anders als Locke freilich verneint Kant wie Hobbes die Möglichkeit eines Widerstandsrechts. S. Theorie-Praxis-Schrift (Fn. 103), $299 \mathrm{ff}$. Bei Rousseau finden sich Andeutungen von Subjektivierung im Contrat social (Fn. 92), 1. Buch, Kap. 4, 14: „Auf seine Freiheit verzichten heißt, auf seine Würde als Mensch, auf die Menschenrechte, ja sogar auf seine Pflichten verzichten." An der Stelle wendet sich Rousseau gegen die Sklaverei und die Veräußerung von Menschen.

111 S. Metaphysik der Sitten (Fn. 102), $\$ \$ 45 \mathrm{ff}$.

112 Zur ambivalenten Haltung Kants s. W. Brugger Liberalismus, Pluralismus, Kommunitarismus, $1999,156 \mathrm{ff}$. 
ronomie, also Freiheit vor Sicherheit. Aber das Gegenteil gilt auch: Ohne Sicherheit keine Freiheit, ${ }^{113}$ insbesondere soweit es um Gefahren für Leib und Leben geht. ${ }^{114}$ Menschen stoßen mit ihren Möglichkeiten der freiwilligen Selbstorganisation an Unsicherheits- und Gehorsamsgrenzen, womit unabhängig von pessimistischeren oder optimistischeren Menschenbildern à la Hobbes und Locke zwangsbewehrtes Recht und eine Organisation staatlicher Macht notwendig werden. ${ }^{115}$ Da diese aber zur Gefahr von Willkür führt, ${ }^{116}$ ist weitergedacht demokratische Kontrolle durch die eigentlich Begünstigten, das Volk, notwendig. Freiheitssicherung bedarf des demokratisch legitimierten allgemeinen Gesetzes und gewaltenteiliger Umsetzung, ja sogar grundrechtlicher Absicherung.

In den bürgerlichen Revolutionen Amerikas und Frankreichs ${ }^{117}$ sind diese Einsichten umgesetzt worden; mit der Entscheidung des U.S. Supreme Court in Marbury v. Madison vor 200 Jahren tritt die Verfassungsgerichtsbarkeit als eigenständiges Element von Freiheitssicherung hinzu. ${ }^{118}$ Doch werfen wir noch einen staatstheoretischen Blick auf die deutsche Entwicklung von Polizei, Rechtsstaat und Sozialstaat im 18. und 19. Jahrhundert.

113 In der Nachfolge Kants hat dies W. v. Humboldt deutlich gesagt: Über die Grenzen der Wirksamkeit des Staates (1792), 1954, 66: „Ohne Sicherheit vermag der Mensch weder seine Kräfte auszubilden, noch die Früchte derselben zu genießen; denn ohne Sicherheit ist keine Freiheit."

${ }^{114}$ Hierzu Chr. Calliess Gewährleistung von Freiheit und Sicherheit im Lichte unterschiedlicher Staats- und Verfassungsverständnisse, DVBl 2003, 1096, $1101 \mathrm{ff}$., 1104, und unten bei Fn. $181 \mathrm{ff}$.

115 S. Humboldt (Fn. 113), 65f.: „[Die] Uneinigkeiten der Menschen ... erfordern allemal schlechterdings eine solche [staatliche] Gewalt" (65), ein die gesamte Gesellschaftsvertragstheorie durchziehendes Motiv (Fn. 64), das auch für die Gegenwartsreflexion bestimmend ist. S. z.B. O. Höffe Demokratie im Zeitalter der Globalisierung, 1999, Kap. 4.

116 S. Montesquieus Monitum, Geist der Gesetze (Fn. 89), 11. Buch, Kap. 4, 215: „Damit die Macht nicht mißbraucht werden kann, ist es nötig, durch die Anordnung der Dinge zu bewirken, daß die Macht die Macht bremse." Ähnlich Kant Metaphysik der Sitten (Fn. 102), § 49: „Eine Regierung, die zugleich gesetzgebend wäre, würde despotisch zu nennen sein ...".

117 Hierzu generell Kriele (Fn. 72), $\$ 37$ ff., sowie speziell unter dem Gesichtspunkt von „Freiheit und Sicherheit" Isensee (Fn. 54), $12 \mathrm{ff}$;; Robbers (Fn. 2), $51 \mathrm{ff}$;; Sommermann (Fn. 25), 91 ff.; Ryffel(Fn. 27), $307 \mathrm{ff}$;; H. Bielefeldt Philosophie der Menschenrechte, 1998, $25 \mathrm{ff}$.

118 Hierzu ausführlich W. Kremp (Hrsg.) 24. Februar 1803. Die Erfindung der Verfassungsgerichtsbarkeit und ihre Folgen, 2003, mit den Beiträgen von W. Brugger Kampf um die Verfassungsgerichtsbarkeit. 200 Jahre Marbury v. Madison, 9 ff., W. Hoffmann-Riem Das Ringen um die verfassungsgerichtliche Normenkontrolle in den USA und Europa: Zweihundert Jahre Marbury v. Madison, $23 \mathrm{ff}$., und Ch. Abernathy The Lost European Aspirations of US Constitutional Law, $37 \mathrm{ff}$. 


\section{Wandlungen von Polizei, Rechtsstaat und Sozialstaat}

Über das ganze Mittelalter und die beginnende Neuzeit war die Sicherungsaufgabe der Herrscher nicht nur begrenzt auf die Abwehr von Gewalt und Willkür; sie erstreckte sich, jedenfalls dem Anspruch nach, auch auf Fürsorge für die Untergebenen durch die Herrscher gegenüber Armut, Krankheit und Unbill, 119 sowie auf die Förderung von Moral und Religion. ${ }^{120}$ „Schutz und Schirm“ sollte der Herrscher gewähren, die Untertanen waren zur Erbringung von Gefolgschaft und Gehorsam verpflichtet. ${ }^{121}$ Mit dem Entstehen der Territorialherrschaft und des Absolutismus sowie der damit verknüpften Polizeiordnungen wurde diese Fürsorgeaufgabe aus den engeren mittelalterlichen Personalverbindungen herausgenommen und breitflächiger obrigkeitlich geregelt. ${ }^{122}$ Der ,guten Policey" war neben der Abwehr von Gefahren gelegen an der Glückseligkeit der Untertanen, dem Wohlergehen aller. ${ }^{123}$ Dies geschah aber un-

\footnotetext{
119 S. schon oben Abschnitt II sowie Willoweit (Fn. 8), 29, zu den Aufgaben des Königs im 8. und 9. Jahrhundert: „Der König hat ... höchst konkret dafür zu sorgen, daß die Menschen nicht zu gewalttätiger Selbsthilfe schreiten und Rechte Einzelner nicht willkürlich verletzt werden. Die Schutzlosen, Kirchen und Kleriker, Witwen und Waisen, kommen daher in den Befehlen des Königs besonders häufig vor."

${ }^{120} \mathrm{Zu}$ einigen notwendigen Relativierungen s. Schulze (Fn. 19), 35 f., aber auch 83.

${ }_{121}$ S. Maier (Fn. 26), 36f.; Schulze (Fn. 19), 25; Kern (Fn. 30), 152, 240, und schon oben Fn. 34 .

$122 \mathrm{Zu}$ diesem Übergang s. A. Benz Der moderne Staat, 2001, $13 \mathrm{ff}$.; Willoweit (Fn. 8), 121; Reinhard (Fn. 19), 300f.; Maier (Fn. 30), 24, 69ff., zusammenfassend 259: „Die Entstehung des modernen Polizeigedankens und der polizeilichen Tätigkeit des Staates ist ein charakteristischer Vorgang der neueren europäischen Verfassungsgeschichte ... das Vordringen der staatlichen ,Polizei (Verwaltung) [hängt] mit der Lockerung der überkommenen ständischen und religiösen Ordnungen zusammen, die im Ausgang des Mittelalters in den meisten europäischen Ländern eintritt. Die Krise der großen mittelalterlichen ,Selbstverwaltungskörper' (L. von Stein) - Kirche, Städte, Grundherrschaft - und die daraus folgenden Störungen im Bereich des politischen und sozialen Lebens rufen den modernen Staat als Ordnungsstifter auf den Plan, der mit seiner Polizei immer tiefer in die bis dahin autonomen, jetzt aber zur Selbstordnung nicht mehr fähigen ständischen Sozialbereiche vordringt und so allmählich das gesamte innere Leben der Gesellschaft seinem Gebot unterwirft.“

123 Zusammenfassend Zippelius (Fn. 33), § 14; Menger (Fn. 52), Rn. 97f.; Schulze (Fn. 19), 97; Stolleis I (Fn. 17), 370, mit einer anschaulichen Beschreibung, und Conze (Fn. 8), 845, zu im 18. Jahrhundert gebräuchlichen Einschätzungen: „Die Verbindung von Lebenssicherung mit Eigentum, Wohlfahrt, Ruhe, Zufriedenheit, Bequemlichkeit und ähnlichen Attributen für die Existenz wohlbehüteter Untertanen, denen der Selbstschutz abgenommen und denen dank der Fürsorge der Obrigkeit ermöglicht worden ist, die Früchte ihrer Arbeit ungefährdet zu genießen.“
} 
ter dem Dach eines nacharistotelischen Paternalismus ${ }^{124}$, zum Teil auch im Rahmen der Natur- und Vernunftsrechtslehren - etwa bei Christian Thomasius und Christian Wolff ${ }^{125}$-, gegen den sich dann der liberale Kant mit seiner Unterscheidung von väterlicher und vaterländischer Regierung wandte. ${ }^{126}$ Glückseligkeits-, Wohlfahrts- und Rechtszweck waren im Deutschland des 17. und 18. Jahrhunderts oft nicht unterschieden. ${ }^{127} \mathrm{Im}$ aufgeklärten Absolutismus gab es liberale Abstriche an diesen expansiven Staatszwecken. ${ }^{128}$ Theokratie und Despotie wurden beschränkt,, ${ }^{129}$ aber die in der Aufklärung eigentlich angelegte Selbstbestimmung eines jeden Menschen und Volkes in materieller wie ideeller, ökonomischer wie politischer Hinsicht blieb im aufgeklärten Absolutismus deutscher Prägung auf halber Strecke stecken, wovon die Entwicklung im zu Ende gehenden 18. Jahrhundert ${ }^{130}$ und im 19. Jahrhundert ${ }^{131}$ Zeugnis ablegt.

Immerhin: Der wachsende Einfluss des Liberalismus zeigt sich in Deutschland in der Zunahme limitierender Staatszwecke, wie sie bei Kant repräsentativ formuliert sind: Gegenseitige Freiheit ist zu sichern, nur dazu darf der Staat Zwang einsetzen, nicht um der Glückseligkeit Einzel-

124 S. Maier (Fn. 26), 25, 50f., 162f., 165ff.; Willoweit (Fn. 8), 184; Schrimm-Heins II (Fn. 4), 209; Kern (Fn. 30), 246f.; Möstl (Fn. 6), 7f. mit zahlreichen Nachweisen.

125 S. näher Sommermann (Fn. 25), $15 \mathrm{ff}$; Maier (Fn. 26), 31; Schrimm-Heins II (Fn. 4), 209; Stolleis I (Fn. 17), 268 ff., mit einer Typologie einschlägiger Naturrechtstypen auf 269.

126 Theorie-Praxis-Schrift (Fn. 103), 291. S. etwa auch den Grundsatz des Freiherrn von Bielfeld: „Die erste Pflicht der Polizey ist, den Bürgern Sicherheit für das Leben und für ihre Personen, für ihre Ehre und ihr Vermögen zu verschaffen." J. F. v. Bielfeld Lehrbegriff der Staatskunst (1761), 3. Aufl., Bd. 1, Breslau und Leipzig 1777, 192.

127 S. Maier (Fn. 26), 24, 73, 185f.; Menger (Fn. 52), Rn. 95.

128 S. Sommermann (Fn. 25), $19 \mathrm{ff} ., 23 \mathrm{ff}$.; Maier (Fn. 26), 190.

129 Das ist nach E.-W. Böckenförde Entstehung und Wandel des Rechtsstaatsbegriffs, in: ders. Recht, Staat, Freiheit, 1991, 143, 149, ein Teil des ursprünglichen Rechtsstaatsbegriffs: „Die polemischen Gegenbegriffe sind nicht Monarchie oder Aristokratie, sondern Theokratie und Despotie."

130 Man denke an das Allgemeine Landrecht für die Preußischen Staaten von 1794, das im ersten Teil von aufklärerischer Freiheit und Gleichheit der Bürger geprägt war, im zweiten Teil dagegen weitgehend die bislang vorherrschende Ständeordnung konservierte. Hierzu H. Hattenhauer Einführung in das ALR, 3. Aufl. 1996, 10ff., 16ff., 19: „Das ALR war für eine Monarchie verfaßt worden, die noch immer eine absolutistische war ... Die Verfassung des Ständestaates bestimmte die Systematik des II. Teils. Die Bausteine der ständischen Hierarchie - Bauern-, Bürger-, Adelsstand und Königtum: ,der Staat ${ }^{*}$ waren das Material des Staatsgebäudes ... Im I. Teil dagegen begegnete der Mensch seinesgleichen unabhängig von seinen ständischen Rechten und Pflichten."

131 Nachweise bei Maier (Fn. 26), 261 f., 287f., 293; Volkmann (Fn. 36), 1059f.; Grimm (Fn. 37), 64f.; Stolleis II (Fn. 49), 99ff., 187ff. 
ner willen, über die keine Einhelligkeit herzustellen ist. ${ }^{132}$ Der Rechtsstaat wird allmählich ${ }^{133}$ vom Polizeistaat geschieden. Der Staat ist primär für Gefahrenabwehr, nur noch sekundär für wohlfahrtsstaatliche Aktivitäten zuständig. Manche liberale Denker und Rechtsstaatstheoretiker sehen die Staatsgewalt nur noch als Rechtssicherungsinstanz, ${ }^{134}$ aber die breite Mehrheit will von, modern gesprochen, sekundären sozialstaatlichen Sicherungen für Arme und Schwache nicht absehen, ${ }^{135}$ wie man exemplarisch am Allgemeinen Landrecht Preußens ${ }^{136}$ und bei Kant ${ }^{137}$ sehen kann. ${ }^{138}$

132. Vgl. als weiteres Beispiel den Polizeiwissenschaftler J. v. Sonnenfels, dargestellt bei Maier (Fn. 26), 187f., wonach die (von Förderungen zu unterscheidende) Zwangsgewalt des Staates sich auf Sicherheitsprobleme konzentrieren sollte, und zwar insbesondere auf „die Sicherheit der Handlungen und Personen, die Sicherheit der Ehre, und die Sicherheit der Güter".

133 S. Maier (Fn. 26), 203, 205, 260.

${ }_{134} \mathrm{~S}$. insbesondere Humboldt (Fn. 113); weitere Nachweise bei Sommermann (Fn. 25), $36 \mathrm{ff}$., Conze (Fn. 8), 851 ff.; Böckenförde (Fn. 129), $150 \mathrm{f}$.

135 S. Böckenförde (Fn. 129), 145f.; Sommermann (Fn. 25), $24 \mathrm{ff} ., 27 \mathrm{ff} ., 48 \mathrm{ff}$; Conze (Fn. 8), $853 \mathrm{ff}$.; Maier (Fn. 26), 207ff., 293; H.-Chr. Link Staatszwecke im Verfassungsstaat, VVDStRL 48 (1989), 7, 34f.; E. Schmidt-Aßmann Der Rechtsstaat, in: HdbStR I, $1987, \$ 24$ Rn. 13.

${ }^{136}$ In dessen Einleitung formuliert $\$ 83$ unter der Überschrift „Quelle des Rechts“: „Die allgemeinen Rechte des Menschen gründen sich auf die natürliche Freyheit, sein eignes Wohl, ohne Kränkung der Rechte eines Andern, suchen und befördern zu können." Die Sicherungsaufgabe des Staates ergibt sich aus Teil II, Titel 17, § 1: „Der Staat ist für die Sicherheit seiner Unterthanen, in Ansehung ihrer Personen, ihrer Ehre, ihrer Rechte, und ihres Vermögens zu sorgen verpflichtet.“ $\$ 76$ der Einleitung, der vom „Verhältnis des Staats gegen seine Bürger" handelt, formuliert sogar subjektiv-rechtlich: „Jeder Einwohner des Staats ist den Schutz desselben für seine Person und sein Vermögen zu fordern berechtigt." Aus diesen Normen ergibt sich folgerichtig die Konzentration der Polizeiaufgaben auf Gefahrenabwehr in Teil II, Titel 17, $\$ 10$ : „Die nöthigen Anstalten zur Erhaltung der öffentlichen Ruhe, Sicherheit, und Ordnung, und zur Abwendung der dem Publico, oder einzelnen Mitgliedern desselben, bevorstehenden Gefahren zu treffen, ist das Amt der Polizey." Aber trotz dieser liberalen Zurücknahme vormals expansiverer Staatszwecke wird dem Wohlfahrtszweck jedenfalls in seiner Schutzfunktion für Arme und Schwache nicht abgeschworen, wie Teil II, Titel 17, §2, deutlich macht: „Dem Staate kommt es ... zu, zur Handhabung der Gerechtigkeit, zur Vorsorge für diejenigen, welche sich nicht selbst vorstehn können, und zur Verhütung sowohl, als Bestrafung der Verbrechen, die nöthigen Anstalten zu treffen."

137 Schon bei Kant ist der Wohlfahrtszweck nicht gänzlich aus der Staatspraxis vertrieben. Die Regierung darf nämlich aus pragmatischen Gründen, ,um [die] Stärke und Festigkeit [des Gemeinwesens] sowohl innerlich, als wider äußerliche Feinde zu sichern", sozialstaatlich tätig werden, solange sie nicht gegen das Rechtsgesetz verstößt: TheoriePraxis-Schrift (Fn. 103), 298. Das relativiert etwas die Einschätzung von Isensee (Fn. 54), 10. S. auch Metaphysik der Sitten (Fn. 102), Allg. Anmerkung nach $\S 49,325$. Näher hierzu $O$. Höffe „Königliche Völker“. Zu Kants kosmopolitischer Rechts- und Friedens- 
Dass die Versuche einer Eliminierung des Wohlfahrtszwecks aus dem Bereich der Staatsaufgaben auf irrealen wirtschaftsliberalen Annahmen über den Zuwachs allgemeinen Reichtums und die Gerechtigkeit der daraus entstehenden Sozialordnung beruhten, ${ }^{139}$ zeigte spätestens die im 19. Jahrhundert einsetzende Industrialisierung. ${ }^{140}$ Der Sozialstaat als Antwort auf die drängende „soziale Frage“ kann als die unter modernen Verhältnissen neu formulierte Schutz-und-Schirm-Verantwortung der im 19. Jahrhundert zunächst rechtsstaatlich gebändigten und dann seit 1919 auch voll demokratisch legitimierten deutschen öffentlichen Gewalt verstanden werden. ${ }^{141}$

\section{Anschlussfähigkeit des klassischen Theorierahmens für die Ordnungsprobleme der Gegenwart?}

Fragt man nach, welche Ordnungsprobleme das 20. und das beginnende 21. Jahrhundert für den modernen Staat gestellt hat bzw. stellt, so sind vier Punkte zu nennen: ökologische und informationelle Bedrohungen, nationalstaatliche Entgleisungen oder Schwächen sowie schließlich Neujustierungen zwischen staatlicher und privater Aufgabenerfüllung. Diese vier Entwicklungsstränge entfaltet die hier skizzierte Staats- und Verfassungstheorie nicht zureichend, ist sie doch im Kern Theorie des

theorie, 2001, 132ff. Zu Versuchen, sozialstaatliche Gehalte in Kants drei Rechtsprinzipien „Freiheit, Gleichheit, Selbständigkeit“ zu thematisieren, s. Brugger Liberalismus (Fn. 112), $156 \mathrm{ff}$. Kritisch hierzu W. Kersting Wohlgeordnete Freiheit. Immanuel Kants Rechts- und Staatsphilosophie, 1993, $58 \mathrm{ff} ., 376 \mathrm{f}$.

${ }^{138}$ S. etwa auch R. v. Mohl: „Wer möchte und könnte in einem Staate leben, der nur Justiz übte, allein gar keine polizeiliche Hülfe eintreten ließe?“ „,.. Ohne unmittelbare Stütze und Hülfe der Rechtspflege kann der Bürger möglicherweise sein ganzes Leben ruhig hinbringen, nicht aber eine Stunde ohne fühlbare Einwirkung einer guten Polizei. Es ist daher geradezu thörigt, von dem ,Polizei'staate als von etwas an sich Verkehrtem und zu Beseitigendem zu reden, ihm den ,Rechts'staat gegenüberzustellen. Der Staat hat sowohl für Polizei als auch für Recht zu sorgen": Polizeiwissenschaft (1831), Bd. I, 3. Aufl. 1866, Anm. 1 zu 5 und Anm. 4 zu 9.

139 S. Grimm (Fn. 37), 65ff., 75; Brugger (Fn. 112), 168f., $202 \mathrm{f}$.

${ }^{140}$ Dazu Conze (Fn. 8), 855f.; Maier (Fn. 26), 267f.; Makropoulos (Fn. 1), Sp. 748f.; Sommermann (Fn. 25), 22 mwN zu den strukturellen Ähnlichkeiten zwischen dem spätabsolutistischen Wohlfahrtsstaat und dem modernen Sozial- oder Leistungsstaat.

${ }_{141}$ Ausführlich hierzu der Sammelband „Sicherheit und Freiheit“ (Fn. 25). Spätestens in Weimar ging mit dem Sozialstaat eine Verschiebung in der Legitimationsgrundlage einher: Der Sozialstaat sollte nicht mehr Fremdsorge, sondern Hilfe bei der Selbstsorge anbieten, damit persönliche und politische Autonomie wirklich werden kann. S. Preuß (Fn. 25), 106, 118ff., 124ff. 
Rechts ihrer Zeit. Doch ist sie anschlussfähig für die meisten dieser Themen, wie die folgende Zusammenfassung in Bezug auf sicherungsbedürftige Rechtsgüter, Erledigungsmodalitäten und Akteure andeuten soll.

Die Schutzgüter sind über viele Jahrhunderte identisch: innere und äuBere Sicherheit, Schaffung und Erhaltung von Frieden, Recht und Ordnung. ${ }^{142}$ Mit den bürgerlichen Revolutionen treten Leben, Freiheit und Eigentum als nunmehr einheitliche und individualisierte Schutzgüter hinzu. ${ }^{143}$ Ferner ist die Familie zu schützen, also weitergedacht die Möglichkeit der Integration in Gemeinschaften zu gewährleisten. ${ }^{144}$ Die Ehre als psychisch-soziale Dimension von menschlicher Integrität wird als schutzwürdig ausgewiesen. ${ }^{145}$ Es geht auch um die Sicherung von wirtschaftlichen und beruflichen Aktivitäten, bis hin zur Sicherheit der Handelswege ${ }^{146}$ - sozusagen ein Vorgriff auf das technische Sicherheitsrecht und grenzenüberschreitenden Handelsverkehr. ${ }^{147}$ Schutzwürdig ist schon nach Bodin „gutes Wasser“ und nach Hobbes „das Recht auf Wasser [und] Luft", worin wir Vorläufer der ökologischen Staatsziele sehen. ${ }^{148}$ Selbst informationelle Sicherungsbedürfnisse werden schon angesprochen, wenn etwa in Günther Heinrich von Bergs, ,Handbuch des Teutschen Policeyrechts" von 1799 gewarnt wird, die Sicherheitspolizei dürfe ihre

${ }^{142} \mathrm{~S}$. neben den Angaben in den vorigen Abschnitten etwa Bull(Fn. 24), 60; G.-J. Glaeßner Sicherheit und Freiheit, Aus Politik und Zeitgeschichte B 10-11 (2002), 50, 57; K. A. Bettermann Der totale Rechtsstaat, 1986, 6f., 21; R. Steinberg Der ökologische Verfassungsstaat, 1998, $41 \mathrm{f}$.

${ }^{143}$ Zuvor waren Freiheit und Eigentum ständisch gegliedert. S. Fn. 34.

${ }^{144} \mathrm{Vgl}$. oben Fn. 10, 20; das sind Vorboten des modernen Kommunitarismus, der daneben auch an assoziative Freiheit anknüpft. S. Brugger (Fn. 112), \$\$ 7 IV und 11.

${ }^{145} \mathrm{Vgl}$. oben Fn. 10, 20, 126, 132, 136 und unten Fn. 149 sowie Hobbes über die Freiheit (Fn. 27), 115, 193; Leviathan (Fn. 56), 17. Kap., 133, 18. Kap., 142; Becker (Fn. 10), 2078; Robbers (Fn. 2), 49, 95, 98, 102, 198, 236, 238, sowie allgemein zur Bedeutung von Ehre im Mittelalter Huizinga (Fn. 3), 22, 347.

146 Vgl. oben Fn. 14, 19, 55. Schon für das Mittelalter diagnostiziert Grimm (Fn. 37), 55: „Fernhandel und Frühformen des Kapitalismus“.

${ }^{147}$ S. unten Fn. 154.

${ }^{148}$ S. oben Fn. 56 zu Hobbes und generell hierzu Bull (Fn. 24), 224ff.; Sommermann (Fn. 25), 247 ff.; Steinberg (Fn. 142); J. Nida-Rümelin/D. v. d. Pfordten (Hrsg.) Ökologische Ethik und Rechtstheorie. Auch bei Bodin finden sich solche ökologischen Gedanken: „Wenn [der Mensch] sich dann den Naturschönheiten zuwendet, wird er entzückt sein von der Vielfalt der Tiere, Pflanzen und Stoffe und sich Gedanken machen über ihre jeweilige Gestalt, Beschaffenheit und Vorzüge, über das, was sie zueinander hinzieht und voneinander abstößt und über die Ursachenkette, durch die sie alle verbunden sind“: Sechs Bücher (Fn. 20), 1. Buch, 1. Kap., 103. Auf S. 102 spricht er davon, wie wichtig „gutes Wasser“ ist und unterscheidet Aufgaben, ,um die man sich in jedem Gemeinwesen zu allererst und mit größter Sorgfalt zu kümmern pflegt“, von solchen, „die einem das Leben erleichtern“. 
Gewalt nie „dazu mißbrauchen, selbst die Sicherheit der Bürger zu stören“. Sie dürfe ,nie in eine mißtrauische Staatsinquisition ausarten, die in das Innere der Familien eindringt, jede gesellschaftliche Freude verbittert, Verdacht unter Freunden und Verwandten ausstreut, schändliche Heuchelei erzeugt, und überall um sich her sclavische Furcht verbreitet" ${ }^{149}$

Privatisierungsdiskussionen, wie sie seit einiger Zeit angesichts leerer staatlicher Kassen und überforderter staatlicher Regelungsmechanismen geführt werden, sind natürlich in der hier vorgestellten Literatur nicht zu erwarten. Trotzdem verdeutlicht schon die mit Locke und Kant einsetzende Liberalisierung im Rechtsdiskurs, dass der Zurücknahme staatlicher Kompetenzen kein Zuständigkeitsvakuum entspricht. Sie soll gerade private und gesellschaftliche Initiative freisetzen..$^{150} \mathrm{Hegel}$ führt dies fort mit seiner Konzeption von ,bürgerlicher Gesellschaft“ und der Unterscheidung von Staat und Gesellschaft. ${ }^{151}$ Damit wird letztlich eine objektive Grenze von Staatsgewalt angezeigt. Weitergedacht führt dies zu einem subjektiven Freiheitsrecht der Bürger und angesichts leerer Staatskassen bis zu einem gewissen Umfang auch zu einer Selbstorganisationsund Versicherungspflicht. ${ }^{152}$

149 Zitiert nach der 2. Aufl., Erster Theil, Hannover 1802, 211. Der Text fährt fort: „Jenes rasche und nachdrückliche Verfahren, wenn gefährliche Plane oder Unternehmungen vereitelt und unterdrückt werden sollen, muß stets den Grundsätzen der Gerechtigkeit gemäß sein, und darf nie die bürgerliche Freyheit oder die Rechte des Eigenthums willkürlich kränken, oder auf einen bloßen leichten Verdacht hin die Ehre des Bürgers verletzen."

${ }^{150} \mathrm{~S}$. hierzu vor allem die Interpretation von Locke durch C. B. Macpherson The Political Theory of Possessive Individualism. Hobbes to Locke, 1962. Hierzu auch Euchner Einleitung (Fn. 27), 10f., 33, 48f.

151 S. die Grundlinien der Philosophie des Rechts (1821), 3. Teil, 2. und 3. Abschnitt und allgemein zu dieser Unterscheidung Grimm (Fn. 37), 59f., 65 f., 67f., 69f. Bei Hegel wird gleichzeitig der "Staat“ mit besonderer Dignität versehen, worin man i.S.d. oben Gesagten einen Rückschritt sehen kann. So Isensee (Fn. 54), 11.

152 Die schon im 17. Jahrhundert einsetzende und dann im 18. und 19. Jahrhundert stärker werdende Assekuranzbewegung ist ein früher Vorläufer dieser im 21. Jahrhundert wieder sich aufdrängenden Not zur Selbstvorsorge. Hierzu Conze (Fn. 8), 848f.: „Nach dem Vorlauf der Assekuranz für Seetransporte ... im 14. Jahrhundert ... kam das moderne Versicherungswesen im 17. Jahrhundert auf. Im 18. Jahrhundert mehrten sich Feuer-, Vieh-, Hagel- und ... Lebensversicherungen ..... Ausführlich zur Entstehung des Versicherungswesens die Beiträge von $P$. Koch in dem von H. L. Müller-Lutz/K.-H. Rehnert hrsg. Sammelband „Beiträge zur Geschichte des deutschen Versicherungswesens“, 1995, insbes. $151 \mathrm{ff}$., $171 \mathrm{ff}$, $224 \mathrm{ff}$. S, auch Kaufmann (Fn. 1), $154 \mathrm{mwN}$ in Fn. 19 und Schrimm-Heins II (Fn. 4), 210ff. mit dem Hinweis darauf, dass der Begriff ,soziale Sicherheit" als „social security“ zum ersten Mal 1935 von dem US-Präsidenten Franklin D. Roosevelt propagiert wurde. Inzwischen ist der Begriff z.B. in die Allgemeine Erklärung der Menschenrechte aufgenommen worden. Vgl. deren Art. 22 und 25. 
Was transnationale oder grenzüberschreitende Rechtsorganisationsformen angeht, die wegen staatlicher Ohnmacht oder Übermacht zur Sicherung wichtiger Rechtsgüter erforderlich sind, so schlossen die seit dem Mittelalter unter dem Dach des Heiligen Römischen Reiches Deutscher Nation entstandenen Bündnisse in Bezug auf äußere Sicherheit oder die Sicherheit der Handelswege nicht nur „Lücken im Leistungsangebot der werdenden Staatsgewalt" ${ }^{\text {"153 }}$, sondern sind auch als Vorboten von Organisationen wie NATO und EU verstehbar. ${ }^{154}$ Solche Bündnisse und Schutzverträge nahmen mit wachsendem Grad von Territorialisierung, Säkularisierung und Machtvereinheitlichung staatliche und im gegenseitigen Verkehr völkerrechtliche Züge an. All das zeigt, dass die bürgerliche, moderne, aber noch vorpostmoderne Staats- und Verfassungstheorie schon für fast alle Gebiete notleidender Sicherheit und Freiheit anschlussfähig ist.

Blenden wir von diesen Schutzgütern über zu den Akteuren und Modalitäten zur Sicherung der betreffenden Güter, so ist zunächst ein naheliegendes Missverständnis abzuwehren. Der Hinweis auf die Schutzbedürftigkeit von Leben, Freiheit, Eigentum, Lebensgemeinschaften, Ehre, Information, Ökologie und grenzüberschreitendem Verkehr führt konzeptionell nicht automatisch zu einer staatlichen Eigenerledigungspflicht. Vielmehr ist zu differenzieren - und lässt sich im Rahmen der dargelegten Theorieentwicklung differenzieren ${ }^{155}$ - zwischen den staatlichen Schutzzwecken, den dazu besten Mitteln sowie den einzuschaltenden Akteuren:

\footnotetext{
153 So Reinhard (Fn. 19), 247.

$154 \mathrm{Vgl}$. zu dem Traditionsstrang zwischen der mittelalterlichen und der europarechtlichen Sicherung von Handelswegen Chr. Calliess Sicherheit im freiheitlichen Rechtsstaat. Eine verfassungsrechtliche Gratwanderung mit staatstheoretischem Kompaß, ZRP 2000, 1, 2, 4, ferner EuGH, Urteil vom 9. Dez. 1997, Rs. C-265/95 - Kommission vs. Frankreich, zur Verpflichtung der Mitgliedstaaten zum Schutz des innergemeinschaftlichen Handelsverkehrs gegen private Gewalt, EuGRZ 1997, 620ff., Rn. 53: „Diese Feststellung ist besonders deshalb geboten, weil die ... Sachbeschädigungen und Drohungen nicht nur die Ein- oder Durchfuhr der von den Gewalttaten unmittelbar betroffenen Erzeugnisse in Frankreich gefährden, sondern auch eine Atmosphäre der Unsicherheit schaffen können, die sich auf die gesamten Handelsströme nachteilig auswirkt."

155 Diesem Schluss scheint die Garde der Souveränitätstheoretiker zu widersprechen, doch unterscheidet schon Bodin zwischen der ersten Frage nach dem höchsten Ziel des Staates - also den zu schützenden Gütern; danach ist „,nach den Mitteln und Wegen zu fragen ..., wie dieses erreicht werden kann": Sechs Bücher (Fn. 20), 1. Buch, Kap. 1, 98. S. auch den bei Sommermann (Fn. 25), 42 zitierten K. S. Zachariä Vierzig Bücher vom Staate, 3 Bde., Heidelberg 1839-42, 5. Buch (= Bd. 1, 1839, 147-168): „Überdies bestimmen die Grundsätze des Rechts in vielen Fällen nur das Ziel, auf welches die Bestrebungen gerichtet sein sollen, nicht aber den Weg, welcher zu dem Ziel führt." Solche Sätze
} 
Den Staat trifft zwar die originäre Aufgabe zur Ausschaltung von Gewalt und Lebensbedrohungen sowie zu geregelter Streitentscheidung, ${ }^{156}$ in Bezug auf die Organisation des Schutzes für weitergehende Staatsziele ist die moderne Staatstheorie aber offen für exklusive, kooperative oder auch in gesellschaftliche Selbstorganisation delegierte Verantwortlichkeiten. Je nach Gefahrenlage und Problemlösungspotenzial ist ein Entscheidungsspielraum eröffnet, der von außerrechtlichen zu privat-, straf- und öffentlichrechtlichen Instrumenten, von Geld über Polizei zu Gesetzen, ${ }^{157}$ von

eröffnen Reflexions- und Entscheidungsmöglichkeiten für bestmögliche - also nicht notwendigerweise staatliche - Erledigungsarten. Ähnliches gilt für Hobbes, dessen Theorie zwar eine souveräne, aber nicht totalitäre Staatsorganisation befürwortet. Hobbes' Theorie leidet an einer gewissen Vereinseitigung durch Anthropologisierung eines historischen Kontextes, nämlich der zu seiner Zeit herrschenden Anarchie und den Bürgerkriegsverwüstungen, die er in sein konfliktträchtiges Menschenbild einbaut. Liest man Hobbes aber kontextgebunden, dann überzeugt sein Plädoyer für die alles überwältigende Staatsmacht vor allem für Situationen ,stechenden Elends, die Anarchie und Rebellion begleiten" (Fn. 79), aber nicht mehr für Situationen, in denen erst einmal Frieden geschaffen worden ist. Dann könnten konzeptionell andere Überlegungen von ihm in den Vordergrund treten. Hobbes formuliert explizit: „Mit Sicherheit ist hier aber nicht die bloße Erhaltung des Lebens gemeint, sondern auch alle anderen Annehmlichkeiten, die sich jedermann durch rechtmäßige Arbeit ohne Gefahr oder Schaden für den Staat erwirbt": Leviathan (Fn. 56), Kap. 30, 255. Das kann man als Freisetzung gesellschaftlich-ökonomischer Initiative ansehen. So sieht es auch Isensee (Fn. 54), 14. Hobbes ist auch kein totalitärer Sicherheitsfanatiker, sondern andeutungsweise liberaler Vorsorgedenker: „[Es] ist ... unmöglich, die Menschen gänzlich vor gegenseitigen Schädigungen zu schützen ... Dagegen kann man Vorsorge treffen, daß kein gerechter Grund zur Furcht besteht" : De Cive, Kap. VI 3, zitiert nach Isensee ebd., 4, und diskutiert bei Murswiek (Fn. 54), 17.

156 S. Grimm (Fn. 37), 82f.; Bull (Fn. 24), 60, 68, 101 f., 217, 348, 352; Böckenförde Freiheit und Recht, Freiheit und Staat, in: ders. Recht, Staat, Freiheit, 1991, 42, 53, 56; A. Scherzberg Wozu und wie überhaupt noch öffentliches Recht?, 2003, 35, 38; Hauer (unten Fn. 163), 5. Deshalb nennt Murswiek diese Sicherheitsaufgabe ,notwendig“: Fn. 54, 8, 13f. Ähnlich G. F. Schupperl Verwaltungswissenschaft, 2000, 82 zu „Sine Qua Non Activities" der Staatsgewalt. Hierzu K. Eichenberger Die Sorge für den inneren Frieden als primäre Staatsaufgabe, in: ders. Der Staat der Gegenwart, 1980, 73, 94: „Es gibt offenbar Aufgabenbereiche [wie die Wahrung des inneren Friedens], die dem souveränen Staat gerade zufolge seiner Souveränität nicht zur freien Disposition stehen. Sie sind ihm wesensgemäß mitgegeben, die Erfüllung unabdingbar vorgegeben". So auch Chr. Starck Frieden als Staatsziel, in: ders. Der demokratische Verfassungsstaat, 1995, 231f. K. Stern Der moderne Staat. Aufgaben Grenzen und Reformgedanken, FS Kirchhoff, 2002, 263, 268, spricht von den „unentbehrlichen Staatsaufgaben“, den „Kernaufgaben“, den „die Staatlichkeit definierenden Tätigkeiten“, „wie Sicherheit nach innen und außen, Gewährleistung von Freiheit und Gerechtigkeit, sowie allenfalls allgemeine Wohlfahrtsförderung“"

${ }^{157}$ So die Einteilung von F. I. Michelman The Protective Function of the State in Constitutional Law, Vortrag bei einer Tagung der Venedig-Kommission an der Universität Göttingen am 23. und 24. Mai 2003 (erscheint demnächst in einem von G. Nolte hrsg. Band über: European and American Constitutionalism). 
Befehl und Zwang bis zu indirekter Steuerung und subsidiärer Auffangverantwortung ${ }^{158}$ reicht. Die Staatstheorie ist schließlich außerhalb des staatlichen Zwangsmonopols offen für eine Auswahl von Akteuren, die vom Nationalstaat bis zu transnationalen oder innerstaatlichen Organisationen genauso reicht, wie sie gesellschaftliche Akteure kennt, die in privatrechtlichen, öffentlichrechtlichen oder gemischten Rechtsformen handeln.

\section{Freiheit und Sicherheit im Grundgesetz}

Wenden wir den Blick von der Staats- und Verfassungstheorie zum Verfassungsrecht. Im Grundgesetz bildet Freiheit einen herausragenden Verfassungswert. ${ }^{159}$ Dagegen fehlt ein vergleichbar prominentes Staatsziel ${ }^{160}$ „Sicherheit“. Das erklärt sich aus der Reaktion der Grundgesetzgeber ${ }^{161}$ gegenüber der weit hinter Hobbes zurückfallenden nationalsozialistischen Schreckensherrschaft. ${ }^{162}$ Die Textlücke im Grundge-

${ }^{158} \mathrm{~S}$. exemplarisch zu neuen Steuerungsformen $E$. Schmidt-Aßmann Das allgemeine Verwaltungsrecht als Ordnungsidee, 1998, 18ff.; Schuppert (Fn. 156), Kap. 2 C, D; Scherzberg (Fn. 156), 15ff., und schon Bull (Fn. 24), 215 und $\S 21$.

159 Dazu ausführlich E. Grabitz Freiheit und Verfassungsrecht, 1976.

160 Zur Terminologie: Die Begriffe Staatszwecke und Staatsziele und weitergedacht Staatsaufgaben werden in der Literatur nicht immer gleich benutzt. Im Vordergrund steht entweder eine Abstufung nach Abstraktionsgrad (von den ganz abstrakten Zwecken zu den auf mittlerer Konkretionsstufe angesiedelten Zielen bis zu den spezifischen Aufgaben) oder eine Differenzierung nach vorpositiven und positiven Feldern staatlicher Tätigkeit (von den vorverfassungsrechtlichen, durch Empirie oder Theorie - etwa Vernunftrecht - ausgewiesenen Zwecken des Staates zu den verfassungsrechtlichen Entsprechungen in Zielen sowie noch konkreteren Aufgaben). Vgl. zum Beispiel Bull (Fn. 24), 43 ff., $114 \mathrm{ff}$.; Link (Fn. 135), 17 ff. und G. Ress Staatszwecke im Verfassungsstaat - nach vierzig Jahren Grundgesetz, VVDStRL 48 (1990), 15, $17 \mathrm{ff}$., $61 \mathrm{ff}$., 108; D. Merlen Über Staatsziele, DÖV 1993, 368ff.; Brugger (Fn. 112), 359 ff.; Murswiek (Fn. 54), $10 \mathrm{ff}$. Es finden sich auch Kombinationen dieser Sichtweisen oder noch andere Unterteilungen. S. Möstl (Fn. 6), $37 \mathrm{ff}$;; Sommermann (Fn. 25), 3, $355 \mathrm{ff}$., $377 \mathrm{ff}$. Auf jeden Fall können Werte wie „Freiheit" und „Sicherheit" sowohl vorpositive Staatszwecke als auch verfassungsintegrierte Staatsziele sein, die dann oft, aber eben nicht automatisch, auch zu Staatsaufgaben iS staatlicher Erledigungspflichten führen.

${ }^{161}$ Die Lage in den Landesverfassungen ist uneinheitlich, aber mehrheitlich dem Grundgesetz vergleichbar. Am ehesten noch in Richtung eines allgemeinen Staatsziels „Sicherheit“ formuliert Art. 99 der Verfassung Bayerns: „Die Verfassung dient dem Schutz und dem geistigen und leiblichen Wohl aller Einwohner. Ihr Schutz gegen Angriffe von außen ist gewährleistet durch das Völkerrecht, nach innen durch die Gesetze, die Rechtspflege und die Polizei.“

$162 \mathrm{~S}$. die Berichte von H. Dreier und W. Pauly zu, Die deutsche Staatsrechtslehre in der Zeit des Nationalsozialismus“, VVDStRL 60 (2001), $9 \mathrm{ff}$., $73 \mathrm{ff}$. 
setz ${ }^{163}$ wird nicht nur im historisch-normativen Rückblick deutlich. Die Lücke steht auch vor Augen im Gegenwartsvergleich moderner Verfassungen ${ }^{164}$ sowie europäischer und internationaler Rechtsinstrumente. ${ }^{165}$ Exemplarisch zeigen dies die Formulierungen in Art. 2 und 29 des EUVertrags und Art. 61 des EG-Vertrags vom „Raum der Freiheit, der Sicherheit und des Rechts" sowie Art. 5 Abs. 1 S. 1 der EMRK und Art. 6 der Charta der Grundrechte der EU mit ihrer Aussage: „Jede Person hat das Recht auf Freiheit und Sicherheit."166

Trotz der Textlücke - ja vielleicht gerade wegen ihr - kommt der Sicherheitsauftrag in der Staatsrechtslehre nicht zu kurz. Im Grundgesetz steht die Subjektivierung von Sicherheitsbelangen an dritter Stelle einer Argumentationskette, die vom Rechtsstaat zu den grundrechtlichen Schutzpflichten fortschreitet und schließlich zur Subjektivierung in einem Grundrecht auf Sicherheit führt; ${ }^{167}$ zusätzlich werden Argumente aus

${ }^{163}$ Das gilt auch für Österreich, dessen Bundesverfassungsgesetz ebenfalls kein explizites allgemeines Verfassungsrechtsgut "Sicherheit“" kennt. Doch wird dort wie in Deutschland „Sicherheit“ als implizit verankert angesehen, etwa in Art. 1 B-VG, nach dem „Österreich ... eine demokratische Republik" ist. Vgl. hierzu A. Hauer Ruhe, Ordnung, Sicherheit. Eine Studie zu den Aufgaben der Polizei in Österreich, 2000, 2 ff.: „Die ,Gefahrenabwehr' ist in Österreich von Verfassungs wegen Staatsaufgabe. Der Staat ist kraft besonderen Verfassungsauftrages verpflichtet, Gefahren für bestimmte Schutzgüter, nämlich Gefahren für die Existenz des Staates selbst, dann Gefahren für das Leben, die körperliche Unversehrtheit und die Gesundheit, die Freiheit und das Habe der Menschen sowie letztlich sonstige Gefahren für ein geordnetes und friedliches Zusammenleben in der Gesellschaft, mit Hilfe seiner Organe abzuwehren. Die verfassungsrechtliche Grundlegung einer Staatsaufgabe zur Abwehr dieser Gefahren läßt sich anhand folgender Überlegungen nachweisen“ (2f.). Dann folgt der Hinweis auf Art. 1 B-VG sowie auf Spezialnormen, die mit Sicherheit zu tun haben.

164 Beginnend mit der Grundrechteerklärung von Virginia von 1776, Art. 1, der Präambel der Verfassung der Vereinigten Staaten von Amerika von 1787 und Art. 2 und 16 der französischen Erklärung der Menschen- und Bürgerrechte von 1789. S. als modernes Beispiel etwa Art. 2 der Bundesverfassung der Schweiz von 1999: „Die Schweizerische Eidgenossenschaft schützt die Freiheit und die Rechte des Volkes und wahrt die Unabhängigkeit und Sicherheit des Landes"; die folgenden Absätze enthalten weitere Staats„Zwecke“. S. auch Art. 57, der klarstellt, dass Bund und Kantone im Rahmen ihrer jeweiligen Kompetenzen eine gemeinsame, auf Koordination abzielende Sicherheitsverantwortung haben.

${ }^{165}$ Nachweise bei P. J. Tettinger Freiheit in Sicherheit, FS Kirchhoff, 2002, 281, $292 \mathrm{ff}$.; Möstl (Fn. 6), \$\$ 11, 12.

${ }^{166}$ Die Vorschriften haben allerdings einen spezifischen Bezug zu Einschränkungen der körperlichen Bewegungsfreiheit und Freiheitsentziehungen. S. dazu näher J. Frowein/ W. Peukert EMRK-Kommentar, 2. Aufl., Art. 5 Rn. $1 \mathrm{ff}$. und N. Bernsdorffin: J. Meyer (Hrsg.) Komm. zur Charta der Grundrechte der Europäischen Union, 2003, Art. 6 Rn. 1, $10 \mathrm{ff}$.

167 S. etwa J. Limbach Ist die kollektive Sicherheit Feind der individuellen Freiheit?, AnwBl 2002, 454: „Trotz des Schweigens des Grundgesetzes ergibt sich eine Pflicht des 
den grundrechtlichen Schrankenvorbehalten ${ }^{168}$, dem Demokratieprinzip $^{169}$, dem Sozialstaatsprinzip ${ }^{170}$ und diversen Kompetenztiteln ${ }^{171}$ zur Wahrnehmung der Aufgaben innerer und äußerer Sicherheit genannt. ${ }^{172}$

Streitig ist das "Grundrecht auf Sicherheit“, das 1983 Josef Isensee" ${ }^{173}$ und 1987 Gerhard Robbers ${ }^{174}$ propagiert haben. ${ }^{175}$ Vertreter eines solchen Grundrechts ${ }^{176}$ weisen auf die immer schon und nach wie vor gegebene Gefahr von privater und gesellschaftlicher Gewalttätigkeit und Rechtlosigkeit hin, die stärkere Schutzpflichten des Staates und im Extremfall auch subjektive Ansprüche erfordere. Da der Staat durch das seit der Neuzeit in Anspruch genommene Monopol legitimer Gewaltanwendung private Selbstverteidigungsrechte expropriiert habe, sei es nur angemessen, jedenfalls bei existenziellen Gefahren und klaren Verantwortlichkeiten subjektive Berechtigungen einzuräumen. ${ }^{177}$ Gegner eines Grundrechts auf Si-

Staates, für die Sicherheit seiner Bürgerinnen und Bürger zu sorgen, aus dem Gesamtsinn der Verfassung, vornan aus dem Rechtsstaatsprinzip und dem Recht auf Leben und körperliche Unversehrtheit“, allerdings mit Präferenz für ein „Staatsziel der Sicherheit" vor einem Grundrecht auf Sicherheit, ebd., 455.

168 S. etwa Art. 13 Abs. 4, 7 GG. Zum weiteren Umfeld gehören auch Art. 8 Abs. 1, Art. 26 sowie die weiter unten behandelten Vorschriften zur wehrhaften Demokratie.

169 Das Demokratieprinzip in Art. 20 Abs. 1 und 38 Abs. 1 GG weist darauf hin, dass die Entscheidung der Bürger im politischen Prozess, die letztlich auf ein Gesetz über die Balance von Freiheit und Sicherheit hinausläuft, jedenfalls starke Beachtung verdient.

${ }^{170}$ Das Sozialstaatsprinzip weist darauf hin, dass in vielen Fällen Bürger nicht selbst oder in privatrechtlicher Form für ausreichende innere Sicherheit sorgen können; dann gebietet das Sozialstaatsprinzip ein staatliches Eingreifen.

171 S. insbesondere Art. 24 Abs. 2; 35 Abs. 2; 73 Nr. 1, 6, 10; 74 Abs. 1 Nr. 1, 2, 3, 4, 6, 11 a, 22; 80 a; 87 Abs. 1; 87 a; 115 a ff.

172 Zusammenfassend V. Götz Innere Sicherheit, in: HdbStR III, 1988, § 79 Rn. 2; Chr. Gusy Polizeirecht, 5. Aufl. 2003, Rn. $72 \mathrm{ff}$.

173 Oben Fn. 54.

174 Oben Fn. 2.

175 S. K. Stern Ein Beitrag zur Inpflichtnahme des Staates für die Optimierung der Grundrechte, FS Korinek, 2002, 1, 19 zum ,umstrittensten Problem der objektiv-rechtlichen Dimension der Grundrechte".

$176 \mathrm{Vgl}$. neben Isensee und Robbers z. B. Bundesinnenminister O. Schily, zitiert in Horst Meier Ein Grundrecht auf Sicherheit?, Merkur 2003, 174: „Ich orientiere mich an dem Grundrecht auf Sicherheit ... Wer durch Terror und Kriminalität bedroht wird, lebt nicht frei. Das Grundrecht auf Sicherheit steht auch, zwar nicht direkt, aber sehr wohl indirekt, im Grundgesetz"; Calliess Sicherheit (Fn. 154), 6.

177 Dieser Zusammenhang wird schon im Preußischen Allgemeinen Landrecht von 1794 in der Einleitung, 1. Teil, im Abschnitt „Verhältniß des Staats gegen seine Bürger“ in den $\$ \$ 76$ und 77 hervorgehoben: ,Jeder Einwohner des Staats ist den Schutz desselben für seine Person und sein Vermögen zu fordern berechtigt. Dagegen ist niemand sich durch eigne Gewalt Recht zu verschaffen befugt." Im Grunde greift dieser Zusammen- 
cherheit ${ }^{178}$ sehen damit die Stufung von privater Freiheit und staatlicher Reglementierung auf den Kopf gestellt; Sicherheit rücke vor Freiheit; das könne dazu führen, dass der Staat nicht mehr den Freiheitseingriff, sondern der Bürger seine Freiheitsausübung rechtfertigen müsse. Gewisse Akzentverschiebungen zwischen den beiden Lagern sind bei konkreten Abwägungsfragen zu erwarten, aber die Unterschiede sind nicht dramatisch. Denn die „Erfinder“ des Grundrechts auf Sicherheit haben von Anfang an dieses subjektive Recht nur selten durchschlagen lassen. Das zeigt sich an der Rechtsprechung des Bundesverfassungsgerichts, die sich weitgehend innerhalb des von Isensee und Robbers vorgezeichneten Rahmens ${ }^{179}$ hält. Das Gericht sieht die Sicherheit von Staat und Bürgern als unverzichtbare Verfassungswerte und Staatsziele an ${ }^{180}$, hält an der Priorität der abwehrrechtlichen Dimension der Grundrechte fest, sieht aber auch bei Gefahren insbesondere für Leib und Leben staatliche Schutzpflichten vorliegen. Diese sind zwar primär durch gesetzgeberische Gestaltung zu konkretisieren, aber je nach der Art des bedrohten Rechtsguts, dem Bedrohungsgrad und Verantwortungszusammenhang kann die Schutzverpflichtung zunehmen. ${ }^{181}$ Droht ein Untermaß an Schutz und liegt ein überschaubarer Begünstigtenkreis vor, kann sich die Schutzpflicht zu einem Anspruch auf Einschreiten verdichten. ${ }^{182}$ Meist aber liegt zwischen dem Untermaßverbot gegenüber dem von dritter Seite bedrohten Opfer und dem Übermaßverbot gegenüber dem von einem staatlichen Eingriff bedrohten Privaten ein deutlicher legislativer oder auch exekutiver Einschätzungsspielraum.

hang schon auf das Verbot der Fehde im Ewigen Landfrieden von Worms im Jahr 1495 zurück (Fn. 11, 47, 48).

${ }^{178}$ S. z. B. M. Kniesel „Innere Sicherheit" und Grundgesetz, ZRP 1996, 482, 486; Gusy (Fn. 172), Rn. 74; W. Hassemer Zum Spannungsverhältnis von Freiheit und Sicherheit. Drei Thesen, Vorgänge 2002, 10f.; Meier (Fn. 176), 174ff.; E. Denninger Der gebändigte Leviathan, 1990, 33, 47, 377.

179 S. Isensee (Fn. 54), $34 \mathrm{ff}$; ders. Das Grundrecht als Abwehrrecht und staatliche Schutzpflicht, in: HdbStR V, 1992, § 111, Rn. 77 ff., 86ff.; Robbers (Fn. 2), 204, $246 \mathrm{ff}$. Zu neueren Verfeinerungen dieses Ansatzes s. exemplarisch Möstl (Fn. 6), 84ff., 108, und Calliess Gewährleistung (Fn. 114), $1102 \mathrm{ff}$.

${ }^{180}$ S. BVerfGE 49, 24, 56f. unter Bezugnahme auf BVerwGE 49, 202, 209: „Die Sicherheit des Staates als verfaßter Friedens- und Ordnungsmacht und die von ihm zu gewährleistende Sicherheit seiner Bevölkerung sind Verfassungswerte, die mit anderen im gleichen Rang stehen und unverzichtbar sind, weil die Institution Staat von ihnen die eigentliche und letzte Rechtfertigung herleitet.“

${ }^{181}$ S. BVerfGE $39,1,42 ; 46,160,164 ; 49,24,53 ; 49,89$, 140ff.; 53, 30, 57 ff.; 56, 54 , $73 \mathrm{ff}$; $88,203,251$.

${ }^{182}$ S. neben Fn. 181 die neueren Nachweise bei Stern (Fn. 175), 16, $19 \mathrm{f}$. 


\section{Das Beispiel Volksverhetzung}

Die zwei Beispiele behandeln nicht klare Gefahren für Leib und Leben, die evidente staatliche Schutzpflichten auslösen; ${ }^{183}$ vielmehr stehen grundrechtlich geschützte Aktivitäten im Vordergrund, die nicht sicher, sondern nur möglicherweise und mit zeitlichem Abstand zu Risiken für Rechtsgüter führen und somit die Frage nach staatlicher Vorsorge auslösen. Es geht also um Spannungslagen von Freiheit und Sicherheit, bei deren Auflösung neben Rechtstext und einschlägiger Dogmatik wohl auch eher libertäre oder sekuritäre Vorverständnisse eine Rolle spielen. $\S 130$ Abs. 1 Nr. 1 und Abs. 2 Nr. 1 und 2 StGB enthält ein Verbot von Volksverhetzung ${ }^{184}$ in der Variante des Aufstachelns zum Hass gegen Teile der Bevölkerung. ${ }^{185}$ Die Tathandlung besteht in Äußerungen, die dem Schutzbereich der Meinungsfreiheit unterfallen, da es nach Art. 5 Abs. 1 GG gleichgültig ist, ob ein Werturteil begründet oder grundlos, rational oder emotional, wertvoll oder wertlos, harmlos oder gefährlich,

${ }^{183}$ In Bezug auf solche Lagen verstärken sich Freiheits- und Sicherheitsinteressen gegenseitig, so dass besonders starke Gründe für eine staatliche Schutzverpflichtung sprechen. S. Humboldt (Fn. 113); Schily (Fn. 176); Calliess Sicherheit (Fn. 154), 5f.; ders. Gewährleistung (Fn. 114), 1096, $1100 \mathrm{ff}$. Staatlicher Zwang zur Erzwingung einer Aussage einer in Polizeigewahrsam befindlichen Person ist als „Folter“ unter allen Umständen verboten, auch wenn die Person klar Gefahrverursacher ist und die gesuchte Information ein Menschenleben oder viele Menschenleben retten könnte. Das ergibt sich z. B. aus $\$ 35$ Polizeigesetz Baden-Württemberg, Art. 104 Abs. 1 S. 2 GG und mehreren völkerrechtlichen Konventionen, etwa Art. 3 EMRK. Zur Problematik eines solchen absoluten Verbotes s. W. Brugger Darf der Staat ausnahmsweise foltern?, Der Staat 35 (1996), $67 \mathrm{ff}$.; ders. Vom unbedingten Verbot der Folter zum bedingten Recht auf Folter?, JZ 2000, $165 \mathrm{ff}$.; J. Isensee Der Verfassungsstaat als Friedensgarant, in: R. Mellinghoff u.a. (Hrsg.) Die Erneuerung des Verfassungsstaates, 2003, Abschnitt VI 2.

184 Ausführlich zu diesem Paragraphen samt dessen Abs. 3 sowie zum parallelen Ehrenschutz in den $\$ \S 185 \mathrm{ff}$. StGB W. Brugger Verbot oder Schutz von Haßrede? Rechtsvergleichende Beobachtungen zum deutschen und amerikanischen Recht, AöR 128 (2003), $372 \mathrm{ff}$; ders. Schutz oder Verbot aggressiver Rede? Ein Streit zwischen den Vereinigten Staaten von Amerika und Deutschland, JöR N.F. (erscheint demnächst); ders. Constitutional Treatment of Hate Speech, in: E. Riedel (Hrsg.) Stocktaking in German Public Law, 2002, $117 \mathrm{ff}$.

185 Die beiden anderen Varianten in Abs. 1 und 2 beziehen sich auf Aufforderungen zu Gewalt- und Willkürmaßnahmen, bei denen das Meinungselement zurücktritt und die Gefahr für subjektive Rechtsgüter der Angegriffenen zunimmt, sowie auf Angriffe auf die Menschenwürde, die ein Zurücktreten der Meinungsfreiheit rechtfertigen, s. BVerfGE 93, 266, 293. Bei der letztgenannten Alternative taucht das hier behandelte Problem allerdings in anderer Einkleidung auf: bei der Frage, ab welcher engeren oder weiteren Sicht man von einem Angriff auf die Menschenwürde ausgehen kann. Dazu einige Hinweise in meinen Fn. 184 zitierten Arbeiten sowie unten Fn. 200 zum Gedicht „Der Asylbetrüger in Deutschland". 
ausgeglichen oder überspitzt ist. ${ }^{186}$ Lässt sich diese Strafvorschrift über die Schranke des „allgemeinen Gesetzes“ in Art. 5 Abs. 2 GG rechtfertigen? ${ }^{187}$

Auf den ersten Blick ist das nicht der Fall, denn was $\S 130$ Abs. 1, 2 StGB verbietet, ist klar "Sonderrecht“, Verbot und Sanktionierung gerade einer bestimmten Meinungsäußerung. In einem liberalen Gemeinwesen sollte die staatliche Steuerung der Meinungsbildungsprozesse über Strafrechtssanktionen verdächtig und mit einer Vermutung der Verfassungswidrigkeit belegt sein. ${ }^{188}$ Wenn man mit der hM trotzdem Sonderrecht gegen Meinung zulässt, soweit im Einzelfall das öffentliche Rechtsgut den Wert der Meinungsfreiheit überwiegt, ${ }^{189}$ dann liegt jedenfalls auf dem Strafrechtsverbot eine hohe Begründungslast, die dadurch noch gesteigert wird, dass die Meinungsfreiheit im Grundgesetz als besonders wertvolles Gut gilt. ${ }^{190}$

Welches konkurrierende Rechtsgut soll durch $\S 130$ Abs. 1 und 2 StGB in der Variante des Aufstachelns zum Hass geschützt werden?

(1) Die moralische oder sittliche Empörung über die Äußerung des Volksverhetzers kann nicht ausreichen, denn Sinn und Zweck einer Garantie der Meinungsfreiheit ist es gerade, von herrschenden Einschätzungen abweichende Positionen zu schützen. ${ }^{191}$

$186 \mathrm{Vgl}$. etwa BVerfGE 33, 1, 14f.; 61, 1, 7f.; 54, 129, 138f.; 61, 6, 7; 66, 116, 151; 76, 171, 192; 90, 241, 247; 102, 347, 366; Th. Wandres Die Strafbarkeit des Auschwitz-Leugnens, 2000, 277f.; D. Grimm Die Meinungsfreiheit in der Rechtsprechung des Bundesverfassungsgerichts, NJW 1995, 1697, 1698.

${ }^{187}$ Die Prüfung der Schranke „Recht der persönlichen Ehre“ bleibt außer Betracht. Sie betrifft die $\$ \S 185 \mathrm{ff}$. StGB; bei $\S 130$ StGB kommt sie bei einigen Tatalternativen indirekt zur Geltung.

188 Andeutungsweise in diese Richtung BVerfGE $69,315,346 ; 95,220,235 \mathrm{f}$. und mwN Jarass/Pieroth, GG, 6. Aufl. 2002, Art. 5 Rn. 56. Art. 3 Abs. 3 GG spricht ebenfalls für diese Einschätzung. Allgemein hierzu D. Grimm Politische Parteien, in: HdbVfR, 2. Aufl., $\S 14$ Rn. 28: „Es kommt verfassungsrechtlich ... darauf an, daß die staatliche Beteiligung am Willensbildungsprozeß dessen Offenheit nicht beeinträchtigt. Der Staat darf weder meinungs- noch interessenunterdrückend oder -manipulierend tätig werden noch die Kommunikationsmittel monopolisieren, um dadurch den Kreislauf zu unterbinden". Deutlich strenger ist insoweit der U.S. Supreme Court, s. die Nachweise bei Brugger Verbot (Fn. 184), bei Fn. 38 .

189 S. etwa BVerfGE 7, 198, 209; 62, 230, 244; 71, 162, 175f.; 97, 125, 146.

190 S. BVerfGE 7, 198, 203; 66, 116, 150; 69, 315, 344f.; 71, 206, 214; 93, 266, 295f;; NJW 2001, 61 ff.; Grimm (Fn. 186), 1698, 1700f.; W. Hoffmann-Riem Nachvollziehende Grundrechtskontrolle. Zum Verhältnis von Fach- und Verfassungsgerichtsbarkeit am Beispiel von Konflikten zwischen Medienfreiheit und Persönlichkeitsrecht, AöR 128 (2003), 173, 196ff., $213 \mathrm{ff}$.

191 S. Abschnitt I in Brugger Schutz (Fn. 184); ders. Verbot (Fn. 184), sowie BVerfGE 69, 315, 347 (,effektiver Minderheitenschutz ${ }^{*}$ ) zu Art. 8 und implizit auch Art. 5 GG; 
(2) Gegen eine Bestrafung von Meinungen wegen Unmoral spricht auch die allgemein vertretene Ansicht, man könne im Bereich der Meinungen nicht nach Wahrheit und Falschheit unterscheiden. ${ }^{192}$ Wer das auf Schutzbereichsseite behauptet, kann dem nicht auf Schrankenseite prompt den Boden entziehen.

(3) Nach hM dient der $\S 130$ StGB dem öffentlichen Frieden. ${ }^{193}$ Das ist so überzeugend wie problematisch. Denn dieses Rechtsgut umfasst objektive und subjektive Elemente, die sich schwer präzis bestimmen und in ein klares Verhältnis setzen lassen: Objektiv ist auf reale Gefahren für individuelle oder kollektive Rechtsgüter abzustellen, subjektiv auf das Gefühl der Bevölkerung, sicher leben zu können.

(4) Das Problem zeigen zahlreiche Äußerungen aus Gesetzgebungsgeschichte ${ }^{194}$, Rechtsprechung und Lehre, wonach die Strafbarkeit der Volksverhetzung einem guten politischen Klima dienen ${ }^{195}$ oder zumindest ein feindliches Klima zwischen den Bevölkerungsteilen ausschließen soll. ${ }^{196}$ Der Konflikt mit der Meinungsfreiheit spitzt sich zu, wenn Vor-

H. Maurer Das Verbot politischer Parteien. Zur Problematik des Art. 21 Abs. 2 GG, AöR 96 (1971), 203, 213 ff. Vgl. auch generell zum „Gefühlsschutz“ T. Hörnle Grob anstößiges Verhalten. Normen zum Schutz von Moral, Gefühlen und Tabus im Strafgesetzbuch, Münchener Habilitationsschrift 2002 (erscheint 2004), Einleitung und $\S 3.4$ c.

192 Vgl. schon Fn. 186.

193 Hörnle (Fn. 191), $\$ \$ 4.1$ und 15.1 mwN.; je nach Tatbestandsvariante tritt der Würdeschutz hinzu. Von dieser generellen Einordnung ist das gleichlautende einschränkende Tatbestandsmerkmal in $\S 130$ Abs. 1 StGB zu unterscheiden.

194 S. BT-Drucks.12/8588, 8 zu $\$ 130$ Abs. 3 StGB und BGHSt 46, 36, 40; 46, 212, $221 \mathrm{f}$.

195 S. E. v. Bubnoff Leipziger Kommentar zum StGB, 11. Aufl., $\$ 125$ Rn. 41, wonach sich aus einer Analyse des Begriffs erkennen lässt, „daß der öffentliche Friede, sieht man in ihm einen Zustand einträchtigen Mit- und Nebeneinanderlebens, gegen Störungen leicht anfällig ist, da ihn schon Unfriedlichkeiten harmloserer Art, etwa der Ausbruch heftiger Meinungsverschiedenheiten, in Frage stellen können ...“. S. auch $M$. Wehinger Kollektivbeleidigung, Volksverhetzung. Der strafrechtliche Schutz von Bevölkerungsgruppen durch die $\S \S 185 \mathrm{ff}$. und $\S 130 \mathrm{StGB}, 1994,83$ : „Öffentlicher Friede läßt sich grob umschreiben als das harmonische und einträchtige Zusammenleben der Menschen ... Das ,soziale Phänomen' des gesellschaftlichen Friedens ... teilt sich dem einzelnen vor allem als eine soziale Atmosphäre, ein gesellschaftliches Klima mit ... Der öffentliche Friede wird ... nicht nur durch schwere gesellschaftliche Spannungen oder durch Rechtsbrüche gestört. Bereits das Vorhandensein latenter Feindseligkeiten, etwa zwischen Angehörigen verschiedener Bevölkerungsgruppen, kann zu einer Friedensstörung führen, indem es beispielsweise zu Diskriminierungen oder heftigen Auseinandersetzungen und Meinungsverschiedenheiten kommt, eben zu, Unfrieden aller Art “.

196 Nachweise bei Brugger Schutz (Fn. 184) in Fn. 65, 72; ders. Verbot (Fn. 184), Fn. 68ff.; Hörnle (Fn. 191), $\$ 4.3$ und 4.4; W. Kargl Rechtsextremistische Parolen als Volksverhetzung, Jura 2001, 176, 180 mit Fn. 47, 58; Wandres (Fn. 186), 213; G. Jacobs Kriminalisierung im Vorfeld einer Rechtsgutverletzung, ZSW 97 (1985), 751, 774, $779 \mathrm{ff}$. 
schriften zum Schutz des öffentlichen Friedens ein „öffentliches Klima, das nicht durch Unruhe, Unfrieden oder Unsicherheit gekennzeichnet ist“, schützen wollen, „unabhängig davon, ob auf diese Weise zugleich ein latentes Gefahrenpotential produziert wird“.197

Damit wird ohne Gefährdung individueller Rechtsgüter politischer Klimaschutz betrieben durch Bestrafung von Meinungen, welche die Mehrheit oder aufgeklärte Minderheiten empören. Wenn das richtig ist, wären fast alle Aussagen des BVerfG zum Schutzbereich der Meinungsfreiheit durch die Schranke der „allgemeinen Gesetze“ konterkariert. Weil man das nicht unterstellen kann, bestehen gegen strafrechtliche Sanktionen ${ }^{198}$ zugunsten des Rechtsguts „politischer Klimaschutz" erhebliche verfassungsrechtliche Bedenken. ${ }^{199}$

Nehmen wir ein Beispiel. Ein Kritiker der Ausländerpolitik gibt öffentlich folgende Stellungnahme ab: „Schluss mit der Invasion und Überfremdung unseres Landes durch diese kriminellen Ausländer, die unsere Freiheit und unser Eigentum bedrohen und uns mit Drogen überschwemmen." ${ }^{200}$ Es spricht vieles dafür, dass diese Äußerung nach $§ 130$ Abs. 1, 2 StGB strafbar wäre, wenn man sie im Lichte des Klimaschutzes interpretiert. 201

197 So Schönke/Schröder-Lenckner StGB, 26. Aufl., § 126 Rn. 1, auch zu $\$ 130$.

198 Das schließt nicht aus, sondern ein, dass die Förderung eines „guten" politischen Klimas (wie immer man dieses bestimmt) eine individuelle und kollektive Tugend sein sollte, für die man eintreten und für die man in Erziehung und Schule Werbung machen sollte. Hierzu Robbers (Fn. 2), 226; W. Brugger Schutz oder Verbot aggressiver Rede? Argumente aus liberaler und kommunitaristischer Sicht, Der Staat 42 (2003), $77 \mathrm{ff}$.

199 S. Hörnle (Fn. 191), $\$ 4.4$ und $\S 15.3 \mathrm{c}$ am Ende, die dem Gesetzgeber empfiehlt, diese Variante des $\$ 130 \mathrm{I}$ Nr. $1 \mathrm{StGB}$ zu streichen, und allgemein zur Bedeutung nicht durch Strafrechtssanktionen bedrohter Rede BVerfGE 54, 129, 139 und 61, 1, $9 \mathrm{f}$.

200 Das Beispiel wird in meinem Aufsätzen „Verbot“; „Schutz“ und „Constitutional Treatment“ (Fn. 184), erörtert. Es ist angelehnt an VG Frankfurt, NJW 1993, 2067f.; kritisch zu dieser Entscheidung G. Roellecke Keine Freiheit den Feinden der Freiheit, NJW 1993, $3306 \mathrm{ff}$. Einengend auch VG Regensburg, NJW 1994, 2040f., und VGH BW, DVB1 1993, 1314f. S. auch die Gerichtsentscheidungen zu dem Gedicht „Der Asylbetrüger in Deutschland“", abgedruckt in BayObLG, NJW 1994, 952, die zum Teil zu einer Bestrafung nach $\S 130$ StGB geführt haben, zum Teil nicht. Dort stand die $§ 130$-Variante „Angriff auf die Menschenwürde“ im Vordergrund, aber zum „Aufstacheln zur Volksverhetzung“ finden sich ebenfalls Äußerungen: OLG Frankfurt, NJW 1995, 143 ff. gegenüber BayObLG, NJW 1995, 145f. Hierzu auch OLG Karlsruhe, MDR 1995, 735f.; KG JR 1998, $213 \mathrm{ff}$.; BverwG, NJW 1997, 2341 f., und Hörnle (Fn. 191), § 152 b, cc.

201 Eine solche Äußerung, könnte man sagen, stachelt zum Hass gegen Ausländer als einem Teil der Bevölkerung auf, schafft durch Übertreibung der Kriminalitätsrate ein feindliches Klima und bereitet so der ausländischen Bevölkerung vermutlich ein Rechtsunsicherheitsgefühl. Die hM interpretiert das Merkmal „Aufstacheln“ wie folgt: „Aufsta- 
Grundrechtlich betrachtet, handelt es sich bei dieser Äußerung aber um eine politische, ja hochpolitische Äußerung, denn sowohl Zuwanderung als auch Kriminalität sind innenpolitische Kernfragen, ${ }^{202}$ somit sollte vor der Bestrafung einer solchen Äußerung eine besonders hohe Hürde liegen. ${ }^{203}$ Eine solche liegt aber beim Strafrechtsgut „politischer Klimaschutz" sicher nicht vor, denn dahinter verbirgt sich parteipolitische Strategie ${ }^{204}$ oder politische Korrektheit oder der herrschende Zeitgeist, vielleicht eine plausible Moral oder sogar die eine richtige Moral. Trotzdem

cheln zum $\mathrm{Haß}$ ist eine verstärkte, auf die Gefühle des Adressaten abzielende, über bloße Äußerung von Ablehnung und Verachtung hinausgehende Form des Anreizens zu einer emotional gesteigerten feindseligen Haltung ... Nicht ausreichend ist eine ... Darstellung von negativ zu wertenden Tatsachen (z.B. Kriminalitätsbelastung einzelner Bevölkerungsgruppen), sofern sie nicht durch einseitige Verzerrungen und wahrheitswidrige Verfälschung auf eine ,Stimmungsmache‘ abzielt." So mwN Tröndle/Fischer StGB, 51. Aufl., $\$ 130 \mathrm{Rn}$. 8. Man sieht deutlich, dass bestimmte „Haltungen“, „Gesinnungen“ abgeschreckt werden sollen. In diesem Sinne tatsächlich P. Bockelmann, zitiert bei Hörnle \$ 4.1; s. auch W. Mitsch Das deutsche Strafrecht und die Bekämpfung rassischer Diskriminierung und Gewalttaten, in: E. Klein (Hrsg.) Rassische Diskriminierung. Erscheinungsformen und Bekämpfungsmöglichkeiten, 2002, 147, 163f. Verfassungsrechtlich ist „Stimmungsmache" nichts Negatives, da unstreitig ist, dass durch Meinungen Wirkungen erzielt werden sollen. Ferner stellt sich bei „Hass“ immer die Frage, ob hinter ihm ein aus Sicht des Äußerers wichtiges Anliegen oder Problem liegt, das ihn nicht nur rational, sondern auch emotional bewegt, bis hin zu negativen Gefühlsausbrüchen; s. Brugger (Fn. 198), 84. Stellt man auf, „einseitige Verzerrung“ ab, so ist höchst unklar, was darunter zu verstehen ist: Soweit es um reine Wertungen geht, sind diese subjektiv so, wie sie sind. Soweit es um Interpretation von Fakten geht, fallen diese nach hM unter die Kategorie von Werturteilen. Will man einen ,ausgeglichenen“ Konnex von Urteil und Faktum verlangen, ist man bei Sorgfaltspflichten der Ermittlung einschlägiger Faktenlagen, was jedenfalls bei politischen Urteilen von Einzelpersonen unverhältnismäßig wäre.

202 Generalanwalt $K$. Nehm Ein Jahr danach, NJW 2002, 2665, 2671 hält zum Beispiel eine „Neubesinnung“ für nötig: „Lässt man die Lebensläufe der Beschuldigten unserer Verfahren [nach dem 11. September 2001] Revue passieren, so fällt immer wieder auf, wie sehr vermeintliche religiöse Toleranz und Fremdenfreundlichkeit sowie eine großzügige Duldungs- und Einbürgerungspraxis zu einer islamistisch-fundamentalistischen Subkultur in unserem Lande beigetragen haben." Diese Meinung muss man nicht teilen, aber sie macht den „politischen“ Charakter der hier diskutierten Fragen deutlich.

${ }^{203}$ Anderes mag gelten für private oder geschäftliche Äußerungen oder reine Tatsachenbehauptungen.

204 Ein wichtiger Gesichtspunkt: Meist ist es so, dass bei den in Parlamenten vertretenen Parteien die konservativste Partei keine Partei „rechts“ von ihr und die „linkeste“ Partei keine Partei „links“ von ihr sehen will. Gerade diese vom Mainstream abweichenden Meinungen und Parteien sind auf Grundrechtsschutz angewiesen. Ein dazu passendes Beispiel aus der Rechtsprechung ist der Versuch der CSU, nicht mit der NPD in Verbindung gebracht zu werden: BVerfGE $61,1$. 
gilt: Diese darf staatlicherseits genauso wenig mit dem Strafrecht verordnet werden wie die richtige Religion. ${ }^{205}$

Das Problem einer Bestrafung dieser Art von Hassrede liegt darin, dass sie abstrakte Gefährdungen betrifft, die deutlich vor einer Beantwortbarkeit der Frage liegen: „Wer soll wo und wann was gegen wen tun?“206 Es liegt also nur die Gefahr einer Gefahr, ${ }^{207}$ vielleicht nur ein nicht gänzlich auszuschließendes Restrisiko eines Eingriffs in Leben, Freiheit oder Eigentum irgendeiner Person durch irgendeinen Aufgehetzten irgendwann in der Zukunft vor. ${ }^{208}$ Gleichzeitig steht aber fest, dass $§ 130$ Abs. 1, 2 StGB in der geschilderten Variante unmittelbar, direkt und gezielt in die durch eine Vermutung der Freiheit geschützte und in dem Beispielsfall hochpolitische Äußerung eingreift. ${ }^{209}$ Ein offensichtlicher Konflikt zwischen Freiheit und Sicherheit!210

${ }^{205} \mathrm{Zu}$ diesem Punkt allgemein E. Denninger Verfassungstreue und Schutz der Verfassung, VVDStRL 37 (1979), 7, 31: „das Dekretieren letzter Wahrheiten und existenzieller Sinngebung ist [dem Staat] ebenso verwehrt wie einer politischen Partei die Durchsetzung eines mit dem Anspruch auf den Besitz absoluter Wahrheit auftretenden Programmes. Die freiheitliche Demokratie muß streitbar sein ...".

206 S. Wandres (Fn. 186), S. 213; Hörnle (Fn. 191), § 15.3 b. Der Rechtscharakter der Vorschrift wird beschrieben als abstrakt-konkretes Gefährdungsdelikt, als potenzielles Gefährdungsdelikt, als Eignungsdelikt, als konkretes Gefährdungsdelikt oder als abstraktes Gefährdungsdelikt mit tatbestandlicher Restriktionsmöglichkeit. S. die Nachweise bei Hörnle ebd., \$ 15.4 a.

207 So treffend Wandres (Fn. 186), 221.

${ }^{208}$ Hörnle (Fn. 191), $\S 4.3$, stellt berechtigterweise die Frage, ,wie weit der Strafbarkeitsbereich nach vorne verlagert werden darf ... wie ,verdünnt' das Gefahrenpotenzial für ein Individualrechtsgut sein darf, damit eine Strafbarkeit noch gerechtfertigt werden kann. Diese schwierige Frage des notwendigen Zusammenhangs von Handlung und Gefährdung wird umgangen, wenn man sich auf ein kollektives Rechtsgut, öffentlicher Friede' zurückzieht. Die bequeme Formel vom , aufgehetzten Klima' verschleiert die dahinter liegenden Probleme, anstatt zu einer rationalen Debatte über Gefährdungspotenziale beizutragen.“ Ähnlich Mitsch (Fn. 201), 171 f.; Jacobs (Fn. 196), 783: „Daß die Klimadelikte in das Strafrecht eines freiheitlichen Staates nicht passen, heißt nicht, das betreffende Verhalten sei wünschenswert oder auch nur sozial neutral, sondern heißt einzig, daß es keine Zwangswirkung hat und daß deshalb auch nicht per Strafrechtszwang darauf reagiert werden sollte." Das gilt alles schon ohne Berücksichtigung der besonderen Bedeutung des Art. 5 Abs. 1 GG!

${ }^{209}$ S. neben Fn. 202 BVerfGE 69, 315, 345: „Die Gefahr, daß ... Meinungskundgaben demagogisch mißbraucht und in fragwürdiger Weise emotionalisiert werden können, kann im Bereich der Versammlungsfreiheit ebensowenig maßgebend für die grundsätzliche Einschätzung sein wie auf dem Gebiet der Meinungs- und Pressefreiheit"; ferner Grimm (Fn. 186), 1701, $1703 \mathrm{f}$.

210 Dieser nationale Konflikt spiegelt sich auch supranational wider: vor allem im Rahmen der Auslegung des UN-Paktes zur Beseitigung jeder Form von Rassendiskriminierung vom 7. 3. 1966, BGBI 1969 II 962. Hierzu einige Hinweise bei Brugger (Fn. 184). 
Die Rechtsprechung ist nicht aus einem Guss, es gibt der Meinungsfreiheit mehr oder auch weniger gewogene Entscheidungen. ${ }^{211} \mathrm{Klar}$ ist, dass bei scharfen und faktisch vielleicht übertriebenen ausländerkritischen oder gar antisemitischen Äußerungen der $§ 130$ Abs. 1 und 2 StGB der Meinungsfreiheit den Rang abläuft; jedenfalls besteht die reelle Gefahr einer Kriminalsanktion.212 Dieser Abschreckungseffekt ist bewusst und gewollt, was man angesichts unserer Geschichte für moralisch vertretbar oder geboten halten mag. Aber verfassungsrechtlich enthüllt dieser „chilling effect“ für freie politische Rede gewisse rhetorische Mitnahmeeffekte der herrschenden Dogmatik ohne entsprechenden Substanzwert. Man muss sich beim „Strafklima“ 213 schon entscheiden: Meint politischer „Klimaschutz“ Schutz nur der mitteleuropäisch ausgeglichenen Mainstreamkommunikation mit geringen Temperaturschwankungen nach oben und unten, um extremere Meinungen und Haltungen von vornherein zu eliminieren, ${ }^{214}$ oder soll politische Auseinandersetzung auch Eiszeiten und hitzige Turbulenzen umfassen dürfen in der Hoff-

211 Dazu liefern die StGB-Kommentare zu $§ 130$ sowie, parallel hierzu, $\$ \S 185 \mathrm{ff}$. StGB, umfangreiches Material. Zur Haltung der Rechtsprechung s. die vorigen Fußnoten sowie, in einem versammlungsrechtlichen Zusammenhang, die meinungsfreiheitsfreundlichen Beschlüsse der 1. Kammer des Ersten Senats, NJW 2001, $2069 \mathrm{ff} ., 2072 \mathrm{ff}$. Anders stellt sich das Bild dar bei der Entscheidung zur Verfassungsmäßigkeit der Strafbarkeit auch der einfachen Auschwitzleugnung, BVerfGE 90, 241. Dazu meine Kritik in den oben Fn. 184 zitierten Aufsätzen.

${ }^{212}$ S. Hörnle(Fn. 191), $\$ \$ 15.2$ b; 15.3 b; 15.3 c; Ergebnisse Nr. 13; Mitsch (Fn. 201), 171 und J. Jahn Strafrechtliche Mittel gegen Rechtsextremismus. Die Änderungen der $\$ \$ 130$ und 86 a StGB als Reaktion auf fremdenfeindliche Gewalt im Licht der Geschichte des politischen Strafrechts in Deutschland, 1998, etwa 13, $231 \mathrm{f}$. Zur Parallelsituation bei Versammlungsverboten s. die Auseinandersetzung zwischen dem OVG Münster und dem BVerfG, oben Fn. 211, sowie V. Neumann Feinderklärung gegen rechts? Versammlungsrecht zwischen Rechtsgüterschutz und Gesinnungssanktion, in: C. Leggewie/H. Meier (Hrsg.) Verbot der NPD oder mit Rechtsradikalen leben?, 2002, 155, 167: „Der Exkurs in das Versammlungsrecht hat gezeigt, daß nicht alle Behörden und Gerichte das Recht fachgerecht anwenden und dagegen gefeit sind, Gesinnungen statt konkreter Verhaltensweisen zu sanktionieren."

213 Ausdruck von Hassemer (Fn. 178), 13.

214 Wandres (Fn. 186), 212 hält $\mathrm{mE}$ treffend fest: „Die Schreckgespenster der Volksverhetzung heißen ,Pogrom', ,Massaker' und, Genozid'. Der Tatbestand der Volksverhetzung richtet sich daher im Kern gegen Verhaltensweisen, die bei denkbar ungünstigem Verlauf geeignet sein könnten, erneut einem Verbrechen gegen die Menschlichkeit deutschen Boden zu bereiten." Ähnlich Hörnle (Fn. 191), § 15.2 a. Wenn man tatrichterlich den „denkbar ungünstigsten Verlauf" annimmt, wird es natürlich schwierig, die inkriminierte Äußerung meinungsfreiheitsfreundlich zu interpretieren. So der Tendenz nach auch die Einschätzung von Hörnle ebd., $\$ 4.4$ c. 
nung, auch radikale Meinungen einzubinden, solange nicht wirklich reale Gefahren für Leben, Freiheit und Eigentum drohen? ${ }^{215}$

\section{Das Beispiel Parteiverbot}

Das Parteiverbot in Art. 21 Abs. 2 GG $^{216}$ weist viele Parallelen zur Spannung zwischen der Meinungsfreiheit und dem Verbot der Volksverhetzung auf. Bei allen kommunikativen Freiheiten ist nicht nur die ÄuBerung, sondern auch deren Wirkung geschützt; ${ }^{217}$ das muss auch für politische Parteien gelten, die Regierungsmacht erringen wollen. Folglich kann es nicht darauf ankommen, ob die Parteimeinungen rational oder emotional, nützlich oder schädlich, richtig oder falsch sind. Denn wenn die später im Parlament erlassenen Gesetze einen Rückbezug auf freie und gleiche Bürger in Anspruch nehmen wollen, sich als Selbst- und nicht als Fremdgesetzgebung ausweisen wollen, ${ }^{218}$ müssen alle Parteimeinungen gleichermaßen eine Chance gehabt haben, zur Mehrheit zu werden.

${ }^{215}$ Idealtypisch wird diese Sicht vom US-Verfassungsrecht vertreten. Dazu meine oben Fn. 184, 198 genannten Aufsätze. Meine Kritik hier ist aber mit dem US-Ansatz nicht identisch. Wie dargelegt scheint mir in Teilen der Rechtsprechung eine Spannung mit der überkommenen deutschen Dogmatik der Meinungsfreiheit vorzuliegen. Beide oben beschriebenen Tendenzen haben ihre Gefahren. Die Gefahr des „politisch korrekten“ Verständnisses von Meinungsfreiheit (welch ein Widerspruch, aber man muss ihn benennen!) ist Ausklammerung intensiver, auch emotional aufgeheizter Diskussion gerade hochpolitischer Fragen, im Endeffekt: „Quietismus", so W. Leisner Ungeeignete Themen für Wahlkämpfe - Zurück zum unmündigen Bürger?, NJW 2002, 1699f.; s. auch Grimm (Fn. 186), 1704 zu ,affirmatives Meinungsklima“. Die Gefahr rhetorischer Turbulenzen und Eiszeiten ist eine Brutalisierung des öffentlichen Dialogs. Dazu Brugger (Fn. 198), $92 \mathrm{ff}$.

${ }^{216}$ Rechtsvergleichend zum Parteiverbot G. P. Boventer Grenzen politischer Freiheit im demokratischen Staat. Das Konzept der streitbaren Demokratie in einem internationalen Vergleich, 1985; G. Nolte/G. Fox Intolerant Democracies, in: G. H. Fox/B. R. Roth (eds.) Democratic Governance and International Law, 2000, $389 \mathrm{ff}$; $M$. Morlok Parteiverbot als Verfassungsschutz. Ein unauflösbarer Widerspruch?, NJW 2001, 2931 ff., mit der Schlussfolgerung: „Nach diesem Befund kennen ältere Demokratien keine eigenen Regelungen des Parteiverbots, sondern rekurrieren gegebenenfalls auf das allgemeine Vereinsverbot ... die bundesrepublikanische Rechtslage ... entspricht im Wesentlichen dem Standard postdiktatorischer Rechtsordnungen" (2936).

${ }^{217}$ S. z.B. BVerfGE 7, 198, 210; 30, 173, 189; 93, 266, 289.

${ }_{218} \mathrm{Zu}$ diesen autonomiebezogenen und demokratietheoretischen Grundlagen s. Grimm (Fn. 188), § 14 Rn. 28; Morlok(Fn. 216), 2933; U. Volkmann BKGG, Stand 2001, C Art. 20 Rn. 13 ff. 
Trotzdem enthält der Art. 21 GG in Form des Parteiverbots eine Sonderrechtsschranke gegen spezifische Meinungen sowie daraus folgende Handlungen, die gegen die freiheitlich-demokratische Grundordnung gerichtet sind, ${ }^{219}$ dem Pendant zum Schutzgut öffentlicher Friede bei $\S 130$ Abs. 1, 2 StGB. Die Abschirmung der freiheitlich-demokratischen Grundordnung (= fdGO) gegenüber Beschädigung durch radikale Parteien jeder Couleur soll allgemeine Freiheit und Sicherheit gewährleisten, allerdings unter Inkaufnahme der Einschränkung von Freiheit und Gleichheit mancher Bürger und Parteien. ${ }^{220}$

Die dieser Konzeption innewohnenden Spannungen sind vielfach erörtert worden, ${ }^{221}$ von den Staatsrechtslehrertagungen 1958 und $1978^{222}$ bis zur Diskussion um das Verbot der NPD in den letzten Jahren. ${ }^{223}$ Klar ist, dass dem Grundgesetz im Allgemeinen wie dem Art. 21 Abs. 2 GG im Besonderen eine material geprägte Sicht von Freiheit und Demokratie entspricht. ${ }^{224}$ Rein formale Sichtweisen von Freiheit, die den Willen zur Unfreiheit von sich selbst oder anderen in Form der Selbst- oder Fremdversklavung einschließt,225 oder von Demokratie, die den Mehrheits-

219 Solche Sonderrechtsverbote sind, wie schon oben Fn. 188 erwähnt, in einer liberalen Ordnung prinzipiell verdächtig. Sie bedürfen spezieller Begründung, sonst könnte in einer Formulierung von Denninger (Fn. 205), 17, das „Licht der für die freiheitliche Demokratie schlechthin konstitutiven Bedeutung der Meinungsfreiheit“ „in der streitbaren Atmosphäre nur noch spärlich unter dem Scheffel der allgemeinen Mißbrauchsabwehr" flackern.

${ }^{220}$ Man kann eine solche Einschränkung entweder als äußere Begrenzung oder als innere, schon in der „Freiheit" oder „Demokratie“ selbst angelegte Grenze ansehen, wie H. Dreier Grenzen demokratischer Freiheit im Verfassungsstaat, JZ 1994, 741, 751, darlegt. Man könnte sie auch verstehen iSd Unterscheidung von Regeln erster Ordnung (die die Regeln des Spiels darlegen) und Regeln zweiter Ordnung (die dann den Wettbewerb im Rahmen des Spiels um den Gewinn - hier von Wählerstimmen - betreffen). Zu dieser Unterscheidung G. Brennan/J. Buchanan, Die Begründung von Regeln. Konstitutionelle Politische Ökonomie, 1993, Kap. 1 III.

221 S. schon BVerfGE 2, 1, 11 f.; 5, 85, $134 \mathrm{ff}$; $H$. Steinberger Konzeptionen und Grenzen freiheitlicher Demokratie, 1974, $196 \mathrm{ff}$., und jüngst etwa $K$. Groh Der NPD-Verbotsantrag. Eine Reanimation der streitbaren Demokratie?, ZRP 2000, 500, 503f.; Morlok (Fn. 216), 2931 f., 2941 f.

222 S. die Beiträge von $K$. Hesse und G. E. Kafka zu „Die verfassungsrechtliche Stellung der politischen Parteien im modernen Staat", VVDStRL 17 (1959), $11 \mathrm{ff}$., $53 \mathrm{ff}$. sowie von E. Denninger und H. H. Klein zu "Verfassungstreue und Schutz der Verfassung“, VVDStRL 37 (1979), $7 \mathrm{ff}$., $53 \mathrm{ff}$.

223 Dazu etwa der Sammelband von Leggewie/Meier (Fn. 212).

224 S. jüngst M. Thiel (Hrsg.) Wehrhafte Demokratie. Beiträge über die Regelungen zum Schutze der freiheitlichen demokratischen Grundordnung, 2003.

225 S. G. Dietze Reiner Liberalismus, 1985, 5, 13, 35, 47, 62, 79. 
willen zu ihrer Abschaffung achtet, ${ }^{226}$ sind ausgeschlossen. Doch wie verträgt sich diese materiale Sicht mit der für die Kommunikationsfreiheiten vertretenen These, dass der Staat die Wahrheit oder Falschheit von Meinungen nicht beurteilen kann? Handelt es sich hier um königliche Schutzbereichskleider, die sich beim Blick auf die Schranken als Jammerlappen erweisen? Nicht unbedingt, aber die Auflösung dieser Spannung ist kompliziert ${ }^{227}$ und in der Staatsrechtslehre nicht konsentiert.

Vier Konzeptionen zum Parteiverbot lassen sich unterscheiden.

(1) Man könnte für ein Verbot von Parteien rein wegen der Unmoral und Ungerechtigkeit der Parteiziele eintreten, verglichen mit der materialen Grundordnung des Grundgesetzes. ${ }^{228}$

(2) Nach der „Wehret-den-Anfängen“-Ansicht bedarf es zumindest eines Restrisikos für die fdGO, sollte die Partei politischen Einfluss gewinnen und andere Bürger per Gesetz und Zwang im allgemeinen Freiheits- und Gleichheitsstatus verletzen.

(3) Etwas enger könnte man für das Erfordernis einer abstrakten Gefahr für die fdGO als Voraussetzung des Parteiverbots eintreten. Dann wären reale Anhaltspunkte für eine wahrscheinliche Beeinträchtigung der fdGO durch das Parteihandeln notwendig, ohne dass in jedem Einzelfall ein konkreter Schaden drohen muss. 229

226 Viele Staatsrechtslehrer der Weimarer Zeit hielten eine legale Abschaffung der Demokratie für möglich. S. mwN Groh (Fn. 221), 503 mit Fn. 47; Volkmann (Fn. 218), C Art. 21 Rn. 92 Fn. 604. S. etwa H. Kelsen Reine Rechtslehre, 2. Aufl. 1960, 389: „Das Prinzip der majoritären Selbstbestimmung steht einer totalitären Demokratie nicht im Wege." Darstellung der Kelsenschen Haltung bei $H$. Dreier Rechtslehre, Staatssoziologie und Demokratietheorie bei Hans Kelsen, 2. Aufl. 1990, 262 ff., 266.

${ }^{227}$ Hierzu aus der älteren Literatur Steinberger(Fn. 221), 1. Teil 2. und 3. Abschnitt und 595 ff., sowie unten Fn. 231.

228 Diese Überlegung klingt bei Volkmann (Fn. 218), C Art. 21 Rn. 95 an, wenn er primär auf das Ausmaß des materialen Gegensatzes zwischen Parteiziel und fdGO abhebt und Fragen der Gefährdung dahinter zurücktreten lässt. Die Parallele bei der Volksverhetzung wäre die von Lenckner vertretene Ansicht, oben Fn. 197.

229 Dieses Verständnis von abstrakter Gefahr knüpft an an W.-R. Schenke Polizei- und Ordnungsrecht, 2. Aufl. 2003, Rn. 70, der diese unter Verweis auf BVerwG, DÖV 1970, 713,715 , und neuestens BVerwG, DVBI 2002, 1562, 1564 dann für gegeben hält, „wenn eine generell-abstrakte Betrachtung für bestimmte Arten von Verhaltensweisen oder Zuständen zu dem Ergebnis führt, daß mit hinreichender Wahrscheinlichkeit ein Schaden im Einzelfall einzutreten pflegt und daher Anlaß besteht, diese Gefahr mit generell-abstrakten Mitteln, also einem Rechtssatz, insbesondere einer Polizeiverordnung, zu bekämpfen, was wiederum zur Folge hat, daß auf den Nachweis eines Schadens im Einzelfall verzichtet werden kann.“ Schon die „Möglichkeit" eines Schadens lässt Lisken/Denninger-Denninger, Handbuch des Polizeirechts, 3. Aufl. 2001, E 32, ausreichen: Nach ihm ,bezeichnet die ,abstrakte Gefahr‘ nur die gedachte Möglichkeit einer konkreten Gefahr. Bei ihr handelt es sich um, eine nach allgemeiner Lebenserfahrung 
(4) Eine konkrete Gefahr für die fdGO als Voraussetzung für ein Parteiverbot zu verlangen, widerspräche klar dem Wortlaut des Art. 21 Abs. 2 GG, der ein Beeinträchtigungsziel ausreichen lässt und keine drohende Beseitigung verlangt. 230

Welche Sichtweise des Parteiverbots ist vorzugswürdig? Die meisten Stellungnahmen konzentrieren sich auf die Konzeptionen (2) und (3), also das Erfordernis eines Restrisikos oder einer abstrakten Gefahr für die fdGO. ${ }^{231}$ Die Intensität der wissenschaftlichen Auseinandersetzung folgt nicht zuletzt daraus, dass die zwei Parteiverbotsurteile des Bundesverfassungsgerichts Argumente für beide Sichtweisen enthalten. ${ }^{232}$

oder den Erkenntnismitteln fachkundiger Stellen mögliche Sachlage, die im Falle ihres Eintritts eine Gefahr ... darstellt“". Dieser weite Begriff entspricht hier eher der Restrisikokonzeption.

230 Das wird von Groh (Fn. 221), 505, übersehen. K. Hesse, Grundzüge des Verfassungsrechts der Bundesrepublik Deutschland, 20. Aufl. 1995, Rn. 717, spricht ebenfalls von der „konkreten Gefahr der ,Beeinträchtigung““.

231 Wenngleich der Wortlaut des Art. 21 Abs. 2 GG es nicht ausschließt, für das Verbot einer Partei schon deshalb einzutreten, weil deren Ziele schlicht unmoralisch und ungerecht sind, wie dies Konzeption (1) voraussetzt, ist diese Sicht doch abzulehnen. Entweder widerspräche sie der für Art. 5 wie 21 GG vertretenen These, man könne richtige und falsche Meinungen nicht unterscheiden. Oder aber man verabschiedete sich von dieser dogmatischen Aussage. Dann bräuchte man allerdings eine "starke" kognitivistische Theorie, die Wahrheits- und Gerechtigkeitsansprüche klar identifizieren kann; solche Theorien sind aber umstritten; s. etwa A. Engländer Diskurs als Rechtsquelle. Zur Kritik der Diskurstheorie des Rechts, 2002. Selbst wenn man die Erkenntnisansprüche negativ auf „evident ungerechte “Ziele reduzierte, was politisch auch nicht-kognitivistische Theorien mittragen könnten, bestehen starke Bedenken. Diese rühren zum einen daher, dass ein solches Zielverbot ohne unterstützende Aktivitäten einen starken Einschlag von Gesinnungssanktion hätte; s. Morlok (Fn. 216), 2939. Zum anderen würde man die Partei mit ihren Mitgliedern ihres Freiheits-, Gleichheits- und politischen Mitwirkungsstatus berauben, ohne dass auf der Gegenseite Einbußen in den entsprechenden Rechten zur Debatte stehen. Das sollte für ein Parteiverbot nicht ausreichen und reicht nach hM auch nicht aus. S. etwa Maurer (Fn. 191), 229: „Wenn [die demokratische Ordnung] nicht bedroht ist, dann bedarf sie auch keines Schutzes"; ähnlich Morlok (Fn. 216), 2940; Horst Meier In der Nachfolge der NSDAP? Das SRP-Urteil und das Verfahren gegen die NPD, Blätter für deutsche und internationale Politik, 2003, 485, 494. Im SRP-Urteil allerdings ist die Rede davon, „der Sinn des verfassungsgerichtlichen Spruches“ sei es, „diese Ideen selbst aus dem Prozeß der politischen Willensbildung auszuscheiden": BVerfGE 2, 1, 73.

${ }^{232}$ S. mit Anklängen an die Restrisikothese BVerfGE 5, 85, $143 \mathrm{f}$. BVerfGE 25, 88, 100 kann man so lesen, dass schon die Tatsache der Existenz einer Organisation das Restrisiko begründet. Im technischen Bereich führt ein Restrisiko in der Regel nicht zu einem Verbot; s. z.B. BVerfGE 49, 89, $140 \mathrm{ff}$. Zur Restrisikothese am besten passt die Aussage, dass der Grundsatz der Verhältnismäßigkeit nicht zu prüfen ist bzw. durch Art. 21 Abs. 2 GG ersetzt werde - gerade ein frühes Verbot führe zu einer Freiheits- und Gleichheits- 
Zwei Ansichten zur abstrakten Gefahr lassen sich unterscheiden eine engere und eine weitergehende. Eine idealtypische restriktive Sicht des Parteiverbots ${ }^{233}$ verlangt (1) eine größere Partei, die vielleicht schon (2) einmal oder - enger - (3) mehrfach in einem Parlament vertreten war oder (4) aktuell vertreten ist. Noch restriktiver, schon nahe an eine konkrete Gefahr für die fdGO heranreichend, wären (5) das Erfordernis einer Koalitionsfähigkeit der zu verbietenden Partei in einem Landes- oder im Bundesparlament sowie die Prüfung, ob (6) manche oder viele Parteimitglieder oder sonst ihr zurechenbare Personen individuell Strafrechtsgrenzen überschritten haben, also dasjenige praktizieren, was bei einem Erfolg der Partei als Eingriff in wichtige Individualrechtsgüter zu erwarten wäre. Schließlich müsste man (7) verlangen, dass die Ziele und Strukturen der zu verbietenden Partei denjenigen der nationalsozialistischen Herrschaft ähnlich ${ }^{234}$ oder - enger - fast gleich sind ${ }^{235}$, wobei allerdings „linke“ Bedrohungen wie ,rechte“ Bedrohungen der fdGO zu behandeln sind, man also eigentlich eine Wesensverwandtschaft zum Totalitarismus fordern muss. ${ }^{236}$

sowie Demokratieverkürzung für weniger Parteimitglieder als ein spätes; das BVerfG hat in seinen beiden Urteilen die Verhältnismäßigkeit nicht geprüft. Etwas enger, zur abstrakten Gefahr tendierend, sind die Aussagen des BVerfG, die eine aktiv-kämpferische Haltung und eine planmäßige Hetze verlangen, ohne dass das Stadium strafbarer Vorbereitungs- oder Versuchshandlungen erreicht sein muss: BVerfGE 5, 85, 141 f., 384f. S. aber auch die Anklänge an Konzeption (1) in Fn. 231 am Ende.

233 Dieser Sichtweise neigen zu Hesse (Fn. 230), Rn. 715, 717; G. F. Schuppert in: Mitarbeiterkomm. zum BVerfGG, 1992, Vor $\$ \S 43 \mathrm{ff}$. Rn. 1, $12 \mathrm{ff}$.; $\S 46 \mathrm{Rn}$. 9ff.; Morlok (Fn. 216), 2939f.; R. Wassermann Aktivierung der wehrhaften Demokratie. Zum Antrag auf NPD-Verbot, NJW 2000, 3760, 3762; Meier (Fn. 231); R. Streinz in: v. Mangoldt/ Klein/Starck (Hrsg.) GG, 4. Aufl. 2000, Art. 21 Rn. 226, 228, 232 ff. (für eine „engere Auslegung" eintretend, mit allerdings weitgehenden Erläuterungen).

234 Eine Variante dieses Arguments ist die von Maurer (Fn. 191), 216f., vertretene These, Handlungen jenseits des rein geistigen Meinungskampfes, die auf physischen und psychischen Terror, Irreführung, Diffamierung, Massensuggestion und Hetzpropaganda hinausliefen, indizierten reale Gefahren für die fdGO, womit offenbar der Anschluss an BVerfGE 2, 1, $51 \mathrm{ff}$.; 5, 85, 384f. hergestellt wird. Das überzeugt, abgesehen von ,physischem Terror", nicht ohne weiteres, wenn man Partei-Meinungen im Rahmen der Meinungsfreiheitsdogmatik sieht, die ja gerade überzogene Werturteile in politischen Angelegenheiten zulassen will: Fn. 186. Ob eine Äußerung als „Hetzpropaganda“ oder als legitimer, wenngleich überzogener Beitrag zur Politik angesehen wird, hängt oft vom Standpunkt des Hörers ab. Dazu schon oben Fn. 201, 215.

235 Dieser Punkt geht zurück auf BVerfGE 2, 1, 69.

${ }^{236} \mathrm{Zu}$ diesem Punkt s. BVerfGE 2, 1, 12: „Daher ist die Grundordnung eine wertgebundene Ordnung. Sie ist das Gegenteil des totalen Staates ... “; R. Dreier Verfassung und „streitbare Demokratie“, in: Leggewie/Meier (Fn. 212), 81, 84f. 
Weitergehende Ansichten einer abstrakten Gefahr für die fdGO verneinen oder relativieren diese Erfordernisse. ${ }^{237}$ Sonach sind auch kleinere Parteien außerhalb der Parlamente einem Parteiverbot ausgesetzt; eine Verhältnismäßigkeitsprüfung entfällt. Für die Einschätzung des Gefahrengrades spielen Argumente eine Rolle, die implizit oder explizit auf die besondere Gefährdung gerade Deutscher durch - Frage: falls überhaupt, nur? - rechtsradikale Verführungen abheben ${ }^{238}$, sei es allgemein oder jedenfalls in Krisenlagen etwa ökonomischer Art oder bei Zunahme von "Ausländerfeindlichkeit". ${ }^{239}$ Dazu kann man zwei Haltungen vertreten: (a) Entweder man geht davon aus, dass diese Gefahr einer Gefahr durch die Machtübernahme des Nationalsozialismus in Deutschland ein für allemal bewiesen sei; Deutsche hätten eben einen autoritären Charakter und seien für Rechtsradikalismus anfällig sowie tendenziell unbelehrbar, jedenfalls in schwierigen Zeiten. ${ }^{240}$ Genau dies sei in der Textfassung des Art. 21 Abs. 2 GG zum Ausdruck gekommen; dessen historische Ausle-

237 S. etwa Stern (Fn. 45), 207; J. Ipsen in: Sachs (Hrsg.) GG, 3. Aufl. 2003, Art. 21 Rn. 156 und 168 (sogar die Bedeutungslosigkeit der Gefahrenfrage andeutend, i.S.v. Konzeption [1]); Volkmann(Fn. 218), C Art. 21 Rn. 93, 97; Chr. Gusy in: AKGG, 3. Aufl. 2001, Art. 21 Rn. 115, 118; R. Streinz, in: von Mangoldt/Klein/Starck (Fn. 233), Art. 21 Rn. 233.

238 Daneben wird gelegentlich auf einen Punkt hingewiesen, der anders geartet ist: Sollten außenpolitische Belange für die Möglichkeit eines weitergehenden Parteiverbots sprechen, insbesondere bei ausländerkritischen oder antisemitischen Parteien? S. die Hinweise bei Meier (Fn. 231), 491, und in den Beiträgen in Leggewie/Meier (Fn. 212), 104, 143, 150. Schon im Lüth-Urteil kommt ein solcher außenpolitischer Aspekt zur Sprache: BVerfGE 7, 198, 216.

${ }^{239}$ Allgemein hierzu Schuppert (Fn. 233), Vor $\$ 43$ ff., Rn. 7: Es geht um ,das unterschiedliche Maß des Vertrauens in die Selbstregulierungskräfte des Prozesses freier politischer Auseinandersetzungen“. Was „Ausländerfeindlichkeit“ angeht, ist allerdings Vorsicht geboten. Die Meinungsfreiheit und die Parteienfreiheit müssen es ermöglichen, zu Fragen von Inklusion und Exklusion deutlich Stellung zu beziehen, sonst gewinnt ,political correctness" gegen das doch als so bedeutend eingestufte Gut der Meinungsfreiheit. Hierzu Volkmann (Fn. 218), C Art. 21 Rn. 95; Brugger (Fn. 184, 198) und oben Abschnitt VI.

${ }^{440}$ S. z.B. E. Stein/G. Frank Staatsrecht, 17. Aufl., § 41 IV 3; Groh (Fn. 221), 501, 505 mit Verweis auf $K$. Sontheimer Deutschlands politische Kultur, 1990, $33 \mathrm{ff}$. - s. dort auch 32, 152; Hörnle(Fn. 191), § 15.6 c, cc; Kaufmann(Fn. 1), 346. Dort 192, 237 Fn. 74 zu einschlägigen Thesen von Th. Adorno. Adornos Untersuchungen zum ,autoritären Charakter" sind primär tiefenpsychologisch angelegt und wurden mit anderen in den USA durchgeführt. Es finden sich aber auch Aussagen zu Deutschland. S. Th. Adorno Studien zum autoritären Charakter, 1973, 13f. Zur These, die Deutschen seien speziell für Antisemitismus anfällig, s. die umstrittenen Thesen von D. J. Goldhagen Hitlers willige Vollstrecker. Ganz gewöhnliche Deutsche und der Holocaust, 1996, insbes. Kap. 15, 439, 440, 446ff., 451, 454 ff., 460, 464f., 466f., 484 (zum „dämonisierenden Rassenantisemitismus der Deutschen"). 
gung sei damit auch diejenige der Gegenwart. Damit unterscheiden sich Bonn und Berlin insoweit nicht von Weimar; den Anfängen ist nach wie vor zu wehren. (b) Oder aber man unterscheidet damals von heute und gesteht der großen Mehrheit der Deutschen einen Lernprozess zu, der sich auch in schwierigen Zeiten bewähren werde. ${ }^{241}$ Dann spricht bei kleineren, parlamentarisch nicht oder nur sporadisch erfolgreichen, im Übrigen aber von den etablierten Kräften gemiedenen Parteien viel dafür, diese nur als Restrisiko und nicht als reales abstraktes Risiko für die fdGO anzusehen. Dann dürfte eine solche Partei nur gemäß der Restrisikokonzeption verboten werden. ${ }^{242}$ Diese lässt sich im Rahmen des Wortlauts des Art. 21 Abs. 2 GG zweifellos vertreten, der ein eher expansives Verständnis des Parteiverbots nahelegt, insbesondere wenn man ihn mit starker Betonung auf der damaligen und vielleicht auch heutigen $\mathrm{Ge}-$ fahr von Radikalismus in Deutschland liest. Interpretiert man Art. 21 Abs. 2 GG dagegen systematisch mit Blick auf die Parteien als primär gesellschaftliche Gebilde, die staatliche Herrschaft von unten nach oben legitimieren sollen, unter Einbezug aller Meinungen und Interessen, auch der uns abstoßenden, dann spricht im Hinblick auf die Bedeutung der kommunikativen Freiheiten und die gewachsenen demokratischen Strukturen in Deutschland mehr für die enge Sicht der notwendigen abstrakten Gefahr für die fdGO als Voraussetzung eines Parteiverbots. ${ }^{243}$ Dann sollte man dem deutschen Volk die Lösung von politischen Klimakonflikten ${ }^{244}$

\footnotetext{
${ }^{241}$ S. etwa BVerfGE 20, 56, 103: „Die freiheitliche Demokratie nimmt prinzipiell die Risiken in Kauf, die darin liegen, daß die politische Willensbildung der Urteilskraft und der Aktivität der Bürger anvertraut ist", allerdings im harmloseren Zusammenhang der Parteienfinanzierung; Morlok (Fn. 216), 2042: „Immerhin hat sich die Demokratie in der Bundesrepublik als gefestigt erwiesen und eine gesicherte Identität gefunden." Ähnlich Meier (Fn. 231), 490. Morlok spricht ebd. auf S. 2033 einen oft übersehenen Gesichtspunkt an: Durch politische Reaktionen gegen extreme Meinungen und Parteien werden gemeinsame Grundwerte vor dem Vergessen oder vor der Erstarrung und bloß gebetsmühlenartiger Wiederholung gerettet. Das ist ein klassisch-liberaler Gedanke, der schon von J. St. Mill in Kap. 2 von „On Liberty“ (1859) betont worden ist. Hierzu Brugger (Fn. 198), 77.

${ }^{242}$ Andeutungsweise in diese Richtung H. Dreier Grenzen demokratischer Freiheit im Verfassungsstaat, JZ 1994, 741, 752, der zwar von der „über viele Jahre stabilen westdeutschen Demokratie“ spricht, dann aber in der dazugehörigen Fn. 161 relativiert: „Eine echte Bewährungsprobe steht dem Grundgesetz wohl erst noch bevor." Ein - nicht hinnehmbares? - Restrisiko bleibt also!

243 Unterstützend könnte man anfügen, dass außerhalb des Parteiverbots, für nicht verbotene Parteien, ein streng formaler Grundsatz der Wahlrechtsgleichheit gilt, s. etwa BVerfGE 88, 322, $337 \mathrm{f}$.

244 Wegen des engen sachlichen Zusammenhangs zwischen Meinungs- und Parteienfreiheit verwundert es nicht, dass auch bei letzterer die bei der Volksverhetzung ganz pro-
} 
zutrauen, die jenseits des Spektrums von hanseatischer Kühle bis zu bayerischer Hitze auch noch gelegentliche Eiszeiten und hochgradige Turbulenzen umfassen. ${ }^{245}$

minente Begifflichkeit des Klimaschutzes (oben Fn. 195f.), auftaucht. S. Morlok(Fn. 216), 2042 mit einer engen Fassung von Klimaschutz: „Das Institut des Parteiverbots ist aber mit dem Risiko belastet, einen Druck in Richtung ,politischer Korrektheit' auszuüben. Gegen die aus der Drohung und gar dem Einsatz des Parteiverbots erwachsende Gefahr für das politische Klima sind Maßnahmen des politischen Klimaschutzes geraten: durch forcierte Rechtsstaatlichkeit.“

245 S. zur „Demokratie“ als „Ruhepunkt, zu dem der nach rechts und links ausschlagende politische Pendel immer wieder zurückkehren muß ${ }^{*}$ - besser: kann und sollte -, H. Kelsen Vom Wesen und Wert der Demokratie, 2. Aufl. 1929, 68. 
Leitsätze des 1. Berichterstatters über:

\section{Gewährleistung von Freiheit und Sicherheit im Lichte unterschiedlicher Staats- und Verfassungsverständnisse}

\section{Vormoderne Sichtweisen von Freiheit und Sicherheit}

I. Im Römischen Reich und im christlichen Europa bis zur frühen Neuzeit besteht eine weitgehende Kontinuität in der normativen Bestimmung herrschafilicher Aufgaben: Es geht um Schaffung von Frieden und Recht, Schutz und Sicherung der Untertanen in Leib, Leben, Besitz, Familie und Ehre, im Ausgleich für Treue- und Dienstpflichten. Die Schutzwürdigkeit dieser Güter steht auch heute außer Frage. Jedoch kann eine moderne Reflexion nur beschränkt an die geistigen Voraussetzungen dieser Tradition anknüpfen. Dafür gibt es fünf Gründe:

2. (1) Die normative Verankerung dieser Ziele erfolgt in antiken oder christlichen Ordoverständnissen vorgegebener und vernünftiger Natur- oder Gottesordnung. (2) Die Minimalziele politischer Organisation - Rechtsgüterschutz und Landfriede - sind tendenziell verknüpft mit Maximalzielen wie Tugend und Glückseligkeit im Gemeinwesen. (3) Die Wahrung von Frieden und Recht geschieht in ständisch gestuften Ordnungen mit asymmetrischen Freiheiten und Würden. (4) Die Bindungen des Herrschers an Tradition, Gott, Natur und Vernunft vermischen sich oft mit der Rechtsbindung. Letztere ist lange stärker personalrechtlich als territorial und staatsrechtlich geprägt. An der Stelle einer strikten Rechtsbindung steht oft ein Widerstandsrecht. (5) Es existiert noch kein ausgebildetes subjektives Recht des Volkes gegen den Herrscher auf effektiven Schutz wichtiger Individualgüter, das mit einem Recht auf Durchsetzung vor unabhängigen Gerichten gekoppelt wäre.

\section{Moderne Staatszwecklehren in der Gesellschafisvertragstheorie}

3. Die Theorien von Hobbes, Locke, Rousseau und Kant unterscheiden sich von den vormodernen Sichtweisen von Freiheit und Sicherheit kaum in der Bestimmung der schutzwürdigen Rechtsgüter. Wichtiger ist der normative Paradigmenwechsel in der Herrschafisbegründung: Gemeinschaft ordnet nicht 
mehr Freiheit, sondern die gleiche Freiheit der Menschen führt zu einer Ordnungsaufgabe.

4. Hobbes' Theorie geht über die Sicherung von Leben weit hinaus. Sie umfasst auch „das Recht auf Wasser, Luft, Körperbewegung, auf Verbindungswege von Ort zu Ort, sowie auf alle Dinge, ohne die ein Mensch nicht oder nicht angenehm leben kann“, sowie die Sicherheit, „sich durch eigenen Fleiß und von den Früchten der Erde ernähren und zufrieden leben zu können“. Seine Souveränitätstheorie passt für „Schwärme stechenden Elends, die Anarchie und Rebellion begleiten“, bedarf aber für Zustände geordneter Verhältnisse rechtsstaatlicher Mäßigung.

5. Locke und Kant leisten diese Fortentwicklung der Staatstheorie durch Hineinnahme der Rechte aus dem Naturzustand in den bürgerlichen Zustand, durch Verankerung der Gewaltenteilung sowie durch die Rechtsbindung des Herrschers an erlassene Gesetze. Demokratie tritt bei Rousseau in den Vordergrund, allerdings in identitärer Verkürzung. Kant nimmt den Zustimmungsgedanken auf und betont den repräsentativen Charakter aller Herrschaft. Zudem ist der Staatszwang auf äußere Handlungen beschränkt, greift also nicht wie bei Rousseau auf Innerlichkeit zu. Autonomie steht so vor Heteronomie, Freiheit vor Sicherheit, aber Persönlichkeitsentfaltung bedarf der Sicherung durch Recht, im Staat, durch demokratische Festlegung, gewaltenteilige Umsetzung und weitergedacht auch verfassungsgerichtliche Kontrolle.

\section{Wandlungen von Polizei, Rechtsstaat und Sozialstaat}

6. Glückseligkeits-, Wohlfahrts- und Rechtszweck sind im Deutschland des 17. und 18. Jh. oft nicht geschieden. Mit der Zunahme liberalen Denkens werden die expansiven durch restriktivere Staatsziele ersetzt. Der Staat in Deutschland war jedoch nicht reiner Rechtssicherungsstaat, sondern subsidiär auch Wohlfahrtsstaat. Die soziale Frage im 19. Jh. erwies vollends die Notwendigkeit sozialstaatlichen Engagements.

IV. Anschlussfähigkeit des klassischen Theorierahmens für die Ordnungsprobleme des 20. und 21. Jahrhunderts

7. Vier neue Ordnungsprobleme treten insbesondere hinzu: ökologische und informationelle Bedrohungen, nationalstaatliche Entgleisungen oder Schwächen sowie notwendige Neujustierungen des Verhältnisses von staatlicher und privater Aufgabenerfüllung. Der klassische Theorierahmen analysiert diese Probleme zwar nicht im Detail; trotzdem liegt weitgehend Anschlussfähigkeit vor. 


\section{Freiheit und Sicherheit im Grundgesetz}

8. Im Grundgesetz bildet, historisch verständlich, Freiheit den herausragenden Verfassungswert. Die Textlücke in Bezug auf das Staatsziel Sicherheit wird durch die Verfassungsrechtsdogmatik geschlossen. Grundlegend ist ein Dreischritt von Argumenten, die vom Rechtsstaatsprinzip über grundrechtliche Schutzpflichten zum umstrittenen Grundrecht auf Sicherheit führen; aus dem Demokratie- und Sozialstaatsprinzip sowie aus grundrechtlichen Schrankenvorbehalten und Kompetenzvorschrifien lassen sich ebenfalls Argumente für das Staatsziel Sicherheit gewinnen.

\section{Das Beispiel Volksverhetzung}

9. $\$ 130$ Abs. I Nr. I StGB bestraft Volksverhetzungen: „Wer in einer Weise, die geeignet ist, den öffentlichen Frieden zu stören, 1. zum Haß gegen Teile der Bevölkerung aufruft ... wird ... bestraft. “ Abs. 2 enthält eine gleichgerichtete Vorschrift für Schriften und Rundfunk. Diese Sonderrechtsnorm begegnet verfassungsrechtlichen Bedenken, soweit sie als „politisches Klimadelikt“ eingesetzt wird, denn die drohenden Schäden sind weit entfernt. Sie bilden nur die Gefahr einer Gefahr, vielleicht nur ein Restrisiko, während der Eingriff in die Meinungsfreiheit direkt und gezielt ist.

\section{Das Beispiel Parteiverbot}

10. Das Parteiverbot gehört ebenfalls zu den Kategorien „Sonderrechtsnorm " und "politischer Klimaschutz". Es ist Ausdruck einer material geprägten Sicht von Freiheit und Demokratie. Diese steht in Spannung zu der These, über die Richtigkeit oder Falschheit von Meinungen könne und dürfe der Staat nicht urteilen. Vier Positionen zum Parteiverbot sind zu unterscheiden: (1) Verbot wegen der Falschheit der Ideen, auch wenn keine Bedrohung der freiheitlich-demokratischen Grundordnung vorliegt. (2) Erfordernis eines Restrisikos oder (3) einer abstrakten Gefahr oder gar (4) einer konkreten Gefahr für die freiheitlich-demokratische Grundordnung. Im Mittelpunkt stehen die Positionen (2) und (3).

11. Sieht man „abstrakte Gefahr“ enger, ist an folgende Prüfkriterien für ein Parteiverbot zu denken: (1) Größere Partei; (2) einmalige oder (3) mehrmalige Parlamentspräsenz zumindest in der Vergangenheit oder (4) auch in der Gegenwart; (5) Koalitionsfähigkeit; (6) Strafrechtsdelikte ihrer Mitglieder; (7) Ähnlichkeit oder Wesensverwandtschaft mit der NS- oder einer sonstigen totalitären Ideologie. Versteht man den Begriff weiter, werden diese Kriterien relativiert. Lässt man sie ganz weg, führt dies zur Restrisikokonzeption. 
Zweiter Beratungsgegenstand:

\title{
Gewährleistung von Freiheit und Sicherheit im Lichte unterschiedlicher Staats- und Verfassungsverständnisse
}

\author{
2. Bericht von Prof. Dr. Christoph Gusy, ${ }^{1}$ Bielefeld
}

Inhalt

Seite

I. Theoretischer Bezugsrahmen . . . . . . . . . . . 153

1. Freiheit und Sicherheit als unterschiedliche Staats-

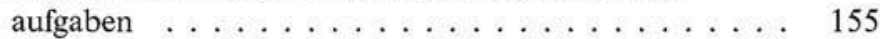

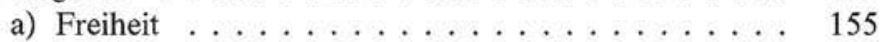

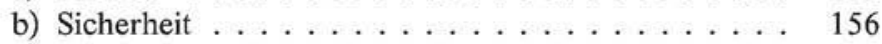

aa) Dynamisierung der Sicherheit . . . . . . . . . 157

bb) Subjektivierung der Sicherheit . . . . . . . . . 159

cc) Das Paradoxon der Sicherheit . . . . . . . . . . 160

dd) Ein theoretisches Zwischenergebnis . . . . . . . 161

2. Einige theoretische Syntheseversuche ... . . . . 162

a) Ideale Zuordnung: Die neuere Sozialvertragslehre . . 162

b) Sozialethische Zuordnung: Ethisierung des Freiheitskonzepts . . . . . . . . . . . . . 163

c) Sozialanthropologische Zuordnung: Keine Freiheit ohne Sicherheit? . . . . . . . . . . . . . 164

d) Zusammenfassung . . . . . . . . . . . . . 166

II. Die Aufgaben des Rechts . . . . . . . . . . . . . . . . . 166

1. Ein „Raum der Freiheit, der Sicherheit und des Rechts“ 166

2. Freiheit und Sicherheit: Akteure .............. 168

a) „Grundrecht auf Sicherheit"? . . . . . . . . . 168

b) Gestufte Sicherheitsverantwortung ........ 170

\footnotetext{
${ }^{1}$ Für ausdauernde Diskussionsbereitschaft und unermüdliche Unterstützung danke ich den wiss. Mitarb. Frau Dr. K. Groh, Herrn C. Schewe und Herrn M. Klein. Freundliche Anregungen erhielt ich von Prof. Dres. R. Harzer und W. Krohn. Ihnen allen bin ich sehr verpflichtet.
} 
3. Freiheit und Sicherheit: Instrumente . . . . . . . . 173

a) Der liberale Rechtsstaat: Neue Herausforderungen . . 174

aa) Staatsaufgabenlehre im Wandel . . . . . . . 175

bb) Relativierung des Grundrechtsschutzes:

Die unbegrenzte Abwägung? . . . . . . . . . 176

cc) Identität von Geschütztem und Verantwortlichem?

Probleme des Schutzpflichtkonzepts . . . . . . . 177

dd) Grenzen des Übermaßverbots bei irrationalem

Angreifer . . . . . . . . . . 178

ee) Wandel der Gewaltenbalance: Funktionseinbußen

der Justiz . . . . . . . . . . . . . . . 178

ff) Zusammenfassung . . . . . . . . . 179

b) Der demokratische Rechtsstaat: Neue Aufgaben . . 180

aa) Die grundrechtliche Verteilung der

Argumentationslast . . . . . . . . . 180

bb) Das demokratische Legitimationsverfahren . . . . 182

cc) Grundgesetzliche Differenzierungsgebote . . . . 183

dd) Legitimation durch Kontrolle . . . . . . . . . . 184

c) Ein Sonderfall: Bundeswehr und innere Sicherheit . . 186

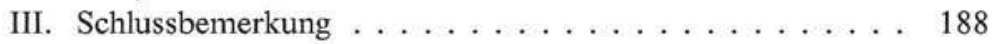


Die tragischen Ereignisse des 11 . September $2001^{2}$ haben zwar möglicherweise nicht alles, wohl aber Sicherheitsdiskurse und Sicherheitsrecht erheblich verändert. ${ }^{3}$ Statt der Alltagsfragen von ,zero tolerance“ erscheinen die Ausnahmeereignisse des internationalen Terrorismus als neue Paradigmata der Diskussion. Damit stellt sich das ewige Thema der Zuordnung von Freiheit und Sicherheit ein weiteres Mal unter neuen Vorzeichen.

\section{Theoretischer Bezugsrahmen}

Rechtsschutz und Rechtsgüterschutz sind essentielle Legitimationsgrundlagen und Aufgaben des Staates. So unbestritten dieser Befund von den ältesten bis zu den modernsten Staatstheorien ist, ${ }^{4}$ so hat er doch nur ganz vereinzelt Aufnahme in Verfassungsdokumente gefunden..$^{5}$ Hinge-

\footnotetext{
${ }^{2}$ Aus der unüberschaubaren Literatur zum 11. September 2001 Aust/Schnibben (Hrsg.) 11. September - Geschichte eines Terrorangriffs, 2003; O. Schröm/D. Laabs Tödliche Fehler - Das Versagen von Politik und Geheimdiensten im Umfeld des 11. September, 2003; Sielke (Hrsg.) Der 11. September 2001: Fragen, Folgen, Hintergründe, 2002. Wichtig u.a. U. Beck Das Schweigen der Wörter, 2002; Hoffmann/Schoeller (Hrsg.) Wendepunkt 11. September 2001, 2001; juristisch K. Nehm NJW 2002, 2665; U. Kersten Polizei 2002, 7. Die inzwischen nicht mehr überschaubare Diskussion zum Thema des Terrorismus ist bibliographiert und strukturiert bei Münkler (Hrsg.) Kommentierte Bibliographie zum Internationalen Terrorismus, 2002. Danach wichtig noch etwa ders. Die neuen Kriege, 5. Aufl. 2003; W. Laqueur Krieg dem Westen - Terrorismus im 21. Jh., 2003; W. Schluchter Fundamentalismus, Terrorismus, Krieg, 2003; D. Luiz Zukunft des Terrorismus und des Friedens, 2002; E. Eppler Vom Gewaltmonopol zum Gewaltmarkt?, 2002; O.E. Czempiel Weltpolitik im Umbruch, Die Pax Americana, der Terrorismus und die Zukunft der internationalen Beziehungen, 2002; P. Sloterdijk Luftbeben: An den Quellen des Terrorismus, 2002; S. Scheerer Die Zukunft des Terrorismus, 2002; F. v. Aretin Der 11. September, die Politik und die Kulturen, 2002; T. Meyssan Der 11. September 2001, 2002.

${ }^{3}$ Aus jüngster Zeit etwa O. Schily Der Tagesspiegel vom 7. 9. 2003, 8; zu zahlreichen weiteren, hier auch aus Zeit- und Raumgründen nicht behandelten Fragestellungen C. Calliess DVBI 2003, 1196; G. Schild DSt 2003, 329.

${ }^{4}$ S. nur T. Hobbes Leviathan, 1651, Kap. 17; A. Benz Der moderne Staat, 2001, $98 \mathrm{f}$.

${ }^{5}$ S. dazu Präambel VerfFrankreich v. 27. 10. 1947 (Ziel der frz. Union, ,ihre Zivilisation zu entwickeln, ihren Wohlstand zu mehren und ihre Sicherheit zu gewährleisten"); Art. 5 Abs. 1 VerfPolen v. 2. 4.1997 („Die Republik schützt ... die Sicherheit der Staatsbürger"). Wichtig auch Präambel und öfter EUV i.d.F v. 2. 10. 1997 (gleichzeitige Gewährleistung von Freizügigkeit und Sicherheit durch Aufbau eines „Raumes der Freiheit, der Sicherheit und des Rechts"); Art. 3 Abs. 2, 41 Abs. 1 EUVerfassungsE. Historischer Rückblick auf frühere, durchaus heterogene Erwähnungen bei $P . J$. Tettinger FS Kirchhoff, $2002,281,282 \mathrm{ff}$.
} 
gen hat die Freiheit seit der Pazifizierung der „alten“ Bürgerkriege als weiteres Um-Willen von Staaten und Verfassungen ihren Platz nicht nur in zahlreichen Staatstheorien, sondern auch in den meisten Verfassungen erlangt. ${ }^{6}$ Auf diese Weise nehmen beide Ziele einen je verschiedenen Status ein: „Sicherheit" ist Verfassungsvoraussetzung,7 Freiheit ist Verfassungsinhalt. Dies mag der Grund dafür sein, das Thema hier aus der Sicht „unterschiedlicher Staats- und Verfassungsverständnisse“ zu erörtern.

Der Schutzzweck des Staates richtet sich nach innen und außen. Beide Dimensionen rücken im Zeichen heraufziehender "Weltinnenpolitik" näher aneinander heran. ${ }^{8}$ Trennlinien verschieben sich und werden schwächer, doch bleiben auch unter den neuen Prämissen Unterschiede analytisch erkennbar und rechtlich bedeutsam. Hier muss aus zeitlichen und

Anders Art. 5 Abs. 1 EMRK (Recht auf Freiheit und Sicherheit) als Sicherheit vor staatlichen Eingriffen in die persönliche Freiheit; so zutreffend $E$. Trautwein Freiheitsentzug im Verwaltungsrecht, 2003, $61 \mathrm{ff}$; L. Jaeckel Schutzpflichten im deutschen und europäischen Recht, 2001, 113 ff.; im Sinne einer Schutzpflicht Diskussion bei M. Klugmann Europäische Menschenrechtskonvention und antiterroristische Maßnahmen, 2002, 82f. Überblick bei $P$. Szczekalla Die sogenannten grundrechtlichen Schutzpflichten im deutschen und europäischen Recht, 2002, $771 \mathrm{ff}$. Nach dem Vorbild des Art. 5 EMRK s.a. Art. 7 Abs. 2 EUGrundrechtecharta („Recht auf Freiheit und Sicherheit“); s.a. $\$ 7$ VerfRepFinnland v. 1. 3. 2000 („Leben, persönliche Freiheit, körperliche Unversehrtheit und persönliche Sicherheit“); Art. 27 I VerfPortugal v. 2. 4. 1976 („Recht auf Freiheit und Sicherheit"); ebenso Art. 17 Abs. 1 VerfSpanien v. 29. 12. 1978; Art. 19 VerfTürkei v. 13. 9. 1982; Art. 94 S. 1 VerfLettland idF v. 30.4.2002; Art. 23 Abs. 1 VerfRumänien v. 21. 11. 1991. S.a. Präambel VerfBulgarien v. 12. 7. 1991 („Rechte der Persönlichkeit, ihre Würde und Sicherheit“); Art. 34 VerfSlowenien v. 23. 12. 1991 („Recht auf persönliche Würde und Sicherheit"); Art. 55 Abs. 1 VerfUngarn idF v. 24. 8. 1990; Sec. 32 VerfMalta idF v. 13. 12. 1974 (Recht auf Leben, Freiheit, Sicherheit); Art. 20 Abs. 1 VerfEstland v. 28. 6. 1992; Art. 11 Nr. 1 VerfZypern v. 16. 8. 1960.

${ }^{6}$ Grundlegend J. Locke Two Treatises of Government, 1690, $\$ 1123 \mathrm{ff}$.; zur anders verlaufenden deutschen Entwicklung D. Klippel Politische Freiheit und Freiheitsrechte im deutschen Naturrecht des 18. Jh., 1976, $113 \mathrm{ff}$.

$7 \mathrm{Zu}$ den Verfassungsvoraussetzungen umfassend $J$. Krüger FS Scheuner, 1973, 285, $286 \mathrm{ff}$., 292f.; J. Isensee in: ders./Kirchhof (Hrsg.) HStR V, 1992, \$ 115 Rn. $163 \mathrm{ff}$.

${ }^{8}$ Überblick bei Weidenfeld (Hrsg.) Herausforderung Terrorismus. Die Zukunft der Sicherheit, 2003. Nach Beck (Fn. 2), 45, stärkt der Terroranschlag vom 11. 9. „den Staat, entwertet jedoch seine zentrale historische Form, den Nationalstaat." Zum Komplex von Globalisierung und Weltinnenpolitik $H$. Hess KJ 2002, 450; H. Düx ZRP 2003, 189. K. Kaiser in: ders./Schwarz (Hrsg.) Die neue Weltpolitik, 2000, 591, 592ff.; D.S. Lutz in: Bartosch/Wagner (Hrsg.) „Weltinnenpolitik“, 1998, $132 \mathrm{ff}$; E. v. Bubnoff NJW 2002, $2672 \mathrm{ff}$; M. Steinerin: Bundesakademie für Sicherheitspolitik (Hrsg.) Sicherheitspolitik in neuen Dimensionen: Kompendium zum erweiterten Sicherheitsbegriff, 2001, $31 \mathrm{ff}$;; s.a. O. Höffe Demokratie im Zeitalter der Globalisierung, Neuausgabe 2002, $352 \mathrm{ff}$. 
thematischen Gründen die innerstaatliche Komponente im Vordergrund stehen. ${ }^{9}$

\section{Freiheit und Sicherheit als unterschiedliche Staatsaufgaben}

Seit den jüngeren Staatsvertragslehren steht im Zentrum staatlicher Schutzaufgaben nicht mehr allein die physische Existenz, sondern zudem die moralische Persönlichkeit der Menschen in rechtlich anerkannter und garantierter Freiheit. Doch sind Freiheits- und Schutzauftrag nicht gleichgerichtet, sie sind vielmehr unterschiedlich und vielfach gegenläufig. Sicherheit ist die Abwesenheit von Risiken; Freiheit hingegen verursacht und steigert Risiken. Und die „Staatsaufgabe Freiheit“ individualisiert Entscheidungszuständigkeiten; die "Staatsaufgabe Sicherheit“ kollektiviert Entscheidungszuständigkeiten.

\section{a) Freiheit}

Grundrechtsschutz der Freiheit bedeutet rechtliche Offenhaltung der Auswahl zwischen faktischen Alternativen und Individualisierung der Entscheidung über diese Auswahl. ${ }^{10}$ Wer frei ist, hat grundsätzlich die Wahl zwischen risikovermeidenden und risikofreudigen Handlungsalternativen. Risiken sind prognostizier- und steuerbare negative Folgen von Entscheidungen." Sie können aus eigenen Entscheidungen entstehen: Nur wer sich auf die Straße traut, kann dort zu Schaden kommen. Sie können aber auch aus Verhaltenweisen anderer Menschen resultieren: Wer sich auf die Straße getraut hat, kann dort durch Entscheidungen anderer ge-

\footnotetext{
${ }^{9} \mathrm{Zu}$ völkerrechtlichen Aspekten etwa C. Tomuschat EuGRZ 2001, 585; J. Delbrück GYIL 2001, 9; U. Häußler ZRP 2001, 537; M. Krajewski KJ 2001, 363; ders. AVR 2002, 183; T. Bruha AVR 2002, 383; ders. in: Koch (Hrsg.) Terrorismus - Rechtsfragen der inneren und äußeren Sicherheit, 2002, 51; S. Oeter in: Koch, ebd., 29; ders. AVR 2002, 422; M. Kotzur AVR 2003, 454; D. Blumenwitz ZRP 2002, 102; M. Ruffert ZRP 2002, 247; C. Stahn ZaöRV 2002, 183; C. Tietje NZWehrr 2002, 1; D. Kugelmann Jura 2003, 376 (Nachw.). Überblick bei G. Kümmel/S. Collmer Asymmetrische Konflikte und Terrorismusbekämpfung, 2003.

${ }^{10} \mathrm{Zu}$ den Freiheitsbegriffen als Grundlagen grundrechtlichen Freiheitsschutzes näher H. Hofimann JZ 1992, 165 ff.; B. Schlink EuGRZ 1984, 457; G. Lübbe-Wolff Grundrechte als Eingriffsabwehrrechte, 1988, $13 \mathrm{ff}$., $20 \mathrm{ff}$., $75 \mathrm{ff}$;; M. Morlok Selbstverständnis als Rechtskriterium, 1993, 380ff.; A. v. Arnauld Die Freiheitsrechte und ihre Schranken, 1999, $15 \mathrm{ff}$., $38 \mathrm{ff} ., 110 \mathrm{ff}$; E.-W. Böckenförde NJW 1974, 1529ff.; R. Poscher Grundrechte als Abwehrrechte, 2003, $110 \mathrm{ff}$. Zur sozialen Funktion dieses Konzepts, seiner Entstehung und seinen Grenzen D. Grimm Die Zukunft der Verfassung, 1991, 67ff., $82 \mathrm{ff}$., $86 \mathrm{ff}$.; H. Dreier Dimensionen der Grundrechte, 1993, $27 \mathrm{ff}$.; $T$. Vesting in: Grabenwarter u.a. (Hrsg.) Allgemeinheit der Grundrechte und Vielfalt der Gesellschaft, 1994, 9 ff.

11 Beck (Fn. 2), 16.
} 
schädigt werden. Die Freiheit des einen ist immer auch das Risiko des anderen. Wo Freiheit die Grundlage von Wettbewerb, technischem Fortschritt oder gesellschaftlicher Innovation ist, ${ }^{12}$ steigen Handlungsalternativen und Störungsanfälligkeit exponentiell an. Hier kann und soll nicht die Diskussion um die technische Sicherheit nachgezeichnet werden. Doch bewirken die neuen Medien, ${ }^{13}$ Verfahren und Anlagen, ${ }^{14}$ auf welchen moderne Gesellschaften basieren, eine Explosion von Einwirkungsmöglichkeiten und Risiken durch Gebrauch und Missbrauch der neuen Möglichkeiten. Freiheit ist also grundsätzlich geeignet, Komplexität und Kontingenz der Umwelt zu steigern, die daraus entstehenden Risiken zu erhöhen und umgekehrt die Sicherheit zu mindern.

\section{b) Sicherheit}

Sicherheit - verstanden als innere Sicherheit - ist ein modernes Konzept. Bis in die sechziger Jahre hinein wurde der Begriff fast ausschließlich in speziellen militärischen, technischen und sozialen Kontexten verwendet. ${ }^{15}$ Und bis in die jüngste Vergangenheit befassten sich Politik- und Sozialwissenschaft weniger mit der Sicherheit als vielmehr mit ihrem Gegenteil, dem Risiko.16 Die Redeweise von „der Sicherheit“ indiziert so

12 Klassisch J. St. Mill On Liberty, 1859, Kap. 2, 3; aus neuerer Zeit etwa F.A. v. Hayek Die Verfassung der Freiheit, 3. Aufl. 1991, $30 \mathrm{ff}$.

${ }^{13}$ Eher dramatisierend P. Dieterle/U. Schrölel/U. Bux Kriminalistik 2003, 330 (,information warfare“). Guter Überblick bei Roßnagel (Hrsg.) Sicherheit für Freiheit?, 2003; s.a. R. Hutterin: Frank (Hrsg.) Sicherheitspolitik in neuen Dimensionen, 2001, 483; KES/ KPMG, Zeitschrift für Kommunikation und EDV-Sicherheit 2002, H. 4, $16 \mathrm{ff}$.

14 Zur Sicherung von Atomkraftwerken $U$. Battis in: Ossenbühl (Hrsg.) Deutscher Atomrechtstag 2002, 2003, 27ff.; T. v. Danwitz Rechtsfragen terroristischer Angriffe auf Kernkraftwerke, 2002; H.-J. Koch/M. John DVB1 2002, 1578; F. Ossenbühl NVwZ 2002, $290 ; H$. Sendler NVwZ 2002, 681.

is Grundlegend nach wie vor F-X. Kaufmann Sicherheit als soziologisches und sozialpolitisches Problem, 2. Aufl. 1973, $10 \mathrm{ff}$., $49 \mathrm{ff}$., $53 \mathrm{ff}$. Zur Begriffsgeschichte $W$. Conze in: Brunner/Conze/Koselleck (Hrsg.) Geschichtliche Grundbegriffe 5, 1984, $831 \mathrm{ff}$.

16 Wirkungsmächtig nach wie vor $U$. Beck Die Risikogesellschaft, 1986, insbes. $265 \mathrm{ff}$., $300 \mathrm{ff}$; wichtig auch C. Perrow Normale Katastrophen, 2. Aufl. 1992, insbes. $57 \mathrm{ff}$.; A. Bora in: ders. (Hrsg,) Risikomanagement: Form, Funktion und Leistungsfähigkeit des Rechts in der Risikogesellschaft, 1999, 9 ff.; historisch P. Bernstein Wider die Götter, 1997. Bibliographie bei G. Banse Interdisziplinäre Risikoforschung, 1998. Danach etwa M.A.H. Dempster (Hrsg.) Risk Management: Value at risk and beyond, 2002; C. Ohl Staatliche Umweltregime und transnationales Risikomanagement, 2003. Für die Politikwissenschaft stellt die wichtige Untersuchung von H.-J. Lange Innere Sicherheit im politischen System der Bundesrepublik Deutschland, 1999, (Nachw.), keine Ausnahme von dem im Text genannten Grundsatz dar. Sie befasst sich nicht mit Sicherheits- und Risikoforschung, sondern enthält eine Politikfeldanalyse. Vgl. aber auch H.A. Hesse Der Schutzstaat, 1994, 
eher den Wandel als die Kontinuität des staatlichen Schutzauftrages. Dieser Wandel vollzog sich in mehreren Richtungen.

\section{aa) Dynamisierung der Sicherheit}

Die Dynamisierung des Sicherheitsdenkens setzt die Abkehr von einem primär repressiven Verständnis des staatlichen Schutzauftrages voraus. ${ }^{17}$ Dieser basierte auf einem statischen Schutzgutkonzept: Es ging um die Sicherung bestehender Rechtsgüter gegen rechtswidrige Beeinträchtigung durch Dritte. Deren Schutz sollte primär durch repressive Mittel erreicht werden. Im Idealfall war Sicherheit gewährleistet, wenn alle Straftäter bestraft waren. Jenes traditionelle Konzept wird in der neueren Diskussion durch ein dynamisches Schutzgutkonzept ergänzt. Es geht nicht mehr nur um den reaktiven Schutz bestehender Rechtsgüter, sondern zudem um Garantie und Kontinuität zukünftiger Rechte und Ansprüche, etwa aus der Daseinsvorsorge. ${ }^{18}$ Diese Aufgabe bezieht den Schutz von Allokationsfähigkeit und Zuteilungsgerechtigkeit des Gemeinwesens einschließlich der dafür erforderlichen informationellen und technischen Infrastruktur ${ }^{19}$ sowie letztlich die Handlungsfähigkeit der zuständigen Entscheidungs- und Verantwortungsträger ein. ${ }^{20}$ Gewandelt hat sich aber

$115 \mathrm{ff}$; H.-J. Lange in: ders. (Hrsg.) Die Polizei der Gesellschaft. Zur Soziologie der inneren Sicherheit, 2003, $427 \mathrm{ff}$.

${ }^{17}$ Dazu näher Hobbes (Fn. 4), Kap. 14, 21, der den Schutzzweck des Staates außerhalb des (Bürger-)Krieges aus Selbsthilfe- und Notwehrrecht begründen will. Noch deutlicher in diese Richtung Locke (Fn. 6), $\$ \S 128,130$. Zum Folgenden grundlegend D. Grimm KritVj 1986, 38, $40 \mathrm{ff}$. Zum steigenden Sicherheitsbedürfnis der Gesellschaft $G$. Calliess Prozedurales Recht, 1999, 56ff.

18 Überblick bei P.J. Tettinger RdE 2002, 225, 226ff.

${ }^{19} \mathrm{~S}$. dazu allgemein T. Kingreen Das Sozialstaatsprinzip im europäischen Verfassungsverbund, 2003, $116 \mathrm{ff}$., $187 \mathrm{ff}$., 192ff., $204 \mathrm{ff}$; Überblick bei $M$. Knauff VR 2003, $269 \mathrm{ff}$.; G. Hermes Staatliche Infrastrukturverantwortung: Rechtliche Grundstrukturen netzgebundener Transport- und Übertragungssysteme zwischen Daseinsvorsorge und Wettbewerbsregulierung am Beispiel der leitungsgebundenen Energieversorgung in Europa, 1998, $123 \mathrm{ff} ., 323 \mathrm{ff}$; P. Lerche FS Friauf, 1996, $251 \mathrm{ff}$; zur informationellen Infrastruktur: F. Schoch VVDStRL 57 (1998), 158, 199, 204; H.-H. Trute in: ebd., 216, 249ff.; R. Scholz/R. Pitschas Informationelle Selbstbestimmung und staatliche Informationsverantwortung, 1984; zur Telekommunikation M. Freund Infrastrukturgewährleistung in der Telekommunikation: staatliche Gewährleistungsverantwortung, Universaldienst, Wegerechte, 2002, $53 \mathrm{ff}$;; ders. NVwZ 2003, 408ff.; C. Theobald NJW 2003, $324 \mathrm{ff}$; K.M. Eifert Grundversorgung mit Telekommunikationsleistungen im Gewährleistungsstaat, 1998, $19 \mathrm{ff} ., 31 \mathrm{ff} ., 175 \mathrm{ff}$;; zur Energiewirtschaft J.-P. Schneider Liberalisierung der Stromwirtschaft durch regulative Machtorganisation, 1999, $123 \mathrm{ff}$.

${ }^{20} \mathrm{Zur}$ „Funktionsfähigkeit" öffentlicher Einrichtungen als Schutzgut des Polizei- und Ordnungsrechts s. E. Denninger in: Lisken/Denninger (Hrsg.) Handbuch des Polizeirechts, 3. Aufl. 2001, E Rn, 10; B. Pieroth/B. Schlink/M. Kniesel Polizei- und Ordnungs- 
auch die Schutzrichtung: Es geht nicht mehr allein um aktuelle Schädigungen und reaktive Repression, sondern um die Verhütung zukünftiger Risiken $^{21}$ durch proaktive Prävention. ${ }^{22}$ Dadurch potenziert sich das schwierige Problem der Risikosuche einschließlich der Abschätzung seiner Eintrittsbedingungen und -folgen. Das gilt um so mehr, als mit dem Übergang vom Gefahren- zum Risikodenken ${ }^{23}$ die tradierten Kriterien der deterministischen Linearität und Kausalität durch solche der statistischen Wahrscheinlichkeit, komplexer Wirkungszusammenhänge und worst-case-Szenarien ergänzt werden. ${ }^{24}$ Risiken sind nirgends ausgeschlossen, können stets neu oder verändert auftreten und sich tendenziell unendlich potenzieren. Ein Beispiel ist die aktuelle Diskussion über den grenzüberschreitenden Terrorismus. ${ }^{25}$ Ex ante weiß man allzu oft nur, dass etwas passieren kann und wer potenzielle Urheber sein könnten. Unbekannt sind die realen Akteure, ihre durch die Verletzlichkeit der infrastrukturellen Voraussetzungen moderner Gesellschaften dramatisch vervielfältigten Angriffsziele und die durch technische Vernetzung und Öffnung von Grenzen hoch potenzierten Angriffsmöglichkeiten. Auch ex post bleiben erhebliche Teile der Erkenntnisse über Verantwortliche, Kausalitäten und zukünftige Bedrohungen letztlich schwer verifizierbare

recht, 2002, Rn. 36; W.-R. Schenke Polizei- und Ordnungsrecht, 2002, Rn. 53; B. Drews/G. Wacke/K. Vogel/W. Martens Gefahrenabwehr: allgemeines Polizeirecht (Ordnungsrecht) des Bundes und der Länder, 9. Aufl. 1986, § 15, 233; C. Gusy Polizeirecht, 5. Aufl. 2003, Rn. 83.

${ }^{21}$ Zum Übergang vom Gefahrenabwehr- zum Vorsorgeprinzip grundsätzlich G. Lübbe-Wolffin: Bizer/Koch (Hrsg.) Sicherheit, Vielfalt, Solidarität, 1998, 47 ff.; U. di Fabio FS Ritter, 1997, 807; R. WahVI. Appel in: Wahl (Hrsg.) Prävention und Vorsorge: von der Staatsaufgabe zu den Verwaltungsinstrumenten, 1995, 1, 13 ff.; für das Polizei- und Nachrichtendienstrecht $J$. Aulehner Polizeiliche Gefahren- und Informationsvorsorge, 1998, $47 \mathrm{ff}$., $545 \mathrm{ff}$.; H.-H. Trute GS Jean d'Heur, 1999, 403, 404ff.; Grimm (Fn. 17), 38, 40; K. Waechter Polizei- und Ordnungsrecht, 2000, Rn. 92 ff.; R. Pitschas in: ders. (Hrsg.) Kriminalprävention und „Neues Polizeirecht": Zum Strukturwandel des Verwaltungsrechts in der Risikogesellschaft, 2002, 241, $242 \mathrm{ff}$.; M. Albers Die Determination polizeilicher Tätigkeit in den Bereichen der Straftatenverhütung und der Verfolgungsvorsorge, 1999, $97 \mathrm{ff}$., $116 \mathrm{ff} ., 250 \mathrm{ff}$., $347 \mathrm{ff}$.; M. Zöller Informationssysteme und Vorfeldmaßnahmen von Polizei, Staatsanwaltschaft und Nachrichtendiensten, 2002, $77 \mathrm{ff}$. (alle mwN).

22 So die Formulierung von E. Denninger KJ 2002, 467, 472; ähnlich auch $O$. Schily RuP 35 (1999), 1, 2. Ausführliche Beschreibung dieses Prozesses bei $M$. Möstl Die staatliche Garantie für die öffentliche Sicherheit und Ordnung, 2002, $147 \mathrm{ff}$.

${ }^{23} \mathrm{Zu}$ den damit verbundenen Wandlungen des Polizeirechts eindrucksvoll $K$. Waechter JZ 2002, 854.

${ }^{24}$ S. dazu näher U.K. Preuß in: Grimm (Hrsg.) Staatsaufgaben, 1994, $526 \mathrm{ff}$., $531 \mathrm{ff}$. (Nachw.).

${ }^{25}$ Dazu o. Fn. 2. 
Hypothesen. ${ }^{26}$ Gewiss, solche Probleme sind nicht der Alltag der meisten Sicherheitsbehörden, ${ }^{27}$ wohl aber derjenigen der neueren Risiko- und Sicherheitsdiskurse.

\section{bb) Subjektivierung der Sicherheit}

Die Subjektivierung des Sicherheitsdenkens erstreckt dessen Reichweite auf den Schutz des Sicherheitsgefühls. Darin liegt mehr als eine immanente Fortentwicklung des alten Schutzguts. Es ist ein Unterschied, ob etwas sicher ist oder ob ich (mir) sicher bin. ${ }^{28}$ Sicherheit ist die Abwesenheit von Risiken in einer großen Zahl von Fällen, Sicherheitsgefühl das individuelle Empfinden ihrer Abwesenheit im Einzelfall. Gegenwärtig darf als empirisch gesichert gelten: Beide Phänomene entwickeln sich unabhängig voneinander. ${ }^{29}$ So war etwa der 11. September sehr wohl geeignet, das Sicherheitsgefühl zu beeinträchtigen; die objektive Sicherheit war von ihm höchstens peripher betroffen. ${ }^{30}$ Schwieriger und zweifelhafter ist die

\footnotetext{
${ }^{26}$ Frühe Bestandesaufnahme in Bundeskriminalamt (Hrsg.) Islamischer Terrorismus, 2002. Aus jüngerer Zeit einerseits $H$. Frank/K. Hirschmann Die weltweite Gefahr: Terrorismus als internationale Herausforderung, 2002; andererseits M. Broeckers Fakten, Fälschungen und die unterdrückten Beweise des 11. 9., 2003.

${ }^{27} \mathrm{Im}$ Alltag sind die Erkenntnismöglichkeiten häufig besser. Je stabiler individuelles Verhalten und dessen soziale Bedingungen, desto prognostizierbarer mag die Zukunft sein. Umgekehrt gilt aber auch: Je flexibler das Verhalten der Einzelnen und je offener die sozialen Kontakte, desto schwieriger wird die Prognose. Zum Wandel der Handlungsformen von Sicherheitsbehörden näher $N$. Dose/K. König in: Lenk/Prätorius (Hrsg.) Eingriffsstaat und öffentliche Sicherheit: Anträge zur Rückbesinnung auf die hoheitliche Verwaltung, 1998, $94 \mathrm{ff}$. (politikwissenschaftlich); s.a. R. Pitschas (Fn. 21).

28 Richtig schon Kaufimann (Fn. 15), $72 \mathrm{ff}$.

${ }^{29}$ Hierzu etwa K. Boers Kriminalitätsfurcht: Über den Entstehungszusammenhang und die Folgen eines sozialen Problems, 1991, $57 \mathrm{ff}$. u. pass.; ders. Neue Kriminalpolitik 2001, H.2, 10, 13; T. Feltes Kriminalistik 1997, 538; K.-H. Reuband Neue Kriminalpolitik 1999, 16, 18; ders. Kölner Zeitschrift für Soziologie und Sozialpsychologie 1992, 341; ders. ZfS 1989, 470, 472f.; M. K. Schweer/B. Thies Kriminalistik 2000, 336, 338; F. Kreuter Kriminalitätsfurcht: Messung und methodische Probleme, 2002, 25; Leithäuser u.a. (Hrsg.) Gewalt und Sicherheit im öffentlichen Raum, 2002; J. Wehrheim Die überwachte Stadt: Sicherheit, Segregation und Ausgrenzung, 2002, 17 ff.; H.-J. Kerner Kriminalitätseinschätzung und innere Sicherheit, 1980, 137 ff.; B. Frevel in: Lange (Fn. 16), 321 ff. Schon früher grundlegend M. Murck Soziologie der öffentlichen Sicherheit: eine staatliche Aufgabe aus der Sicht der Bürger, 1980, 42ff.; W.G. Skogan/M.G. Maxfield Coping with Crime: individual and neighbourhood reactions, 1981, 257. Zu Einzelfragen etwa $R$. Hefendehl KJ 2000, $174 \mathrm{ff}$;; T. Feltes Kriminalistik 2003, 277; J. Burgheim/A. Sterbling Kriminalistik 2003, 437; T. Kasperzak Stadtstruktur, Kriminalitätsbelastung und Verbrechensfurcht, $2000,125 \mathrm{ff}$.

${ }^{30}$ Das gilt für Einzelereignisse praktisch stets; zum Zusammenhang von 11. 9. und Sicherheitsgefühl grundlegend W. Sofsky in: Hoffmann/Schoeller (Fn. 2), 27, 33f.; ders. Zeiten des Schreckens, 2002, 95f.; s.a. D. S. Lutz in: Koch (Fn. 9), 9; empirisch A. Sterb-
} 
Begründung jener Ausweitung. Einerseits ist es prinzipiell eine grundrechtlich geschützte, dem Kernbereich des Persönlichkeitsrechts zuzuordnende Angelegenheit der Menschen, ob sie sich fürchten oder nicht. ${ }^{31}$ Andererseits können solche Gefühle gerade dem demokratischen Staat nicht völlig gleichgültig sein. Wenn er den Bürgern das Recht zubilligt, frei und aus eigenen Motiven Wahlentscheidungen zu treffen, dann ist die Rationalität bzw. Irrationalität dieser Motive ohne rechtlichen Belang. Hängt jedoch die Akzeptanz der gewählten Volksvertreter ebenso wie diejenige der demokratischen Staatsform auch von Gefühlen ab, so wäre es politisch fatal, solche Befindlichkeiten zu missachten oder auch nur gering zu schätzen. Das Sicherheitsgefühl thematisiert vielmehr eine ungeschriebene Existenzvoraussetzung zumindest des demokratischen Staates. ${ }^{32}$

\section{cc) Das Paradoxon der Sicherheit}

Dynamisierung und Subjektivierung der Schutzgüter bewirken schon theoretisch Unerreichbarkeit der Sicherheit. Sicherheit ist relativ. Ziel kann nicht die völlige Vermeidung von Risiken, sondern nur Optimierung ihres Managements sein. ${ }^{33}$ Am Ende der Skala steht das Paradoxon der Sicherheit: Der Staat, der alle Risiken ausschließen soll, muss alles wissen, alles können und alles dürfen. ${ }^{34}$ Das wäre nicht nur das Ende jeglicher Freiheit. Ein solcher Staat würde vielmehr selbstwidersprüchlich. ${ }^{35} \mathrm{Er}$ würde zu einer Quelle dessen, was er eigentlich ausschließen wollte: der Unsicherheit.

ling/J. Burgheim Polizei 2003, 181; C. Weller Die massenmediale Konstruktion der Terroranschläge am 11. September 2001, 2002.

${ }^{31}$ Hier liegt das Grundproblem der viel diskutierten „Freiheit von Furcht“. S. dazu R. Herzog Grundrechtsbeschränkung nach dem GG und EMRK, Diss. 1958, $17 \mathrm{ff}$.; E. Denninger VVDStRL 37 (1979), 7, 26ff.; A. Arndt NJW 1961, 897, 898 und öfter.; G. Frankenberg KJ 1977, 353, 356; H. Hofmann Rechtsfragen der atomaren Entsorgung, 1981, 308f.; A. Roßnagel Grundrechte und Kernkraftwerke, 1979, 44f.; G. Robbers Sicherheit als Menschenrecht, 1987, 223 ff.; $U$. di Fabio Risikoentscheidungen im Rechtsstaat, 1994, 41 f.; O. Lagodny Strafrecht vor den Schranken der Grundrechte, 1996, 2, 4, 22 ff., 197f.: Die Diskussion rankt sich nicht zuletzt um einige Aussagen des BVerfG; namentlich BVerfGE 49, 89, 143; H. Simon/H. Heußner in: BVerfGE 53, 30, 69ff.; BVerfGE 65, 1, 3f.; 78, 290, 304; 83, 216, $230 \mathrm{ff}$.

${ }^{32}$ Doch bleibt es dabei: Subjektive Sicherheit ist im Verhältnis zur objektiven Sicherheit kein Minus, sondern ein Aliud. Zur juristischen Relevanz dieses Befundes s. II $3 \mathrm{c}$ ) aa).

${ }^{33}$ Eindringlich H.P. Bull in: ders. Sicherheit durch Gesetze?, 1987, 15 ff.; H. Hohmann DSt $1988,588,598$.

${ }^{34}$ Grimm (Fn. 17), $46 \mathrm{ff}$.

35 Dazu grundlegend Grimm (Fn. 17), 38ff.; E. Denninger KJ 1988, 1, $10 \mathrm{ff}$.; ders. (Fn. 22), 470ff. 


\section{dd) Ein theoretisches Zwischenergebnis}

Insgesamt bleibt festzuhalten: Der neue „erweiterte Sicherheitsbegriff“ ${ }^{* 36}$ ist nur terminologisch eine Fortführung des alten; in Wirklichkeit geht es um Neues und Anderes. Ist „Sicherheit“ ein modernes Konzept, so ist auch die Diskussion um ihr Verhältnis zur Freiheit notwendig eine moderne Diskussion. ${ }^{37}$ Dieser Befund mahnt zur Zurückhaltung bei dem Versuch, die neuen Fragen mit alten Aussagen der Klassiker zu beantworten. Das zeigt ein kleines Beispiel. Die geschilderte Dynamisierung des Schutzguts verlagert die politische Argumentationslast im Sicherheitsdiskurs, genauer: die Umkehrung eines tradierten Regel-Ausnahme-Verhältnisses im Begründungszusammenhang. Fragte das repressive Konzept ${ }^{38}$ allein danach, ob eine Person Straftaten begangen hat oder nicht, so konnte bejahendenfalls aber auch nur dann ${ }^{39}$ - ihre Bestrafung die Sicherheit erhöhen. Die Begründungslast liegt hier regelmäßig auf der Seite der Strafenden. Anders verhält es sich im dynamischen Konzept. Dem Staatsziel ${ }^{40}$ „Risikominimierung“ ist Freiheit wegen ihrer generellen Tendenz zur Risikoerhöhung regelmäßig abträglich. Soll dennoch beides - Freiheit und Sicherheit - verwirklicht werden, muss in jedem Einzelfall geprüft werden, ob eine konkrete Variante der Freiheitsausübung ausnahmsweise risikoneutral sein kann oder nicht. Die Begründungslast trägt dann regelmäßig, wer sich auf die Freiheit beruft. ${ }^{41}$ Neue Fragen provozieren neue Antworten.

\footnotetext{
${ }^{36}$ Grundlegend hierzu E.H. Ahlf Polizei 2002, 93; s.a. Bundesakademie für Sicherheitspolitik (Hrsg.) (Fn. 8); K.-L. Kunz Bürgerfreiheit und Sicherheit: Perspektiven von Strafrechtstheorie und Kriminalpolitik, 2000, 53, $57 \mathrm{ff}$;; G. Fricke FS Forndran, 2003, $35 \mathrm{ff}$;; M. Schultze in: ebd., $71 \mathrm{ff}$.; D.S. Lutz in: ders./Peach/Scheerer (Hrsg.) Zukunft des Terrorismus und des Friedens. Menschenrechte - Gewalt - Offene Gesellschaft, 2002, $27 \mathrm{ff}$; G. Erbel DVBI 2001, 1714ff.; E. Forndran Demokratie und demokratischer Staat in der Krise, 2002, 155; W. Hoffmann-Riem ZRP 2002, 497, 499f.; R. Pitschas DÖV 2002, $221,223$.

37 W. Hassemer Vorgänge 3/2002, 10.

${ }^{38}$ S.o. I 1 b) aa).

${ }^{39}$ So explizit Hobbes (Fn. 4), 26. Kap.: „Denn das unveränderliche und göttliche Naturgesetz verbietet, einen Unschuldigen zu strafen.“

40 J. Isensee in: ders./Kirchhof (Hrsg.) HStR I, 2. Aufl. 1995, $\$ 13$ Rn. $74 \mathrm{ff}$;; C. Calliess ZRP 2002, $1 \mathrm{ff}$;; K.-P. Sommermann Staatsziele und Staatszielbestimmungen, 1997, 105f., $113 \mathrm{ff} ., 199 \mathrm{ff}$.; J. Limbach AnwBl 2002, 454, 455.

${ }^{41}$ Denninger (Fn. 22), 472, unter Berufung auf $H$. Prantl Verdächtig, 2002, 9; ähnl. auch P.-A. Albrecht Die vergessene Freiheit, 2003, 76f., 136ff.; M. Kniesel ZRP 1996, 482, 487; F. Roggan Auf legalem Weg in einen Polizeistaat: Entwicklungen des Rechts der inneren Sicherheit, 2000, 22f., 216, 223f.; ders. Handbuch zum Recht der inneren Sicherheit, 2003, 279; M. Dolderer NVwZ 2001, 130; U. Volkmann NVwZ 2000, 361, 367; N. Paech in: Kutscha/Paech (Hrsg.) Im Staat der ,inneren Sicherheit“: Polizei, Verfassungsschutz, Geheimdienste, Datenkontrolle im Betrieb, 1981, 28, 43f.; H. Lisken ZRP 1994, 264, $266 \mathrm{ff}$.
} 


\section{Einige theoretische Syntheseversuche}

Unser Thema fragt nicht nach Freiheit oder Sicherheit, sondern Freiheit in Sicherheit ${ }^{42}$ und nach Sicherheit in Freiheit. Beide stehen in einem notwendigen Ergänzungsverhältnis. Sicherheit stabilisiert und garantiert die Verkehrsregeln der Freiheitsausübung. ${ }^{43}$ Doch gilt für diese Verkehrsregeln, was für alle Verkehrsregeln gilt: Es ist nicht ihre bloße Existenz, welche den Verkehr zum Laufen oder zum Erliegen bringt. Dafür kommt es vielmehr auf den Inhalt jener Regeln an.

Hierzu lässt sich nicht einfach ein Vorrang der Freiheit aus der ökonomischen Annahme herleiten, dass für den Grundrechtsträger Freiheit kostenlos, Sicherheit hingegen nur mit erheblichem Aufwand an Steuern oder sonstigen Mitteln zu erreichen sei. Denn Freiheitsausübung verlangt vom Einzelnen nicht selten erhebliche Arbeit und Kosten. Dagegen ist Sicherheit ein öffentliches Gut, ${ }^{44}$ welches vom Staat zur Verfügung gestellt wird. Sie kostet im Einzelfall meistens nichts - oder noch eher: Der Bürger hat schon bezahlt, nämlich durch Steuern und Abgaben. Aus dieser Mikroperspektive ist Sicherheit die günstigere Alternative: Warum soll der Einzelne seine Wohnung durch teure technische Anlagen oder Wachdienste sichern lassen, wenn er den Schutz kostenlos von der Polizei verlangen kann?

\section{a) Ideale Zuordnung: Die neuere Sozialvertragslehre}

Die neuere Sozialvertragslehre ${ }^{45}$ nimmt ihren Ausgangspunkt beim Übergang von der "vor-gesellschaftlichen“ individuellen zur sozialvertraglich begründeten gesellschaftlichen Freiheit. Der Gesellschaftsvertrag

\footnotetext{
${ }^{42}$ Dazu Tettinger (Fn. 5), 281.

${ }^{43}$ Formulierung nach D. Suhr Entfaltung der Menschen durch die Menschen, 1976, $129 \mathrm{ff}$.

${ }^{44}$ Zur Theorie der öffentlichen Güter im Recht $C$. Gramm Privatisierung und notwendige Staatsaufgaben, 2000, 190ff.; zur öffentlichen Sicherheit als öffentliches Gut ebd., $395 \mathrm{ff}$;; zu Fragen der Nutzung und der Tragung der Kosten dieses öffentlichen Gutes Jachmann/Stober (Hrsg.) Finanzierung der inneren Sicherheit unter Berücksichtigung des Sicherheitsgewerbes, 2003; C. Gusy Staatswissenschaften und Staatspraxis (StWStP) 1994, 187, 197 ff.; ders. in: Hoffmann-Riem/Schmidt-Aßmann (Hrsg.) Effizienz als Herausforderung an das Verwaltungsrecht, 1998, 175, $189 \mathrm{ff}$;; ders. Privatisierung von Polizeikosten?, 1996, $12 \mathrm{ff}$.

${ }^{45}$ Zum Folgenden grundlegend $J$. Rawls Eine Theorie der Gerechtigkeit, 1975, $140 \mathrm{ff}$. $\mathrm{Zu}$ den Vertragsgrundlagen der Fairness ebd., 19ff.; zur Gerechtigkeit ebd., 74ff.; ders. Gerechtigkeit als Fairness: ein Neuentwurf, 2003, $38 \mathrm{ff}$., $73 \mathrm{ff}$., $132 \mathrm{ff}$. Das zitierte Prinzip des „gleichen Rechts ... “ findet sich als 1. Grundsatz der Gerechtigkeit in: ders. Theorie, 81. Begründungen dazu ebd., $274 \mathrm{ff}$., $332 \mathrm{ff}$. Doch ist der ganz überwiegende Teil des Bandes der Begründung des 2. Gerechtigkeitssatzes (ebd., 81) gewidmet.
} 
dürfe Freiheit nur um der Freiheit willen einschränken. Unter den Bedingungen von Gerechtigkeit und Fairness entstehe so „das Recht auf das umfangreichste System gleicher Grundfreiheiten, das mit dem gleichen System für alle anderen verträglich ist". Doch fragt jene Lehre nicht nach den sozialtheoretischen Prämissen ihrer Konsequenzen. Hier kann es durchaus Situationen geben, welche den hypothetischen Vertragsparteien nahe legen, nicht die Freiheit, sondern die Sicherheit zu optimieren und in deren Interesse auf wesentliche Teile ihrer Freiheit zu verzichten. Die Staatstheorie ist voll von Beispielen. ${ }^{46}$ Der notwendige Vorrang der Freiheit mag so unter idealen Vertragsbedingungen begründet sein. Unter realen Bedingungen ist er hingegen begründungsbedürftig.

\section{b) Sozialethische Zuordnung: Ethisierung des Freiheitskonzepts}

Die Kommunitarismustheorien qualifizieren Gemeinwohl und Sicherheit als notwendige Folgen von Freiheitsbetätigung. Ihr Ausgangspunkt ist die Kritik am Sozialmodell des tradierten Liberalismus, dem homo oeconomicus. ${ }^{47}$ Reale Menschen handelten nicht ausschließlich egoistisch. Vielmehr folge aus ihrer "gesellschaftlichen Natur" ihre Gemeinschaftsbezogenheit und Gemeinschaftsbindung und damit eine natürliche Berücksichtigung der Belange anderer bei der Ausübung individueller Freiheit. Das Gemeinwohl sei so schon Element und Folge „richtiger“ gesellschaftlicher Freiheitsbetätigung. Anders - und konventioneller - ausgedrückt: Der Freiheit sei die Verantwortung immanent. ${ }^{48}$ Die Zuord-

\footnotetext{
${ }^{46}$ In der Wirklichkeit ist der Schleier des Nichtwissens (Rawls ebd., 159ff.) oftmals durchsichtig und lückenhaft. Zur Rawls-Diskussion L. Meyer J. Rawls und die Kommunitaristen, 1996; F. Wilkes John Rawls, Theorie der Gerechtigkeit, und Ronald Dworkin, These der Rechte, 1997; C. Kauffmann Strauss und Rawls: Das philosophische Dilemma der Politik, 2000, 215 ff. u. pass. Zur Verfassunggebung als Reaktion auf aktuelle bzw. vergangene Krisen s. W. Strau $\beta$ DÖV 1948, 272; R. Bäumlin Staat, Recht und Geschichte, 1961,17 u. pass.; $R$. Mufgnug FS Thieme, 1993, 141, 143; K. Hesse Die normative Kraft der Verfassung, 1959, 13.

${ }^{47}$ Grundlegend $M$. Waltzer in: Honneth (Hrsg.) Kommunitarismus. Eine Debatte über die moralischen Grundlagen moderner Gesellschaften, 1993, $157 \mathrm{ff} ., 170 ;$ C. Taylor in: ebd., $103 \mathrm{ff}$; ders. Negative Freiheit? Zur Kritik des neuzeitlichen Individualismus, 1988, 118, 125; M. Sandel Liberalism and the Limits of Justice, 1982, 64f., $168 \mathrm{ff} ., 172 \mathrm{ff}$.; W. Reese-Schäfer Grenzgötter der Moral, 1997, 294f., 303 ff.; A. MacIntyre Der Verlust der Tugend, 1995, $197 \mathrm{ff}$., $221 \mathrm{ff}$. Zur Rolle des Staates im kommunitaristischen Modell insbes. A. Etzioni Die Verantwortungsgesellschaft: Individualismus und Moral in der heutigen Demokratie, 1999, 32, 35, 132f., $165 \mathrm{ff}$. Zur Rezeption des Kommunitarismus in der deutschen Rechtswissenschaft $W$. Brugger Zeitschrift für Rechtsphilosophie 2003, 1; ders. AöR 1998, 337; s.a. U. Haltern KritVj 2000, 153.

48 Eingehend hierzu K. Stern Das Staatsrecht der Bundesrepublik Deutschland, III/2, 1994, 1022 ff. (Nachw.), $1023 \mathrm{f}$.
} 
nung wird somit in den Freiheitsbegriff hinein verlagert. Auch hier bleibt die Frage nach den sozialen Vorbedingungen offen. Schon die vielerorts anzutreffende Figur des „Trittbrettfahrers“ zeigt: Nicht jeder, der an den Vorteilen der Gemeinschaft teilhat, ist natürlicherweise bereit, auch in die Gemeinschaft zu investieren. Dazu machen die treffenden Beschreibungen vom „Markt der Tugend “ 49 deutlich: Hier wie überall stellen sich funktionsfähige Märkte nicht von selbst ein, sondern müssen von außen hergestellt und erhalten werden. Erst wo und wenn diese Funktionsbedingungen garantiert sind, kann sich ein ausgewogenes Verhältnis von Freiheit und Sicherheit herstellen. Anders - und erneut konventioneller ausgedrückt: Freiheit ist mehr und anderes als bloße Folge von Freiheit. Unter welchen Voraussetzungen welche Verantwortung von wem eingefordert werden kann, ist keine Frage des Inhalts, sondern der Schranken der Freiheit. ${ }^{50}$ Wie gering die individuelle Freiheit, wie stark hingegen der Grad der Fremdbestimmung sein kann, zeigen die Regularien der meisten "gated communities" in den USA, welche den Staat weitgehend außen vor lassen wollen, diesen Zustand kollektiver Autonomie ${ }^{51}$ aber wenn überhaupt - lediglich um den Preis eines hohen Grades an Regulierung und Konformismus für die Mitglieder erreichen..$^{52}$

\section{c) Sozialanthropologische Zuordnung: Keine Freiheit ohne Sicherheit?}

Am Anfang der sozialanthropologischen Zuordnung steht zumeist die These, es könne keine Freiheit ohne Sicherheit geben..$^{53}$ Pragmatisch wird darauf hingewiesen, dass freie Entscheidungen nur möglich seien, wenn ihre Folgen einigermaßen kalkulierbar blieben. Wer bei jedem Vertragsschluss Lieferbedingungen und Erfüllungsmodalitäten, Gewährleistung und Schiedsgerichte neu vereinbaren müsse, werde bald von Vertrags-

49 Dazu grundlegend M. Baurmann Der Markt der Tugend, 1996, $283 \mathrm{ff}$., $345 \mathrm{ff}$., $471 \mathrm{ff}$. Wichtige Grundlagen dazu schon bei $M$. Olson Die Logik kollektiven Handelns, 3. Aufl. 1992, 2f., 9, 12 ff., $20 \mathrm{ff}$. Wieder anders B. Grzeszick JZ 2003, 647, 650ff., der explizit vom Sozialmodell des homo oeconomicus ausgehen will.

50 Zutr. G. Britz DSt 2003, 35, 54f.; C. Gusy JZ 1982, 657, 661; ähnlich wohl auch H. Hofmann in: Isensee/Kirchhof (Hrsg.) HStR V, 1992, § 114 Rn. 42 ff.

51 Zutreffend spricht $O$. Lepsius in: Gewirtz/Cogan (Hrsg.) Global Constitutionalism: Privacy, Proportionality, Terrorism and Civil Liberties, 2002, III7-III24, V95-V103, von der „Entindividualisierung der Freiheit" durch das neue Sicherheitsdenken. Ferner C. Möllers NVwZ 2000, 382, 387.

52 S. dazu näher Wehrheim (Fn. 29), 168ff.; ferner $U$. Volkmann NVwZ 2000, $361 \mathrm{ff}$.

53 W. $v$. Humbold $t$ Ideen zu dem Versuch, die Grenzen der Wirksamkeit des Staates zu bestimmen, 1792/1851, 51 ff. Diese Formulierungen sind weitaus differenzierter und zurückhaltender als der Slogan einzelner Verfassungsschutzbehörden: „Freiheit - aber sicher!". 
schlüssen absehen. Freiheit setze stabile Rahmenbedingungen, soziale Regeln und Rechtsnormen voraus. So wichtig diese Einsicht ist, so wenig sagt sie doch über den notwendigen Grad von Sicherheit und den möglichen Grad von Freiheit. ${ }^{54}$ Freiheit ist mehr und anderes als eine Folge von Sicherheit. ${ }^{55}$

Anspruchsvollere Begründungen des Satzes „Keine Freiheit ohne Sicherheit" liefern einzelne Varianten der Systemtheorie. Sie gehen von der Eigenschaft des Menschen als „Mängelwesen“ nicht bloß im idealen Naturzustand, sondern auch im gesellschaftlichen Zustand aus. ${ }^{56} \mathrm{Kom}$ plexität und Kontingenz der Umwelt führten zu einer Überforderung des Einzelnen und dem Bedürfnis nach Selektion und Orientierung, u.a. durch soziale Institutionen, Regeln und Recht. Im Zentrum steht die Frage, inwieweit die Menschen die Systeme oder die Systeme die Menschen prägen. Diejenigen Vertreter der Systemtheorie, welche ein hohes $\mathrm{Maß}$ an Eigenständigkeit sozialer Systeme postulieren und das individuelle Verhalten tendenziell auf Systemfunktionen reduzieren, ${ }^{57}$ ersetzen die anthropologisch begründete individuelle Unfähigkeit zur Freiheit durch eine institutionell begründete soziale Unfähigkeit zur Freiheit. Das zur Ermöglichung von Entscheidungsalternativen begründete Bedürfnis nach Regeln erweist sich so als paradox, wenn diese Regeln die Alternativen zugleich reduzieren - im Extremfall auf Null. So konsumiert das Bedürfnis nach Sicherheit das Desiderat der Freiheit. Doch ist dieser Schluss auch aus systemtheoretischer Sicht nicht zwingend. Gewiss: „Es ist beruhigend zu wissen, wovor man sich zu fürchten hat". 58 Doch ist unübersehbar: Außerhalb ganz kleiner, immobiler Gemeinschaften gibt es konkurrierende Systeme zur Befriedigung ähnlicher sozialer Bedürfnisse. Welchem von ihnen sich der Einzelne anschließt, ist zumindest nicht stets durch jene Systeme vorgegeben. Zudem stehen Systeme mit thematischer und personeller Überschneidung, inhaltlicher Porosität und institutioneller Kooperation nicht isoliert nebeneinander, sondern beeinflussen

\footnotetext{
54 Aussagekräftiger ist hier die Feststellung Humboldts, wonach Sicherheit „Gewissheit der gesetzmäßigen Freiheit" sei; s. ebd., 97f.; zustimmend Tettinger(Fn. 5), 281, 296. Vor der Folie einer „Staatsaufgabe Sicherheit“ würde dies bedeuten: Freiheit ist, was die Gesetze an Freiräumen lassen. Damit würde sich die Freiheit nach dem Maßstab des Gesetzes, nicht hingegen - wie von Art. 1 Abs. 3 GG juristisch zwingend vorgegeben - das Gesetz am Maßstab der Freiheit bemessen. S. dazu u. II $3 \mathrm{c}$ aa).

55 Kritisch zu der Formel „Freiheit durch Sicherheit“ Denninger (Fn. 22), 467.

${ }^{56}$ Zum Folgenden N. Luhmann in: Gumbrecht/Pfeiffer (Hrsg.) Materialität der Kommunikation, 1988, 884ff.; ders. in: Simon (Hrsg.) Lebende Systeme, 1988, $10 \mathrm{ff}$.; ders. Soziale Systeme, 1987, 67f., 346.

57 In diese Richtung N. Luhmann Die Gesellschaft der Gesellschaft, 1997, $24 \mathrm{ff}$.

38 Kaufmann (Fn. 15), 17.
} 
und verändern sich wechselseitig. ${ }^{59}$ Hier entstehen Räume individueller und kollektiver Freiheit. Deren Verhältnis zu den vorausgesetzten Institutionen und Regeln ist aber erneut klärungsbedürftig.

\section{d) Zusammenfassung}

Die wenigen Stichworte mögen zeigen: Die angesprochenen Sozialund Staatstheorien können zwar wichtige Einsichten und Argumente aufzeigen. Doch bleibt das oft als „Quadratur des Zirkels“ bzw. „gordischer Knoten" beschriebene Problem der Zuordnung von Freiheit und Sicherheit nach wie vor aktuell.

\section{Die Aufgaben des Rechts}

\section{Ein „Raum der Freiheit, der Sicherheit und des Rechts“}

Die Zuordnung von Freiheit und Sicherheit ist demnach primär eine Aufgabe des Rechts. Vorbildlich ist sie im EU-Vertrag als „Aufbau eines Raumes der Freiheit, der Sicherheit und des Rechts" (Präambel; Art. 2, 29 EUV) beschrieben. ${ }^{60}$ Alle drei Ziele sind aufeinander bezogen und prägen einander sowohl inhaltlich als auch instrumentell. Es ist das Mittel des Rechts, welches Freiheit und Sicherheit konkretisieren und schützen muss. ${ }^{61}$ Diese anspruchsvolle Synthese gerät allerdings aus der Balance, wenn die Kommission beginnt, jenen einheitlichen Raum in drei unterschiedliche, nebeneinander stehende Räume aufzuteilen und so die einzelnen Ziele voneinander zu isolieren. ${ }^{62}$ Eine solche Dogmatik würde die Idee des Vertrages nicht konkretisieren, sondern beschädigen.

${ }^{59} \mathrm{Zu}$ diesem Gedanken der „Penetration“ bzw. „Interpenetration“ sozialer Systeme Luhmann Soziale Systeme (Fn. 56), 286ff. Dieser Gedanke ist m. E. für das Verständnis demokratischer Potentiale der Systemtheorie noch ausbaufähig. Zur Luhmann-Kritik im dargestellten Kontext wichtig auch (soziologisch) H. Willke Stand und Kritik der neueren Grundrechtstheorie, 1975, $243 \mathrm{ff}$; (juristisch) F. Hufen VVDStRL 47 (1989), 142, 147, 155; Aulehner (Fn. 21) 270ff.; O. Lepsius Steuerungsdiskussion, Systemtheorie und Parlamentarismuskritik, 1999, 42ff. u. pass.

${ }^{60}$ Eingehend hierzu H.J. Blanke in: Calliess/Ruffert (Hrsg.) Kommentar zu EU-Vertrag und EG-Vertrag, 2. Aufl. 2002, Art. 2 Rn. 11; M. Böse in: Schwarze (Hrsg.) EU-Kommentar, Art. 29 EUV, Rn. $3 \mathrm{ff}$.

61 S. etwa V. Röben in: Grabitz/Hilf (Hrsg.) Das Recht der Europäischen Union, Stand: April 2003, Vorbem. Art. 29 EUV, Rn. 28. Konkretisierend z. B. H.P. Bull in: Bizer/Koch (Fin. 21), 13, 21.

62 Solche Ansätze finden sich etwa in dem Aktionsplan der Kommission, ABI der EG C 19 vom 23. Januar 1999, 3 ff. 
Das Grundgesetz differenziert die Aufgabe der Zuordnung von Freiheit und Sicherheit weiter aus. Dies ist wichtig wegen seines umfassenden Geltungsanspruchs für staatliches Handeln. ${ }^{63}$ Sobald und soweit Verfassungsrecht gilt, darf es keine Staatsaufgabe geben, welche im Widerspruch zu ihm ausgeübt wird. Dies ist keine Identität von Staat und Verfassung. ${ }^{64}$ Verfassungsraison ist vielleicht nicht die ganze Staatsraison, doch die Verfassung bindet die ganze Staatsraison. ${ }^{65}$ Und die Verfassung prägt damit zugleich die Zuordnung von Freiheit und Sicherheit durch das Recht.

Jene Zuordnung ist vom Grundgesetz jedenfalls nicht abschließend vorgenommen. Doch lässt sich feststellen: Angesichts der hier nur angedeuteten Eigenschaften von Risiken ${ }^{66}$ besteht eine Staatsaufgabe zur „umfassenden Risikosteuerung "67 nicht-oder aber sie läuft leer. Dem Grundgesetz lassen sich nur einzelne normative Vorgaben eines differenzierten staatlichen Risikomanagements entnehmen. Es begründet einige spezielle Staatsaufgaben auf dem Gebiet der Sicherheit und lässt andere zu. Deren Sammelbezeichnung als „Staatsaufgabe Sicherheit" kann allein klassifikatorisch verstanden werden: Ihr Ganzes ist also die Summe seiner Teile und nicht mehr. ${ }^{68}$

\footnotetext{
${ }^{63}$ Zum umfassenden Geltungsanspruch des GG näher $H$. Schulze-Fielitz Die Verwaltung 1999, 241, 248 ff.; G.F. Schuppert StWStP (Fn. 44) 1991, 122, $126 \mathrm{ff} . ;$ K. Hesse Grundzüge des Verfassungsrechts der Bundesrepublik Deutschland, 20. Aufl. 1995, Rn. 9; D. Grimm Deutsche Verfassungsgeschichte 1776-1866, 2. Aufl. 1990, $12 \mathrm{f}$.

${ }^{64}$ Grundlegend zum Verhältnis von Staat und Verfassung unter dem Grundgesetz s. einerseits etwa J. Isensee in: ders./Kirchhof (Hrsg.) HStR I, 2. Aufl. 1995, \$13 Rn. 4 ff., $26 \mathrm{ff}$; K. Stern Das Staatsrecht der Bundesrepublik Deutschland, Bd. I, 2. Aufl. 1984, 10f.; andererseits etwa Hesse (Fn. 63), Rn. 16ff.; ders. in: Benda/Maihofer/Vogel (Hrsg.) Handbuch des Verfassungsrechts, 2. Aufl. 1994, Rn. 5.

${ }^{65}$ In Anlehnung an eine Formulierung von Arndt (Fn. 31), 897, 899: „Ein ,Verfassungsstaat ' hat keine andere Raison als seine Verfassung."

${ }^{66}$ S.o. I 1.

${ }^{67}$ Eine solche Aufgabe postuliert etwa Aulehner (Fn. 21), $171 \mathrm{ff}$. Ähnlich jedenfalls der Formulierung nach der Titel der Referate von J. Ipsen VVDStRL 48 (1990), 177; D. Murswiek ebd., 207; B. Schlink ebd., 235. Die Referate selbst differenzieren jenen Titel dann inhaltlich weiter aus.

${ }^{68}$ Umfassend jetzt dazu Möstl (Fn. 22), $119 \mathrm{ff} .$, der neben dem Verfassungs- auch das Gesetzesrecht einbezieht. Für eine Differenzierung und gegen die Gleichsetzung der ,inneren Sicherheit" mit der ,öffentlichen Sicherheit" zutr. H.P. Bull Staatsaufgabe Sicherheit, 1994, 14.
} 


\section{Freiheit und Sicherheit: Akteure}

\section{a) „Grundrecht auf Sicherheit“?}

Das viel diskutierte „Grundrecht auf Sicherheit"69 soll dem Staatsziel des Rechtsgüterschutzes einen Platz im Grundgesetz zuweisen. Die ungeschriebene Garantie wird partiell aus einer Gesamtschau der grundrechtlichen Schutzpflichten, ${ }^{70}$ partiell darüber hinaus aus dem Vertrauensschutz und einer Subjektivierung objektiver Verfassungsprinzipien hergeleitet. ${ }^{71}$ Seine postulierten Rechtsfolgen sind überaus vielschichtig. $\mathrm{Da}$ ist zunächst die auch grundrechtlich radizierte Konstitutionalisierung der "Staatsaufgabe Sicherheit" als gesetzlich unaufgebbare Kompetenz der öffentlichen Hand. ${ }^{72}$ Aus der Einheit jener Staatsaufgabe wird der Schluss auf die Notwendigkeit ihrer einheitlichen Erfüllung gezogen. So begründe das Grundrecht nicht nur Staatsaufgaben, sondern auch Behördenaufgaben. ${ }^{73}$ Der Verfassungsrang des neuen Rechts könne das Recht und ggf. die Pflicht der Staatsorgane begründen, entgegenstehende Grundrechte einzuschränken. ${ }^{74}$ Der subjektiv-rechtliche Gehalt der neuen Garantie binde zudem im Einzelfall das Behördenermessen und könne einen Anspruch auf polizeilichen Schutz begründen. ${ }^{75}$

Jene Anliegen mögen auf den ersten Blick geradezu als optimale Synthese von Freiheit und Sicherheit erscheinen. Sie scheint die Dichotomie aufzulösen, wonach Freiheit in den Grundrechten und bei den Einzelnen, Sicherheit bei den Staatsaufgaben und der öffentlichen Hand zu verorten sei. Doch darin erschöpft sich ihre Leistungsfähigkeit. Die neuen Anliegen sind nämlich wenig geeignet, Inhalt eines neuen Grundrechts zu wer-

${ }^{69}$ Grundlegend hierzu J. Isensee Das Grundrecht auf Sicherheit, 1983; ders. VVDStRL 37 (1979), 130; Robbers (Fn. 31); H. Bethge DVB1 1989, 841, 848; U. Karpen JZ 1989, 899; T. Giegerich Privatwirkung der Grundrechte in den USA, 1992, 27, 34. R. Pilschas UTR 1996, 212; Möstl (Fn. 22), 84ff.; ähnliche Begründungsansätze auch bei E. Klein NJW 1989, $1633 \mathrm{ff} . ;$ J. Isensee in: ders./Kirchhof (Hrsg.) HStR V, 1992, § $111 \mathrm{Rn} .77 \mathrm{ff}$; H.H. Klein DVB1 1994, 489; P. Unruh Die Dogmatik der grundrechtlichen Schutzpflichten, 1997, $37 \mathrm{ff}$.

70 So etwa Isensee Grundrecht auf Sicherheit (Fn. 69), 33 f.; Sommermann (Fn. 40), 204; ähnlich Möstl (Fn. 22), $84 \mathrm{ff}$.

7 So etwa Robbers (Fn. 31), $190 \mathrm{ff} ., 193 \mathrm{ff}$. Überblick über unterschiedliche Begründungen bei $R$. Poscher Grundrechte als Abwehrrechte, 2003, $180 \mathrm{ff} ., 192 \mathrm{ff}$.

72 S. hierzu etwa Möstl(Fn. 22), $37 \mathrm{ff}$., $42 \mathrm{ff}$., $84 \mathrm{ff}$., welcher in die Begründung und Konkretisierung der „Staatsaufgabe Sicherheit" auch das „Grundrecht auf Sicherheit" einbezieht.

73 Dazu etwa Möstl (Fn. 22), $400 \mathrm{ff}$.

74 Dazu paradigmatisch etwa Scholz/Pitschas (Fn. 19), $110 \mathrm{ff}$.

75 Näher dazu Isensee Grundrecht auf Sicherheit (Fn. 69), 53 ff.; Robbers (Fn. 31), $228 \mathrm{ff} ., 246 \mathrm{ff}$. 
den. ${ }^{76}$ Sicherheit ist relativ und nicht einfach da oder nicht da. ${ }^{77}$ Schon theoretisch können daher die grundrechtlichen Sicherheitsansprüche nie „erfüllt" werden. Aus diesem Grund kann ein Grundrecht auf Sicherheit nichts anderes begründen als den subjektiv-rechtlich formulierten Appell an die Grundrechtsadressaten, Rechtsgüterschutz bei der Erfüllung der eigenen Aufgaben zu berücksichtigen. ${ }^{78}$ Damit stellt sich ganz grundsätzlich die Frage nach den Rechtsfolgen des neuen Rechts. Eine allgemeine Nichtstörungspflicht kann es nicht bewirken, da Private keine Grundrechtsadressaten sind. ${ }^{79}$ Für Träger öffentlicher Gewalt entstehen eigenständige Verpflichtungen nur, wenn das Sicherheitsgrundrecht inhaltlich über die ohnehin geltenden grundrechtlichen Schutzpflichten hinausgehen soll. ${ }^{80}$ Aber selbst dann geraten die neuen Verpflichtungen rasch an ihre Grenzen. Was für vergleichsweise einfach strukturierte Grundrechte wie das Recht auf Leben ${ }^{81}$ noch begründbar sein mag, wird für die meisten Freiheitsrechte paradox. ${ }^{82}$ Es ist widersinnig, einerseits für die Bürger immer neue Modalitäten der Freiheitsausübung und damit der Begründung von Risiken zu postulieren und andererseits die Verpflichtung zur Bewältigung dieser Risiken ausschließlich dem Staat anzulasten. Dadurch würde die Grundrechtsausübung unter den Möglichkeitsvorbehalt des staatlichen Risikomanagements gestellt. ${ }^{83}$

Die in der Lehre vom Grundrecht auf Sicherheit vorausgesetzte Privatisierung der Freiheit bei gleichzeitiger Verstaatlichung des Risiko-

\footnotetext{
${ }^{76}$ Ablehnend etwa E. Denninger Menschenrechte und Grundgesetz, 1994, 13, 48f.; H. Garstka DVB1 1998, 981, 990; W. Berka Die Grundrechte, 1999, 63; G. Ress VVDStRL 48 (1990), 56, 92; J. Dietlein Die Lehre von den grundrechtlichen Schutzpflichten, 1992, $149 \mathrm{ff}$.; G. Haverkate Verfassungslehre, 1992, 216f.; E. Schmidt-Jortzig in: Theobald (Hrsg.) Von der Europäischen Union zur „Europäischen Sicherheitsunion“?, 1997, 130.

77 S.o. I 1 b) aa). Zur Relativität der Staatsaufgabe Sicherheit C. Gusy DÖV 1996, 573, $578 \mathrm{ff}$.

78 S.a. Isensee Grundrecht auf Sicherheit (Fn. 69), 44: „Das gesetzesmediatisierte Grundrecht auf Sicherheit“.

${ }^{79}$ Dies betont $E$. Denninger KJ 1988, 1, 13. Eine unmittelbare Drittwirkung des "Grundrechts auf Sicherheit" wird von Isensee Grundrecht auf Sicherheit (Fn. 69), 35f., verneint; aufgeschlossener dagegen Robbers (Fn, 31), $201 \mathrm{ff}$.

${ }^{80}$ Dies verneint etwa Szczekalla (Fn. 5), 247f., der zwischen den rhetorischen und den rechtlichen Wirkungen (,kein dogmatisches Bedürfnis“) einer solchen sprachlichen Neuschöpfung unterscheidet.

${ }^{81}$ Dazu umfassend G. Hermes Das Grundrecht auf Schutz von Leben und Gesundheit, $1987,187 \mathrm{ff}$.

82 Die aus unterschiedlichen Grundrechten herzuleitenden Schutzpflichten können nach Inhalt und Wirkungen durchaus differenziert sein; s. dazu Szczekalla (Fn. 5), 332ff.; $\operatorname{Dietlein}(\mathrm{Fn} .76), 86 \mathrm{f}$.

${ }^{83}$ Richtig schon H. Steiger Mensch und Umwelt, 1975, $51 \mathrm{ff}$.
} 
managements folgt auch nicht mittelbar aus anderen Staats- und Verfassungstheorien. Insbesondere begründen sie kein staatliches Monopol. Neo-etatistische Ansätze wollen ein solches aus dem Gewaltmonopol ${ }^{84}$ herleiten. ${ }^{85}$ Doch vermag diese ursprünglich soziologische Idee jene Herleitung nicht zu tragen. Sie nahm einen allein deskriptiven Status ein und sollte die Herausbildung organisierter Staatlichkeit im Verhältnis zu anderen Herrschaftsverbänden beschreiben. Aus jener Perspektive sei „legitime Gewaltsamkeit" Mittel, nicht hingegen Zweck des Staates. Aus ihr folgte also keine Staatsaufgabe ${ }^{86}$ - und erst recht kein Monopolanspruch im Verhältnis zu den Bürgern. Etwas anderes folgt auch nicht aus ihrer juristischen Wendung, etwa mittels des Rechtsstaatsprinzips. ${ }^{87} \mathrm{Ihm}$ werden u.a. die Rechtsbindung des Staates sowie seine Verpflichtung zur Rechtssetzung und Rechtsdurchsetzung entnommen. ${ }^{88}$ Doch folgt daraus nicht notwendig ein Monopol. Weder ist der Staat aus dem Rechtsstaatsprinzip verpflichtet, jedes von ihm geschaffene oder anerkannte Rechtsgut stets selbst und mit eigenen Mitteln zu schützen, noch darf allein er zu diesem Zweck Gewalt anwenden. Den rechtsstaatlichen Anforderungen ist vielmehr Genüge getan, wenn der Staat berechtigt ist, über Legitimität bzw. Illegitimität von Gewalt zu entscheiden, wenn er in diesem Rahmen den Umfang legitimer Gewalt bestimmen und illegitime Gewalt mit eigenen Mitteln - notfalls mit Gewalt - verhindern kann. ${ }^{89}$ Es bleibt demnach dabei: Ein „Grundrecht auf Sicherheit“ kann über die allgemeinen grundrechtlichen Schutzpflichten hinaus allenfalls appellative Wirkungen haben.

\section{b) Gestufie Sicherheitsverantwortung}

Hat der Staat demnach kein verfassungsrechtlich anerkanntes Monopol der Rechtsdurchsetzung, so eröffnet dies die Möglichkeit einer Einbeziehung von Privaten und Unternehmen in jene Aufgaben. Dieser

${ }^{84}$ Dazu grundlegend Max Weber Wirtschaft und Gesellschaft, 1922, 1, 28ff. Zu modernen Wandlungen auf dem Wege zu einer Soziologie der Macht $P$. de Marinis in: Hanack/ Stangl (Hrsg.) Innere Sicherheiten, 2003, 39, 46ff. Interessante Fallstudie zum Staatsversagen bei $P$. Waldmann Der anomische Staat, 2002.

${ }^{85}$ Dazu näher V. Götz in: Isensee/Kirchhof (Hrsg.) HStR III, 1988, § 79 Rn. 7 ff., $17 \mathrm{ff.;}$ W. Schmitt Glaeser Private Gewalt im politischen Meinungskampf, 1990, $143 \mathrm{ff}$., $156 \mathrm{ff}$., 159; Möstl (Fn. 22), 48; Bethge (Fn. 69), 844f.; P. Tettinger (Fn. 5), $290 \mathrm{f}$.

${ }^{86}$ Eine Definition des Staates durch Angaben seines Zwecks lehnte $M$. Weber vielmehr explizit ab; s. ders. Wirtschaft und Gesellschaft, 1922, 30; s.a. ebd., 1, $28 \mathrm{f}$.

${ }^{87}$ Dazu insbes. D. Merten Rechtsstaat und Gewaltmonopol, 1975, 29ff.; K. Sobota Das Rechtsstaatsprinzip, 1997, 500f.

${ }^{88}$ E. Schmidt-Aßmann in: Isensee/Kirchhof (Hrsg.) HStR I, 2. Aufl. 1995, \$ 24 Rn. $21 \mathrm{ff}$., $75 \mathrm{ff}$; Sobota (Fn. 87), 493.

${ }^{89}$ Dazu mit Begründung Gusy (Fn. 77), $575 \mathrm{ff}$. 
Befund schafft Freiräume zur Berücksichtigung einer weiteren Determinante, der Ressourcenfrage. ${ }^{90}$ Kostenlos zur Verfügung gestellte öffentliche Sicherheit ist als öffentliches Gut tendenziell knapp. Umso größerer Bedarf besteht nach optimaler Ressourcenallokation und Ressourcennutzung. Sie ist zugleich Grundlage und Grenze individueller Schutzansprüche gegen die öffentliche Hand: Was der Staat nicht leisten kann, können die Bürger auch nicht beanspruchen. ${ }^{91}$ Dem dürfte eine teilhaberechtliche Deutung angemessener sein als die Qualifikation als individueller Schutzanspruch.

Im Verhältnis von öffentlicher und privater Sicherheitsproduktion sind Rechtsgrundlagen, Rechtsbindung und Legitimation beider Sektoren unterschiedlich. ${ }^{92}$ Doch sind die jeweiligen Wirkungsbereiche verfassungs-

90 Theoretische und empirische Befunde aus politik- und sozialwissenschaftlicher Sicht bei Lenk/Prätorius (Hrsg.) Eingriffsstaat und öffentliche Sicherheit, 1998; H. Beste in: Gusy (Hrsg.) Privatisierung von Staatsaufgaben: Kriterien - Grenzen - Folgen, 1998, 180; H.-J. Lange ebd., 215; A. Steegmann ebd., 237; H. Beste Die Morphologie der Macht, 2000.

91 Zum Anspruch auf polizeilichen Schutz und seinen Grenzen grundlegend BVerwGE 11, 95; 25, 243; 37, 112; BVerwG, DVB1 1968, 154; NJW 2003, 601; VGH Mannheim, NVwZ 1987, 1101; J. Dietlein DVBI 1991, 685; D. Wilke FS Scupin, 1983, 831; R. Breuer FS BVerwG, 1978, 103; H.U. Erichsen VVDStRL 35, 210ff.; F.L. Knemeyer ebd., 249ff.; F. Schoch JuS 1994, 758f.; F. Rachor in: Lisken/Denninger (Fn. 20), F Rn. 139.

92 Als Ausgangspunkt bleibt festzuhalten: Staatlicher und privater Rechtsgüterschutz weisen rechtlich kaum Gemeinsamkeiten, hingegen zahlreiche Unterschiede auf. Sie sind höchstens sehr eingeschränkt kommensurabel. Der staatliche Rechtsgüterschutz nimmt verfassungsrechtlich oder gesetzlich vorgeschriebene Aufgaben wahr. Über das „Ob“ ihrer Wahrnehmung kann die öffentliche Hand nicht, über das „Wie" nur eingeschränkt disponieren. Schutzgut jenes Auftrages sind einerseits Rechtsgüter Privater, andererseits aber auch rechtlich anerkannte und geschützte Belange des Staates und der Allgemeinheit. Zur Erfüllung jener Aufgabe stehen der öffentlichen Hand rechtlich begründete und begrenzte Befugnisse zur Verfügung. Deren Ausübung ist an die Maßstäbe des gebundenen Ermessens und das Übermaßverbot geknüpft. Die Legitimation der staatlichen Aufgabenwahrnehmung erfolgt demnach aus der Rechtsordnung, namentlich den ihr inhärenten tragenden demokratischen und rechtsstaatlichen Grundsätzen. Der private Rechtsgüterschutz ist rechtlich völlig anders konstituiert. Er ist grundsätzlich nichts anderes als die Summe der rechtlich zugelassenen Selbstverteidigungs- und Selbsthilfe-, Notwehr- und Nothilferechte der Menschen selbst. Sie sind berechtigt, eigene Rechte und bestimmte Rechtsgüter Dritter zu schützen. In diesem Kontext ist die Tätigkeit privater Sicherheitsunternehmen rechtlich nichts anderes als die gewerbliche Ausübung jener Individualrechte ihrer Auftraggeber. Soweit diese Rechte grundrechtlich gesichert sind, leisten die Unternehmen Hilfe zur Grundrechtsausübung Dritter. Daneben kann noch die Gewerbefreiheit der Unternehmen selbst hinzutreten. Rechtsgüterschutz durch Sicherheitsunternehmen ist dann in zweifacher Hinsicht Freiheitsausübung. Sie ist nicht im Einzelfall durch das Recht legitimationsbedürftig, sondern bereits durch die Freiheitsrechte und ihr Schutzgut, die Freiheit, legitimiert. Freiheit unterliegt anderen rechtlichen 
rechtlich nur relativ schwach konturiert. ${ }^{93}$ Als Prämisse ist festzuhalten: Die öffentliche Hand muss ihre Aufgabe grundsätzlich mit eigenen Ressourcen, insbesondere mit eigenem Personal erfüllen. Das Verfassungsrecht mit seinen Vorkehrungen zur Legitimation aller Zweige der Staatsgewalt bezieht sich zuvörderst auf das Handeln der verfassungsgebundenen Organe selbst. ${ }^{94}$ Andere Akteure, welche in die Erfüllung staatlicher Aufgaben eingebunden sein sollen, nehmen an dieser Legitimation nicht unmittelbar teil. Es bedarf insoweit also zusätzlicher Mechanismen, um die Wahrnehmung öffentlicher Aufgaben gerade durch sie sicherzustellen.

Hierzu kann es unterschiedliche Instrumente geben. ${ }^{95}$ Dazu zählt etwa die Aktivierung von Eigensicherung durch die Bürger selbst. ${ }^{96}$ Ihre Frei-

Regeln als staatliche Kompetenzausübung. Die Berechtigten können sowohl über das „Ob" als auch über das „Wie“ ihres Handelns selbst disponieren. Schutzgut dieser Freiheitsrechte sind allein private Rechte, nicht solche des Staates oder der Allgemeinheit. Diese sind weder selbsthilfe- noch notwehrfähig. Der Umfang des privaten Schutzes dieser Rechte ist Freiheitsausübung, nicht Ermessensbetätigung; und er ist nur eingeschränkt an das Übermaßverbot gebunden. Demnach bleibt festzuhalten: Die staatlichen Sicherheitsaufgaben und die private Freiheit zum Schutz eigener oder fremder Rechtsgüter stehen rechtlich selbständig nebeneinander. Unterschiedlich sind ihre Legitimation, ihre Aufgaben, ihre Rechtsbindungen und damit die zu ihrer Wahrnehmung zulässigen Handlungen. Angesichts solcher Unterschiede liegt es näher, von verschiedenen als von gleichgerichteten Aufgaben zu sprechen. Dies machen auch zahlreiche gesetzliche Bestimmungen deutlich, wenn sie der öffentlichen Hand nicht „die“ Sicherheit, sondern die „öffentliche" Sicherheit anvertrauen. Die Tätigkeit Privater auf diesem Gebiet mag das Sicherheitsniveau der von ihnen geschützten Rechtsgüter und möglicherweise selbst das allgemeine Sicherheitsniveau erhöhen; der öffentlichen Sicherheit kommt diese Erhöhung allenfalls mittelbar zugute.

93 Aus der inzwischen völlig unübersehbar gewordenen Literatur grundlegend G. Nitz Private und öffentliche Sicherheit, 2000, $44 \mathrm{ff}$., $312 \mathrm{ff}$. (ebd., $98 \mathrm{ff}$. mit Überblick über den Diskussionsverlauf); s.a. Möstl (Fn. 22), 290ff.; F. Huber Wahrnehmung von Aufgaben im Bereich der Gefahrenabwehr durch das Sicherheits- und Bewachungsgewerbe, 2000, 51 ff.; Pitschas/Stober (Hrsg.) Quo vadis Sicherheitsgewerberecht, 1998; R. Weiß/ M. Plate Privatisierung polizeilicher Aufgaben, 1996.

94 H. Dreier Hierarchische Verwaltung im demokratischen Staat, 1991, $108 \mathrm{ff}$.; Hesse in: Benda/Maihofer/Vogel (Fn. 64), Rn. 7.

95 Zum Formenkanon M. Burgi Funktionale Privatisierung und Verwaltungshilfe, 1999, $71 \mathrm{ff}$., $100 \mathrm{ff}$., $145 \mathrm{ff}$.; M. Heintzen VVDStRL 62 (2003) $243 \mathrm{ff}$; $A$. Voßkuhle ebd., $299 \mathrm{ff}$.

96 Von daher sind die zahlreichen Regelungen, welche Privaten - auch gewaltsames Handeln zum Schutz bzw. zur Durchsetzung ihrer Rechte gestatten, zwanglos zu erklären. Sie sind eher Teil des Systems als Ausnahmen vom System. S. etwa $\$ \S 32,34$ StGB; $\$ \$ 227,228,229,562$ b, 859, 860, 904 BGB; $\$ 127$ StPO; Art. 20 Abs. 4 GG. Dazu Merten (Fn. 87), 59; J. Isensee FS Sendler, 1991, 39, 52 (,immanente Schranken des Gewaltmonopols"); jüngst $O$. Werner Staatliches Gewaltmonopol und Selbsthilfe im Rechtsstaat, 1999. 
heit zum Selbstschutz oder zum Risiko bedeutet nicht, dass sämtliche Risikofolgen allein dem Staat zur Last fallen müssen. Wer erhöhte Risiken für sich selbst oder Dritte schafft, darf oder muss am Risikomanagement beteiligt werden. ${ }^{97}$ Für solche privaten Sicherheitsaktivitäten bedarf es dann aber auch eines rechtlichen Rahmens, welcher den Sicherheitsinteressen der Auftraggeber ebenso Rechnung trägt wie den Belangen potentiell Betroffener und der Allgemeinheit. Gänzlich anders sind die Legitimationsbedürfnisse bei der Übertragung staatlicher Sicherheitsaufgaben auf Private. ${ }^{98}$ Sie stellt einen Sonderfall der Einbeziehung Privater in die Erfüllung öffentlicher Aufgaben dar. Die dabei entstehenden Fragen rechtlich einzufordernder Gemeinwohlverantwortung waren Thema der letztjährigen Tagung. ${ }^{99}$ Hier bleibt festzuhalten: Eine adäquate Erfassung des Übergangs vom ursprünglich bipolaren Anspruch auf polizeilichen Schutz zu einem differenzierten multipolaren System aus Schutzrechtsverhältnis, Erfüllungsrechtsverhältnis und Durchsetzungsverhältnis ist noch nicht in allen Teilen gelungen. ${ }^{100}$ Doch erscheint es möglich, bei Anerkennung aller rechtlichen Besonderheiten dieser Materie mit Hilfe der bekannten Kategorien der Regulierungs-, Gewährleistungs-, Erfüllungs- und Kontrollverantwortung angemessene Lösungen zu formulieren. ${ }^{101}$

\section{Freiheit und Sicherheit: Instrumente}

Sicherheit erfordert unterschiedliche Eingriffe in die Freiheit. Am Anfang steht die Risikoaufklärung. Ein Zentralproblem des Risikomanage-

${ }_{97}$ Grundlegend BVerfGE 49, 89, 143; H. Hofmann in: Isensee/Kirchhof (Hrsg.) HStR V, 2. Aufl. 2000, $\S 114$ Rn. 23f. Zu solchen Eigensicherungspflichten etwa BVerwG, DVBI 1989, 517 (Atomkraftwerke); M. Ronellenfitsch VerwArch 1995, 307 (Flughäfen); C.D. Bracher Gefahrenabwehr durch Private, 1987, 43 ff.; Möstl (Fn. 22), 299ff., $335 \mathrm{ff}$. Zu Ausgestaltungsmöglichkeiten $W$. Frenz Freiwillige Gefahrenprävention, 2003.

${ }_{98} \mathrm{Zu}$ rechtlichen Voraussetzungen und Grenzen jüngst S. v. Danwitz KritVj 2002, 347; C. Gusy VerwArch 2001, 344; B. Kirsch KJ 2002, 233.

99 Heintzen (Fn. 95), 220; Voßkuhle (Fn. 95), 266.

100 Nicht ausreichend ist insbesondere die Verweisung der Problematik aus der Rechtswissenschaft hinaus in die Verwaltungswissenschaft, wie sie in der Kategorie der PublicPrivate-Partnership (oder der Police-Private-Partnership) anklingt; so etwa bei $R$. Stober DÖV 2000, 261; ders. ZRP 2001, 260, 263 u. pass.; ebenso wenig genügt hierzu allein der Verweis auf den „kooperativen Rechtsstaat"; so aber R. Pitschas DÖV 1997, 393, 398. Ökonomisch hierzu G. Engelhardt Innere Sicherheit und Police-Private-Partnership aus ökonomischer Sicht, 1997.

${ }^{101}$ Dazu mit unterschiedlicher Akzentuierung grundlegend E. Schmidt-Aßmann in: Hoffmann-Riem/Schmidt-Aßmann, Reform des Allgemeinen Verwaltungsrechts, 1993, 43f.; H. Bauer VVDStRL 54 (1994), 277 ff.; G.F. Schuppert StWStP (Fn. 44) 1994, 541, 553, 559ff.; W. Hoffmann-Riem DÖV 1997, 433, 438ff. 
ments besteht darin zu erforschen, wo überhaupt welche Risiken sind. ${ }^{102}$ Die Erhebung und Verarbeitung derartiger - auch personenbezogener Informationen bezieht sich längst nicht mehr nur auf (potentielle) Störer. Anfangs-103 oder Gefahrverdacht haben ihre ermittlungssteuernde und -begrenzende Funktion in vielen Fällen verloren. Neuere Maßnahmen finden nicht selten im „Vorfeld"104 oder gänzlich anlassunabhängig105 statt; sie richten sich auch gegen Außenstehende, etwa Kontakt- oder Begleitpersonen, ${ }^{106}$ gegen jedermann - wie etwa Kontrollstellen oder offene Videoüberwachung - und damit auch gegen diejenigen, die durch die Eingriffe geschützt werden sollen. Zur Risikoaufklärung hinzu tritt das Risikomanagement, klassisch etwa durch Maßnahmen der Gefahrbeseitigung.

\section{a) Der liberale Rechtsstaat: Neue Herausforderungen}

Das liberal-rechtsstaatliche Denken hat die Grundlagen unseres Polizei- und Ordnungsrechts geprägt. ${ }^{107}$ Es geht von der Idee tendenziell unbegrenzter individueller Freiheit bei gleichzeitiger Begrenztheit des Staates, seiner Aufgaben und seiner Mittel aus. ${ }^{108}$ Danach bedarf jede Einschränkung der Freiheit ihrer Rechtfertigung durch einen vorrangigen öffentlichen Zweck. Deren Zwischenschritte sind Bestimmtheitsgebote, ${ }^{109}$ Skalierbarkeit rechtlich geschützter Belange, ${ }^{110}$ das Übermaßverbot als

102 Beck (Fn. 16), 35 ff., $95 \mathrm{ff}$.

${ }^{103}$ Dazu jüngst G. Haas Vorermittlungen und Anfangsverdacht, 2003.

104 Dazu näher E. Weßlau Vorfeldermittlungen - Probleme der Legalisierung „vorbeugender Verbrechensbekämpfung “ aus strafprozessualer Sicht, 1989; C. Hoppe Vorfeldermittlungen und Spannungsverhältnis von Rechtsstaat und der Bekämpfung organisierter Kriminalität, 1999; M.A. Zöller Informationssysteme und Vorfeldmaßnahmen von Polizei, Staatsanwaltschaft und Nachrichtendiensten, 2002, 319ff.; E. Denninger in: Lisken/ Denninger (Fn. 20), E Rn. 194ff.; M. Kniesel ZRP 1989, 329; H. Hund ZRP 1991, 463; O. Müller StV 1995, 602.

105 S. hierzu grundsätzlich H. Lisken NVwZ 1998, 24; dagegen J. Schwabe NVwZ 1998, 709; s.a. R. Müller-Terpitz DöV 1999, 329, 335; K. Waechter DöV 1999, 138; C. Möllers NVwZ 2000, 382; B. Kastner VerwArch 2001, 216.

106 S. BVerfG, NVwZ 2001, 1261; LVerfG MV, LKV 2000, 354; Bbg VerfG, LKV 1999, 450; M. Kutscha NJ 2000, 63; Albers (Fn. 21), $135 \mathrm{ff}$.

107 Überblicke etwa bei $H . J$. Wolff VVDStRL 9 (1952), 134; O. Gönnenwein ebd., 181; H. U. Erichsen VVDStRL 35 (1977), 171; F. L. Knemeyer ebd., 221.

108 Zum rechtsstaatlichen Verteilungsprinzip C. Schmitt Verfassungslehre, 1928, 126.

109 Hierzu grundsätzlich BVerfGE 49, 168, 181; 53, 104, 114; 64, 261, 280; 69, 1, 43; 71, 354, 362; Schmidt-Aßmann (Fn. 88), § 24 Rn. 60; Stern I (Fn. 64), 829ff. S.a. D. Kugelmann Der polizeiliche Gefahrenbegriff in Gefahr?, DÖV 2003 (Heft 19). Eine vergleichbare Diagnose findet sich bei $H$. Butzer Flucht in die polizeiliche Generalklausel?, VerwArch 2002, 506.

110 Dazu theoretisch B. Schlink Abwägung im Verfassungsrecht, Diss. 1976. 
Abwägungsmaxime ${ }^{111}$ und die Möglichkeit gerichtlicher Nachprüfung.112 So wichtig jene Gebote nach wie vor sind, so sind doch Bedingungen und Grenzen ihrer Erfüllbarkeit in der Diskussion.

\section{aa) Staatsaufgabenlehre im Wandel}

Die Begrenzung der Staatszwecke kollidiert mit anderen Staatszielbestimmungen. Staatsaufgaben ${ }^{113}$ werden nicht mehr allein rechtsstaatlich, sondern auch demokratisch bestimmt. Sicherheitsbedürfnisse und -ansprüche der Menschen können im demokratischen Wettbewerb von Ideen und Parteien kaum ignoriert werden. Das gilt umso mehr, seit Normen und Institutionen sozialer Selbstregulierung sich in Auflösung befinden ${ }^{114}$ und die Legitimation für Freiheitsbeschränkungen nahezu ausschließlich durch Recht, Rechtsdurchsetzung und damit den Staat vermittelt werden kann. Das gilt insbesondere, wenn „die Sicherheit “ als Staatszweck bestimmt wird. Hier folgt nicht mehr die Sicherheitsgewährleistung den Staatsaufgaben; vielmehr folgen die Staatsaufgaben der tendenziell unbegrenzt expansiven Logik von Risiko- und Sicherheitsdenken. ${ }^{115}$ Der rechtsstaatliche Ausgangspunkt ist damit verlassen.

${ }^{111} \mathrm{Zu}$ dessen Entwicklung und Bedeutung im Polizei- und Ordnungsrecht grundlegend Drews/Wacke/Vogel/Martens (Fn. 20), $389 \mathrm{ff}$., $416 \mathrm{ff}$.; B. Remmert Verfassungs- und verwaltungsrechtsgeschichtliche Grundlagen des Übermaßverbots, 1995; M. Jakobs Der Grundsatz der Verhältnismäßigkeit, 1995; W. Krebs Jura 2001, 238. Zu der Notwendigkeit einer Redimensionierung des Übermaßverbots angesichts der neuen Polizeiaufgaben D. Neumann Vorsorge und Verhältnismäßigkeit, 1994, $95 \mathrm{ff}$., $143 \mathrm{ff}$., $193 \mathrm{ff}$.

112 Vgl. dazu im Polizei- und Ordnungsrecht H. Lisken in: Lisken/Denninger (Fn. 20), K insbes. Rn. 66ff.; K. Waechter (Fn. 21), Rn. 812; Drews/Wacke/Vogel/Martens (Fn. 20), $571 \mathrm{ff}$.

113 Dazu allgemein H. Krüger Allgemeine Staatslehre, 2. Aufl. 1966, $759 \mathrm{ff}$.; unter dem Grundgesetz H.P. Bull Die Staatsaufgaben nach dem Grundgesetz, 1977, 44f.; Sommermann (Fn. 40), 364f.

114 Dazu näher C. Gusy (Fn. 44), 187f. Zur Krise der „öffentlichen Ordnung“ näher E. Denninger Polizei in der freiheitlichen Demokratie, 1968, 22ff.; N. Achterberg FS Scupin, 1973, 35ff.; F.J. Peine DV 1979, 25, 30ff. Zur Diskussion um ihre Renaissance F. Fechner JuS 2003, 734; G. Erbel DVBI 2001, 1714; R. Störmer DV 1997, 234; Möstl (Fn. 22), 136ff.; A. Wieschhörster Die Aufrechterhaltung der öffentlichen Ordnung und der Schutz der inneren Sicherheit gem. Art. 64 I EGV, 2001, 40ff., M. Nolte NordÖR 1999, 52; K. Waechter NVwZ 1997, 729. Zur partiellen Sonderproblematik des Versammlungsrechts BVerfG, NJW 2001, 2069, 2071; W. Hoffimann-Riem NVwZ 2002, 247, $261 \mathrm{ff}$; U. Rüh/NVwZ 2003, 531; S. Beljin DVBl 2002, 15, $19 \mathrm{ff}$.

115 Dazu o. I 1 b) cc). 


\section{bb) Relativierung des Grundrechtsschutzes: Die unbegrenzte Abwägung?}

Wo - wie in mancher neueren Sicherheitsdiskussion - jede Beeinträchtigung von Rechtsgütern Dritter zugleich als Angriff auf die „Sicherheit“ und damit die Rechtsordnung insgesamt verstanden wird, gerät die individuelle Handlungsfreiheit bei der Abwägung notwendig in das Hintertreffen. ${ }^{116}$ Denn die Integrität der Rechtsordnung ist Voraussetzung der Wirksamkeit der Verfassung und damit auch der in ihr enthaltenen Grundrechte. Wer Rechtsgüter Dritter gefährdet, beeinträchtigt in jener Logik zugleich die Grundlage der eigenen Rechtsposition und handelt so geradezu selbstwidersprüchlich. ${ }^{117}$ Ein solches Verhalten muss bei jeder Abwägung zurücktreten. Der Grundrechtsschutz wird so vollständig relativierbar.

Dies illustriert im Extrem die jüngere Diskussion über die ausnahmsweise Zulässigkeit der Folter und damit die Relativierung der Art. 1 Abs. 1 S. 1, 104 Abs. 1 S. 2 GG; Art. 3 EMRK. ${ }^{118}$ Die überwiegend rechtsphilosophisch angeleitete Konstruktion von Fällen, in welchen Folter zulässig sein soll, wenn eindeutig feststehe, dass nur der Betroffene bestimmte Informationen zum Schutz überragender Verfassungswerte preisgeben könne, ${ }^{119}$ hat für die Praxis keinerlei Orientierungswert. Polizeiliche Ermittlungshandlungen sind Handlungen unter relativer Unwissenheit über Tatsachen bei gleichzeitig notwendigem Wissen über die rechtlichen Grenzen der eigenen Befugnisse. Die über 3000 Jahre alte Geschichte der

\footnotetext{
${ }^{116}$ Dazu jüngst Lepsius (Fn. 59), 35f.; grundlegend T. Darnstaedt Gefahrenabwehr und Gefahrenvorsorge, 1983, $75 \mathrm{ff}$.

${ }_{117}$ Paradigmatisch die Formulierung in BVerfGE 49, 24, 56: „Die Sicherheit des Staates als verfaßter Friedens- und Ordnungsmacht und die von ihm zu gewährleistende Sicherheit seiner Bevölkerung sind Verfassungswerte, die mit anderen im gleichen Rang stehen und unverzichtbar sind, weil die Institution Staat von ihnen die letzte und eigentümliche Rechtfertigung herleitet."

118 Zu Art. 3 EMRK näher J.A. Frowein/W. Peukert EMRK, 2. Aufl. 1996, Art. 3 Rn. 10ff.; M. Villiger Handbuch EMRK, 2. Aufl. 1999, Rn. $279 \mathrm{ff}$. Zu den völkerrechtlichen Vorgaben für das deutsche Recht ausführlich R. Alleweldt EuGRZ 1998, 245; J.A. Frowein FS Matscher, 1990, 59; M. Nowak EuGRZ 1985, 109; 1988, 537; M. Rass Der Schutz vor Folter im Völkerrecht, 1989; H. Welsch BayVBl 2003, 481, 485f.; K. Ambos AVR 37 (1999), 318.

119 Grundlegend W. Brugger DSt 1996, 67, 69; ders. JZ 2000, 165; ders. VBIBW 1995, 414 ff., 446 ff.; ders. FAZ v. 10. 3. 2003, 8. Ähnlich M. Herdegen in: Maunz/Dürig (Hrsg.) Grundgesetz, Art. 1 Rn. 45, 90. Schon früher E. Albrecht Der Staat - Recht und Wirklichkeit, 1976, 174. Zur Realität von Polizeigewalt J.-P. Brodeur in: Heitmeyer/Hagen (Hrsg.) Internationales Handbuch der Gewaltforschung, 2002, 270ff.; zur Bundesrepublik Deutschland J. Feest/C. Wolters Verhütung von Folter und unmenschlicher oder erniedrigender Behandlung oder Strafe, 1994; T. Singelnstein MSchRKrim 2003, 1.
} 
Folter ${ }^{120}$ ist nahezu ausschließlich eine Geschichte erfolgreicher Versuche der Vorverlagerung jener Grenzen. Hier gibt es kein Halten - außer am Anfang. ${ }^{121}$

\section{cc) Identität von Geschütztem und Verantwortlichem? Probleme des Schutzpflichtkonzepts}

Die Idee grundrechtlicher Schutzpflichten basierte auf der Idee der Horizontalwirkung der Freiheit: Der Staat sollte berechtigt und ggf. sogar verpflichtet sein, durch Eingriffe in die Rechte eines Menschen die Rechte anderer zu schützen. ${ }^{122}$ Es geht um den Ausgleich der Rechte des potentiellen Täters mit denjenigen des potentiellen Opfers. Jenes Modell wird durch die neuen Jedermanneingriffe verlassen, wenn an Kontrollstellen, ${ }^{123}$ bei der offenen Videoüberwachung ${ }^{124}$ oder der Rasterfahn-

${ }^{120}$ Dazu näher W. Sofsky Traktat über die Gewalt, 1997, 80. S.a. R. Kiesow Zeitschrift für Rechtsgeschichte 2003 (erscheint demnächst). Ferner E. Peters Folter, 1991, 140ff.; Burschel/Diestelrath/Lembke (Hrsg.) Das Quälen des Körpers, 2000; W. Schild „Von peinlicher Frag“, 2000; R. Crelinstein in: Heitmeyer/Hagen (Fn. 119), 240, 249f. Zur Folterkritik der Neuzeit näher G. Jerouschek ZStW 1996, 243; 1998, 658; M. Schmoeckel Humanität und Staatsraison, 2000, $112 \mathrm{ff}$.; M. Soiné Kriminalistik 1993, 575. Aufschlussreiche Detailbeobachtungen bei Rolf Meier Dialog zwischen Jurisprudenz und Literatur: Richterliche Unabhängigkeit und Rechtsabbildung am Beispiel von E.T.A. Hoffimanns „Das Fräulein von Scuderi“, 1993, $74 \mathrm{ff}$.

121 Gegen die - auch ausnahmsweise - Zulassung der Folter oder der Aussagenerpressung unter dem Grundgesetz etwa G. Jerouschek/R. Kölbel JZ 2003, 613; J. Wilhelm Polizei 2003, 198; R. Hamm NJW 2003, 946; C. Schaefer NJW 2003, 94; B. Kretschmer RuP 2003, 102; Welsch (Fn. 118), 481; T. MushoffForum Recht 2003, 97; S. Schnor/V. Wissing ZRP 2003, 142; eher wohl differenzierend $O$. Miehe NJW 2003, 1219.

122 Vgl. hierzu grundlegend BVerfGE 39, 1, 42; 46, 120, 164f.; 49, 89, $140 \mathrm{ff} . ; 53,30$, 65f.; 79, 174, 202; 81, 242, 254ff.; 88, 203, 251; BVerfG, NJW 2002, 1638. Aus der Literatur wichtig in unserem Kontext $R$. Wahl/J. Masing JZ 1990, 553; K. Waechter (Fn. 23), $854 \mathrm{f}$.

${ }^{123}$ Hierzu näher LVerfG MV, DÖV 2000, 71, 72ff., einerseits; SachsAnh VerfG, NVwZ 2002, 1370, andererseits; E. Denninger FS Stein, 2003, 15; J. Martell NVwZ 2002, 1372; F. Schnekenburger BayVB1 2001, 129 ff.; C. Möllers NVwZ 2000, 382; M. Kutscha (Fn. 106), 65f.; K. Waechter (Fn. 105), 138; R. Müller-Terpitz DÖV 1999, 329; H. Lisken (Fn. 105), 22; M. Schütte ZRP 2002, 393; J. Martinez Soria NVwZ 1999, 270; I. Schmid LKV 1998, 477; D. Moser v. Filseck BWVP 1996, 272; dagegen J. Schwabe DVB1 2000, 1815; U. Stephan DVBI 1998, 81; R. Harzer FS Wolf, 1998, 85. Überblick bei N. Castillon Dogmatik und Verfassungsmäßigkeit neuer Befugnisse zu verdachts- und anlassunabhängigen Polizeikontrollen, 2003; F. Roggan Handbuch zum Recht der inneren Sicherheit, 2003, $139 \mathrm{ff}$.

124 Dazu eingehend VGH Mannheim, 1 S 377/02; VG Karlsruhe, NVwZ 2002, 117; VG Halle, LKV 2000, 164; K. Fischer VBIBW 2001, 90 f; H. Garstka DuD 2000, 192; M. Göddecke NVwZ 2002, 1232; L. Hasse ThürVBl 2000, 169; R. Hefendehl StV 2000, 270; M. Kutscha LKV 2003, 114; K. Möller/F. v. Zezschwitz Videoüberwachung - Wohltat oder Plage?, 2000; Rachor (Fn. 91), F Rn. 117ff.; R. Röger in: Zilkens (Hrsg.) Datenschutz in 
dung ${ }^{125}$ Eingriffe gegenüber Betroffenen stattfinden, um ihre eigenen Rechte zu schützen. Die überwältigende Mehrheit der Adressaten solcher Eingriffe sind Geschützte, nicht potentielle Störer. Hier verliert das Abwägungsprogramm der Schutzpflichtendogmatik seine Anwendbarkeit.

\section{dd) Grenzen des Übermaßverbots bei irrationalem Angreifer}

Die jüngere Terrorismusdiskussion hat eine neue Anwendbarkeitsgrenze des Übermaßverbots gezeigt. Dieses Gebot der Rationalisierung staatlichen Agierens kann seine Wirkung nur entfalten, wenn es prognostizierbare Zusammenhänge zwischen der behördlichen Maßnahme und dem Verhalten der Betroffenen gibt. Solche Zusammenhänge sind um so stabiler, je rationaler beide Seiten handeln. Umgekehrt gilt: Gegen einen völlig irrational handelnden, den eigenen Tod in Kauf nehmenden Terroristen versagen die tradierten Grundsätze des mildesten Mittels und der Angemessenheit. ${ }^{126}$

\section{ee) Wandel der Gewaltenbalance: Funktionseinbußen der Justiz}

Die zunehmend präventive Orientierung der Sicherheitsproduktion hat das Gefüge der Gewaltenteilung zwischen Exekutive und Justiz verändert. Die Ahndung von Straftaten ist eine originäre Aufgabe der Justiz, die in jedem Fall beteiligt ist. ${ }^{127}$ Hingegen fällt die Prävention in die $\mathrm{Zu}-$ ständigkeit der Exekutive. Die Gerichte können nur noch im Einzelfall auf Antrag Betroffener tätig werden. Deren Möglichkeiten zur Erlangung gerichtlichen Rechtsschutzes sind ohnehin begrenzt. Ein Antrag ist wenig

der Kommune, 2003, 103; F. Roggan NVwZ 2001, 139; dagegen R. Maske NVwZ 2001, 1248; G. Saeltzer DuD 2000, 194; M. Scholand DuD 2000, 202; A. Schmitt Glaeser BayVB1 2002, 584; D. Schneider/A. Rick Kriminalistik, 2003, 103; S. Schnorr ZRP 2001, 291; K. Schwarz ZG 2001, 2346; J. Vahle NVwZ 2001, 165; K. Waechter NdsVB1 2001, 77; dagegen J. Schwabe NdsVBI 2002, 46. Überblick bei D. Büllesfeld Polizeiliche Videoüberwachung öffentlicher Straßen und Plätze zur Kriminalitätsvorsorge, 2002; Roggan (Fn. 123), $105 \mathrm{ff}$.

125 S. hierzu näher VGH Kassel, NVwZ 2003, 755; OLG Frankfurt, NVwZ 2002, 626, 627; OVG Koblenz, DÖV 2002, 743; OLG Düsseldorf, NVwZ 2002, 629; 630; KG Berlin, NVwZ 2002, 1537; OVG Bremen, NordÖR 2002, 372; VG Trier, NJW 2002, 3268; H.D. Horn DÖV 2003, 746; J. Meister JA 2003, 83; W. Achelpöhler/H. Nichaus DÖV 2003, 49; M. Kniesel Polizei 2003, 89; H. Lisken NVwZ 2002, 513; L. Seel Polizei 2002, 192; W. Bausback BayVBI 2002, 713; C. Gusy KritVj 2002, 474; M. Warntjen/D. Kissler Forum Recht 2002, 49; B. Nedden DuD 2001, 710; R. Gerling/C. Langer/R. Roßmann DuD 2001, 746.

126 Hoffmann-Riem (Fn. 36), 499.

127 BVerfGE 22, 49, 79; 125, 130; 27, 18, 28f.; 36, 40; 45, 272, 288f.; zu Einzelheiten auch BVerfGE 54, 358, 372; 86, 288, 318; 89, 120, 129; BVerfG, EuGRZ 1994, 591, 592f.; BVerfGE 103, 44, 66ff;; partiell problematisch BVerfGE 57, 250, 274. 
wahrscheinlich, wenn der Eingriff verdeckt stattfand; ${ }^{128}$ und er ist wenig effektiv, wenn der Eingriff sich kurzfristig erledigt hat. ${ }^{129}$ Im Verfahren ist der Zugang des Gerichts zu relevanten Informationen eingeschränkt. ${ }^{130}$ Die Architektur der Gewaltenbalance wird durch diese Entwicklung erheblich modifiziert. ${ }^{131}$

\section{ff) Zusammenfassung}

Dies alles bedeutet nicht, dass mit dem viel zitierten Übergang vom Rechtsstaat zum Präventionsstaat ${ }^{132}$ alle tradierten Unterprinzipien funktionslos geworden wären. Doch ist die Diskussion um den Rechtsstaat im Sicherheitsrecht voll von Larmoyanz. ${ }^{133}$ Wichtig erscheinen zwei Folgerungen: Einerseits die Notwendigkeit, die rechtsstaatlichen Anfor-

\footnotetext{
${ }^{128}$ Hier fehlt es regelmäßig an der notwendigen Kenntnis Betroffener von stattgefundenen Eingriffen. Zur kompensierenden nachträglichen Bekanntgabepflicht grundlegend BVerfGE 30, 1, 31 f.; zur Realität etwa $O$. Backes/C. Gusy Wer kontrolliert die Telefonüberwachung?, 2003, $71 \mathrm{ff}$.

129 Zur Notwendigkeit des Fortsetzungsfeststellungsrechtsschutzes in solchen Fällen zutr. BVerfGE 96, 27, 38ff.; NJW 1998, 2432; M. Sachs JuS 1998, 265; C. Roxin StV 1997, 654.
}

${ }^{130}$ Dafür gibt es eine Vielzahl tatsächlicher und rechtlicher Ursachen. Polizeiliches Handeln ist vielfach eilbedürftig und somit weniger förmlich. Daher finden sich nicht selten weniger Akten oder sonstige schriftliche Aufzeichnungen als in sonstigen Verwaltungsverfahren. Zu Aufzeichnungs- und Dokumentationspflichten wichtig BVerfGE 103, 142. Zu den Grenzen des $\$ 99$ VwGO bei der Vorlage von Informationen an die Verwaltungsgerichte näher T. Mayen NVwZ 2003, 537; C. Gusy in: Bundesministerium des Innern (Hrsg.) Verfassungsschutz - Bestandsaufnahme und Perspektiven, 1998, 182ff. Zur Notwendigkeit kompensierenden Rechtsschutzes, im Notfall durch In-Camera-Verfahren näher BVerfGE 101, 106, 130. Zur fehlenden Kennzeichnung von Polizeibeamten näher A. Greifeld ZRP 1982, 318; R. Rupprecht ZRP 1989, 93. Zur polizeilichen Zeugenbetreuung s. D. Krause Polizei 1981, 119.

131 Zur Entwicklung im europäischen Raum grundlegend C.H. Ludwig Die Rolle des Europäischen Gerichtshofes im Bereich Justiz und Inneres nach dem Amsterdamer Vertrag, 2002.

132 Zitat nach E. Denninger Vom Rechtsstaat zum Präventionsstaat, unveröff. Vortragsmanuskript, Frankfurt 2003; früher präferierte er die Formel „Rechtsstaat versus Präventionsstaat"; s. ders. KJ 2002, 467, 470.

${ }^{133}$ Explizit kritisch etwa Hoffmann-Riem (Fn. 36), 500: „Der Blick auf diese rechtsstaatlichen Zäune und die ihnen im 19. Jh. zugrunde gelegten Fundamente provoziert die Frage, ob sie auch heute Schutz geben." Eine Antwort versucht etwa D. Grimm (Fn. 17), 54 , wonach die „Breschen, die neuartige Staatsaufgaben und Instrumentarien in die verfassungsrechtliche Disziplinierung der Staatsgewalt schlagen, nur indizieren, dass die Verfassung auf eine Problemlage bezogen ist, die der heutigen nicht mehr entspricht." Gegen ein „krampfhaftes Festhalten am Rechtsstaatsprinzip in seiner überholten Striktheit“ auch C. Hohmann-Dennhardt Sicherheit durch Recht in Zeiten der Globalisierung?, unveröff. Vortragsmanuskript, Frankfurt 2003, 3. 
derungen angemessen zu reformulieren und in die neuen rechtlichen Rahmenbedingungen einzubringen; ${ }^{134}$ andererseits die Aufgabe, neue Instrumente und Verfahren zu entwickeln, wo die alten ihre verfassungsrechtlich notwendigen Funktionen nicht mehr erfüllen können.

\section{b) Der demokratische Rechtsstaat: Neue Aufgaben}

Freiheit setzt stets ein gewisses $\mathrm{Maß}$ an Unsicherheit voraus. Diese ist Chance und Preis der Freiheit zugleich. Die maßgebliche Frage ist stets neu, welchen Preis die Träger der Freiheit für diese Chance zu zahlen bereit sind. 135

\section{aa) Die grundrechtliche Verteilung der Argumentationslast}

Das Schlüsselwort zahlreicher Risikodiskurse ist das Wort „Entscheidung“. ${ }^{136}$ Die Verrechtlichung des Verhältnisses von Freiheit und Sicherheit ${ }^{137}$ macht die Zuordnung beider Ziele von Entscheidungen abhängig. Dabei geht es nicht (allein) um die Wahrheit von Argumenten, sondern um die Legitimation des Rechts. Je intensiver das Recht als Mittel politischer Steuerung und sozialer Gestaltung in Anspruch genommen wird, um so größer ist die Bürde, welche die demokratische Legitimation der Staatsgewalt tragen muss. ${ }^{138}$ Darin liegt weniger eine Überwindung als vielmehr eine Ergänzung rechtsstaatlicher Prinzipien: Die Menschenund Bürgerrechte legitimieren sowohl den Rechtsstaat als auch das auf Aktivierung, Partizipation, Selbstregulierung und Minderheitenschutz angelegte Demokratieprinzip. ${ }^{139}$ Die positive Verbindung beider Prinzipien

${ }^{134}$ Dafür z.B. E. Denninger Normbestimmtheit und Verhältnismäßigkeit im Sächsischen Polizeigesetz. 1995. Vorbildlich etwa SächsVfGH, JZ 1996, 957, 962 ff. Zu weitgehend m.E. jedenfalls der Titel des Bandes von W. Schild (Hrsg.) Der Rechtsstaat verschwindet, 2003. Ähnlich überspitzend der Titel der Abhandlung von F. Roggan Auf legalem Weg in einen Polizeistaat, 2000, die allerdings eine Reihe wichtiger Einzelbeobachtungen enthält.

135 Diese Frage stellt Hoffmann-Riem (Fn. 36), 500f. Ergänzend weist $M$. Kniesel ZRP 1996, 482, 487, darauf hin: „Freiheit und Sicherheit sind nicht gleichzeitig und ohne Abstriche zu haben. Sicherheit gibt es nicht zum Nulltarif.“

136 S. näher U. Beck Die Erfindung des Politischen, 1993, 169: „Die Moderne verwandelt alles in Entscheidungen." Zur Entscheidungsabhängigkeit des Risikokonzepts s.o. I 1 a).

137 S. o. II 1. Zum Folgenden grundlegend Hoffmann-Riem (Fn. 36), 500 f.

138 J. Habermas Faktizität und Geltung, 1998, 517; s.a. ebd., 528.

$139 \mathrm{Zu}$ solchen Überschneidungen näher Sommermann (Fn. 40), 218f.; E.-W. Böckenförde Recht, Staat, Freiheit, 1991, 168f.; ders. in: Isensee/Kirchhoff (Hrsg.) HStR I, $\$ 22$ Rn. $82 \mathrm{ff}$; E. Schmidt-Aßmann in: ebd., $\$ 24$ Rn. 30ff.; H. Schulze-Fielitz in: Dreier (Hrsg.) Grundgesetz Art. 20 Rn. 15f;; W. Maihofer in: Benda/Maihofer/Vogel (Fn. 64), $\$ 12$ Rn. $100 \mathrm{ff}$. 
zeigt sich etwa in Normen wie Art. 9 Abs. 2; 10 Abs. 2; 11 Abs. 2 EMRK, wonach bestimmte Rechte nur durch solche Gesetze eingeschränkt werden dürfen, die ,in einer demokratischen Gesellschaft ... notwendig“ sind. 140

Die maßgebliche grundgesetzliche Argumentationsregel für die Zuordnung von Freiheit und Sicherheit enthalten die Freiheitsrechte. ${ }^{141}$ Auch wenn Sicherheit als grundrechtlich geschuldet oder als staatliche Leistung qualifiziert wird, so bewirken doch die meisten Maßnahmen zu ihrer Herstellung Freiheitseingriffe. Daraus folgt zugleich die Verteilung der Argumentationslast: Begründungsbedürftig ist nicht die Freiheit, sondern der Eingriff. Soweit staatliche Maßnahmen zur Garantie von Sicherheit in die Freiheitsrechte eingreifen, sind sie legitimationsbedürftig - und nicht der Freiheitsanspruch der Bürger. Die Eingriffsvorbehalte des Grundgesetzes weisen diese Aufgabe ganz wesentlich dem Gesetzgeber und seiner maßgeblichen Legitimationsquelle, dem demokratischen Verfahren, zu. Auch wenn man nicht jeder Einzelheit einer vernunftrechtlich orientierten Diskurstheorie des Rechts ${ }^{142}$ oder auch nur des Gesetzgebungsverfahrens zustimmen möchte, so gilt doch: Offenheit und Transparenz namentlich des parlamentarischen Verfahrens ${ }^{143}$ sind zentrale Quellen von Artikulations-, Partizipations- und Akzeptanzchancen des Rechts. Zu deren Einlösung bedarf es der Formulierung belastbarer (Mindest-)Standards einer Beteiligung des Parlaments und der demokratischen Öffentlichkeit an den Prozessen der Entscheidungsfindung und -kontrolle. ${ }^{144}$ Hier ist der Ort, die erforderlichen Begründungsleistungen zu erbringen und die notwendigen Entscheidungen zu treffen. ${ }^{145}$ Es gibt eben keine Demokratie ohne ein ausreichendes Maß an Sicherheit. Und es gibt erst recht keine Demokratie ohne ein ausreichendes Maß an Freiheit.

Ein wichtiges Fundament der Demokratie ist ein hinreichendes Sicherheitsgefühl der Menschen. ${ }^{146}$ Dessen Pflege ist keine eigenständige

\footnotetext{
$140 \mathrm{Zu}$ dieser Formel näher Campbell EuGHMRE 233, Ziffer 44; K. Hailbronner FS Mosler, 1983, 359 ff.; Gashin EuGHMRE 160, Ziffer 49.

141 Zum Folgenden grundlegend B. Schlink EuGRZ 1984, 457.

142 Dazu eingehend Habermas (Fn. 138), $78 \mathrm{ff}$., 109 ff., $367 \mathrm{ff}$.; s.a. ders. Strukturwandel der Öffentlichkeit, 1990, $151 \mathrm{ff}$.

143 Grundlegend dazu BVerfGE 40, 237, 249.

${ }^{144}$ Diese Fragestellung war ein anderes Thema der letztjährigen Tagung; vgl. dazu M. Herdegen VVDStRL 62 (2003), $7 \mathrm{ff}$; M. Morlok ebd., $37 \mathrm{ff}$.

145 Dem entspricht die Forderung nach einer "Sicherheitskultur" bei $M$. Kniesel ZRP 1996, 482, $487 \mathrm{ff}$., die ihrerseits durch eine Freiheitskultur zu ergänzen wäre. Wichtige Elemente hierzu bei $M$. Kötter KJ 2003, 60, $78 \mathrm{ff}$. S.a. T. Groß KJ 2003, 1, $10 \mathrm{ff}$.

$146 \mathrm{~S}$. dazu o. I 1 b) bb); zum Folgenden Bull (Fn. 68), 15ff.; Kötter (Fn. 145), $71 \mathrm{ff}$. Hierzu und zur notwendigen Aufklärungsaufgabe des Staates näher BVerfGE 44, 125,
} 
Staatsaufgabe, sondern als Folge ansonsten zulässiger und rechtmäßiger Staatstätigkeit zu begreifen. ${ }^{147}$ Hierzu zählen auch die allgemeinen Eingriffsbefugnisse. Hingegen ist der Schutz des Sicherheitsgefühls nicht geeignet, eigenständige Befugnisse zu Eingriffen in Rechte Dritter zu begründen.

\section{bb) Das demokratische Legitimationsverfahren}

Im Gesetzgebungsverfahren müssen Freiheits- und Sicherheitsbedürfnisse stets neu artikuliert und abgewogen werden. Diese Aufgabe verträgt sich schwerlich mit einer Gesetzgebungstechnik, welche eine Vielzahl von Schubladenentwürfen ${ }^{148}$ in umfangreichen "Sicherheitspaketen“ zusammenfasst ${ }^{149}$ und bei gegebenen Anlässen in das Parlament einbringt, um sie sodann unter größtem Zeitdruck durch Ausschüsse, Sachverständigenanhörungen und Plenum zu „peitschen“. Durch solche Gesetzgebungstechnik wird das Legitimationspotential parlamentarischer Verfahren eher beschädigt als genutzt. ${ }^{150}$

Die erwähnte Begründungsbedürftigkeit von Grundrechtseingriffen bedarf der verfahrensrechtlichen Einlösung. Der Hinweis auf erwartete oder vermutete Zugewinne an Sicherheit reicht dafür allein umso weniger aus, als die Abschätzung zukünftiger Risikolagen ebenso wie der Versuch

147; 105, 252, $268 \mathrm{ff} ., 279,301 \mathrm{ff}$. Zur Funktion symbolischer Staatshandlungen am Beispiel symbolischer Gesetze in diesem Kontext $M$. Führ KritVj 2003, $5 \mathrm{ff}$.

${ }^{147}$ Ein Instrument hierzu kann der periodisch angelegte Sicherheitsbericht sein; s. Bundesministerium des Innern/Bundesministerium der Justiz (Hrsg.) Erster periodischer Sicherheitsbericht, 2001. Auch A. Buro Vorgänge $3 / 2002,82,87 ;$ B. Krause FS Forndran (Fn. 36), 229, $232 \mathrm{ff}$.

${ }^{148}$ Darauf weist zu Recht Hoffimann-Riem (Fn. 36), 498, hin. Inhaltlich zeigen sich erhebliche Kontinuitäten der Sicherheitsdiskussion angesichts diskontinuierlicher Herausforderungen. Das gilt seit der Zeit der Außerparlamentarischen Opposition, soweit diese auch als behördlich zu bekämpfendes Sicherheitsproblem wahrgenommen wurde, über die Zeiten der RAF, also eines innenpolitisch motivierten, überwiegend innerstaatlich radizierten Terrorismus, über die Diskussion zu der sog. „Organisierten Kriminalität “, welche auch grenzüberschreitende Züge aufwies, bis hin zum „Internationalen Terrorismus“. In der Diskussion um die Bekämpfung dieser Herausforderungen wurde regelmäßig ein abgegrenzter Set von Instrumenten vorgeschlagen, diskutiert, ggf. verworfen und dann erneut eingeführt. Eine Geschichte dieser Entwicklung von trial and response ist noch nicht geschrieben. Umgekehrt fehlt es aber auch an einer wirksamen Evaluation von Instrumenten, die, einmal eingeführt, nicht ganz selten als Reserveinstrumente für unabsehbare Notfälle beibehalten werden. Vgl. auch F. Sack in: Lutz/Peach/Scheerer (Fn. 36), 47, $50 \mathrm{ff} ;$ N. Nolte DVBl 2002, $573 \mathrm{ff}$.

149 Zur Kritik am Verfahren des sog. "Sicherheitspakets II" etwa E. Denninger StV 2002, 96; Groß (Fn. 145), 16f; B. Hirsch SZ v. 2. 11. 2001, 17.

150 Ein solches Verhalten muss auf Situationen extremen, objektiv nachweisbaren Zeitdrucks begrenzt bleiben. 
ihrer Steuerung selbst notwendig risikobehaftet ist. Umso eher bietet sich hier eine angemessene Befristung von Gesetzen ${ }^{151}$ und ihre ausreichende Evaluation ${ }^{152}$ vor der Entscheidung über eine mögliche Verlängerung an. Doch ist auch festzuhalten: Geeignete Kriterien für eine solche Evaluation stehen im Sicherheitsbereich aber noch ebenso aus wie ein bereichsspezifisches Evaluationsverfahren.

\section{cc) Grundgesetzliche Differenzierungsgebote}

Ist der Gesetzgeber aufgefordert, das Verhältnis von Freiheit und Sicherheit im Verfahren auszutarieren, so unterliegt er dabei dem Gebot inhaltlicher Differenzierung. Es gibt nicht „die“ Zuordnung von Freiheit und Sicherheit. Vielmehr bedarf es der je konkreten, bereichsspezifischen Zuordnung beider Ziele. Maßgeblich dafür sind die erkennbare Risikobelastung einerseits und die Eingriffstiefe in die betroffene Freiheit andererseits. Hier kann es erhebliche Unterschiede ausmachen, ob etwa legale oder illegale Handlungen kontrolliert ${ }^{153}$ oder reguliert werden; ob Privat-, ${ }^{154}$ Betriebs- oder Geschäftssphäre ${ }^{155}$ oder aber die Öffentlichkeitssphäre ${ }^{156}$ betroffen sind; ob es um vergleichsweise nahe liegende $\mathrm{Ge}$ fahren oder um ferner liegende Risiken in Vorsorgebereichen geht; ${ }^{157} \mathrm{ob}$ die zu steuernden Risiken von Handlungen, Anlagen oder Produkten mehr oder weniger prognostizierbar sind; ${ }^{158}$ ob eine erkennbare $\mathrm{Ge}$ - oder Missbrauchsgefahr für kriminelle Handlungen besteht oder nicht. Hier werden im Gentechnik-, im Arzneimittel- oder im Atomrecht andere

${ }^{151} \mathrm{~S}$. dazu allgemein $H$. Kindermann in: Schaeffer/Triffterer (Hrsg.) Rationalisierung der Gesetzgebung, 1984, $133 \mathrm{ff}$.

152 Dazu allgemein E. Braun/M. Kilching Die Kriminalprävention 2002, 45.

${ }^{153}$ Hierzu am Beispiel der Unterscheidung von Kontrollzuständigkeiten der Polizei und der Nachrichtendienste C. Gusy DV 1991, 467; ders. KritVj 1994, 242, 245 ff.

154 Zum Grundrechtsschutz der Privatsphäre BVerfG, NJW 2000, 1021.

155 Zum Schutz der betrieblichen oder geschäftlichen Sphäre BVerfGE 32, 54, 68 ff.; 76, 83,88 .

156 Dieser Schutz ist bislang explizit wenig thematisiert. Äußerungen oder Handlungen in der Öffentlichkeit sind nicht völlig schutzlos; sie genießen jedoch einen qualitativ anderen Schutz als denjenigen in privaten oder bestimmten geschäftlichen Sphären. S. dazu etwa C. Gusy VerwArch 2001, $344 \mathrm{ff}$.

${ }^{157}$ Hier differenzieren zu Recht schon die Länderpolizeigesetze, wenn sie zu bestimmten Vorsorge- oder Vorbeugungszwecken nur einzelne Befugnisse einräumen, wie es etwa $\S 1$ Abs. 5 NRWPolG tut. Vergleichbare Unterschiede gelten auch zwischen dem Polizeiund dem Verfassungsschutzrecht. Doch ist dies - entgegen der Wahrnehmung Möstls (Fn. 22), 408 Fn. 48, nicht das zentrale Kriterium für die Abgrenzung von Polizei und Nachrichtendiensten. So explizit C. Gusy (Fn. 153), $244 \mathrm{f}$.

${ }^{158}$ Dazu im Bereich des Atomrechts BVerfGE 49, 89, 131 ff.; s. näher di Fabio (Fn. 31), $76 \mathrm{ff}$. 
Maßstäbe gelten als im „einfachen“ Polizeirechtsfall.159 Das gesetzliche Risikomanagement hat demnach bereichsspezifisch zu differenzieren und Eingriffsverfahren, -tiefe und mögliche Sanktionen an dem Ergebnis dieser konkreten Abwägung auszurichten. ${ }^{160}$

Sind so unterschiedliche Aufgaben mit unterschiedlichen Mitteln und Befugnissen wahrzunehmen, so rechtfertigt dies auch das Gebot organisatorischer Differenzierung und Spezialisierung innerhalb des Staates. ${ }^{161}$ Aus guten Gründen enthält das Grundgesetz keine Zuweisung der ,inneren Sicherheit" an einzelne Körperschaften oder gar Behörden. Maßgeblich für solche Trennungsgebote-Gedanken sind weniger Vorbehalte der Alliierten bei der Genehmigung des Grundgesetzes ${ }^{162}$ als vielmehr grundrechtliche, datenschutzrechtliche und rechtsstaatliche Gesichtspunkte. Wenn Behörden unterschiedliche Aufgaben mit unterschiedlichen Instrumenten und unterschiedlichen Befugnissen erfüllen, so spricht mehr dafür, sie zu trennen, als dafür, sie zusammenzufassen. ${ }^{163}$ Die Idee einheitlicher Megabehörden ist ohnehin ein Leitbild, das der Vergangenheit angehört. Grundgesetz und Gesetze gehen zu Recht von den Gedanken funktioneller und befugnismäßiger Differenzierung, organisatorischer Verselbstständigung und bereichsspezifischer Kooperation aus. ${ }^{164}$

\section{dd) Legitimation durch Kontrolle}

Das so verabschiedete Recht muss, um seine Legitimationswirkung zu erhalten, für die Exekutive als Verhaltens- und für die Justiz als Kontroll-

\footnotetext{
159 Jüngster Überblick über Gemeinsamkeiten und Unterschiede bei P.T. Stoll Sicherheit als Aufgabe von Staat und Gesellschaft, 2003, $13 \mathrm{ff}$.

${ }^{160}$ Dies schließt die Notwendigkeit und Möglichkeit wissenschaftlicher Erarbeitung gemeinsamer Grundstrukturen nicht aus, wie sie etwa von di Fabio (Fn. 31), $445 \mathrm{ff}$., und Stoll (Fn. 159), 266ff., unternommen werden.

${ }_{161}$ Zum Desiderat der Gewaltenteilung in der Verwaltung W. Leisner FS Maunz, 1971, 267; ders. DÖV 1969, 405. Zum Folgenden grundlegend H.P. Bull in: ders. (Hrsg.) Sicherheit durch Gesetze?, 1987, 15, $25 \mathrm{ff}$.

${ }^{162} \mathrm{Zu}$ der hierdurch gespeisten Diskussion um das Trennungsgebot zwischen Polizei und Nachrichtendiensten s. etwa W.D. Remmele in: Bundesministerium des Innern (Fn. 130), 312, 327; F.A. Baumann FS Posser, 1997, 299; H. Albert ZRP 1995, 108; H. Roewer DVBI 1988, 666; M. Kutscha ZRP 1986, 194f.; E. Denninger ZRP 1981, 231; M. Brenner Bundesnachrichtendienst im Rechtsstaat, 1990, $48 \mathrm{ff}$.

${ }^{163}$ Zur Entwicklung und Begründung dieses Gedankenganges näher C. Gusy ZRP 1987, 45; ders. CuR 1989, 628; ders. DV (Fn. 153), 467; ders. KritVj (Fn. 153).

${ }^{164}$ Hierzu und zu dem Gedanken der Einheit der Verwaltung näher B.O. Bryde VVDStRL 46 (1988), 181, $196 \mathrm{ff}$. Zum Ganzen auch B. Schlink Die Amtshilfe, 1982. Überlegungen zur Optimierung von Zuständigkeiten von Sicherheitsbehörden aus politikwissenschaftlicher Sicht bei R. Lhotta DV 2003, 171; s.a. E.H. Ritter Perspektiven der inneren Sicherheit im politischen Mehrebenensystem, 1999.
} 
norm wirken können. Wenn der Gesetzgeber das Wesentliche des Wesentlichen selbst regeln muss, kommt dem Bestimmtheitsgebot ${ }^{165}$ gerade im Bereich weitreichender Grundrechtseingriffe eine hohe Bedeutung zu. Insbesondere sind defizitäre materiell-rechtliche Regelungen nicht einfach durch Verfahrensregelungen surrogierbar: Auch Behördenleiter ${ }^{166}$ oder Richter müssen bei der Ausübung von Behördenleiter- oder Richtervorbehalten aus dem Gesetz erkennen können, unter welchen Voraussetzungen sie einen Eingriff vornehmen oder nicht vornehmen dürfen. ${ }^{167}$ Im Einzelfall bedürfen Grundrechtseingriffe namentlich dann einer besonderen Kontrolle, wenn der Rechtsschutz seine Wirkungen aus tatsächlichen Gründen nicht ausreichend erfüllen kann. ${ }^{168}$ Diesem Anliegen kann allerdings durch die routinemäßige Mitwirkung von - oft außenstehenden, überlasteten und bisweilen nicht hinreichend fachkundigen Richtern allein nicht ausreichend Rechnung getragen werden. ${ }^{169}$

$\mathrm{Zu}$ erwägen ist deren Ergänzung durch objektive Kontrollverfahren, etwa Beauftragte, ${ }^{170}$ Ombudspersonen oder politische Gremien. ${ }^{171}$ Hinzutreten sollten Berichtspflichten, wie sie etwa in Art. 13 Abs. 6 GG $^{172}$ ansatz-

165 Jüngst BVerfGE $105,135,152 \mathrm{ff}$.

$166 \mathrm{Zu}$ den Behördenleitervorbehalten näher H. Lisken/R. Mokros NVwZ 1991, 609; G. Aschmann Die Polizei 2002, 40, schlägt eine Ausweitung von Behördenleitervorbehalten vor, um die politische Kontrolle des Behördenhandelns zu optimieren.

${ }^{167}$ Hierzu näher E. Weßlau KritVj 1997, 243; C. Gusy StV 1992, 484, 486; P.-A. Albrecht DRiZ 1998, 333.

${ }^{168}$ BVerfGE 103, 142, $151 \mathrm{ff}$;; Vorschläge bei H.H. Trute (Fn. 21), 403, $419 \mathrm{ff}$.

${ }^{169}$ Dies belegen die Evaluationsergebnisse von H.J. Albrecht/C. Dorsch/C. Krüpe Rechtswirklichkeit und Effizienz der Überwachung der Telekommunikation nach den $\$ \S 100 \mathrm{a}$, b StPO und anderer verdeckter Ermittlungsmaßnahmen, 2003; Backes/ Gusy (Fn. 128). Schon früher D. Helmken StV 2003, 193; A. Schieder KritVj 2000, 218; G. Asbrock StV 2001, 322; ders. ZRP 1998, 17, 18; H. Wolter DÖV 1997, 938.

170 Zum - inzwischen allerdings wieder abgeschafften - Hamburger Polizeibeauftragten M. Brusten NKP 1997, 16; J. Kersten NKP 1998, 15. Zur Kontrolle durch Datenschutzbeauftragte Überblick bei $H$. Bäumler in: Lisken/Denninger (Fn. 20), J, $98 \mathrm{ff}$.

171 BVerfGE 30, 1, 23f, sieht deren Wirken unter bestimmten Voraussetzungen als der Gerichtskontrolle annähernd gleichwertig an. Dagegen sind die in einigen Bundesländern bestehenden Polizeibeiräte - s. etwa $\$ \$ 14$ NRWPOG; 13 BbgPOG; 10 f. SHPOG - als Kontrollorgane untauglich.

172 Näher hierzu H.-J. Papierin: Maunz/Dürig (Fn. 119) Art. 13 Rn. 117ff.; P. Kunigin: v. Münch/Kunig (Hrsg.) Grundgesetz, Art. 13 Rn. $51 \mathrm{ff}$; J. Berkemann in: AK-GG, 3. Aufl., Art. 13 Rn. 192ff;; G. Gornig in: v. Mangoldt/Klein/Starck (Hrsg.) Grundgesetz I, 4. Aufl. 1999, Art. 13 Rn. 145. Vergleichbare Berichte über Eingriffe in das Fernmeldegeheimnis gem. $\$ 88$ TKG s. etwa J. Ehmer in: Büchner (Hrsg.) Beck'scher TKG-Kommentar, 2. Aufl. 2000, $\$ 88$ Rn. 84; G. Löwnau-Iqbal in: Scheurle (Hrsg.) Telekommunikationsgesetz, 2002, $\$ 88 \mathrm{Rn}$. $15 \mathrm{ff}$. 
weise, wenn auch noch auf zu hoher Ebene und damit zu hohem Allgemeinheitsgrad, vorgesehen sind. Solche Instrumente neuer Art werden namentlich im Sicherheitsrecht erst unzureichend genutzt. Sie könnten die Einsicht wach halten, dass Legitimation und Kontrolle der Sicherheitspolitik untrennbar zusammengehören. Hierzu zählt etwa, dass die Kontrolle nicht nur im individuellen Interesse Betroffener und auf deren Veranlassung hin notwendig ist. Vielmehr liegt sie zugleich im öffentlichen Interesse und hat permanent und von Amts wegen stattzufinden. So kann dann auch sichergestellt werden, dass die demokratisch zu leistende und zu verantwortende Abwägung zwischen Freiheit und Sicherheit nicht bloß auf dem Papier des Gesetzblatts steht, sondern gerade dort Wirksamkeit erlangt, wo das Machtgefälle zwischen Handelnden und Betroffenen am größten ist: bei der Steuerung verdeckter oder imperativer Handlungen von Sicherheitsbehörden. ${ }^{173}$

\section{c) Ein Sonderfall: Bundeswehr und innere Sicherheit}

Die zunehmend beobachtete Vernetzung innerer und äußerer Sicherheit hat eine Diskussion um mögliche Bundeswehreinsätze auch zur inneren Krisenintervention - über die gegenwärtig engen verfassungsrechtlichen Grenzen hinaus - ausgelöst. Hier gilt ungeachtet aller Wandlungen im Detail nach wie vor der Grundsatz: Zweck und Mittel polizeilichen und militärischen Handelns sind verschieden. Die Polizei soll sichern, dass die Menschen in Frieden zusammen leben können; das Militär soll hingegen sichern, dass die Menschen in Frieden getrennt voneinander leben können. Diese Unterschiede prägen Strategien, Handlungsweisen, Ausbildung und Ausrüstung beider Organisationen.

Das Militär denkt und handelt grundsätzlich in den Kategorien von „Angriff“ und „Verteidigung“, Ertragsmaximierung und Verlustminimierung, "Sieg“ und „Niederlage“. ${ }^{174}$ Prototypen dieses Denkens sind nach wie vor der Krieg, seine Führung bzw. Vermeidung. Darauf ist nicht nur das Denken, sondern auch das Handeln, die Ausbildung und die Ausrüstung der Soldaten ausgerichtet. Die Herausbildung der Polizei ist hingegen historisch als Konsequenz der Einsicht zu begreifen, dass militärisches Denken und Handeln zur Aufrechterhaltung des inneren Friedens

${ }^{173}$ Der weit verbreitete Gedanke, dass mehr Recht nicht notwendig zu einer vermehrten Steuerung durch Recht führt, ist näher ausgeführt bei D. Grimm (Hrsg.) Wachsende Staatsaufgaben - sinkende Steuerungsfähigkeit des Rechts, 1990.

174 Dazu nach wie vor grundlegend C. v. Clausewitz Vom Kriege, 1832/2003, $27 \mathrm{ff}$., $92 \mathrm{ff} ., 113,178 \mathrm{ff}$., $217 \mathrm{ff}$., $369 \mathrm{ff}$., $394 \mathrm{ff}$., $592 \mathrm{ff}$.; jüngst $S o f s k y$ (Fn. 30), 182f.: „Das Militär ist ausgerüstet zum Kampf gegen einen militärischen Gegner.“ 
nicht mehr adäquat ist. ${ }^{175}$ Sie denkt und handelt in den Kategorien punktueller Intervention, der Pazifizierung der Gesellschaft, der Aufwandsminimierung und der Deeskalation. Strategien, Ausbildung und Ausrüstung der Polizei sind zentral auf (Bürger-)Kriegsvermeidung, Aufrechterhaltung eines Mindestmaßes an gesellschaftlicher Ordnung, Deeskalation und ( $\mathrm{Re}$-)Integration Andershandelnder in eine relativ heterogene Gesellschaft ausgerichtet.176

Gewiss: In jüngerer Zeit haben sich hier neue Herausforderungen und einzelne Annäherungen der Handlungsstrategien ergeben. ${ }^{177}$ Doch bleiben in der Alltagspraxis die grundsätzlichen Unterschiede nach wie vor prägend. Daher sind militärische und polizeiliche Sicherheitsproduktion nicht einfach kommensurabel: Die eine kann nicht durch die andere ersetzt werden. Angesichts der Eigenlogik des jeweiligen Handelns reicht es auch nicht aus, dass das Militär bei Einsätzen nach innen der Verantwortung der hier zuständigen Organe unterstellt ist. Diese können Strategie und Instrumentarium des militärischen Handelns nicht einfach durch punktuelle Anweisungen ändern. Daraus folgt: Zur Ausübung von Zwangsgewalt nach innen ist die Bundeswehr grundsätzlich ungeeignet. Ausnahmen können nur in besonders gelagerten Einzelfällen - etwa bei der Luftsicherung ${ }^{178}$ - in Betracht kommen. Daneben mag die Heranziehung von technischem und logistischem Know-how der Bundeswehr gerade bei Katastrophen oder "Großlagen“, deren Vermeidung oder Bewältigung nützlich sein. Für die Übertragung weitergehender Sicherheitsaufgaben und -befugnisse nach innen an das Militär gibt es hingegen keine zureichende sachliche Begründung und erst recht keine verfassungsrechtliche Rechtfertigung. ${ }^{179}$

175 Zur Geschichte H.J. Lange (Hrsg.) Staat, Demokratie und Innere Sicherheit in Deutschland, 2000. W. Knöbl Polizei und Herrschaft im Modernisierungsprozess, 1998.

176 Dazu näher W. Schmidbauer Kriminalistik 2002, 524; M. Walter MschrKrim 1997, 44; R. Haselow/G. Kissmann in: Lange (Fn. 16), $123 \mathrm{ff}$.

177 Zum Wandel der Militärdoktrin näher: Gemeinsame Sicherheit und Zukunft der Bundeswehr. Bericht der Kommission an die Bundesregierung, Bonn 2000, Nr. 1, $14 \mathrm{ff}$;; L. Rühl Aus Politik und Zeitgeschichte 2002, H. 24, 5ff.; H. Meya Aus Politik und Zeitgeschichte 2002, H. 24, 3 ff.; B. Fleckenstein Aus Politik und Zeitgeschichte 2000, H. 43, 3, 4 ff. Wichtig M. v. Creveldt Die Zukunft des Krieges, 2. Aufl. 2001.

178 Einzelheiten bei $P$. Wilkesmann NVwZ 2002, 1316. Zum Sonderfall des Abschusses eines entführten Flugzeugs $G$. Jerouschek FS Schreiber, 2003, 185.

${ }^{179}$ E. Schmidt-Jortzig DÖV 2002, 773, 777f.; zurückhaltend auch J. Wieland Äußere Sicherheit: Von der Landesverteidigung zur Krisenintervention, unveröff. Ms. 2003. 


\section{Schlussbemerkung}

Die jüngeren Diskussionen über den internationalen Terrorismus haben die Perspektive einseitig auf die Risiken der Freiheit gelenkt. Dahinter tritt die andere Blickrichtung, nämlich die Chancen einer Politik zur Herstellung von Freiheit, völlig zurück. Es geht darum, der Sicherheitspolitik eine Freiheitspolitik ${ }^{180}$ zur Seite zu stellen. Sie muss mehr zu bieten haben als Überwachungsmaßnahmen und Grundrechtseingriffe. ${ }^{181}$ Eine notwendig mittel- bis langfristige Freiheitspolitik muss bei den Ursachen ansetzen, welche Risiken wie etwa den Terrorismus hervorbringen. Diese Ursachen sind umrisshaft bekannt. Sie näher zu erforschen und zu beseitigen ist ein Projekt, dessen Konturen hier nicht einmal aufgezeigt werden konnten. Doch erscheinen solche Strategien auch in Zeiten leerer Kassen nicht aussichtslos. Langfristig gesprochen könnten sie sogar die günstigere Alternative sein.

180 Dazu in unterschiedlichen Kontexten W. Hassemer (Fn. 37), 13; A. Baratta KritVj 2003, 210; Albrecht (Fn. 41), 15ff. Ansätze auch bei Kötter (Fn. 145), pass.; W. Heitmeyer in: Hoffmann/Schoeller (Fn. 2), $221 \mathrm{ff}$.

181 M. Kniesel ZRP 1996, 482, 487; W. Hassemer StV 1995, 483; ders. StV 1994, 333; ders. StV 1993, 664. 
Leitsätze des 2. Berichterstatters über:

\section{Gewährleistung von Freiheit und Sicherheit im Lichte unterschiedlicher Staats- und Verfassungsverständnisse}

1. Die Gewährleistung von Freiheit und Sicherheit nimmt in den meisten Verfassungsstaaten einen unterschiedlichen rechtlichen Status ein. Während Sicherheit regelmäßig Verfassungsvoraussetzung bleibt, ist Freiheit jedenfalls in Staaten mit Grundrechtsgarantien Verfassungsinhalt geworden.

2. Freiheit und Sicherheit sind unterschiedliche Staatsziele. Sicherheit ist die Abwesenheit von Risiken; Freiheit verursacht bzw. steigert Risiken. Die „Staatsaufgabe Freiheit “ individualisiert Entscheidungszuständigkeiten; die „Staatsaufgabe Sicherheit“ kollektiviert Entscheidungszuständigkeiten.

3. Der Sicherheitsdiskurs ist ein moderner Diskurs. Er hat ältere Sicherheitskonzepte in Richtung Dynamisierung und Subjektivierung verändert. Das Ziel "der" Sicherheit wird so theoretisch unerreichbar und letztlich paradox.

4. Die Zuordnung von Freiheit und Sicherheit fragt nach Sicherheit in Freiheit einerseits und Freiheit in Sicherheit andererseits. Unterschiedliche Ansätze haben wichtige Einsichten hervorgebracht, aber die viel beschriebene "Quadratur des Zirkels" nicht leisten können.

5. Sicherheit stabilisiert und garantiert die Verkehrsregeln der Freiheit. Ihre konkrete Zuordnung ist durch das demokratisch legitimierte Recht zu leisten. Dies bringt auch die Formel vom „Raum der Freiheit, der Sicherheit und des Rechts" zum Ausdruck.

6. Die bisweilen postulierte Staatsaufgabe einer „umfassenden Risikosteuerung" greift zu weit. Sie läuft entweder leer oder sie existiert in dieser Form nicht. Dem Grundgesetz lassen sich nur einzelne normative Vorgaben eines differenzierten staatlichen Risikomanagements entnehmen. Es begründet einige Staatsaufgaben auf dem Gebiet der Sicherheit und lässt einige andere zu. Deren Sammelbezeichnung als "Staatsaufgabe Sicherheit" kann allein klassifikatorisch verstanden werden: Ihr Ganzes ist also die Summe seiner Teile - und nicht mehr.

7. Ein Grundrecht auf Sicherheit würde Freiheit privatisieren und das Risikomanagement verstaatlichen. Eine derart absolute Funktionsdifferenzierung lässt sich aber weder staatstheoretisch noch staatsrechtlich begründen. Insbesondere die Formel vom Gewaltmonopol gibt hierfür nichts her. Zudem geriete Grundrechtsausübung unter den Möglichkeitsvorbehalt staatlicher Ressourcen. 
8. Ein wirksames Sicherheitsrecht erfordert eine differenzierte Verantwortungsordnung. Wer ein erhöhtes Risiko schafft, darf und muss ggf. am Risikomanagement beteiligt werden. Eine grundsätzlich zulässige Arbeitsteilung zwischen öffentlicher und privater Sicherheitsproduktion bedarf angemessener rechtlicher Rahmenbedingungen.

9. Der liberale Rechtsstaat hat wichtige Instrumente zur Ermöglichung, Steuerung und Begrenzung von Risikoaufklärung und Risikomanagement hervorgebracht. Doch sehen sie sich gegenwärtig neuen Herausforderungen ausgesetzt. Das gilt namentlich für die vorausgesetzte Staatsaufgabenlehre, den Grundrechtsschutz durch Abwägung und Übermaßverbot, das Schutzpflichtenkonzept und die Kontrollkompetenzen der Justiz.

10. Daher bedürfen die tradierten rechtsstaatlichen Instrumente ihrer Ergänzung durch neue Mechanismen zur angemessenen Legitimation und Kontrolle von Rechtssetzung und Rechtsdurchsetzung.

11. Der Schutz des Sicherheitsgefühls ist keine eigenständige Staatsaufgabe und auch nicht geeignet, Eingriffsbefugnisse gegen Dritte zu begründen. Seine Pflege ist allenfalls als Folge ansonsten zulässiger und rechtmäßiger Sicherheitspolitik zu begreifen.

12. Sicherheitspolitik und Sicherheitsrecht unterliegen dem Gebot angemessener sachlicher und organisatorischer Differenzierung.

13. Ungeachtet neuerer Wandlungen der Sicherheitsdoktrin gilt im Grundsatz nach wie vor: Die Polizei soll sichern, dass die Menschen in Frieden zusammen leben können. Das Militär soll sichern, dass die Menschen in Frieden getrennt leben können. Diese Unterschiede prägen Strategien, Handlungsweisen, Ausbildung und Ausrüstung beider Organisationen. Für eine Übertragung von Aufgaben der inneren Sicherheit mit Zwangsgewalt an die Bundeswehr über den gegenwärtigen Rechtszustand hinaus gibt es keine zureichende sachliche Begründung und erst recht keine verfassungsrechtliche Legitimation.

14. Eine überwiegend von dem Problem der Terrorismusabwehr geprägte Sichtweise hat die Risiken der Freiheit in den Vordergrund gerückt. Aus dieser Perspektive erscheint Sicherheitspolitik überwiegend als Aufgabe behördlicher, polizeilicher oder nachrichtendienstlicher Risikobekämpfung. Dadurch ist die Notwendigkeit einer Freiheitspolitik, welche nach den Risikoursachen fragt und diese zu steuern versucht, in den Hintergrund getreten. Sie könnte auch in Zeiten knapper staatlicher Ressourcen langfristig die günstigere Alternative sein. 


\section{Aussprache und Schlussworte}

\section{Gewährleistung von Freiheit und Sicherheit im Lichte unterschiedlicher Staats- und Verfassungsverständnisse}

Vorsitzende (Weber-Dürler): Verehrte Kollegen und Kolleginnen, wir haben 17 Wortmeldungen, und wir haben versucht, sie in vier Blöcken unterzubringen. Der erste größere Block umfasst ungefähr die Hälfte der Wortmeldungen: Freiheit und Sicherheit in ihrem gegenseitigen Verhältnis. Dann einige Meldungen zur sozialen Sicherheit, dann eine Reihe von Voten zum Sicherheitsgefühl, zur subjektiven Dimension und zu den Straftatbeständen, und am Schluss noch eine Äußerung zum ausländischen Staats- und Verfassungsverständnis. Nun also Freiheit und Sicherheit. Wenn ich Herrn Bull als ersten Redner bitten darf.

Bull: Sehr verehrte Kolleginnen und Kollegen, wir sind Herrn Gusy zu Dank verpflichtet für seine wichtigen Differenzierungen und die Schlussfolgerungen aus dem allgemeinen Gebot der Gewährleistung von Freiheit und Sicherheit. Ich möchte anknüpfen an seine These 2: Freiheit und Sicherheit sind unterschiedliche (und mündlich hat er gesagt, vielfach gegenläufige) Staatsziele. Wichtig ist hier, dass sie in der Tat als Staatsziele verstanden werden und nicht als Grundrechte. Als Grundrechte sind „Freiheit" ganz allgemein und „Sicherheit" ganz allgemein nicht realisierbar - auch das hat Herr Gusy schon in Ansätzen dargelegt. Übrigens zeigt sich auch bei der allgemeinen Handlungsfreiheit nach Art. 2 Abs. 1 GG mit ihrem unendlich weiten Schrankenvorbehalt, dass die Freiheit als solche nicht wirklich greifbar ist, sondern dass sich an dieser Stelle des Grundgesetzes vor allem ein rechtstechnischer Ansatz für den Individualrechtsschutz findet.

Wir sollten vielleicht lieber von „Freiheitlichkeit“ und „Sicherheitsstaatlichkeit“ als Staatszielen sprechen, weil wir dadurch die Unterscheidung zwischen Grundrechten und Staatszielen besser herausarbeiten und die zu hohe Abstraktion ein wenig vermeiden, die mit den Begriffen "Freiheit" und „Sicherheit" verbunden ist. Freiheitlichkeit meint - und das kam ebenfalls in den Referaten zum Ausdruck - ein Klima der Liberalität, der Abwesenheit von Unterdrückung, und Sicherheitsstaatlichkeit meint natürlich nicht absolute, vollständige Abwesenheit von Kriminalität oder Risiken, sondern einen erträglichen, einen angemessenen Grad, 
bis zu dem keine Kriminalität begangen wird, und einen relativ hohen Erfolgsgrad der Strafverfolgung. Beide Ziele oder Zielelemente sind anzustreben. Das ist das Wesen eines Staatsziels und einer Staatsaufgabe: Einen Zustand herstellen, in dem sich in dem Staat leben lässt, und nicht eine Rechtsordnung, die dem Einzelnen nun etwa einklagbare Ansprüche auf diese Zustände in seinem persönlichen, individuellen Lebensumfeld und seiner Lebenssituation gewährleistet. Das heißt aber auch, Freiheit und Sicherheit sind im Regelfall nicht unbedingt konfligierende Staatsziele. Betroffen ist normalerweise, im Regelfall, die subjektive Freiheit des einen, damit die Sicherheit der anderen gewährleistet werden kann. Und umgekehrt wäre die Sicherheit der vielen in Gefahr, wenn ausschließlich die Freiheit der anderen garantiert würde. Es gilt, eine Abwägung vorzunehmen und ein Verhältnis herzustellen, in dem sich möglichst viel von beiden Zielen und beiden Zuständen erreichen lässt.

Murswiek: Ja, ich kann daran anknüpfen. Ich sehe es auch so. Es gibt ein Spannungsverhältnis zwischen Freiheit und Sicherheit, wie Herr Gusy das dargelegt hat, ich möchte aber betonen, dass es sich nicht um einen antagonistischen Gegensatz handelt, sondern, im Gegenteil: Sicherheit und Freiheit sind sozusagen zwei Seiten derselben Medaille. Aus der Sicht der liberalen Staatstheorie geht es im Grunde genommen um dasselbe, nur mit verschiedenen Richtungen: Freiheit für den Einzelnen ist da, wenn der Staat überhaupt nichts tut. Insofern wird die Freiheit gesichert durch die negatorischen Ansprüche, Unterlassungsansprüche gegen den Staat. Die Freiheit muss aber auch gesichert werden gegen Eingriffe Dritter, und diese Freiheitssicherung (natürlich Freiheit als Oberbegriff auch für die anderen Rechtsgüter Leben, Eigentum), Freiheit gegenüber Dritten zu sichern, das bezeichnen wir als Sicherheit, und das ist die Aufgabe des Staates, hier muss der Staat tätig werden. In beiden Fällen aber geht es um die Freiheit, also es geht nicht um jeweils etwas anderes. Und zu einer Spannung kommt es meines Erachtens nur deshalb, weil die Freiheit gegenüber Eingriffen Dritter ja nicht nur dann durch staatliche Maßnahmen gesichert werden kann und muss, wenn mit Sicherheit feststeht, dass die Freiheitsausübung des einen zu Freiheitsverletzungen beim andern führen würde, sondern weil es in vielen Fällen ungewiss ist, ob das der Fall ist. In dieser Ungewissheitssituation muss gehandelt, werden, und weil wir keine vollständige Kenntnis der möglichen Geschehensabläufe haben, wird möglicherweise die Freiheit des einen stärker eingeschränkt, als es unbedingt notwendig wäre, um die Freiheit des anderen zu schützen. Das ist die Risikothematik, und auf dieser Ebene muss ein ausgewogener Kompromiss zwischen Freiheit und Sicherheit gefunden werden. Ich glaube, es ist auch richtig, dass das, wie 
Herr Gusy dargelegt hat, in verschiedenen Sachbereichen in unterschiedlicher Weise getan werden kann, und dass hier der Gesetzgeber große Einschätzungsspielräume hat.

Ein kurzes Wort und ein Brückenschlag zum Thema unseres heutigen Vormittags in diesem Zusammenhang: Ich glaube, zur Wahrnehmung der Aufgabe Sicherheit bedarf es nach wie vor des öffentlichen Gewaltmonopols einschließlich des Monopols der öffentlichen Gewalt für Rechtsetzung und Rechtsdurchsetzung. Dieses Monopol kann heute nicht mehr allein dem Staat zugeordnet werden - auch die internationale Ebene ist einbezogen - aber im Verhältnis zu Privaten bedarf es dieser Monopolstellung, sonst ließe sich Sicherheit nicht herstellen. Ich sehe nach wie vor kein anderes überzeugendes Modell, und ich kann auch nicht sehen, wie Sicherheit gewährleistet werden könnte durch irgendein Netzwerk, eine Pluralität von Rechtsordnungen, in denen sich keine klaren Verantwortungsverhältnisse ausmachen lassen. Herstellung von Sicherheit in diesem Sinne setzt innere Souveränität voraus, klare Verantwortungsverhältnisse und eindeutige Befugnisse.

Zum Schluss noch eine Frage an Herrn Gusy: Wie haben Sie das gemeint mit der Privatisierung der Freiheit? Ist Freiheit nicht vom Ansatz her notwendigerweise privat?

Kämmerer: Meine Frage bzw. Anmerkung richtet sich an Herrn Gusy. Vielen Dank für die sehr differenzierte Unterscheidung zwischen Freiheit und Sicherheit, die Sie uns präsentiert haben und die ich recht anregend fand. Nicht ganz klar geworden ist mir allerdings, welchen verfassungsrechtlichen Platz Freiheit und Sicherheit dabei am Ende haben sollen. Sie qualifizieren beide, Freiheit wie Sicherheit, als Staatsziel. Ist das nicht, zumindest was die Freiheit betrifft, noch ein wenig zu kurz gegriffen, zumal ja dieses Staatsziel hinter den vielen konkreten Freiheitsverbürgungen der Verfassung doch am Ende verblassen soll? Wie aber soll sie sonst nach Ihrer Argumentation verankert werden, wenn Sie Begründungen wie die aus dem Gewaltmonopol oder dem Grundrecht auf Sicherheit als Begründung zurückweisen? Was die erste Begründung - die aus dem Gewaltmonopol - betrifft, sehe ich das wie Sie und anders als Herr Murswiek und heute Morgen Herr Grimm. Jedenfalls wenn man der Mehrheitsentscheidung des Bundesverfassungsgerichts in "Reiten im Walde“ folgt, wonach Art. 2 Abs. 1 Grundgesetz schlechthin jedes, also auch gewalttätiges Verhalten des Einzelnen schützt, ist für ein Gewaltmonopol jedenfalls in Max Webers Sinne - nach meiner Ansicht kein Raum mehr. Sie, Herr Gusy, definieren Sicherheit als Abwesenheit von Risiken in größerer Zahl von Fällen, und Freiheit als etwas, was Risiken verursacht oder Risiken steigert. Daraus folgt, dass Sicherheit die Abwesenheit von 
Folgen der Freiheitsausübung ist. Von wem, das ist nun die Frage, soll dieses Risiko fern gehalten werden? Sie wenden sich gegen ein Grundrecht auf Sicherheit, das in gewisser Weise auch neben den Freiheitsgrundrechten stünde, so dass am Ende dann doch wieder die Freiheitsrechte als Verkörperungen der Freiheit im Mittelpunkt stehen, sofern man Sicherungen für die Staatsorgane, die Sicherheit des Staates, ausklammert. Insofern hege ich etwas Zweifel an der Unterschiedlichkeit von Freiheit und Sicherheit als Staatsziel und werfe die Frage auf: Riskieren Sie nicht, indem Sie Sicherheit von Freiheit so weit abstrahieren, dass Eingriffe in Freiheiten, präziser: in Freiheitsrechte, schwieriger zu begründen sein werden als bisher?

Stoll: Beide Referenten haben am Rande die Möglichkeit der Übertragung der Aufgaben der Gewährleistung von Sicherheit an Private erwähnt. Ein Beispiel dafür sind private Sicherheitsdienste. Selbst dann, wenn diese privaten Sicherheitsdienste in gleicher Weise wie staatliche Sicherheitsgewährleistung die Rechtsgüter schützen, wird allgemein angenommen, dass irgendwo eine Grenze für den Einsatz Privater liegt. Können Sie das Verhältnis staatlicher und privater Sicherheitsgewährleistung noch weiter ausführen?

Alexy: Freiheit und Sicherheit sind höchst abstrakte und unbestimmte Begriffe. Deshalb kommt, wie stets bei solchen Begriffen, alles auf Genauigkeit an. Ich gehe auf These 8 von Herrn Brugger ein. Herr Brugger, Sie präsentieren ein dreistufiges Modell. Erst das Rechtsstaatsprinzip, dann die grundrechtlichen Schutzpflichten und dann das umstrittene Grundrecht auf Sicherheit. Ich habe mich gefragt: Warum beginnen Sie mit einem objektiven Prinzip, dem Rechtsstaatsprinzip? Warum beginnen Sie nach Ihrem historischen Überblick, was, wie ich meine, näher gelegen hätte, nicht mit dem Recht auf Leben, Freiheit und Eigentum? Ein solches Recht scheint mir der archimedische Punkt des Ganzen zu sein. Man könnte in ihm sogar den archimedischen Punkt des Staatsrechts überhaupt sehen. Das führt auf den Vormittag zurück. Mir scheint, dass die Schutzpflichten nicht um ihrer selbst willen da sind. Sie sind es um grundrechtlicher Güter willen, wie Leben, Freiheit und Eigentum. Es handelt sich bei ihnen also um Metapflichten und damit, soweit ihnen Schutzrechte korrespondieren, um Metarechte. Man könnte auch, entsprechend der Tradition der allgemeinen Rechtslehre, von „sekundären Rechten" sprechen. Wenn wir aber erst einmal Schutzpflichten und Schutzrechte haben, dann haben wir notwendig den Staat. Wer sonst soll in einem Zustand ohne Bürgerkrieg schützen? Von hier aus - und deshalb habe ich das Bild vom archimedischen Punkt verwendet - können 
wir sogar von der ewigen Notwendigkeit des Staates sprechen. Um den Gegenstand unserer Disziplin brauchen wir uns daher überhaupt keine Sorgen zu machen. Alles Weitere ergibt sich hieraus, und zwar bis in die feinsten Verästelungen des Internationalen.

Ich habe noch eine kleine Bemerkung zu Herrn Gusy. Herr Gusy, Sie sagen mit einem gewissen Recht, ein Grundrecht auf Sicherheit könne es nicht geben. Wenn wir von einem „Grundrecht auf Sicherheit“ sprechen, verwenden wir diesen Ausdruck allerdings oft als Sammelbezeichnung für das, was insgesamt zum Recht auf Schutz gehört. In diesem nichttechnischen Sinne kann man natürlich von einem „Grundrecht auf Sicherheit" sprechen. Ich stimme Ihnen aber ganz darin zu, dass von einem echten Grundrecht auf Sicherheit deshalb nicht die Rede sein kann, weil Sicherheit ein kollektives Gut ist. Es kann keine individuellen Rechte auf kollektive Güter geben. Was ich aber nicht ganz verstehe, ist, dass Sie in Ihrer These 6 sagen, eine Staatsaufgabe „umfassende Risikosteuerung“ greife zu weit. Natürlich, wenn „umfassende Risikosteuerung“ „perfekte Risikosteuerung“ heißt, dann geht das nicht, weil perfekte Risikosteuerung nicht möglich ist. Aber könnte es nicht eine abwägungsfähige Staatsaufgabe der möglichst weitgehenden Risikosteuerung geben?

Schachtschneider: Wenn so grundlegende Fragen erörtert werden wie in den heutigen Referaten, ist es unverzichtbar, die Begriffe, die tragenden Begriffe, zu definieren. Das ist nur zum Teil geschehen. Zunächst zum Begriff des Staates: Wenn wir Staat mit Kant als die Vereinigung, civitas, einer Menge von Menschen unter Rechtsgesetzen definieren, entfallen die meisten Probleme, die Herr Vesting mit dem Staat hatte. Wenn man den Begriff Kants zugrundelegt, gibt es wenig Zweifel, dass auch die internationalen Organisationen, jedenfalls funktional und weitgehend institutionell, Staat sind, jedenfalls zum Staat gehören. Es stellt sich allerdings die Frage der demokratischen Legitimation, die Frau Kokott angesprochen hat. Das andere ist der Begriff der Freiheit, der auch hier fundamental ist. Herr Alexy hat einen Ansatz, die Freiheit zu begreifen, vorgeschlagen. Insofern sind wir unterschiedlicher Auffassung, lieber Herr Alexy. Ich meine, die Freiheit ist nicht unbestimmt, sondern sie ist formal. Aus dem Begriff der Freiheit lässt sich materialisiertes Recht nicht entwickeln, sondern die Freiheit lässt sich nur verwirklichen, nämlich durch allgemeine Gesetze, die allerdings dem Prinzip eines menschheitlichen Rechts entsprechen müssen. Freiheit ist die Unabhängigkeit von eines anderen nötigender Willkür, die ohne innere Freiheit, Sittlichkeit, die der Moralität verlangt, nicht denkbar ist. Freiheit ist niemals das Recht, anderen zu schaden. Deswegen erwächst aus Freiheit auch kein Risiko, Herr Gusy, sondern das Leben bringt Risiken mit sich. Wir können handeln, weil wir 
die Idee der Freiheit haben, und müssen die Risiken des Handelns zu beherrschen versuchen. Es ist alleiniger Zweck des Staates, die Freiheit, die allgemeine Freiheit, zu verwirklichen. Sie verwirklicht sich durch prozedurale und vor allem materiale Rechtlichkeit. Es gilt die Formel: Keine Freiheit ohne Recht, kein Recht ohne Staat. Der Staat ist notwendig, man kann ihn nicht aus der Geschichte verabschieden, indem man ihn nicht begreift. Rechtlichkeit ist der polizeirechtliche Begriff der Sicherheit. Sicherheit heißt: Wirklichkeit des Rechts. Insofern scheint mir das Prinzip Sicherheit im Staatsbegriff selbst zu liegen, ohne dass dieses noch durch eine besondere Formel angesprochen werden müsste. Es gibt denn doch ein subjektives Recht auf „kollektive Güter“, ein Recht auf Recht nämlich, welches Kant bestmöglich begründet hat, das Recht auf die bürgerliche Verfassung und damit ein Recht auf den Staat. Jeder hat ein subjektives Recht darauf, ob die Gerichte das anerkennen oder nicht. Es gibt auch ein Recht auf Stabilität, auf wirtschaftliche Stabilität, auch wenn das Bundesverfassungsgericht ein solches subjektives Recht (jedenfalls aus der Eigentumsgewährleistung) nicht anzuerkennen vermochte. So schließt sich der Kreis. Wir haben sehr viel weniger Probleme, wenn wir eines bedenken: Grundlage des Rechts und des Staates kann nur die Freiheit des Menschen sein. Niemand kann den Menschen verpflichten, als er selbst, als die Autonomie des Willens. Die Freiheit lässt einen Unterschied zwischen Völkerrecht und Staatsrecht in der Verbindlichkeit nicht zu. Der Dualismus sollte überwunden werden. Ich spreche vom umgekehrten Monismus. Das Entscheidende ist, dass alles Recht auf Freiheit beruht, wie auch immer wir das gemeinsame Leben in dieser Welt organisieren.

Isensee: Heute Morgen haben wir den Staat eingeäschert, heute Nachmittag steigt er als Phönix aus der Asche wieder hervor. Jetzt erscheint er als Wohltäter der Freiheit und der Sicherheit, ihr Garant, zugleich aber ihr Widersacher. Krasser kann sich ein Paradigmenwechsel am selben Tag nicht ereignen, als wir ihn gerade erleben. Herr Alexy hat soeben gleichsam als Notar dieser Entwicklung fungiert.

Was Freiheit ist, lässt sich, jedenfalls im Blick auf die Grundrechte als Abwehrrechte, einfach definieren: als Abwesenheit von staatlichem Zwang. Das aber bedeutet nicht schlechthin Abwesenheit des Staates. Denn Voraussetzung der Ausübbarkeit grundrechtlicher Freiheit ist der status civilis, der vom Staat gewährleistete Gesamtzustand der Sicherheit. Ohne diese Gewähr wäre Abwesenheit von staatlichem Zwang Anwesenheit virtueller privater Gewalt. Was nützt das Grundrecht der Freizügigkeit, wenn ich mich nicht auf die Straße wagen kann aus Furcht vor Überfällen? Die rhetorische Frage stellte übrigens Wolfgang Zeidler, der frühere Präsident des Bundesverfassungsgerichts. 
Die Grundrechte richten sich gegen Gefahren von zwei Seiten: in ihrer Abwehrfunktion gegen den staatlichen, in ihrer Schutzfunktion gegen den privaten Übergriff. Dort geht es um Freiheit, hier um Sicherheit. Nun kann man freilich Freiheit auch als Sicherheit vor dem staatlichen Übergriff verstehen. So wurde in den Beratungen des Grundgesetzes die Freiheit der Person, also die räumliche Bewegungsfreiheit, im Verhältnis zum Staat als Sicherheit verstanden. In dieser Bedeutung ist das Wort Sicherheit eingegangen in die Europäische Menschenrechtskonvention und in die Europäische Grundrechtscharta, die jeder Person das Recht auf Freiheit und Sicherheit zuerkennen. Insoweit sind Freiheit und Sicherheit konvertibel. Gegenstand der heutigen Beratung ist jedoch die Sicherheit im Verhältnis zum Nebenmenschen. In der Evolution des Verfassungsstaates liegt die ursprüngliche Aufgabe des Staates darin, diese Sicherheit zu gewährleisten. Auf einer höheren Stufe der Evolution, der Stufe John Lockes, wird Sicherheit auch vor dem Hüter der Sicherheit gewährleistet: die Freiheit.

Die relative Klarheit der Begriffe Freiheit und Sicherheit geht verloren, wenn Herr Gusy Sicherheit als Abwesenheit von Risiken versteht. Risiko, der Gegenbegriff zu Chance, tritt an die Stelle des Begriffs der Gefahr, also der nicht entfernten Möglichkeit eines Schadens. Dem Begriff des Risikos fehlt die innere Begrenztheit des Gefahrbegriffs. Er taugt nicht zur Definition von Freiheit und Sicherheit. Freiheit entbindet Risiken, und Sicherheit vor Risiken ist utopisch. Eine Utopie, die weder erreichbar noch wünschbar ist.

Grimm: Es ist nur ein Zwischenruf. Der Widerspruch, den Herr Isensee eben zwischen heute Vormittag und heute Nachmittag entdeckt zu haben glaubt, löst sich mühelos auf, wenn wir zwischen Staat und öffentlicher Gewalt unterscheiden. Wir brauchen natürlich, wenn wir ein System auf Freiheit gründen wollen und die Freiheit sicher sein soll, eine Gewalt, die dies gewährleistet. Aber der Staat ist eine kontingente Form von öffentlicher Gewalt, die aus historischen Gründen entstanden ist und aus historischen Gründen auch wieder entfallen kann. Dann bleibt aber immer noch, wenn nicht Anarchie ausbricht, die öffentliche Gewalt übrig.

Götz: Eine Bemerkung zum Raum der Freiheit, der Sicherheit und des Rechtes. Er ist eine Innovation des Vertrages von Amsterdam und bestimmt ein Verfassungsziel der Europäischen Union, welches Projektcharakter hat. Dieses Projekt des Raumes der Freiheit, der Sicherheit und des Rechts steht auch für einen ganz spezifischen, europarechtlichen $\mathrm{Zu}$ sammenhang zwischen der Freiheit und der Sicherheit, auf den ich hin- 
weisen möchte. Der Europäische Rat unternahm es, dieses Projekt in einem ersten Schritt 1999 mit Leben zu erfüllen. Auf seiner Ratstagung in Tampere hat er ein ganzes Bündel von Maßnahmen der Bekämpfung der grenzüberschreitenden Kriminalität vorgestellt - ich nenne die Stichworte Europol, organisierte Kriminalität, Drogenkriminalität. Das politische Kalkül dabei war es, dass der europäischen Öffentlichkeit diese Maßnahmen der inneren Sicherheit nicht ohne gleichzeitige Vorlage eines großen neuen Freiheitsprojektes präsentiert würden. Also: - ähnlich wie es in den Schlussbemerkungen von Herrn Gusy anklang, aber vielleicht hat er's sich anders vorgestellt - der Sicherheitspolitik sollte eine Freiheitspolitik an die Seite treten. So kam es, dass die uns allen bekannte Europäische Grundrechtscharta ursprünglich ein Teil dieses Projektes Raum der Freiheit, der Sicherheit und des Rechts ist. Dieser Zusammenhang ist leider später in allen Diskussionen und auch in der Praxis völlig verloren gegangen. Die Freiheitsgewährungen der europäischen Grundrechte bedeuten ursprünglich, dass die Europäer, die grenzüberschreitend durch Aufenthalt und Betätigung ihre Grundfreiheiten wahrnehmen, in den jeweiligen Ländern auch alle grundrechtlichen Freiheiten in Anspruch nehmen können, also dort, wo sie sich aufhalten und arbeiten, die Meinungsfreiheit, die Pressefreiheit, die Versammlungsfreiheit und andere Freiheiten ausüben können. Tendenziell hätte dies eine Bindung der Staaten an die Grundrechtscharta bedeutet. Davon hat man dann aber im Konvent die Finger gelassen. In der Ausarbeitung der Charta ist der Zusammenhang mit dem Raum der Freiheit, der Sicherheit und des Rechts verloren gegangen. In dem neuen Entwurf des Verfassungs-Konvents ist die Charta als Teil II ganz abgekoppelt von einem auf den Sicherheitszweck reduzierten Raum der Freiheit, der Sicherheit und des Rechts. Ich vertraue diese Bemerkung vor allem als kleine historische Facette Herrn Brugger an, dem ich danken möchte dafür, dass er uns in beeindruckender Weise die Zusammenhänge zwischen Sicherheit und Freiheit dargelegt hat.

Schefold: Nur ein kleiner Zwischenruf zu den Thesen 11 und 12 von Herrn Gusy, in denen von der angemessenen sachlichen und organisatorischen Differenzierung die Rede ist. Die Vorbereitung von Polizeigesetzgebung bedarf deshalb, meine ich, vor allem eingehender und verantwortlicher parlamentarischer Beratung. Dem ist es nicht zuträglich, wenn die Vorbereitung von Gesetzesprojekten im undurchsichtigen Geflecht der Zusammenarbeit von Ministerialbürokratien erfolgt. Musterentwürfe sind ein geeignetes Instrument, wenn es um technische Materien geht, allenfalls auch um Verwaltungsverfahren, aber nicht, wenn der Kern der persönlichen Freiheit in Frage steht. Da die Polizeihoheit der Länder für 
das deutsche öffentliche Recht essenziell ist, ist hier ein klassischer Bereich für die Notwendigkeit einer Entflechtung des Föderalismus und einer eigenverantwortlichen Regelung durch die Länder.

Häberle: Verehrte Kolleginnen und Kollegen. Mein Spontanbeitrag knüpft an das Votum von Herrn Götz an. Es muss uns doch gelingen, Erkenntnisse des heutigen Vormittags auf den Nachmittag zu übertragen, Völkerrecht und die Rechtsvergleichung haben mir soeben etwas gefehlt. Das diffizile Verhältnis von Freiheit und Sicherheit hat sich „europäisiert": vor allem im Raum der Freiheit, der Sicherheit und des Rechts nach den EU-Verfassungstexten, es hat sich aber auch internationalisiert: Sicherheit ist ein völkerrechtliches Gemeinwohlgut, auch im Weltraum, als internationale Sicherheit bzw. Frieden, eine Aufgabe spezifisch der UN, denken wir an den UN,„Sicherheitsrat“ als Treuhänder schon dem Wort und Begriff nach. Vielen Dank.

Vorsitzende: Nun wäre der erste größere allgemeine Block abgeschlossen, und wir würden uns dem Thema soziale Sicherheit zuwenden.

Zacher: Ich mahne an, dass von der sozialen Sicherheit zu wenig die Rede war. Ich mahne es deshalb an, weil es zur Ganzheit der Sache wirklich gehört. Sie haben von „innerer Sicherheit“ geredet. Zur inneren Sicherheit ist ein sehr wichtiger Beitrag alles, was Sozialpolitik leisten kann, um die Homogenität der Gesellschaft zu gewährleisten, um die drängende Not zu mindern usw. Ohne soziale Maßnahmen wird niemand wirklich innere Sicherheit erreichen. Sie, Herr Gusy, haben erörtert, dass es die Idee eines „Rechts auf Sicherheit“ gibt, eines „Staatsziels Sicherheit", aber dass das doch nur die Summe der Teile ist. Ich möchte das von der Erfahrung mit ,sozialer Sicherheit" her anders ausdrücken: Dass sich die Schwierigkeit, Sicherheit herzustellen - die Endlosigkeit des Anspruchs auf der einen Seite und die extreme Endlichkeit der Verwirklichung auf der anderen Seite -, gerade am Fall der „sozialen Sicherheit" beweist, dass Sicherheit eigentlich nur aus offenen Enden besteht. Und dennoch: In der Summe der „Sicherheit“, die mir nicht nur so additiv zu sein scheint, wie Sie das sagen, in dieser Summe spielt die „soziale Sicherheit" eine wichtige Rolle. Historisch wäre dazu Folgendes zu sagen. Mit den Anfängen des modernen Verfassungs- und Rechtsstaates um 1800 entsteht auch die erste Institution allgemeiner „sozialer Sicherheit“, die Armenfürsorge. Die im Staat Eingeschlossenen sind nicht mehr einfach dem Verrecken preisgegeben. Das ist wenig genug. Aber immerhin: Es ist eine Perspektive der Sicherheit, für die, die im Lande da sein dürfen und da sind. Ungefähr 80 Jahre später 
kommt dann die Sozialversicherung hinzu, die neben diese situationelle Sicherung, dass man in der Situation der Armut eine minimale Hilfe bekommt, ein Management der Zukunftssicherung stellt. In den Referaten wurde ja auch angedeutet, dass das kollektive Management der $\mathrm{Zu}$ kunftssicherung ein wichtiges Element der Sicherheit ist. Und dieses soziale Management der Zukunftssicherung soll von nun an die „soziale Sicherheit“ weitgehend prägen. Von nun an haben wir zwei Dimensionen, in denen wir die Endlosigkeit und die Endlichkeit gerade von „sozialer Sicherheit" erfahren: Von nun an vollzieht sich eine eminente Ausweitung der Herstellung von ,sozialer Sicherheit“ überhaupt - auch der situationellen, auch des kollektiven Managements der Zukunftssicherung; und beides verbindet sich mit der Idee, dass soziale Sicherung nicht nur Not verhindern, sondern auch Freiheit vermitteln soll. Wir haben eine Multiplikation. Wir haben die Ausdehnung von Sicherheit und die Ausdehnung der Vermittlung von Freiheit durch soziale Sicherheit. Das hat in wenigen Jahrzehnten zu der Überforderung geführt, in der wir jetzt stehen.

Engel: Ich muss mich der - allerdings unbeabsichtigten - Irreführung des Vorstands schuldig bekennen. Die Frage, zu der ich etwas sagen wollte, lautete: Warum sind Sicherheit und Freiheit ein soziales Problem? Gemeint habe ich damit: Warum gibt es Grund zu staatlichem Handeln? Damit verbunden auch: Besteht eigentlich ein Spannungsverhältnis zwischen beiden Zielen?

Ich will versuchen, mit Hilfe einer ökonomischen Perspektive zu dieser Frage etwas auszusagen. Die ökonomische Perspektive scheint mir deshalb hilfreich, weil sie einen Teil abschichten kann. Da, wo zu erwarten ist, dass das gemeine Wohl gerade durch den Gebrauch individueller Freiheit verwirklicht wird, haben wir kein Spannungsfeld. Das ist Adam Smiths unsichtbare Hand.

Diese Erwartung ist aber in zwei Fällen nicht begründet. Das sind zugleich und nicht zufällig Fragen, zu denen sich in ökonomischen Kategorien kaum noch etwas sagen lässt. Im ersten Fall gebraucht jemand physische Gewalt. Mit ökonomischen Kategorien wäre das nur zu erfassen, wenn man es reformulieren könnte als die Zuweisung eines Verfügungsrechts, andere zu schädigen. Das ist an sich eine Formulierung, die wir im Umweltrecht ganz geläufig im Munde führen, um Zertifikate zu begründen. Aber Zertifikate begründen eine tatbestandlich begrenzte Befugnis, während das Gewaltproblem gerade darin besteht, dass das Schädigungspotential kategorial nicht begrenzt werden kann. Der zweite Aspekt von Sicherheit, der in ökonomischen Kategorien nicht zu bewältigen ist, betrifft das generalisierte Vertrauen. Wenn ich erwarten soll, dass die 
Summe der individuellen Egoismen zum gemeinen Wohl führt, dann muss gleichzeitig die Erwartung berechtigt sein, dass sich jeder Einzelne auch in gewissem Masse auf dieses Spiel einlässt.

Das tut er aber nur, wenn er damit die Erwartung verbindet, dass er niemals ganz aus diesem Spiel herausfallen kann. Genau dieses generalisierte Vertrauen, dass man sozusagen nach Regeln spielen wird, ist etwas, was innerhalb dieser Regeln selber nicht herzustellen ist.

Das lässt nun spiegeln auf die Freiheit. Wenn Freiheit darin besteht, das zu tun, was sich schließlich addiert zum gemeinen Ganzen, dann ist sie überhaupt nicht rechtfertigungsbedürftig. Der Gebrauch der Freiheit ist dann nichts anderes als ein Dienst am gemeinen Wohl. So ist Freiheit im Grundgesetz aber nicht gedacht. Grundrechtliche Freiheit ist gerade nicht eine Freiheit, die dadurch gebunden ist, dass sie schließlich durch den Mechanismus der unsichtbaren Hand allen nützt. Sie ist voraussetzungslose Freiheit: Ich darf tun, wozu auch immer ich Lust habe. Damit ist dann gleichzeitig die Pflicht aller anderen (nicht nur des Staats) verbunden, meinen Freiheitsgebrauch auszuhalten. Darin steckt also immer gleichzeitig auch die Duldungspflicht. Solch eine Freiheit und solch eine Duldungspflicht lassen sich in den wohlfahrtstheoretischen Kategorien der Ökonomen nicht begründen.

Vorsitzende: Nun liegen noch fünf Wortmeldungen vor zum Thema Sicherheitsgefühl, subjektive Dimension und zu den Straftatbeständen, und ganz zum Schluss noch eine Wortmeldung, eine Frage zum ausländischen Staats- und Verfassungsverständnis.

Frowein: Frau Vorsitzende, meine Damen und Herren, die beiden anregenden Referate führen mich zu zwei ganz kurzen Vorbemerkungen und dann zu zwei Fragen in dem angedeuteten Zusammenhang. Die Vorbemerkungen: Erstens, ich finde es irgendwo interessant, dass wir bei diesem Spannungsproblem kein Wort bisher, wenn ich's richtig gehört habe, verloren haben, über das, was wir alle miterlebt haben und einige hier im Hause ganz persönlich. Ich meine die Systeme, in denen Sicherheit in vollem Umfang gegenüber dem Nachbarn bestand, Freiheit aber so gut wie keine, also das System des realen Sozialismus in einem Teil Deutschlands und in anderen europäischen Ländern. In Russland kann man ja besonders gut sehen, wie der Umschlag erfolgt ist, und es gibt wahrscheinlich keine tragischere Form von Freiheit ohne Sicherheit als die, die Sie heute in Russland erleben können. Die zweite Vorbemerkung: Die Folterproblematik hat Herr Gusy angesprochen, und ich möchte einfach das, was er gesagt hat, sehr unterstreichen: Wir dürfen die Vorbehaltlosigkeit der Foltergarantien niemals unterlaufen. 
Jetzt meine zwei Bemerkungen zu den Thesen 11 von Herrn Gusy und 9 von Herrn Brugger. Ich glaube, die Bedeutung des Sicherheitsgefühls wird in der These 11 von Herrn Gusy ein wenig unterschätzt. Wenn man alles genau liest, und „eigenständig“ groß unterschreibt und „Eingriffsbefugnis" unterschreibt, dann kann man dem zustimmen. Es ist natürlich keine eigenständige Staatsaufgabe, aber ich meine, die Bedeutung des Sicherheitsgefühls der Bürger darf nicht unterschätzt werden. Polizeipräsenz in diesem Zusammenhang - das kann jeder sehen - spielt eine enorme Rolle. Es soll wohl so sein, dass ein Hamburger Wahlergebnis wesentlich auf dieses Problem zurückzuführen ist, und wir sollten es nicht unterschätzen. Nun zu der These 9 von Herrn Brugger. Ich möchte gerne die Provokation aufnehmen, die er, wie ich finde sehr zu Recht, mit $\S 130$ StGB verbunden hat, aber ich würde gerne sagen, dass $\$ 130$ StGB wirklich scharf interpretiert werden sollte, auch wenn das die Strafrechtler vielleicht nicht immer tun. Nur wenn es ,geeignet ist, den öffentlichen Frieden zu stören", was bedeutet das? Das bedeutet, dass die Minderheitsgruppe - denn die ist es immer - in ihrem Sicherheitsgefühl so zentral gestört werden muss, dass Anlass zum Eingreifen besteht. Die Entscheidung Brandenburg vs. Ohio, die wir beide kennen und die viele hier kennen, ist meines Erachtens ein Gipfel der Fehlentscheidung des Supreme Court. Wenn Kreuze verbrannt werden und damit die Unsicherheit einer Minderheitsgruppe darüber, ob es ihr selber so gehen könnte, oder Puppen verbrannt werden - wenn dieses straflos bleibt, dann unterschätzt der Staat seine Sicherheitsaufgabe.

Pitschas: Frau Vorsitzende, meine Herren Referenten, die Debatte wird nach meinem Eindruck etwas konkreter als die Vorträge. Ich möchte zu diesem Konkretisierungsvorgang beitragen. Vier Anfragen habe ich an Herrn Gusy. Zuerst geht es um eine Frage nach dem Sicherheitsbegriff, der verwendet wird: In den Thesen 1 und 2 argumentieren Sie u.a., die Staatsaufgabe Freiheit werde individualisiert, und es gäbe bei der Staatsaufgabe Sicherheit demgegenüber kollektivierte Entscheidungszuständigkeiten. Vor dem Hintergrund eines umfassenden Sicherheitsbegriffs trifft diese Unterscheidung aus meiner Sicht aber nicht zu. So haben wir bei der Staatsaufgabe Sicherheit in der Alterssicherung individualisierte Entscheidungszuständigkeiten. Umgekehrt lässt sich Freiheit ohne sozialen Schutz auch nicht verwirklichen. Dies ist bereits in anderen Diskussionsbeiträgen angedeutet worden und wird doch vertieft werden müssen.

Ich bin deshalb und mit Blick auf die These 1 auch nicht der Auffassung, lieber Herr Gusy, dass Freiheit nur Verfassungsinhalt und Sicherheit nur Verfassungsvoraussetzung sei. Statt dessen möchte ich meinen, dass in dem Maße, im dem Sie Sicherheit durch soziale Freiheit erst 
ermöglichen, diese ebenso Inhalt der Verfassung sein muss. Damit aber stellt sich die Frage nach dem Sicherheitsbegriff: Schlagen wir innere Sicherheit, technische Sicherheit, soziale Sicherheit über einen Leisten oder bewegen wir uns ausschließlich auf dem Gebiet der inneren Sicherheit?

Wenn ich zu dieser übergehe und auf einen zweiten Punkt aufmerksam machen darf, dann ist das die Frage nach dem Risikobegriff: Ist eigentlich alles Risiko? So hat Herr Isensee schon darauf hingewiesen, dass wir konsequenter Weise unsere gesamte Gefahrenabwehrlehre über Bord werfen müssen, wenn wir im Sicherheitsrecht alles als Risiko und Risikomanagement verstehen. Das scheinen Sie dann doch nicht gemeint zu haben. Vielleicht sind Sie so nett, und könnten dazu etwas sagen? Vielleicht hat die Staatsaufgabensicherheit nichts mit umfassender Risikosteuerung zu tun, aber in der Zuweisung der Befugnis zum Risikomanagement liegt doch die ganze Breite eines veränderten Staatsverständnisses.

Ich will wie Herr Frowein einen dritten Punkt noch anschließen, nämlich auf das subjektive Sicherheitsgefühl eingehen, das von Ihnen in der These 11 mit der These 3 verbunden wird. Der moderne Diskurs in der Praxis des Polizei- und Sicherheitsrechts führt darauf hinaus, dass sich die Polizeibehörden der Bedeutung eines beeinträchtigten subjektiven Sicherheitsgefühls der Bevölkerung in bestimmten Regionen oder städtischen Bezirken sehr bewusst sind. Sie sind es deshalb, weil davon zugleich die objektive Aufgabe der Sicherheit abhängt. Deswegen zweifle ich an der These 11, in der Sie lediglich von der Sicherheitspflege sprechen. Dieser Begriff ist mir zu weich. Ich würde eher sagen, es geht bei dem Schutz des subjektiven Sicherheitsgefühls doch um dem Bestandteil einer eigenständigen Staatsaufgabe und abschließend zu Ihrer These Nr. 13: Sie haben Recht, das Trennungsgebot gilt und die Polizei ist nicht die Bundeswehr! Doch haben wir es im Fall des Frankfurter Flughafens nur dem Votum der beteiligten Ministerpräsidenten und des Verteidigungsministers zu verdanken, dass die Probleme auch ohne ein Koordinationsgesetz gelöst werden konnten. Ich würde gerne auf ein entsprechendes Koordinationsrecht zurückgreifen und auch einen Satz dazu in der Verfassung sehen wollen.

Battis: Verehrte Frau Vorsitzende, meine Damen und Herren, eigentlich finde ich es überraschend, dass die beiden Referate trotz ihres doch sehr unterschiedlichen ductus und auch ihres sehr unterschiedlichen $\mathrm{Zu}$ griffs, soweit sie konkret geworden sind, zu überraschend ähnlichen - ja, ganz ungeschützt - liberalen Ergebnissen gekommen sind. Das gilt uneingeschränkt für die beiden konkreten Beispiele von Herrn Brugger. Bei Herrn Gusy - ich bitte, mir das zu verzeihen trotz unseres Näheverhält- 
nisses, dass ich das jetzt etwas kritisch sage - da finden sich auf abstraktem Niveau sehr viele glänzende, süffige Formulierungen, die ich immer schon an Ihnen besonders geschätzt habe, Herr Gusy, aber manchmal frage ich mich dann doch, und das klang ja zuvor schon ein wenig an: Was bringt das konkret? Ich meine, auch suggestiv sehr einnehmende Formulierungen, also: „Die Polizei soll sichern, dass die Menschen in Frieden zusammen leben können. Das Militär soll sichern, dass die Menschen in Frieden getrennt leben können." Bei dieser Formulierung ging durch den Saal gleich ein Raunen, ist ja auch eine wirklich schöne Formulierung. Aber angesichts der Probleme mit dem Luftsicherheitsgesetz - der Gesetzesentwurf liegt ja vor - und der Fragen, die sich da jetzt stellen, bringt eine solche Formulierung meines Erachtens gar nichts.

Was den Punkt Sicherheitspolitik und das Gebot angemessener sachlicher organisatorischer Differenzierung betrifft, hätte ich die Frage: Ist das ein rechtliches Gebot? Dann woraus? Oder ist das ein organisationswissenschaftliches Gebot? Dann würde ich nur sagen: Angesichts der Zusammenfassung von 160000 Beschäftigten in den USA in ein neues Ministerium trägt das nicht als Feststellung. Herr Schefold sprach vorher von der gebotenen Entflechtung - also ich sehe die Entflechtung bei uns nicht: Ich sehe einen Wettbewerb der Länderpolizeien um neue Techniken, und was die Bundesebene betrifft, etwa Sicherheitspaket I und II, da hatte man den Eindruck, alle Ideen, die jeder Referent in der zuständigen Abteilung in den letzten acht Jahren ausgebrütet hat, sind aus den Schreibtischen geholt und in ein Gesetzespaket zusammengeschnürt worden. Dann hat man ein ganz klein wenig an den Rändern noch abgeschnippelt, aber es war immer noch entschieden zu viel.

Letzte Bemerkung, und das ist eigentlich für mich das Schwierigste: „Der Schutz des Sicherheitsgefühls ist keine eigenständige Staatsaufgabe." Das ist richtig, das sehe ich auch so, aber Sie sehen das Sicherheitsgefühl zugleich als eine Grundlage von Politik, eine Grundlage auch von demokratischer Politik. Wenn das so ist: Woher kommt dann Ihr Vertrauen in demokratische Prozeduren, in Partizipation und in anderes mehr? Wir müssen jetzt nicht Hamburg herausnehmen, aber das ist eigentlich kein gutes Beispiel, um Vertrauen zu gewinnen, zu einem positiven Verständnis von Sicherheitsgefühl als Grundlage für demokratische Verfahren (z.B. Wahlen).

Gersdorf: Sehr geehrte Frau Vorsitzende, sehr geehrte Damen und Herren. Ich möchte mich direkt an Sie wenden, Herr Brugger. Sie hegen, wenn ich Sie richtig verstanden habe, Zweifel an der Verfassungskonformität des $\S 130 \mathrm{StGB}$. Ich möchte den Versuch unternehmen, diese Zweifel auszuräumen. Zunächst einmal: Ich stimme Ihnen sicherlich darin zu, 
dass ein Grundrechtseingriff nur zum Schutze eines konkreten Rechtsgutes zulässig ist; und das „politische Klima“, um Ihre Kategorie aufzugreifen, ist ein solches konkretes Rechtsgut zweifelsfrei nicht. Nur, fürchte ich, ich muss Sie verlassen, wenn Sie die "Gefahr einer Gefahr“ als Legitimationstitel für einen Grundrechtseingriff nicht für ausreichend und für zulässig erachten. Konsequent zu Ende gedacht hieße dies, dass jedes (oder nahezu jedes) abstrakte Gefährdungsdelikt nach dem Strafgesetzbuch oder nach anderen Strafgesetzen das Schicksal der Verfassungswidrigkeit ereilen müsste. Ist das Ihre Meinung?

Welches konkrete Rechtsgut verbirgt sich nun hinter $\S 130$ StGB? Vor allem die persönliche Ehre sowie Leib und Leben bestimmter Bevölkerungsteile sind Schutzgüter des $\S 130$ StGB. Nur sind diese Rechtsgüter und dies ist das Besondere des $\S 130 \mathrm{StGB}$ - nicht konkret, sondern nur abstrakt gefährdet. Für die verfassungsrechtliche Würdigung bedeutet dies: $\S 130$ StGB könnte nur dann vor der Verfassung keinen Bestand haben, wenn es keinen Fall gäbe, in denen die Aufstachelung zum Hass gegen Teile der Bevölkerung zu Übergriffen auf diese Bevölkerungsgruppe führte; und davon kann wohl kaum die Rede sein. Nicht die Norm als solche löst verfassungsrechtliche Zweifel aus. Verfassungsrechtliche Probleme können sich allein auf der Ebene der konkreten Normanwendung des $\S 130$ StGB ergeben.

Kugelmann: Herr Brugger, ich möchte eine Anmerkung zu Ihrem zweiten Beispiel, den Parteiverboten, machen und eine Frage stellen. Die Anmerkung bezieht sich im Dienste der Europäisierung und Internationalisierung auf Urteile des Menschenrechtsgerichtshofs in Straßburg. Es gibt zwei Urteile aus den letzten Jahren, die Parteiverbote in der Türkei, nämlich einmal die Kommunistische Partei und einmal die islamistische Wohlfahrtspartei, betreffen. Der Menschenrechtsgerichtshof hat in den Voraussetzungen, die er anlegt, die Alternativen, die Sie dargestellt haben, sehr verengt. Sie haben zwar die innerstaatliche Rechtslage geschildert. Im Sinne einer Konvergenz europäischen Grundrechtsverständnisses scheint mir als Voraussetzung für ein Parteiverbot aber nur noch die Auslegung einer wirklichen Gefährdung, einer Erhöhung des Risikos für die innerstaatliche Rechtsordnung vertretbar. Alle anderen Theorien halte ich für inzwischen schwer begründbar. Die Frage richtet sich sodann darauf, ob das Beispiel der Parteiverbote überhaupt in den Zusammenhang passt. Denn wenn ich Freiheit als den Schutz individueller Freiheit verstehe und Sicherheit als die Gewährleistung der Voraussetzungen für die Ausübung der Freiheit, dann habe ich bei Parteiverboten doch eine ganz andere Situation. Hier geht es darum, im Verhältnis Staat-Gesellschaft die Grundlagen einer bestimmten, nämlich der konkreten staat- 
lichen Herrschaft, der demokratischen Ordnung, zu schützen. Und da sind doch, im Sinne der bereichsspezifischen Differenzierung, die Herr Gusy angemahnt hat, völlig andere Rahmenbedingungen in der Abwägung, in dem Verhältnis der beiden Schutzgüter maßgebend, als wir gängigerweise bei den normalen Fällen von Freiheit und Sicherheit haben. Sonst kommen wir irgendwann, im Sinne Ihres Klimaschutzes, zum Verkauf von Gefährdungszertifikaten und das wollen wir ja nicht. Man müsste sich hinsichtlich der Parteiverbote nochmals überlegen, ob dieses Beispiel überhaupt ertragreich ist, um das Verhältnis von Freiheit und Sicherheit weiter zu klären.

Vorsitzende: Nun noch ein Blick - oder eine Frage - zum ausländischen Staats- und Verfassungsverständnis, also der letzte Beitrag von Herrn Geis.

Geis: Mein Beitrag knüpft an die Äußerungen von Herrn Götz und Herrn Häberle an. Als ich das Generalthema „Unterschiedliche Staatsund Verfassungsverständnisse" gelesen habe, da dachte ich spontan, dass man das nicht auf die Staats- und Verfassungsverständnisse in Deutschland beschränken kann. Denn drängt sich der Blick auf die unterschiedlichen Staats- und Verfassungsverständnisse im Ausland nicht geradezu auf? Freiheit und Sicherheit und ihr Verhältnis, wird in Ansehung des Grundgesetzes bei uns seit Jahrzehnten diskutiert, insgesamt wohl seit Jahrhunderten. Herr Brugger, Sie haben sehr sinnvoll die Linie Hobbes Locke - Kant noch einmal nachgezeichnet. Damit ist natürlich die Entwicklung nicht zu Ende. Sicher liegt hier eine gemeinsame Wurzel für das Verhältnis Freiheit und Sicherheit in Europa, worunter ich hier - geographisch falsch - auch Amerika rechnen möchte. Aber die Tücke besteht darin, dass sich das Verhältnis Freiheit-Sicherheit in der Feinabstimmung ja in den verschiedenen Staaten unterschiedlich entwickelt hat. Herr Brugger und Herr Gusy, in Ihren beiden Thesen 1 kommt dies ja noch zum Ausdruck. Die unterschiedliche Entwicklung, die sich hier gerade in den letzten Jahrhunderten ergeben hat, die sollten wir doch vielleicht weiter untersuchen, auch im Grundlagenreferat. Denn wenn wir schon den 11. September 2001 als Aufhänger nehmen - und insofern, Herr Brugger, würde ich Ihre These 7 noch ergänzen um das Phänomen, internationale Bedrohungen durch den Terrorismus“ (sicherlich auch ein neues Phänomen, mit dem sich die Sicherheitspolitik befassen muss) -, dann denke ich, hat die Diskussion vor allem dann Sinn, wenn Sie auf der Basis des Verhältnisses von Freiheit und Sicherheit das „Schwarzbrot" der verwaltungsrechtlichen, grenzübergreifenden Massnahmen gründen und koordinieren können. Denn ich denke, wenn wir uns solchen internationalen 
Bedrohungen stellen, dann ist es auch unsere Aufgabe, über einen gemeinsamen Nenner der Vorstellungen des Verhältnisses von Freiheit und Sicherheit in Europa und den angrenzenden Staaten zu überlegen. Und deswegen abschließend die Frage an beide Referenten: Was würden Sie - als Substrat Ihrer Referate - als gemeinsamen Nenner eines solchen gemeinsamen Verständnisses von Freiheit und Sicherheit einbringen wollen?

Vorsitzende: Nun erhält als erster Herr Gusy die Gelegenheit zum Schlusswort.

Gusy: Frau Vorsitzende, meine sehr verehrten Damen und Herren. Zunächst möchte ich mich für die vielfältigen, sehr differenzierten Anregungen bedanken. Sie betrafen zum Teil Ideen, die ich in den Vortrag eingebracht hatte, zum Teil Ideen, die ich gerne eingebracht hätte, aber die Diskussions- und Nachdenkkapazität ist theoretisch unbegrenzt, die Diskussions- und vor allem Vortragszeit nicht. Ich bitte daher um freundliche Nachsicht, wenn einige Themen im Vortrag nicht behandelt wurden, obwohl ich weiß, dass sie sehr wichtig waren.

Ich habe das Thema so verstanden, dass wir auf die gestellten Fragen eingehen sollten aus der Sicht unterschiedlicher Staats- und Verfassungsverständnisse. Das heißt, dass die verfassungstheoretische Ebene jedenfalls nicht völlig ausgeblendet werden sollte. Dies führt natürlich zu dem Problem - Herr Battis hat es zutreffend beschrieben -, dass man mit Ausführungen auf dieser Ebene nicht immer jene Konkretisierungsebene erreichen kann, welche dann die Möglichkeit gibt, einzelne Fälle zu lösen. Dies ist mir bewusst. Ich habe wegen der Fassung des Themas hier bei der Konkretheit einige Abstriche gemacht. Und Herr Battis, wir kennen uns lange genug, als dass Sie wissen, dass ich nicht nur ,süffige Formulierungen" produziere, sondern manchmal auch sehr konkret bin.

Zum Thema Sozialstaatsprinzip: Herr Zacher, Sie haben hier etwas sehr Wichtiges angesprochen. Die soziale Dimension der Sicherheit ist die Voraussetzung der Sicherheit überhaupt. Ich würde sagen: Ohne soziale Sicherheit gibt es überhaupt gar keine Sicherheit. Ich habe allerdings, ich gebe es gerne zu, nur in meiner Schlussbemerkung einen kleinen Ausblick auf diese Fragen gegeben. Doch weiß ich sehr wohl, dass dies eine wichtige Frage ist, die allerdings ein eigenes Vortragsthema hätte abgeben müssen und natürlich, Herr Pitschas, alle Fragen des Sozialstaatsprinzips hätte mit einbeziehen müssen. Dies hätte auch positivrechtlich möglicherweise zu anderen Fragen geführt.

$\mathrm{Zu}$ der Frage: „Warum reden wir eigentlich vom Risiko? Ist das Risiko eine Kategorie, die in so einem Vortrag, in so einer Diskussion eigentlich 
vorkommen sollte?": Unterschiedliche wissenschaftliche Disziplinen reden vom Risiko, und diese Diskussionen schlagen natürlich in die Frage um „Was ist eigentlich die Aufgabe des Staates? Was ist eigentlich die Aufgabe der Sicherheitsbehörden?" Ich meine, wir müssen uns diesen Fragen stellen und Antworten geben. Das geht natürlich nicht, ohne dass man vom Risiko redet. Die Aufgabe (ich darf es einmal so formulieren) des Risikomanagements muss natürlich in eine juristische Dogmatik eingebracht werden, eine juristische Dogmatik, welche das Konzept der Gefahrenabwehr, der Vorsorge und weitere dogmatische Konzepte erfasst. Allerdings ist diese Übersetzungsleistung von der Dogmatik erst zu leisten, und die Voraussetzung dafür ist, dass man sich den Fragen - etwa aus der Risikodiskussion - überhaupt stellt. Die These vom „umfassenden staatlichen Risikomanagement" ist nicht meine These. Sie ist eine These, die ich aus der Literatur genommen habe und hinsichtlich derer ich allerdings der Auffassung bin, dass sie zu weit greift. Von dieser These wollte ich mich distanzieren im Hinblick auf ein differenziertes staatliches Risikomanagement. Für diese Differenzierungen habe ich einige wenige Anhaltspunkte liefern wollen - selbstverständlich könnte man weitere hinzufügen. Zum Thema „Sicherheitsgefühl" hatte ich ganz am Anfang auf den wichtigen Konnex zwischen Sicherheitsgefühl und Demokratie hingewiesen. Wichtig in dem Zusammenhang ist tatsächlich, dass das Sicherheitsgefühl möglicherweise nicht nur die Voraussetzung der Demokratie, sondern darüber hinaus auch die Voraussetzung jeder organisierten Staatlichkeit ist. Auf der anderen Seite stellt sich die Frage, wie man dieses Sicherheitsgefühl erhalten, konsolidieren oder möglicherweise erst herbeischaffen kann. Ganz wichtig ist hierbei (das wissen wir ja alle), dass der Staat nicht alle Voraussetzungen, auf denen er basiert, selbst schaffen kann. Aber beim Sicherheitsgefühl stellt sich die Aufgabe meines Erachtens nicht primär als eine Aufgabe gerade der Sicherheitsbehörden - im Gegenteil. Die „Pflege“ des Sicherheitsgefühls ist eine Aufgabe der Politik wie der Behörden im Rahmen ihrer allgemeinen Aufgabenerfüllung. Diese allgemeine Aufgabenerfüllung kann gleichsam als „Annex“ auch auf das Sicherheitsgefühl zurückwirken. Solche Wirkungen sind bei den einzelnen staatlichen Maßnahmen, den einzelnen Handlungen, zu beachten. Wichtig aber ist mir: Spezielle Eingriffsbefugnisse - verstanden in dem Sinne, dass hier öffentliche Gewalt in Grundrechtsgarantien eingreift -, gerade zur Pflege des Sicherheitsgefühls, bestehen für staatliche Behörden nicht. Es gibt eine verbreitete Diskussion namentlich im Umfeld des Bundeskriminalamts, die dies anders sieht - dem möchte ich widersprechen.

Zum Thema private Sicherheitsdienste habe ich tatsächlich einige wenige, ich denke, zu wenige Andeutungen gemacht. Diese Andeutungen 
sollten bitte in folgender Weise verstanden werden: Die privaten Sicherheitsdienste verfügen als solche zunächst über eine andere rechtliche Legitimationsgrundlage als der Staat. Sie sind Fortsetzung der Freiheitsausübung der Bürgerinnen und Bürger. Wenn Sicherheit und Sicherheitsherstellung einer besonderen Legitimation bedürfen, so kann diese vom Grundgesetz nur für den Staat selbst geleistet werden. Nur die Staatsorgane selbst sind an die Grundrechte und an das Demokratieprinzip gebunden. Wenn private Sicherheitsunternehmen also tätig werden möchten, so bedürfen sie anderer eigenständiger Handlungsgrundlagen, entweder aus privatem Recht (Notrechte usw.) oder aber besonderer staatlicher Übertragungsakte. Solche Übertragungsakte müssen dann sichern, dass die Sicherheitsdienste sich im Rahmen der staatlichen Aufgaben und der staatlichen Gemeinwohlverantwortung verhalten. Doch ist dies bei der St. Galler Tagung bereits hinreichend diskutiert worden. Ich will darauf und auf die differenzierten Ausführungen der Referenten und der Diskussion damals verweisen.

Ein ganz kleiner, letzter Punkt zum Thema Bundeswehr. Das militärische und das polizeiliche Denken und die daraus folgenden Strategien sind tatsächlich unterschiedlich - ich habe diese verkürzt, aber meines Erachtens noch nicht verfälschend dargestellt. Ich weiß, dass es hier Konvergenzen gibt - ich weiß, dass es hier Änderungen gibt. Diese Änderungen sind allerdings bislang über das Stadium von Randkorrekturen noch nicht hinausgekommen. Wichtig in dem Zusammenhang scheint mir Folgendes zu sein: Die Bundeswehr hat gegenwärtig bestimmte Möglichkeiten, nach innen tätig zu werden. Dazu zählt auch die umstrittene Luftsicherung; und der Frankfurter Fall ist sicherlich ein Fall, der die Grenzen austariert. Ich meine allerdings, dass er auch die Grenzen bezeichnet hat. Es gibt nach dem gegenwärtigen Stand der militärischen Diskussion wie auch der verfassungsrechtlichen Lage keine Möglichkeit, darüber hinaus zu gehen. Und ich sehe vor allen Dingen auch kein Bedürfnis dazu. Es gibt keinen Bereich, in dem gegenüber den Bürgern gerade der Bedarf nach militärischer Sicherheit bestehen würde; im Gegenteil: Die polizeilichen Befugnisse und diejenigen der übrigen Sicherheitsbehörden reichen hierzu aus. Ich gebe zu, man könnte viel mehr sagen, möchte es aber hierbei belassen.

Brugger: Ich bedanke mich für die Wortmeldungen, die ich zum Teil im Vortrag berücksichtigt habe, zum Teil in den Fußnoten, zum Teil müssen sie von mir erst noch bedacht werden. Lassen Sie mich in der Reihenfolge der Wortmeldungen vorgehen. Herr Stoll, Sie und Herr Engel haben gefragt nach der Rolle von privater Aufgabenerledigung im Kontrast zur staatlichen Aufgabenerledigung. Ich kann dazu im Rahmen meines ide- 
engeschichtlichen Rückblickes sagen, dass die private Aufgabenerfüllung, so seltsam das klingen mag, schon bei den Souveränitätstheoretikern anklingt. Bodin unterscheidet die Ziele von den bestmöglichen Mitteln. Ähnliches findet sich bei Zachariä. Die Ziele im Sinne der einschlägigen Rechtsgüter sind klar, aber das bestmögliche Mittel zu deren Schutz besteht nicht automatisch in staatlicher Eigenerledigung. Als Schutzmittel kommt auch privates oder gesellschaftliches Handeln in Betracht, sofern dieses besser, produktiver und mit weniger Nebenkosten verbunden ist. Dieses Argument gewinnt natürlich an Stärke, seit wir die liberalen Theoretiker haben, die den Staat insgesamt zurückdrängen wollen und damit strukturell Markt dem Staat nebenordnen und zum Teil auch vorordnen. Das wird oft übersehen. Wir sollten beachten, dass die Souveränitätstheorie vor allem eine „Zieltheorie“ ist; diese ist nicht automatisch gekoppelt mit staatlicher Eigenregie, gar reduziert auf Polizei und Militär. Herr Alexy, Sie fragten: Warum nicht ein subjektives Recht auf sicheres Leben, Freiheit und Eigentum als Ausgangspunkt der Reflexion, warum mit dem Organisationsprinzip Rechtsstaat beginnen? Wenn wir nur mit Lagen konfrontiert wären, in denen der Staat linear eingreift in Leben, Freiheit und Eigentum des Bürgers, würde ich sagen: In der Tat, warum nicht mit dem subjektiven Recht und der grundrechtlichen Abwehrdimension beginnen? Aber schon in der hier vorgestellten Verfassungstheorie zeigt sich, dass Lagen genauso wichtig sind - Herr Isensee hat darauf hingewiesen -, in denen Gefahren und Risiken durch Aggressionen Privater gegen Private entstehen. Dann wird die Aufgabe komplexer, dann müssen wir schwierige Abwägungen treffen, dann müssen wir von der Mikrodimension zur Makrodimension wechseln. Dann stellt sich der Anfang mit einem subjektiven Recht gegen den Staat auf ein bestimmtes Handeln, gar vor einem Gericht einklagbar, als zu punktuell, zu isoliert, zu einseitig dar. Das Einsetzen beim „Rechtsstaat" hat den Vorteil, dass wir in ihm einen Strukturbegriff haben, der durch die ganze Ideengeschichte, und zwar schon vor der Entwicklung des spezifisch deutschen Rechtsstaatsbegriffs, zwei Komponenten aufeinander bezieht: „Recht" und „Staat“. Das meint Folgendes: Recht steht für Sicherung des Friedens, Staat steht für „notfalls mit dem Schwert“. Erst wenn wir diese beiden Komponenten strukturell eingerichtet haben, können wir über zivilisiertere Formen, über Gerichte und Klagebefugnisse und ähnliches reden und einzelnen Bürgern - jedenfalls in bestimmten Extremsituationen - ein subjektives Recht auf Sicherung in Leben, Freiheit oder Eigentum zusprechen. Herr Götz, Sie haben den europäischen Raum der Freiheit, der Sicherheit und des Rechts angesprochen. Ich habe das in meinem Referat nicht behandelt, er kommt kurz in den Fußnoten vor, aber lassen Sie mich dialektisch oder provokativ vielleicht Folgendes dazu sagen: Je weniger National- 
staat wir in Europa und der Welt haben, desto mehr Staat brauchen wir. Damit meine ich Folgendes: Je mehr an Rechtsetzungsbefugnissen oder Gerichtsbefugnissen vom Nationalstaat wegwandert hin zu anderen, supranationalen oder gesellschaftlichen Organisationen, desto mehr nimmt die Bedeutung der Durchsetzungs- und Zwangskomponente von Polizei und Militär zu. Das bringt den Staat in eine ganz seltsame Lage: Früher gehörte die ,ganze“ Staatlichkeit im Wesentlichen noch zusammen - Gesetzgebung, Exekutive und Judikative, das war ein Kompetenzbündel zur Erledigung umfänglicher öffentlicher Aufgaben, in gestufter Kompetenz, in der Vorteile und Kosten der institutionellen Aufteilung einigermaßen klar ersichtlich waren. Heute rückt aufgrund der erwähnten Abwanderungsbewegung für den Staat zunehmend die Zwangsdimension in den Vordergrund - die für sich genommen ,attraktiveren“ Formen von Staatlichkeit, Rechtsetzung und Gerichtsbarkeit, werden zum Teil von anderen Akteuren wahrgenommen. Das ist für den Staat eine schwierige Situation, weil er oft - zu oft? - in der Funktion des Polizisten und Soldaten auftritt, während die stärker konsensualen oder auf Streitentscheidung bezogenen Aufgaben dem ersten Zugriff von anderen Akteuren unterliegen. Herr Häberle, das bringt mich zu einem Punkt, den Sie angesprochen haben. Selbst wenn wir an das Völkerrecht denken, an den Sicherheitsrat der UNO, sehen wir genau das als Beispiel. Es gibt dort eben keine Polizei und kein Militär. Exekutivmacht muss bereitgestellt werden von Nationalstaaten, die sagen: Wir treten hier ein, wir lassen unser Militär agieren. Das ist ein positiver Fall, aber der ist natürlich auch gekoppelt mit negativen Fällen des eigentlich gebotenen militärischen Eingreifens, in denen keine ausreichende Unterstützung durch Mitgliedstaaten der UNO vorhanden ist. Empirisch und rechtlich ist es so, wie heute Morgen auch beschrieben, dass vieles vom Staat weggewandert ist. Aber wann immer es Schwierigkeiten gibt mit der Durchsetzung, gar mit Zwang, sind wir nach wie vor und immer mehr auf seine Exekutivgewalt angewiesen.

Herr Zacher, soziale Maßnahmen sind bei mir kurz vorgekommen, aber vielleicht nicht ausreichend. Soziale Maßnahmen sichern Frieden, haben Sie gesagt, und das zu Recht. Die ganze geschichtliche Abfolge von Theorien, die ich in Kürze vorgestellt habe, unterstreicht das eigentlich, denn Historiker betonen zum Beispiel schon für das Mittelalter, dass die Könige dafür zu sorgen hatten, dass die Rechte Einzelner nicht willkürlich verletzt werden. Die Schutzlosen, Kirchen und Kleriker, Witwen und Waisen kommen in den Befehlen des Königs besonders häufig vor. Inzwischen ist das ein Kreis, der zu eng gezogen ist. Der Kreis umfasst nunmehr auch Kranke, Arbeitslose, von Unfällen Betroffene. Aber in der Tat: Obwohl der Kreis der Schutzbedürftigen weiter ist, bleibt das 
Problem das gleiche - effektive Hilfe für Arme und Schwache. Was sich allerdings ereignet hat zwischen der vormodernen und der modernen Staatstheorie ist etwas, auf das Sie auch hingewiesen haben. Diese Hilfe soll nämlich inzwischen Hilfe zur Selbsthilfe statt nur wohltätige Fremdhilfe sein. Herr Preuß hat dazu in einem Aufsatz richtig bemerkt: Es ist Hilfe für Arme, Schwache und Kranke, damit diese als Bürger im Staat effektiv mitwirken können - ein sehr schöner kantischer Gedanke, wenn man das Prinzip „Selbständigkeit“ bei Kant sozialstaatlich auslegt.

Herr Frowein und Herr Gersdorf, Sie haben mein Beispiel des $\S 130$ Strafgesetzbuch mit der Volksverhetzung angesprochen und darauf hingewiesen, dass das Sicherheitsgefühl gerade für die Minderheiten wichtig ist, damit sie sich frei entfalten und ihre Persönlichkeit einbringen können. Das, was ich als Kritik zu $\S 130$ StGB geäußert habe, gründet nicht auf einer Übernahme der amerikanischen Free-Speech-Theorie - Sie haben Brandenburg vs. Ohio zitiert -, wo der Supreme Court gesagt hat, der Staat dürfe erst dann gegen Rede vorgehen, wenn eine unmittelbare Gefahr des Umschlagens von Rede in Tätlichkeit zu gewärtigen ist. Darum geht es mir nicht. Ich habe darauf hingewiesen, dass nach Teilen der Rechtsprechung, nicht notwendigerweise nach der Norm selbst, schon ein Restrisiko ausreicht, um zu sagen, hier liegt Volksverhetzung vor, weil möglicherweise irgendwann irgendwo irgendetwas passieren könnte. Das führt zu einem Problem der Bestimmung der abstrakten Gefahr. Und zwar im Polizeirecht, bei der Volksverhetzung im Strafgesetzbuch wie auch beim Parteiverbot im Grundgesetz. Die abstrakte Gefahr wird nämlich unterschiedlich bestimmt. Sie wird etwa in dem Polizeirechtslehrbuch von Herrn Denninger und seinen Kollegen definiert als "gedachte Möglichkeit einer konkreten Gefahr", und sie wird bestimmt bei Herrn Schenke in seinem Polizeirechtslehrbuch als ,hinreichende Wahrscheinlichkeit" des Eintritts des Schadens für bestimmte Situationen. Das ist ein folgenreicher Unterschied im Bereich der Volksverhetzung, wenn man starke, heftige Auseinandersetzungen um Inklusion und Exklusion als Beispiel nimmt. Wenn es ausreicht, bei solchen Diskussionen den $§ 130$ StGB zur Anwendung zu bringen, weil die „Möglichkeit“ besteht oder nicht ausgeschlossen werden kann, dass irgendwo irgendjemand aufgrund irgendeiner Äußerung nun in Leben, Freiheit und Eigentum einer Minderheit eingreift, dann ist das im Verhältnis mit der Meinungsfreiheit überzogen. Solche meinungsfreiheitsunfreundlichen Tendenzen gibt es aber zum Teil in der Rechtsprechung. Man mag das wegen der Bedeutung des öffentlichen Friedens für rhetorisch angegriffene Minderheiten für richtig halten, dann sollte man allerdings konsequenterweise das Gegenrecht, nämlich die Meinungsfreiheit, die hinter den entsprechenden politischen Stellungnahmen ,volksverhetzender" Art steht, nicht mehr 
als besonders wichtiges Recht anpreisen, wie das seit der Lüth-Entscheidung geschieht. Dann sollte man die einschlägige Rhetorik etwas zurückfahren. Also was ich sage, ist nicht: „Der $\S 130$ Abs. 1 StGB in der Variante, die ich beschrieben habe, ist verfassungswidrig". Dasjenige, was uns eigentlich vorschwebt als reale abstrakte Gefahr, nämlich Aufrufe zu Gewalttätigkeit oder Menschenwürdeverletzungen, das sind andere Varianten als das Aufstacheln zum Hass gegen Teile der Bevölkerung, gefährlichere Varianten. Die hier beschriebene Variante der Volksverhetzung hat keinen klaren Bezug zu Gewalttätigkeit und Würdeverletzungen, weswegen manche Strafrechtler zu Recht sagen: „Diese Sanktion brauchen wir nicht. Hier wird die Strafbarkeit zu weit vorgezogen." Es geht also um ein Problem der Meinungsfreiheit in der Auslegung des $\S 130 \mathrm{StGB}$. Die Rechtsprechung, so habe ich das zusammengefasst, ist gespalten: Es gibt meinungsfreiheitsfreundliche und es gibt meinungsfreiheitsunfreundliche Entscheidungen. Allein die Tatsache, dass es meinungsfreiheitsunfreundliche Entscheidungen gibt, zeigt aber, dass eine Abschreckungsstrategie am Werk ist, die politisch durch Teile der Rechtsprechung und viele Rechtswissenschaftler abgesegnet wird, mit folgender Botschaft: „In diesen Fragen sollte man sich nicht zu laut und zu deutlich äußern." Diese Botschaft möchte ich als Bürger unterstreichen: Wir sollten eintreten für zivilisierte, sachliche und fachliche Diskussionen, auch um Inklusion oder Exklusion. Aber wenn denn einer auftritt und drastisch-plastisch die Dinge benennt oder auch schrecklich übertreibt, dann sollten wir noch nicht das Strafrechtsschwert zücken und Volksverhetzungsstrafen anordnen. In dieser Hinsicht bin ich ein klassischer Liberaler.

Vorsitzende: Wir sind am Ende angelangt und müssen uns beeilen, weil der Abendanlass früh beginnt. Mein Dank gilt den beiden Referenten für ihre große Arbeit, den Diskutanten für ihre anregenden Anstöße und Ihnen allen, verehrte Kolleginnen und Kollegen, für die große Aufmerksamkeit, mit der Sie dieser Veranstaltung gefolgt sind. 